\title{
Estratificação vertical de Anopheles cruzii, Anopheles bellator e outros mosquitos (Diptera: Culicidae) no município de Ilha Comprida, São Paulo
}

\author{
Helene Mariko Ueno
}

Tese apresentada ao Programa de PósGraduação em Saúde Pública para obtenção do título de Doutor em Saúde Pública.

Área de Concentração: Epidemiologia Orientador: Prof. Dr. Oswaldo Paulo Forattini

São Paulo 2004

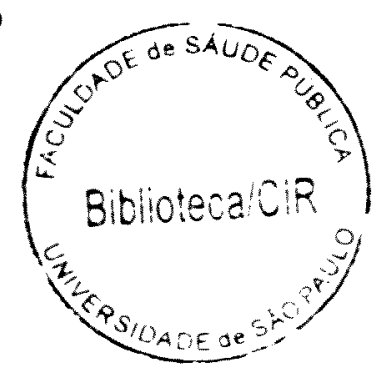


Autorizo, exclusivamente para fins acadêmicos e científicos, a reprodução total ou parcial desta tese, por processos fotocopiadores. Assinatura:

Data: São Paulo, 18 de novembro de 2004.

$$
4565312005 \text { doc }
$$


Dedico

Aos meus pais,

Kyo e Suyoko Ueno.

Ao José Fernando Panhan Júnior, "Zé”, com amor e gratidão. 


\section{AGRADECIMENTOS}

Ao meu orientador, Prof. Cat. Oswaldo Paulo Forattini, com admiração, carinho e gratidão pelo apoio constante e pelos ensinamentos adquiridos nesses anos de trabalho e convivência.

À FAPESP, pelo auxílio financeiro (processos 01/00839-3 e 99/10517-1).

À Profa. Dra. Iná Kakitani e Dra. Roseli La Corte, membros da banca examinadora, pela leitura crítica, pelas longas discussões (em campo e na escola) e, acima de tudo, pela amizade.

Ao Prof. Delsio Natal, membro da banca examinadora, pela confiança e incentivo constantes, pelas contribuições a este trabalho e minha formação, desde o início da pós-graduação.

À Dra. Gisela Rita A. M. Marques, membro da banca examinadora, pelas indicações de leitura e por sempre contribuir com sua experiência de trabalho na Sucen.

Ao Dr. Eduardo Sterlino Bergo, pela leitura atenciosa, pela prontidão com que aceitou participar na banca examinadora, contribuindo para este trabalho.

À Profa. Eunice Aparecida Bianchi Galati, pelas indicações de leitura e discussões sobre a análise estatística dos dados, parte essencial e dificil!

Aos participantes do "VI Seminário Laveran \& Deane sobre Malária", em 2001, especialmente aos organizadores Dr. Cláudio Tadeu Daniel Ribeiro e Maria de Fátima Ferreira da Cruz, pela realização do evento. Este trabalho é resultado de nossas discussões durante o seminário. 
Ao Departamento de Oceanografia Física do Instituto Oceanográfico da USP pelo fornecimento dos dados climáticos da região no período estudado e ao Meteorologista Fernando Nunes por me ajudar a entendê-los!

Aos biólogos Mario Cajuhy e Leandro Giatti pelo ensinamento precioso e cuidadoso das técnicas de escalada, ponto de partida para este trabalho.

Ao Prof. Dr. Fernando Ferreira, do Departamento de Medicina Veterinária Preventiva e Saúde Animal da Faculdade de Medicina Veterinária e Zootecnia USP, pela concessão do mapa da região, detalhado no Laboratório de Epidemiologia e Bioestatística.

Ao pessoal de campo - Chico, Décio, Jair, Luiz e Rui. Sem essa equipe o trabalho não teria sido possivel. Da mesma forma, minha gratidão ao pessoal do laboratório Rosa e Justo, pela montagem das larvas, e ao biólogo Aristides Fernandes pela paciência com que me ensinou a identificar o material.

Ao atencioso e incansável pessoal da Biblioteca pelo trabalho eficiente e organizado Em especial, agradeço à Maria Lúcia Ferraz - em quem descobri uma grande amiga pela paciência com eu me ensinou a fazer buscas e levantamentos de informações, requisito essencial para a realização de trabalhos científicos e pela revisão das referências deste trabalho.

À professora de inglês Sonia Pinto, pela revisão do resumo em inglês, por tudo o que tem me ensinado, mas acima de tudo, pela amizade.

Às amigas e companheiras de trabalho - hoje doutoras - Keilla Miki Kobayashi, Jaqueline Martins e Zoraida Grillo, e também à Juliana Telles de Deus (Juli), meu carinho e gratidão.

A todos aqueles que contribuíram, de alguma forma, para a realização deste trabalho. 


\section{RESUMO}

Ueno, HM. Estratificação vertical de Anopheles cruzii, Anopheles bellator e outros mosquitos (Diptera: Culicidae) no município de Ilha Comprida, SP. São Paulo, 2004. [Tese de doutorado - Faculdade de Saúde Pública, USP].

Objetivo. Estudar a distribuição: sazonal e vertical de adultos e imaturos de $A n$. cruzii e An. bellator no município de Ilha Comprida, SP. Métodos. Adultos capturas em armadilhas luminosas $\mathrm{CDC}+\mathrm{CO}_{2}$ a $1 \mathrm{~m}, 6 \mathrm{~m}$ e $12 \mathrm{~m}$ do solo, das 17-20h. As densidades foram comparadas pelo Teste de Mann-Whitney. Imaturos aspirações em bromélias de solo e em 11 classes de altura de $1 \mathrm{~m}$. Foi utilizado o Coeficiente de correlação de Spearman para analisar as variáveis: densidade de imaturos, volume de água e altura de fixação das bromélias. Os trabalhos de campo foram quinzenais, de setembro/2001 a setembro/2002 e foram investigadas correlações entre clima e densidade de adultos e imaturos. Resultados. Adultos foram capturados 55226 mosquitos: 13745 a $1 \mathrm{~m}, 9614$ a $6 \mathrm{~m}$ e 31867 a $12 \mathrm{~m}$. An. bellator representou $2 \%$ e $A$ n. cruzii, 3,3\% dos Culicidae a $1 \mathrm{~m}$; respectivamente, $2,7 \%$ e $10,7 \%$ a $6 \mathrm{~m}$; e $2,5 \%$ e $13,9 \%$ a $12 \mathrm{~m}$. Ambas as espécies tiveram maior densidade a $12 \mathrm{~m}$. An. cruzii predominou nos três estratos. Houve correlação positiva entre densidade das duas espécies e temperatura máxima. Imaturos - Foram coletados 34298 Culicidae de 25 espécies, incluindo An. bellator e An. cruzii em todos os estratos. Houve correlação negativa entre chuva e densidade desses anofelinos; para esta variável e altura das bromélias, houve correlação positiva para An. bellator e negativa, para An. cruzii. Conclusões. Confirmou-se o comportamento acrodendrófilo de $A$ n. cruzii e An. bellator. As larvas têm desenvolvimento lento e a baixa densidade por bromélia pode ser compensada pela alta densidade de bromélias. Embora não tenham sido registrados casos de malária no local, a região é receptiva à malária.

Palavras-chave: Anopheles cruzii, Anopheles bellator, estratificação vertical, bromélia-malária, $\mathrm{CDC}+\mathrm{CO}_{2}$, bromélias. 


\section{SUMMARY}

Ueno, HM. Estratificação vertical de Anopheles cruzii, An. bellator e outros mosquitos (Diptera: Culicidae) no município de Ilha Comprida, SP. [Vertical distribution of Anopheles cruzii, Anopheles bellator and other mosquitoes (Diptera: Culicidae) in Ilha Comprida county, São Paulo State] São Paulo (BR), 2004. [Tese de doutorado - Faculdade de Saúde Publica, USP)

Objective. To study the vertical and seasonal distribution of Anopheles cruzii and An. bellator adults and immature stages in Ilha Comprida county, São Paulo State, Brazil. Methods. Adults $-\mathrm{CDC}+\mathrm{CO}_{2}$ traps were set at $1 \mathrm{~m}, 6 \mathrm{~m}$ and $12 \mathrm{~m}$ high, from 17-20h. Comparisons were made by the Mann-Whitney Test. Immature - bromeliads tanks at the ground and at 11 classes of $1 \mathrm{~m}$ high were pumped for larvae collection. The Spearman Correlation Coefficient was calculated for: immature densities, water volume/bromeliad and bromeliad position (height). All the field collections were carried out every 15 days, from Sep/2001 to Sep/2002; correlations between climatic factors and mosquito densities (adults and larvae) were investigated. Results. 55226 adult mosquitoes were collected: 13745 at $1 \mathrm{~m}$ high, 9614 at $6 \mathrm{~m}$, and 31867 at $12 \mathrm{~m}$. An bellator corresponded to $2 \%$, and An. cruzii to $3 \%$ of all Culicidae collected at $1 \mathrm{~m}$; respectively, $2,7 \%$ and $10,7 \%$ at $6 \mathrm{~m}$, and $2,5 \%$ and $13,9 \%$ at $12 \mathrm{~m}$. The densities of both species were higher at $12 \mathrm{~m}$. An. cruzii was dominant at all levels studied. There was a positive correlation between the densities of both species and maximum temperature of the day. 34298 immature of 25 Culicidae species, including $A n$. bellator and An. cruzii at all heights, were collected. There was a negative correlation between rain and anofeline densities; for this variable and bromeliads height, there was a positive correlation for An. bellator, and a negative correlation for An. cruzii. Conclusions. The acrodendrophilic behavior of An. cruzii and An. bellator was confirmed. The larvae have a long period of development and the low larvae density/bromeliad may be balanced by the high bromeliad density. Despite the absence of malaria cases reported in Ilha Comprida, the region is receptive to the malaria transmission.

Key words: Anopheles cruzii, Anopheles bellator, vertical distribution, bromeliadmalaria, $\mathrm{CDC}+\mathrm{CO}_{2}$, bromeliads 


\section{LISTA DE FIGURAS}

Figura 1 Mapa da Região do Vale do Ribeira. A área deste estudo localiza-se no Municipio de Ilha Comprida, Via de Pedrinhas (C).

Figura 2 Esquema da Estrada de Ubatuba, próxima à Vila de

Pedrinhas, onde se localizam os pontos estudados. Ilha Comprida, SP

Figura 3 Dados semanais de chuva acumulada (pptç), temperaturas mínima $(\min )$ e máxima $(\max )$ e respectivas médias (md) semanais. Cananéia, SP, agosto/2001 a setembro/2002.

Figura 4 Densidade de $A n$. cruzii capturados em armadilha luminosa $\mathrm{CDC}+\mathrm{CO}_{2}$, das $17-20 \mathrm{~h}$, a $1 \mathrm{~m}, 6 \mathrm{~m}$ e $12 \mathrm{~m}$ do solo, e temperaturas mínima (mín) e máxima (máx) registradas nos dias de coleta. Coletas quinzenais, de 18/09/2001 a 17/09/2002. Ilha Comprida, SP.

Figura 5 Densidade de $A n$. bellator capturados em armadilha luminosa $\mathrm{CDC}+\mathrm{CO}_{2}$, das $17-20 \mathrm{~h}$, a $1 \mathrm{~m}, 6 \mathrm{~m}$ e $12 \mathrm{~m}$ do solo, e temperaturas mínima (mín) e máxima (máx) registradas nos dias de coleta. Coletas quinzenais, de 18/09/2001 a 17/09/2002. Ilha Comprida, SP.

Figura 6 Freqüência relativa de $A n$. bellator e $A n$. cruzii capturados em armadilha luminosa $\mathrm{CDC}+\mathrm{CO}_{2}$, das 17 20h, a 1 (solo), 6 (meio) e 12 (copa) metros de altura. Ilha Comprida, SP, 18/09/2001 a 17/09/2002

Figura 7 Freqüência de Kerteszia em relação aos demais culicídeos capturados em armadilha luminosa $\mathrm{CDC}+\mathrm{CO}_{2}$, a $1 \mathrm{~m}, \quad 6 \mathrm{~m}$ e $12 \mathrm{~m}$ do solo, 17-20h, $18 / 09 / 2001$ a 17/09/2002. Ilha Comprida, SP

Figura 8 Freqüência de Kerteszia capturados em armadilha luminosa $\mathrm{CDC}+\mathrm{CO}_{2}, 17-20 \mathrm{~h}$, em relação aos estratos ( $1 \mathrm{~m}$ - solo, 6m - meio e $12 \mathrm{~m}$ - copa). Ilha Comprida, SP, $18 / 09 / 2001$ a $17 / 09 / 2002$.

Figura 9 Freqüências (\%) de $A n$. bellator e $A n$. cruzii em relação aos demais culicídeos capturados em armadilha luminosa $\mathrm{CDC}+\mathrm{CO}_{2}$, a $1 \mathrm{~m}, 6 \mathrm{~m}$ e $12 \mathrm{~m}$ do solo, das 17 20h. Ilha Comprida, SP, 18/09/2001 a 17/09/2002. 
Figura 10 Táxons com freqüência relativa superior a $1 \%$ capturados em armadilha luminosa $\mathrm{CDC}+\mathrm{CO} 2,17-20 \mathrm{~h}$, a $1 \mathrm{~m}, 6 \mathrm{~m}$ e $12 \mathrm{~m}$ do solo. Ilha Comprida, SP, 18/09/2001 a $17 / 09 / 2002$.

Figura 11 Precipitação acumulada semanal em 2001 e 2002 no municipio de Cananéia, SP.

Figura 12 Densidade de An. cruzii e An. bellator em bromélias de mata (de solo e epífitas até $12 \mathrm{~m}$ de altura) e precipitação acumulada nos 15 dias anteriores aos de coleta (pptç). Coletas quinzenais, de 18/09/2001 a 17/09/2002. Ilha Comprida, SP.

Figura 13 Intervalo de confiança dos volumes médios, volumes mínimos e máximos de água aspirada por bromélia, segundo estrato (no solo, $\mathrm{P}$-praia e $\mathrm{M}$-mata). Ilha Comprida, set/2001 a set/2002.

Figura 14 Densidades de imaturos de An. bellator e An. cruzii em bromélias de solo e epifitas, segundo classes de altura (no solo, $\mathrm{P}=$ praia e $\mathrm{M}=$ mata). Ilha Comprida, set/2001 a set/2002.

Figura 15 Densidades de imaturos de Culicidae em bromélias de 46 solo e epifitas, segundo classes de altura (no solo, $\mathrm{P}=$ praia e $M=$ mata). Ilha Comprida, set/2001 a set/2002

Figura 16 Espécies de Culicidae com freqüência relativa superiores a $1 \%$. Larvas coletadas em bromélias de solo, na praia e na mata. Ilha Comprida, 18/09/2001 a $17 / 09 / 2002$

Figura 17 Espécies de Culicidae com freqüência relativa superiores a $1 \%$ e do subgênero Kerteszia. Larvas coletadas em bromélias a $[1,2[\mathrm{~m}$ solo, na mata. Ilha Comprida, 04/09/2001 a 17/09/2002.

Figura 18 Espécies de Culicidae com freqüência relativa superiores a $1 \%$ e do subgênero Kerteszia. Larvas coletadas em bromélias a $[2,3[\mathrm{~m}$ solo, na mata. Ilha Comprida, 04/09/2001 a 17/09/2002.

Figura 19 Espécies de Culicidae com freqüência relativa 64 superiores a $1 \%$ e do subgênero Kerteszia. Larvas coletadas em bromélias a $[3,4[\mathrm{~m}$ do solo, na mata. Ilha Comprida, 04/09/2001 a 17/09/2002. 
Figura 20 Espécies de Culicidae com freqüência relativa superiores a $1 \%$ e do subgênero Kerteszia. Larvas coletadas em bromélias a $[4,5[\mathrm{~m}$ solo, na mata. Ilha Comprida, 04/09/2001 a 17/09/2002.

Figura 21 Espécies de Culicidae com freqüência relativa superiores a $1 \%$ e do subgênero Kerteszia. Larvas coletadas em bromélias a $[5,6[\mathrm{~m}$ solo, na mata. Ilha Comprida, 04/09/2001 a 17/09/2002.

Figura 22 Espécies de Culicidae com freqüência relativa superiores a $1 \%$ e do subgênero Kerteszia. Larvas coletadas em bromélias a $[6,7[\mathrm{~m}$ solo, na mata. Ilha Comprida, 04/09/2001 a 17/09/2002.

Figura 23 Espécies de Culicidae com freqüência relativa 66 superiores a $1 \%$ e do subgênero Kerteszia. Larvas coletadas em bromélias a $[7,8[\mathrm{~m}$ do solo, na mata. Ilha Comprida, 04/09/2001 a 17/09/2002.

Figura 24 Espécies de Culicidae com freqüência relativa 66 superiores a $1 \%$ e do subgênero Kerteszia. Larvas coletadas em bromélias a $[8,9[\mathrm{~m}$ do solo, na mata. Ilha Comprida, 04/09/2001 a 17/09/2002.

Figura 25 Espécies de Culicidae com freqüência relativa 67 superiores a $1 \%$ e do subgênero Kerteszia. Larvas coletadas em bromélias a $[9,10[\mathrm{~m}$ do solo, na mata. Ilha Comprida, 04/09/2001 a 17/09/2002.

Figura 26 Espécies de Culicidae com freqüencia relativa superiores a $1 \%$ e do subgênero Kerteszia. Larvas coletadas em bromélias a $[10,11[\mathrm{~m}$ do solo, na mata. Ilha Comprida, 04/09/2001 a 17/09/2002.

Figura 27 Espécies de Culicidae com freqüência relativa 68 superiores a $1 \%$ e do subgênero Kerteszia. Larvas coletadas em bromélias a $[11,12[\mathrm{~m}$ do solo, na mata. Ilha Comprida, 04/09/2001 a 17/09/2002.

Figura 28 Densidade de larvas de Culicidae em bromélias de solo 69 em ambientes de restinga e mata. Ilha Comprida, $18 / 09 / 2001$ a $17 / 09 / 2002$.

Figura 29 Densidade de larvas de Culicidae em bromélias a até $5 \mathrm{~m}$ do solo, em ambiente de mata. Ilha Comprida, 04/09/201 a 17/09/2002. 
Figura 30 Densidade de larvas de Culicidae em bromélias de 5 a $9 \mathrm{~m}$ do solo, em ambiente de mata. Ilha Comprida, $04 / 09 / 201$ a $17 / 09 / 2002$

Figura 31 Densidade de larvas de Culicidae em bromélias de 9 a $12 \mathrm{~m}$ do solo, em ambiente de mata. Ilha Comprida, 04/09/201 a 17/09/2002. 


\section{LISTA DE TABELAS}

Tabela 1 Mosquitos capturados a 1 metro do solo, em armadilha luminosa $\mathrm{CDC}+\mathrm{CO}_{2}, 17-20 \mathrm{~h}, 18 / 09 / 2001$ a $17 / 09 / 2002$. Ilha Comprida, SP.

Tabela 2 Mosquitos capturados a 6 metros do solo, em armadilha luminosa $\mathrm{CDC}+\mathrm{CO}_{2}, 17-20 \mathrm{~h}, 18 / 09 / 2001$ a 17/09/2002. Ilha Comprida, SP.

Tabela 3 Mosquitos capturados a 12 metros do solo, em armadilha luminosa $\mathrm{CDC}+\mathrm{CO}_{2}, 17-20 \mathrm{~h}, 18 / 09 / 2001$ a 17/09/2002. Ilha Comprida, SP.

Tabela 4 Comparações entre An. bellator e An. cruzii capturados em armadilha luminosa $\mathrm{CDC}+\mathrm{CO}_{2}$, das $17-20 \mathrm{~h}$, a 1 (solo), 6 (meio) e 12 (copa) metros acima do solo. Ilha Comprida, SP, 18/09/2001 a 17/09/2002.

Tabela 5 Compartilhamento e constância de gêneros e espécies de Culicidae capturadas em armadilha luminosa tipo $\mathrm{CDC}+\mathrm{CO}_{2}$, das 17 as $20 \mathrm{~h}$, a $1 \mathrm{~m}, 6 \mathrm{~m}$ e $12 \mathrm{~m}$ do solo. Município de Ilha Comprida, 18/09/2001 a 17/09/2002.

Tabela 6 Coletas de larvas de Kerteszia em bromélias. Ilha Comprida, SP, 04/092001 a 17/09/2002.

Tabela 7 Dados referentes ao número de bromélias de solo (brom), volume aquático aspirado ( $\mathrm{vol}$, em $\mathrm{ml}$ ), volume médio por bromélia $\left(\mu_{\mathrm{vol}}, \mathrm{em} \mathrm{ml}\right)$ e positividade para larvas de Kerteszia (Ker). Ilha Comprida, SP, 04/09/2001 a 17/09/2002.

Tabela 8 Dados referentes ao número de bromélias aspiradas até $5 \mathrm{~m}$ de altura (brom), volume ( $\mathrm{vol}$, em $\mathrm{ml}$ ), volume médio por bromélia $\left(\mu_{\mathrm{vol}}, \mathrm{em} \mathrm{ml}\right)$ e positividade para larvas de Kerteszia (Ker). lha Comprida, SP, 04/09/2001 a 17/09/2002.

Tabela 9 Dados referentes ao número de bromélias aspiradas acima de $5 \mathrm{~m}$ de altura (brom), volume (vol, em $\mathrm{ml}$ ), volume médio por bromélia $\left(\mu_{\mathrm{vol}}, \mathrm{em} \mathrm{ml}\right)$ e positividade para larvas de Kerteszia (Ker). lha Comprida, SP, 04/09/2001 a 17/09/2002.

Tabela 10 Número de coletas positivas para larvas de An. cruzii (c) e/ou An. bellator (b) em bromélias na mata e proporção relativa na coexistência de ambas as espécies, segundo estratificação vertical. Ilha Comprida, 04/09/2001 a 17/09/2002. 
Tabela 11 Larvas de Culicidae coletadas em bromélias de solo na praia. Ilha Comprida, SP, 18/09/2001 a 17/09/2002.

Tabela 12 Larvas de Culicidae coletadas em bromélias de solo na mata Ilha Comprida, SP, 18/09/2001 a 17/09/2002.

Tabela 13 Larvas de Culicidae coletadas em bromélias a [1,2[m do solo na mata. Ilha Comprida, SP, 18/09/2001 a 17/09/2002.

Tabela 14 Larvas de Culicidae coletadas em bromélias a [2,3[m do solo na mata. Ilha Comprida, SP, 18/09/2001 a 17/09/2002

Tabela 15 Larvas de Culicidae coletadas em bromélias a [3,4[m do solo na mata. Ilha Comprida, SP, 18/09/2001 a 17/09/2002

Tabela 16 Larvas de Culicidae coletadas em bromélias a [4,5[m do solo na mata. Ilha Comprida, SP, 18/09/2001 a 17/09/2002.

Tabela 17 Larvas de Culicidae coletadas em bromélias a $[5,6[\mathrm{~m}$ do solo na mata. Ilha Comprida, SP, 18/09/2001 a 17/09/2002.

Tabela 18 Larvas de Culicidae coletadas em bromélias a [6,7[m do solo na mata. Ilha Comprida, SP, 18/09/2001 a 17/09/2002.

Tabela 19 Larvas de Culicidae coletadas em bromélias a [7,8[m do solo na mata. Ilha Comprida, SP, 18/09/2001 a 17/09/2002.

Tabela 20 Larvas de Culicidae coletadas em bromélias a [8,9[m do solo na mata. Ilha Comprida, SP, 18/09/2001 a 17/09/2002.

Tabela 21 Larvas de Culicidae coletadas em bromélias a $[9,10[\mathrm{~m}$ do solo na mata. Ilha Comprida, SP, 18/09/2001 a 17/09/2002.

Tabela 22 Larvas de Culicidae coletadas em bromélias a [10,11[m do solo na mata. Ilha Comprida, SP, 18/09/2001 a 17/09/2002.

Tabela 23 Larvas de Culicidae coletadas em bromélias a [11,12[m do solo na mata. Ilha Comprida, SP, 18/09/2001 a 17/09/2002.

Tabela 24 Compartilhamento e constância de espécies de Culicidae coletadas em bromélias, segundo estratos. Ilha Comprida, 04/09/2001 a 17/09/2002. 


\section{ERRATA}

Na página 45, abaixo da Figura 14, onde se lê:

"As larvas de Kerteszia coletadas foram criadas em laboratório. Ao todo, foram criadas 2180 larvas, das quais $2119(\mathbf{9 7 \%})$ desenvolveram-se até a fase adulta, sendo 754 (34\%) An. cruzii e 1002 (46\%) An. bellator (em 363 (16,7\%) dos indivíduos não foi possivel determinar a espécie).", leia-se:

"As larvas de Kerteszia coletadas foram criadas em laboratório. Ao todo, foram criadas 2180 larvas, das quais $1853(85 \%)$ desenvolveram-se até a fase adulta, sendo 815 (44\%) An. cruzii e 996 (54\%) An. bellator (em 42 (2\%) dos indivíduos não foi possivel determinar a espécie).", considere:

Na página $63,2^{\mathrm{a}}$ linha, onde se lê:

"registrada em todo o estudo, contribuindo com $34,5 \%$ das 1709 larvas coletadas", leia-se:

"registrada em todo o estudo, contribuindo com $21,5 \%$ das 1709 larvas coletadas".

Na página $79,3^{\mathrm{a}}$ linha, onde se lê:

"No presente trabalho, Kerteszia representou 36\% dos 55226 Culicidae", leia-se

"No presente trabalho, Kerteszia representou 13,4\% dos 55226 Culicidae".

Na página 87 , penúltima linha, onde se lê:

" $12,5 \mathrm{ml}$ e máximo de $650 \mathrm{ml} / \mathrm{bromélia.",} \mathrm{leia-se:}$

"7,5ml e máximo de $840 \mathrm{ml} /$ bromélia."

Na página 99, Referências, inserir:

Ramirez CCL, Dessen EMB. Chromosomal evidence for sibling species of the malaria vector Anopheles cruzii. Genome 2000; 43:143-51.

Na página 100, Referências, inserir:

Wallner WE. Factors affecting insect population dynamics: differences between outbreak and non-outbreak species. Ann Rev Entomol 1987; 32:317-40. 


\section{ÍNDICE}

1. INTRODUÇÃO 1

2. OBJETIVOS 8

2.1. Objetivo geral 8

2.2. Objetivos específicos $\quad 8$

3. MÉTODOS 9

3.1. Localidades estudadas 9

3.2. Pontos de coleta 11

3.3. Captura de adultos 12

3.4. Coleta de imaturos 13

$\begin{array}{ll}\text { 4. RESULTADOS } & 17\end{array}$

$\begin{array}{ll}\text { 4.1. Adultos } & 17\end{array}$

4.2. Imaturos 33

$\begin{array}{ll}\text { 5. DISCUSSÃO } & 73\end{array}$

6. CONCLUSÕES 90

7. CONSIDERAÇÕES FINAIS 92

REFERÊNCIAS 94

ANEXOS 


\section{INTRODUÇÃO}

A "bromélia-malária" ou "malária de bromélias" é assim chamada devido à associação de sua ocorrência com matas ricas neste tipo de vegetal, onde se desenvolvem as formas imaturas dos mosquitos do subgênero Kerteszia, transmissores da doença (CONSOLI e LOURENÇO-DE-OLIVEIRA 1994).

No Brasil, a bromélia-malária foi considerada endêmica nos estados de São Paulo, Paraná, Santa Catarina e Rio Grande do Sul. No início dos anos 40, a incidência anual da doença era de 4.000 casos/100.000 habitantes (DEANE 1988). Situação mais grave foi registrada em 1944 no litoral paranaense, atingindo 45,4\% da população (LUZ et al 1979)

O encontro de espécimes de Anopheles cruzii infectados por esporozoítos de plasmódio, associado à sua antropofilia e alta densidade, confirmou a transmissão de malária por esta espécie (CORREA 1943). An. bellator e An. homunculus também foram encontrados infectados por esporozoítos, ficando comprovado o envolvimento destas espécies na transmissão da bromélia-malária (DEANE 1986)

Muito do que se conhece sobre as espécies de Kerteszia foi sistematizado e estabelecido nas décadas de 40,50 e 60, visando estratégias mais especificas para o controle do problema bromélia-malária.

Os trabalhos de VELOSO et al (1956), VELOSO (1958) e RACHOU (1958) tornaram-se importantes referências sobre o estudo de larvas dos anofelinos Kerteszia. Larvas de An. cruzii parecem ser indiferentes quanto ao tamanho e localização das bromélias (epífitas ou terrestres), em matas preservadas de planície quaternária. Larvas de An. bellator estão mais associadas a bromélias epífitas que acumulem maior volume de água e expostas ao sol, em áreas de restinga e/ou rupestres. Ficou demonstrado também que não há correlação espécie-específica entre bromélias e anofelinos.

Com base nesses conhecimentos, a eliminação de bromélias, por remoção e/ou aplicação de herbicidas, foi adotada como medida de controle. De acordo com DEANE (1988), tal medida, bem como a aplicação de herbicidas, 
larvicidas e inseticidas reduziram o número de casos a $4.000 \sim 5.000$ nos anos 70 , a 500 casos em 1980 e 71 em 1982.

Diante do conhecimento disponivel até então, foi possivel controlar a bromélia-malária. Porém, há ainda aspectos sobre a biologia das espécies de Kerteszia a serem estudados.

A começar pela morfologia de $A n$. cruzii, ZAVORTINK (1973) havia levantado a hipótese deste anofelino constituir mais de uma espécie, com base na observação de diferenças entre populações dos Estados do Rio de Janeiro e Santa Catarina. Anos depois, o desenvolvimento de novas técnicas de estudo permitiu o teste desta hipótese. RAMIREZ e DESSEN (2000) caracterizaram An. cruzii como complexo de espécies, demonstrando padrões citogenéticos diferentes em populações provenientes de São Paulo e Santa Catarina. Mais recentemente, CARVALHOPINTO e LOURENCCO-DE-OLIVEIRA (2004) observaram padrões isoenzimáticos que distinguiam An. cruzii da Bahia daqueles dos Estados do Rio de Janeiro, São Paulo e Santa Catarina, semelhantes entre si.

O estabelecimento do complexo An. cruzii confirmou hipótese levantada há anos e exigirá pesquisas sobre a identificação e a capacidade vetora de suas espécies. Além disso, será interessante fazer nova leitura de trabalhos anteriores.

Com relação à bionomia de Kerteszia, poucos trabalhos conciliaram dados sobre larvas e adultos, simultaneamente. No municipio de Cananéia, FORATTINI et al (1961) examinaram um total de 942 lotes de 10 bromélias, terrestres e epifitas, e encontraram 58,3\% deles positivos para larvas de Kerteszia. Contudo, o número de imaturos encontrado foi muito baixo: 2,6 An. cruzii e 1,3 An. bellator por lote, o que não correspondeu aos dados de adultos, muito mais abundantes, tanto no intra quanto no peridomicilio junto à mata primitiva. Capturas semanais com isca humana, no horário do crepúsculo vespertino até as 21:00 horas, ao longo de seis meses, totalizaram 258 espécimes de $A n$. cruzii e 208 de An. bellator no intradomicilio, e no peridomicilio, 1055 espécimes de $A n$. cuzii e 505 de $A n$. bellator. Esta pesquisa comprovou que, embora a transmissão extradomiciliar fosse característica da bromélia-malária, os anofelinos Kerteszia freqüentavam o ambiente domiciliar 
SETO (1992) coletou larvas de Culicidae em bromélias na Aldeia dos Índios, no municipio de Peruíbe e encontrou 58,5\% das bromélias examinadas, individualmente, positivas para larvas de mosquitos e $14 \%$ de positividade para o subgênero Kerteszia, representado pelas espécies $A n$. cruzii e $A n$. homunculus.

LUZ et al (1979) discutiram sobre alguns fatores que pudessem justificar a malária residual no litoral paranaense: modificação de comportamento do vetor quanto à freqüência domiciliar e resistência, repelência ou irritabilidade ao inseticida de poder residual. Utilizando a técnica de isca humana, no periodo de março de 1976 a setembro de 1977, os autores registraram média horária mensal máxima de 18,1 para $A n$. cruzii no domicilio, 31,7 no peridomicilio e 62,0 na mata Assim, ficou demonstrado que, apesar da aplicação de inseticida, este anofelino continuava freqüentando habitação humana durante todo o ano

Estudos de alcance de vôo puderam justificar o encontro de adultos em área onde as bromélias haviam sido removidas. CORREA et al (1961) comprovaram que anofelinos Kerteszia foram capazes de cruzar $800 \mathrm{~m}$ sobre o mar, entre os municipios de Ilha Comprida e Cananéia. FERREIRA et al (1969a) registraram vôo de $1.000 \mathrm{~m}$ no Estado do Paraná. RACHOU (1958) referiu vôos de até $2.000 \mathrm{~m}$.

Em levantamentos de fauna as formas adultas de Kerteszia dominam entre os Culicidae em matas primitivas. Em áreas de restinga, An. bellator domina sobre An. cruzii (FORATTINI et al 1996, 1999). Em ambiente de mata no nordeste do Estado de São Paulo, FORATTINI et al (1968) verificaram que 70\% dos mosquitos coletados eram An. cruzii. Em mata primitiva no sudeste do Estado de São Paulo, FORATTINI et al (1986a) registraram predominio de $81 \%$ de mosquitos do subgênero Kerteszia, com destaque para An. cruzii. O comportamento acrodendrófilo desta espécie foi demonstrado por FORATTINI et al (1968) em São Paulo. Os pesquisadores coletaram $83,3 \%$ dos espécimes de $A n$. cruzii a $15 \mathrm{~m}$ de altura, em copa arbórea. No Rio de Janeiro, GUIMARÃES et al (1985) encontraram dado semelhante: $85 \%$ das fêmeas da espécie foram coletadas em estrato arbóreo, a $10 \mathrm{~m}$ do solo. 
DORVILLÉ (1996) estabeleceu o subgênero Kerteszia como bioindicador de degradação florestal para Mata Atlântica no sudeste de São Paulo. Assim, a intensificação de alterações antrópicas levaria à redução ou mesmo ao desaparecimento das espécies deste subgênero. Porém, FORATTINI et al (2000) indicaram certo grau de sinantropia para Kerteszia em função de sua freqüência ao ambiente antrópico em busca de fontes para realizar repasto sangüineo.

Quanto ao horário de atividade hematofágica, tanto An. cruzii quanto An. bellator apresentam atividade contínua ao longo do dia, com um pico no crepúsculo vespertino e outro, menor, no matutino (RACHOU et al 1958; FORATTINI et al 1986b; CONSOLI e LOURENÇO-DE-OLIVEIRA 1994)

Em relação à fonte sangüinea, estes mosquitos são considerados ecléticos, com alta antropofilia, podendo picar também outros mamiferos e aves (CORREA 1943; DEANE 1986; GUIMARÃES et al 1987; FORATTINI et al 1990; WILKERSON e PEYTON 1991). Apesar da antropofilia, aceitava-se que as espécies não apresentavam tendência a permanecer no domicílio. No entanto, tem-se observado em An. bellator maior atividade endofágica do que em An. cruzii (FORATTINI et al 1993, 1999; FORATTINI e MASSAD 1998). Para esta espécie, vetora natural de malária simiana na região Neotropical (DEANE et al 1970), o ecletismo e a mobilidade vertical no sentido copa-solo e vice-versa tornam possivel a ocorrência de infecção humana por plasmódios de macacos em áreas com ocorrência de malária simiana (DEANE 1984).

No municipio de Cananéia, São Paulo, SANTOS (2001) calculou a capacidade vetora de $A n$. (Kerteszia). Embora os valores obtidos tenham sido baixos, a autora demonstrou predomínio de $A n$. bellator sobre $A n$. cruzii, com freqüência ao ambiente domiciliar, tanto no peri quanto no intradomicílio, durante o ano todo e sobrevivência de 59 dias em campo. Além disso, sugeriu discordância gonotrófica para o subgênero, hipótese que havia sido levantada por FORATTINI et al (1993). Tais características biológicas das espécies de Kerteszia, associadas ao histórico de malária na região e a permanência de transmissão de casos esporádicos da doença reforçam a necessidade de monitoramento da região.

Conforme apresentado anteriormente, LUZ et al (1979) haviam alertado sobre mudanças na biologia dos anofelinos Kerteszia como respostas 
adaptativas às medidas de controle da bromélia-malária. No município de Paranaguá, Paraná, LUZ et al (1987) encontraram duas larvas de An. cruzii em vasos de barro em localidade onde não existem bromélias. Os autores levantaram hipótese de transporte passivo das larvas ou de fêmeas que voaram ao acaso até ali e ovipuseram nos vasos por não terem encontrado bromélias.

Todavia, FORATTINI et al (1998b) registraram a presença de duas larvas e uma pupa de An. bellator em caixa d'água com 70 litros, em Ilha Comprida, São Paulo, onde as bromélias são abundantes. FORATTINI (1998) menciona tais variações qualitativas em criadouros, além de outras, em discussão sobre vetores emergentes ou ressurgentes como conseqüência de alterações antrópicas, ecológicas e climáticas. Em relação à malária, o autor cita a chamada "malária aero-portuária", em função de portos e aeroportos onde possam desembarcar vetores de regiões endêmicas.

Apesar do encontro de larvas de Kerteszia em recipientes artificiais, na atualidade seus criadouros naturais estão protegidos sob legislação (Parques e Áreas de Proteção Ambiental) e não se cogita mais o extermínio de bromélias como medida de controle da bromélia-malária. Além disso, tem-se verificado crescente uso deste vegetal para fins decorativos, situação na qual FORATTINI et al (1998a) consideram as bromélias domesticadas como recipientes artificiais. Nesta situação registrou-se encontro de larvas de Aedes aegypti em bromélia no quintal de residência em área urbana, no município de Potim, São Paulo (FORATTINI e MARQUES 2000).

MARQUES (2001) estudou bromélias terrestres em ambiente urbano, periurbano e florestal no município de Ilhabela, São Paulo, com o objetivo de avaliar o potencial de colonização desses vegetais por Aedes albopictus, bem como estabelecer a fauna de larvas de Culicidae nesses criadouros. De fato, a autora registrou a presença de Aedes albopictus nos três ambientes, assim como An. cruzii. A primeira espécie predominou no ambiente urbano, enquanto que a segunda, no florestal. Tal situação merece destaque e monitoramento, pois torna possível a transferência de patógenos transmitidos por mosquitos de um ambiente para outro.

As bromélias são consideradas como ecossistema. Sob este ponto de vista, há estudos sobre composição de fauna, estimativas de diversidade, relações 
tróficas, dinâmica populacional e outros aspectos ecológicos (COTGREAVE et al 1993; RICHARDSON 1999; RICHARDSON et al 2000).

Do ponto de vista de Saúde Pública, as bromélias são consideradas criadouros de alguns grupos de Culicidae, como os anofelinos Kerteszia, tornando fundamental a descrição da composição específica dos culicídeos que nelas se desenvolvem para possibilitar a indicação da presença de vetores. São de igual importância a identificação de fatores abióticos e bióticos reguladores dessas populações. Trabalhos em laboratório constituem complemento essencial para o entendimento da biologia de imaturos, pois permitem o estudo de fatores isoladamente, seja procurando simular condições de campo, seja produzindo condições mais extremas, na tentativa de estabelecer limites de tolerância ao fator estudado, sempre o associando à taxa de mortalidade dos imaturos e ao tempo de desenvolvimento até a emergência do adulto.

De acordo com a Superintendência de Controle de Endemias (Sucen), nos últimos 20 anos, $87 \%$ dos casos de malária autóctone no Estado de São Paulo ocorrem na região da Serra do Mar, quase metade deles em municípios do Vale do Ribeira, com provável transmissão por Kerteszia. Tais casos são de decurso clínico geralmente atípico, brando ou mesmo assintomático.

No municipio de Juquitiba, Vale do Ribeira, São Paulo, CURADO et al (1997) demonstraram prevalência de $73 \%$ de soros positivos para anticorpos contra Plasmodium vivax entre residentes locais, os quais trabalhavam como caseiros de propriedades visitadas em finais de semana e férias. Entre seus proprietários, 18\% apresentaram sorologia positiva para anticorpos contra $P$. vivax. Residentes e não residentes, respondendo a questionário, não relataram ocorrência anterior de malária.

Recentemente, CURADO (2003) demonstrou a ocorrência de malária assintomática no sul do Estado de São Paulo em locais bastante visitados por turistas (PETAR - Parque Estadual Turístico do Alto do Ribeira - e Parque Estadual Intervales, localizados às margens do médio e alto curso do Rio Ribeira, Intervales), por meio da obtenção de sorologia positiva em individuos que não haviam relatado sintomas da doença, bem como o encontro de anofelinos (An. cruzii) infectados por 
plasmódio. A autora levanta a hipótese de que macacos possam estar atuando como reservatórios da doença.

Assim, atividades como extrativismo, pesca e turismo podem colocar a população humana, residente e flutuante, em contato com áreas silvestres, implicando em risco de transmissão de doenças veiculadas por mosquitos e outros artrópodes. Quadros brandos ou inespecificos de tais podem passar despercebidos pelos indivíduos infectados, mas representam sério risco epidemiológico.

Embora poucos casos de malária sejam registrados na região, a transmissão tem se dado continuamente, ano a ano. Deste modo, várias questões sobre a dinâmica de transmissão local da doença precisam ser esclarecidas em relação ao parasita - identificação de variantes menos virulentas de $P$. vivax ou mesmo de plasmódios não humanos; em relação ao hospedeiro - suscetibilidade, diagnóstico e resposta imune da população local e flutuante; em relação ao vetor avaliação atual da densidade relativa de adultos e imaturos, bem como sua distribuição espacial e temporal.

Além disso, se por um lado, o incremento de atividades de ecoturismo pode inserir o homem em ciclos enzoóticos, por outro lado, a domesticação de bromélias pode incentivar extrativismo desses vegetais de seu ambiente natural e dispersar passivamente imaturos de Culicidae que podem encontrar condições favoráveis junto ao homem

Justifica-se assim a necessidade de pesquisar aspectos bio-ecológicos de $A n$. cruzii e An. bellator, bem como o estudo da fauna de Culicidae associada a essas espécies em bromélias na região do Vale do Ribeira. 


\section{OBJETIVOS}

\subsection{Objetivo Geral}

Avaliar a densidade e a distribuição de larvas e adultos de $A n$. cruzii e An. bellator no município de Ilha Comprida, região do Vale do Ribeira.

\subsection{Objetivos Específicos}

- estudar a distribuição sazonal e vertical de adultos de $A n$. cruzii e $A n$. bellator na mata da região;

- estudar a distribuição sazonal de larvas de An. cruzii e An. bellator em bromélias na restinga e mata da região;

- estudar a distribuição vertical de larvas de $A n$. cruzii e $A n$. bellator em bromélias na mata da região;

- identificar a fauna de Culicidae associada às espécies de Kerteszia em bromélias na restinga e mata da região; 


\section{MÉTODOS}

\subsection{Localidades Estudadas}

A região do Vale do Ribeira situa-se entre $24^{\circ}$ e $25^{\circ} 16^{\prime} \mathrm{S}$ e $46^{\circ} 50^{\prime}$ e $49^{\circ} 20^{\prime} \mathrm{W}$, ocupando uma área de aproximadamente $17.000 \mathrm{~km}^{2}$. O clima é tropical superúmido com precipitação média anual de $1800 \mathrm{~mm}$ e temperaturas médias entre 18 e $25^{\circ} \mathrm{C}$. Em relação à fitogeografia local, predomina o aspecto florestal de mata perenifólia higrófila (floresta latifoliada tropical úmida da encosta). Destaca-se a riqueza de bromeliáceas epifitas, terrestres e rupestres em toda a região (FORATTINI et al 1978; FORATTINI e MASSAD 1998).

$\mathrm{Na}$ região, o município de Ilha Comprida localiza-se a $24^{\circ} 91^{\prime} \mathrm{S}$ e $47^{\circ} 80^{\prime} \mathrm{W}$. Localizada no extremo sul do Estado, com aproximadamente $70 \mathrm{~km}$ de extensão e $3 \mathrm{~km}$ de largura, a ilha tem como limite ao sul e ao norte, respectivamente, as desembocaduras de Cananéia e Icapara. Formada por planícies arenosas ("terraços marinhos"), divididas em altas e baixas, conforme as transgressões marinhas sofridas, há dunas em toda a orla atlântica. A vegetação é tolerante ao sal e colonizadora de corpos arenosos. Distanciando-se do oceano, a vegetação se torna mais complexa: atrás das dunas há áreas alagadiças com herbáceas de brejo, que podem formar ribeirões; em terrenos argilo-orgânicos formase mata de restinga e, em torno dos mares interiores, há vegetação de mangue (MARETTI e FILET 1988)

Para o ano de 2004, a população do município está estimada em 8017 habitantes, com taxa de urbanização de $100 \%$. As atividades locais se concentram no setor de serviços e comércio (SEADE 2004).

A Figura 1 representa o mapa da região estudada. A área verde indica cobertura por floresta ombrófila densa e os contornos em vermelho indicam unidades de conservação.

Ao sul da Ilha Comprida, localiza-se a vila de Pedrinhas. O acesso à ilha é feito via balsa, a partir de Cananéia, e a seguir, percorre-se cerca de $16 \mathrm{~km}$, entre o mar e extensa mata de restinga. Próximo à vila, selecionou-se fragmento de mata rico em bromélias, onde foram selecionados 4 pontos de coleta. 


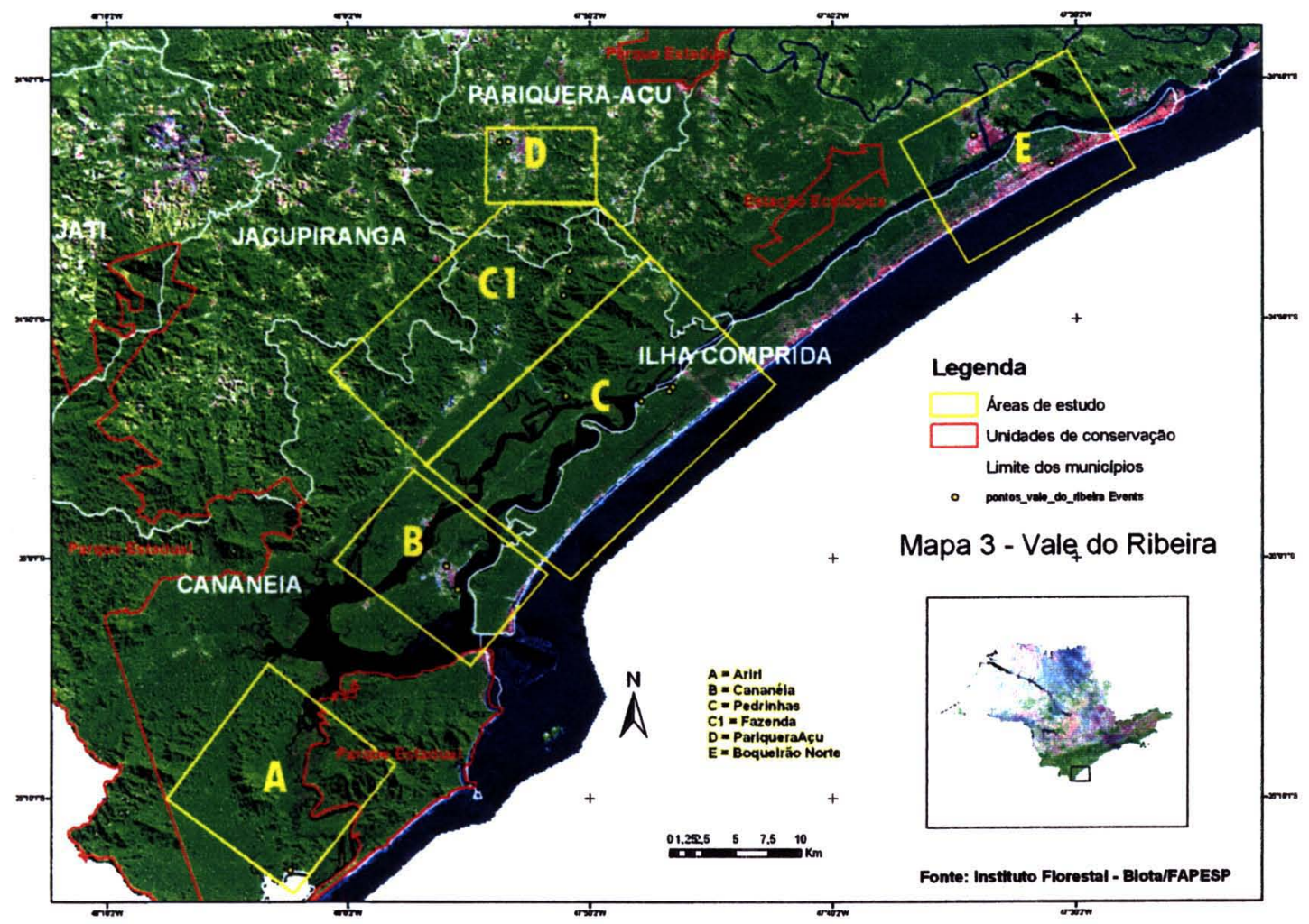

Figura 1: Mapa da Região do Vale do Ribeira. A área deste estudo localiza-se no Municipio de llha Comprida, Via de Pedrinhas (área "C").

Fonte: Imagem - Instituto Florestal. Detalhamento do mapa realizado no Laboratório de Epidemiologia e Bioestatística - Depto. Medicina Veterinária Preventiva e Saúde Animal - FMVZIUSP 


\subsection{Pontos de Coleta}

Conforme descrito anteriormente, foram selecionados quatro pontos de coleta, esquematizados abaixo:

\section{Esquema de Coletas}

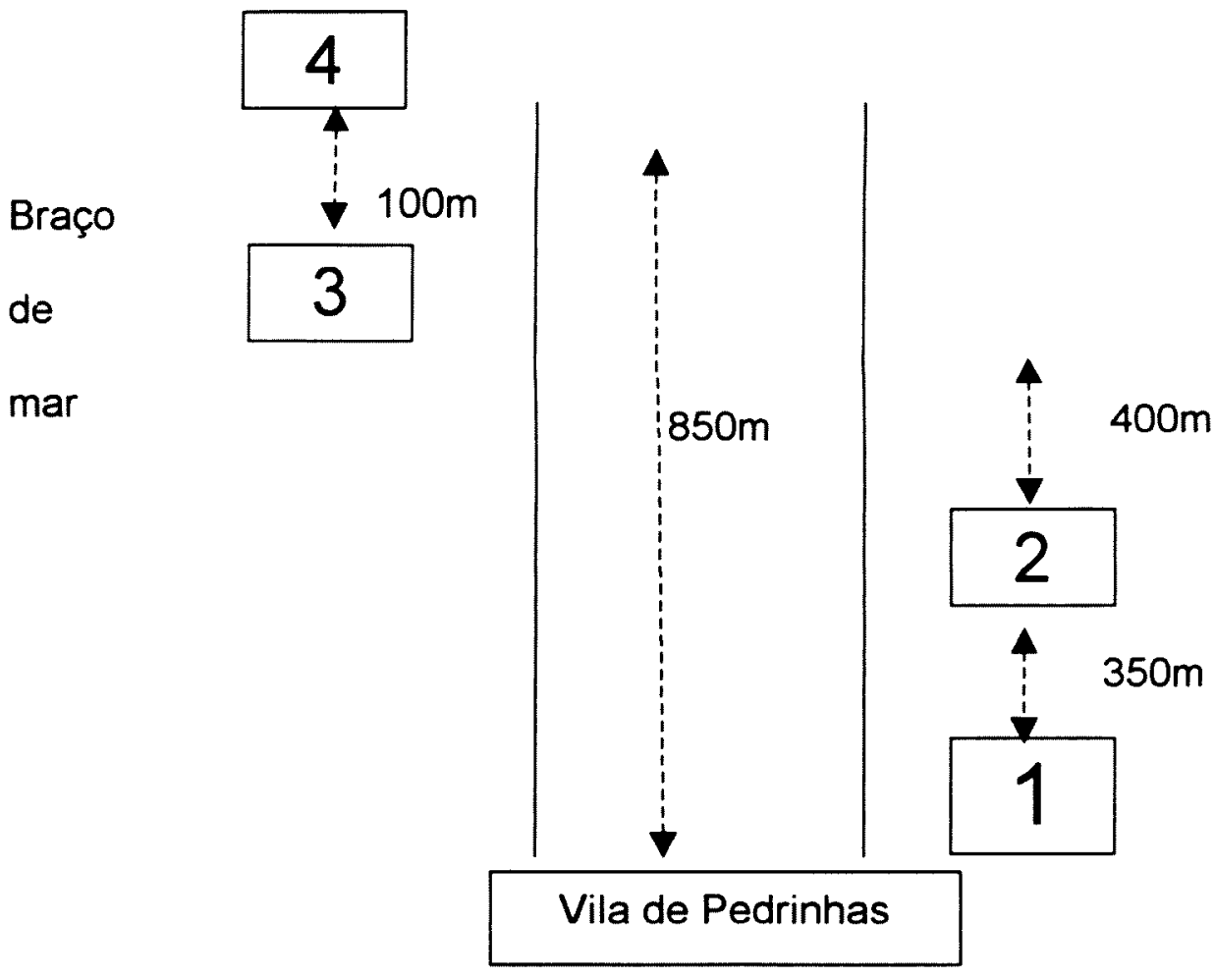

Figura 2: Esquema da Estrada de Ubatuba, próxima à Vila de Pechinhas, onde se localizam os pontos estudados. Ilha Comprida, SP.

As atividades de campo ocorreram quinzenalmente, ao longo de um ano, sempre com equipe de quatro pessoas. 


\subsection{Captura de Adultos}

Para a captura de adultos foram utilizadas armadilhas luminosas tipo $\mathrm{CDC}$, iscadas com cerca de $1 \mathrm{~kg}$ de gelo seco $\left(\mathrm{CO}_{2}\right)$. As armadilhas foram instaladas quinzenalmente nos pontos 1 e 2, no horário das 17 às $20 \mathrm{~h}$, sempre nas mesmas árvores, a $1 \mathrm{~m}$ (solo), $6 \mathrm{~m}$ (meio) e $12 \mathrm{~m}$ (copa) do solo. Para facilitar a instalação das armadilhas, foram marcados pontos de referência nas alturas indicadas e amarrados cordames aos troncos, de modo que as CDCs pudessem ser içadas rapidamente. A equipe dividiu-se em duplas para que as capturas tivessem início simultaneamente.

Ao término do horário de captura, as duplas recolhiam as armadilhas. Os mosquitos foram imediatamente sacrificados em clorofórmio e, em seguida, transferidos para caixas entomológicas previamente etiquetadas para cada ponto ( $1 \mathrm{e}$ 2) e estrato (solo, meio e copa).

Em laboratório, o material foi triado e identificado até gênero. Somente espécimes dos gêneros Anopheles, Aedes e Culex foram identificados até o nivel específico, sempre que possivel.

As capturas ocorreram de 21/08/2001 a 17/09/2002, porém, as duas primeiras foram desconsideradas por terem diferido quanto ao uso do gelo seco nos pontos 1 e 2 .

Os bancos de dados foram elaborados separadamente para os pontos 1 e 2, mas os resultados apresentados levam em consideração a soma dos espécimes de ambos os pontos, já que um dos objetivos era avaliar a densidade populacional de adultos. Tabelas com os dados de cada ponto encontram-se em anexo (Tabelas I, II e III).

A distribuição sazonal e vertical está apresentada em gráficos de dispersão da freqüência relativa do subgênero Kerteszia e suas espécies na área estudada, e outros culicídeos.

Para a análise da distribuição sazonal, foi calculado o Coeficiente de Correlação de Spearman $\left(r_{s}\right)$ para as variáveis temperatura minima, temperatura máxima, amplitude térmica e precipitação em relação à densidade de $A n$. bellator e An. cruzii. Calculou-se pela fórmula de Kendall o valor $t$ associado a $r_{s}$, cuja significância pode ser comprovada pela significância de $t$. Isso foi possivel devido ao 
tamanho da amostra ( $\geq 10)$ (SIEGEL 1975). Os dados de temperatura utilizados no cálculo do coeficiente de Spearman são referentes às datas de coleta e os de precipitação correspondem à chuva acumulada nos 15 dias anteriores ao da coleta. Considerou-se a densidade diária total de $A n$. bellator e An. cruzii, ou seja, a somatória dos dados obtidos a $1 \mathrm{~m}, 6 \mathrm{~m}$ e $12 \mathrm{~m}$ de altura.

As comparações de densidade de $A n$. bellator e $A n$. cruzii em relação aos estratos foram feitas pelo teste não-paramétrico de Mann-Whitney para grandes amostras (maiores que 20). A significância do parâmetro $U$ é dada pelo valor $z$. Foi calculado fator de correção, que leva em consideração a ocorrência de capturas com o mesmo rendimento (repetições), fornecendo o valor zorrigido (SIEGEL 1975).

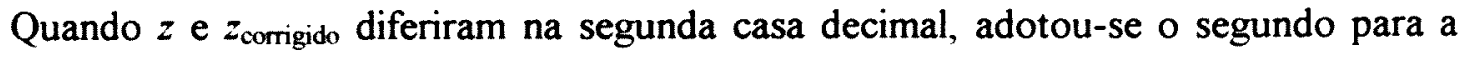
obtenção dos valores de $\mathrm{p}$, estabelecido o nível de significância $\alpha=0,05$.

Além disso, para visualizar melhor os resultados gerais obtidos, utilizou-se o indice de Constância (DAJOZ 1973), dado pela porcentagem de capturas positivas para a espécie (ou gênero). Conforme este valor, as espécies (ou gêneros) são classificadas em: constantes - presentes em mais de $50 \%$ das capturas; acessórias - presentes em 25 a $50 \%$ das capturas; ou acidentais - presentes em menos de $25 \%$ das capturas. Este indice, calculado para todas as espécies e gêneros, possibilita a observação do compartilhamento dos culicídeos capturados nos diferentes estratos e permite inferir comportamento acrodendrófilo.

\subsection{Coleta de Imaturos}

Para a coleta de imaturos, utilizou-se bomba manual de sucção para aspirar o conteúdo aquático das axilas das bromélias. Apesar do uso conhecido de bombas de aspiração tipo fole, neste trabalho sua utilização foi inviável para coletas em bromélias epifitas. Para padronizar o instrumento de coleta, foi adotada bomba simples, com cânula plástica e pêra, funcionando como pipeta. 
As bromélias de solo foram separadas de acordo com o tipo de ambiente - restinga e mata. Devido à grande quantidade desses vegetais, as coletas limitaram-se ao total de 50 bromélias ou 5 litros de água aspirada para cada ambiente. As bromélias da restinga eram aspiradas no início da manhã, a caminho da Vila de Pedrinhas, onde se situa o fragmento de mata estudado. Como a restinga se estende por quase $17 \mathrm{~km}$, à beira mar, não houve repetição de pontos, estabelecidos conforme quilometragem registrada a cada ida ao campo. Todos os membros da equipe trabalhavam simultaneamente no ponto escolhido.

Nos quatro pontos da mata, as coletas foram alternadas: numa quinzena, nos pontos 1 e 3 e, na seguinte, pontos 2 e 4 . As bromélias de solo foram aspiradas ao acaso nos pontos estipulados para a data de coleta. As epífitas foram divididas em 11 classes de altura: [1,2[ até [11,12[m. O volume aspirado em bromélias da mesma classe foi armazenado no mesmo recipiente e estimado em campo, independentemente do ponto trabalhado ( 1 e 3 , ou 2 e 4 ).

As bromélias situadas até 5 metros de altura foram acessadas com escada articulada de alumínio (4 módulos de 3 degraus; $10,2 \mathrm{~kg}$; altura máxima $3,56 \mathrm{~m})$.

$\mathrm{Na}$ classe $[1,2[\mathrm{~m}$ as bromélias eram bastante abundantes, embora menos do que no solo. Assim, ficou estabelecido limite de até 25 bromélias ou 2,5 litros de água aspirada.

A equipe dividiu-se, para que uma dupla aspirasse as bromélias de solo e das classes até $5 \mathrm{~m}$. Em função da grande quantidade de bromélias na classe [4,5[m, foi estabelecido limite de até 30 bromélias ou 3 litros de água aspirada.

Simultaneamente, a outra dupla trabalhou nos demais estratos, acessiveis por meio de equipamento de escalada, após treinamento específico para sua utilização. Foi utilizada técnica similar à descrita por PERRY (1978). Por questões operacionais, as bromélias acessadas com equipamento de escalada foram marcadas e as coletas foram repetidas nas mesmas árvores e bromélias, nos pontos 1 e 2 (as mesmas árvores onde foram instaladas as armadilhas para captura de adultos).

$\mathrm{O}$ volume aquático aspirado foi mantido em laboratório, segundo as classes de altura (e segundo ambiente, para as bromélias de solo) até a véspera da coleta seguinte. Durante o periodo de manutenção em laboratório, a água era 
examinada diariamente para retirada de pupas, as quais foram identificadas pela forma adulta. Além disso, as larvas de Anopheles foram transferidas para recipientes com água destilada, onde foram alimentadas com ração para peixe TetraMin5 $\operatorname{Star}^{\circledR} \mathrm{e}$ tiveram seu desenvolvimento acompanhado, sob temperatura ambiente, até a fase adulta. Na medida do possivel, ainda em campo ou em laboratório, predadores foram retirados com pipeta. As larvas remanescentes eram sacrificadas em água quente $\left(60^{\circ} \mathrm{C}\right)$ e preservadas em álcool $80 \%$ até serem montadas para identificação especifica e contagem.

A distribuição sazonal de imaturos foi analisada pelo Coeficiente de Correlação de Spearman $\left(\boldsymbol{r}_{s}\right)$ para verificar possivel associação entre precipitação acumulada nos 15 dias anteriores aos de coleta e a densidade total de cada espécie, An. bellator e $A n$. cruzii, representada pela soma das densidades obtidas nos estratos onde as espécies tenham ocorrido no dia. Por causa da variação do número de bromélias acessadas e volume de água aspirado entre estratos e coletas, a densidade de imaturos está padronizada como número de imaturos por $100 \mathrm{ml}$. Assim como para as formas adultas, foi possivel calcular o valor de $t$ associado ao $r_{s}$, permitindo a comprovação da significância deste último valor.

Da mesma forma, para a análise da distribuição vertical, utilizou-se o Coeficiente de Spearman $\left(r_{s}\right)$ para verificar possiveis correlações entre volume médio de água aspirado e altura das bromélias, densidade de imaturos de Culicidae e altura, densidade de $A n$. bellator e altura, e densidade de $A n$. cruzii e altura.

Os resultados apresentam-se como tabelas de composição específica por estrato. Ainda por estrato, as espécies com freqüência relativa superior a $1 \%$ foram plotadas em gráficos comparativos com a freqüência relativa das espécies de Kerteszia, mesmo quando abaixo de $1 \%$. Como para as formas adultas, utilizou-se para imaturos o índice de Constância (DAJOZ 1973).

O desenvolvimento das larvas de anofelinos foi acompanhado em condições de laboratório, a fim de produzir informação que pudesse auxiliar a 
compreensão dos dados de campo. Os resultados desse acompanhamento foram registrados em tabela à parte (resultados detalhados na Tabela IV, em anexo) e aqui se restringiram ao nível descritivo.

Os dados climáticos foram fornecidos pelo Instituto Oceanográfico USP e referem-se ao município de Cananéia, representado na Figura 1. Para auxiliar a interpretação dos resultados de sazonalidade, o periodo estudado foi dividido em semanas e os dados climáticos foram ilustrados em gráfico, incluindo dados do mês anterior (agosto/2001). Além disso, foi construído outro gráfico com os dados semanais de chuva, comparando a precipitação de 2001 com a de 2002.

Todos os espécimes, imaturos e adultos, foram identificados segundo as chaves de LANE (1953), CORRÊA e RAMALHO (1956), ZAVORTINK (1973), CONSOLI E LOURENÇO-DE-OLIVEIRA (1994), SALLUM E FORATTINI (1996) e FORATTINI (2002). Foi adotado sistema de abreviaturas de nomes das espécies de REINERT (2001). Não foram levadas em consideração as reclassificações de REINERT (2000), elevando o subgênero Ochlerotatus a gênero, nem a classificação de JUDD (1998) propondo Phoniomyia como subgênero de Wyeomyia, para permitir comparabilidade com outros trabalhos que utilizam a nomenclatura anterior a estas publicações.

Material testemunho será depositado na Coleção Entomológica da Faculdade de Saúde Pública - USP. 


\section{RESULTADOS}

\subsection{Adultos}

Durante o periodo de 18/09/2001 a 17/09/2002 foram capturados 55226 mosquitos: 13745 a 1 metro de altura (solo), 9614 a $6 \mathrm{~m}$ (meio) e 31867 a $12 \mathrm{~m}$ (copa), cujas distribuições encontram-se nas Tabelas 1, 2 e 3, respectivamente. Destacando An. bellator, foram capturados 1341 (2,4\% do total de Culicidae) mosquitos, sendo 278 próximo ao solo, 261 a $6 \mathrm{~m}$ e 802 indivíduos na copa. $\mathrm{Na}$ mesma ordem, 452, 1032 e 4420 adultos de An. cruzii, totalizando 5904 mosquitos desta espécie $(10,7 \%$ do total de Culicidae)

Outros mosquitos que se destacaram pela alta densidade foram os do gênero Coquillettidia, que representaram cerca de $40 \%$ da fauna registrada no solo (5311 mosquitos) e meio (3849 mosquitos), e 64\% na copa (20374 mosquitos). Espécies de Phoniomyia representaram $29 \%$ dos mosquitos no solo, $24 \%$ no meio e $11 \%$ na copa.

As tabelas 1, 2 e 3 incluem os registros de machos. Como era de se esperar, sua proporção é pequena, se comparada com as densidades de fêmeas. No solo, foram capturados 18 machos de Ae. hortator, 1 de $C x$. ribeirensis, 4 de $C x$. sacchettae, 1 de Cx. (Microculex) sp e 49 de Coquillettidia; a 6m, 1 Ae. fulvus, 4 Ae. hortator, $1 C x$. pedroi, $1 C x$. ribeirensis, 1 Cx. sacchettae, 1 Culex Seção Melanoconion, $2 C x$. (Mcx.) sp, 94 Coquillettidia e 1 Psorophora; e na copa, 2 Ae. hortator, 1 Ae. serratus/mubilus; 1 Cx. pedroi, 1 Cx. sacchettae, 1 Culex Seção Spissipes e 301 Coquillettidia. Dentre as espécies de Kerteszia, apenas 2 machos de An. cruzii e 1 de $A n$. bellator, todos na copa. Os exemplares foram preservados para montagem de genitália e posterior identificação até o nível especifico. 
Tabela 1: Mosquitos capturados a 1 metro do solo, em armadilha luminosa $\mathrm{CDC}+\mathrm{CO}_{2}, 17-20 \mathrm{~h}, 18 / 09 / 2001$ a 17/09/2002. llha Comprida, SP

\begin{tabular}{|c|c|c|c|c|c|c|c|c|c|c|c|c|c|c|c|c|c|c|c|c|c|c|c|c|c|c|c|}
\hline \multirow{2}{*}{ Táxon Capture } & \multirow{2}{*}{ set } & \multicolumn{2}{|c|}{ out } & \multicolumn{2}{|c|}{ nov } & \multicolumn{2}{|c|}{ dez } & \multicolumn{2}{|c|}{ jan } & \multicolumn{2}{|c|}{ fer } & \multicolumn{2}{|c|}{ mar } & \multicolumn{2}{|c|}{ abr } & \multicolumn{3}{|c|}{ maio } & \multicolumn{2}{|c|}{ jun } & \multicolumn{2}{|c|}{ jul } & \multicolumn{2}{|c|}{ ago } & \multicolumn{2}{|c|}{ set } & \multirow{2}{*}{ Total } \\
\hline & & 9 & 23 & 6 & 20 & 5 & 18 & 8 & 29 & 5 & 19 & 5 & 19 & 2 & 16 & 1 & 14 & 28 & 11 & 25 & 11 & 23 & 6 & 20 & 3 & 17 & \\
\hline An.bellator & 1 & 1 & 8 & 20 & 0 & 0 & 19 & 4 & 54 & 3 & 14 & 34 & 6 & 0 & 17 & 11 & 34 & 0 & 4 & 5 & 8 & 15 & 14 & 6 & 1 & 2 & 278 \\
\hline Anconzzii & 10 & 1 & 19 & 38 & 2 & 1 & 10 & 11 & 43 & 9 & 13 & 25 & 3 & 1 & 23 & 76 & 53 & 4 & 6 & 14 & $\theta$ & 31 & 14 & 20 & 2 & 14 & 452 \\
\hline An. (Ker.)sp** & 2 & 0 & 0 & 3 & 0 & 0 & 0 & 1 & 4 & 0 & 1 & 0 & 0 & 0 & 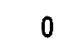 & 0 & 0 & 0 & 0 & 0 & 0 & 0 & 0 & 0 & 0 & 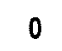 & 11 \\
\hline An. (AnO.) sp' & 0 & 0 & 2 & 1 & 0 & 0 & 0 & 1 & 4 & 9 & 5 & 1 & 1 & 3 & 12 & 4 & 0 & 1 & 2 & 0 & 0 & 5 & 0 & 0 & 0 & 0 & 51 \\
\hline Ae.albopictus & 0 & 0 & 0 & 0 & 0 & 0 & 0 & 0 & 0 & 0 & 0 & 1 & 0 & 0 & 0 & 0 & 0 & 0 & 0 & 0 & 0 & 0 & 0 & 0 & 0 & 0 & 1 \\
\hline Aoffulvus & 0 & 0 & 0 & 0 & 1 & 0 & 0 & 2 & 3 & 21 & 9 & 5 & 1 & 1 & 22 & 8 & 129 & 38 & 25 & 6 & 2 & 0 & 0 & 0 & 0 & 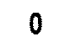 & 273 \\
\hline Ae.hortator & 0 & 0 & 7 & 3 & 0 & 0 & 0 & 7 & 5 & 17 & 4 & 0 & 1 & 0 & 15 & 7 & 8 & 0 & 3 & 0 & 0 & 0 & 0 & 0 & 0 & 0 & 77 \\
\hline Ae.scapularis & 1 & 0 & 10 & 3 & 0 & 0 & 7 & 4 & 0 & 3 & 1 & 3 & 5 & 1 & 19 & 1 & 28 & 1 & 2 & 0 & 0 & 10 & 1 & 2 & 5 & 0 & 107 \\
\hline Ae.serratus & 1 & 0 & 0 & 0 & 1 & 0 & 2 & 7 & 0 & 5 & 5 & 4 & 0 & 3 & 1 & 0 & 1 & 2 & 4 & 0 & 0 & 0 & 0 & 0 & 0 & 0 & 36 \\
\hline Ao.gr.Serretu & 3 & 2 & 20 & 2 & 1 & 2 & 7 & 81 & 0 & 33 & 23 & 33 & 22 & 4 & 13 & 41 & 43 & 17 & 23 & 33 & 13 & 23 & 3 & 2 & 0 & 0 & 444 \\
\hline Ae.sp * & 0 & 0 & 0 & 0 & 0 & 0 & 0 & 0 & 1 & 0 & 0 & 0 & 0 & 1 & 0 & 0 & 1 & 0 & 0 & 0 & 0 & 0 & 0 & 0 & 0 & 0 & 3 \\
\hline Coquillettidia & 71 & 40 & 1902 & 970 & 636 & 142 & 179 & 183 & 0 & 83 & 380 & 156 & 254 & 150 & 66 & 11 & 36 & 23 & 12 & 3 & 1 & 0 & 0 & 0 & 0 & 13 & 5311 \\
\hline$C x_{1}\left(M \in x_{1}\right)$ & 0 & 0 & 1 & 0 & 0 & 0 & 0 & 0 & 0 & 0 & 1 & 0 & 0 & 0 & 0 & 0 & 0 & 0 & 0 & 0 & 0 & 0 & 0 & 0 & 1 & & 3 \\
\hline$C x, a$ & 1 & 0 & 0 & 0 & 0 & 0 & 0 & 0 & 0 & 0 & 0 & 0 & 0 & 0 & 0 & 0 & 0 & 0 & 0 & 0 & 0 & 0 & 0 & 0 & 0 & & 1 \\
\hline Cx.ribeirensis & 4 & 2 & 2 & 1 & 0 & 0 & 0 & 0 & 0 & 0 & 4 & 1 & 2 & 17 & 0 & 0 & 0 & 0 & 3 & 1 & 2 & 0 & 1 & 2 & 0 & & 44 \\
\hline Cx.sacchettae & 49 & 3 & 18 & 9 & 3 & 5 & 12 & 11 & 19 & 8 & 20 & 40 & 14 & 14 & 6 & 9 & 6 & 8 & 14 & 11 & 12 & 13 & 29 & 19 & 2 & 15 & 369 \\
\hline Cx.spissipes & 0 & 0 & O & 0 & 0 & 0 & 0 & 0 & 0 & 0 & 1 & 0 & 0 & 0 & 0 & 0 & 0 & 0 & 0 & 0 & 0 & 0 & 0 & 0 & 0 & & 1 \\
\hline Cx.gr. Atrat, & 0 & 0 & 2 & 0 & 0 & 0 & 0 & 3 & 2 & 2 & 2 & 5 & 7 & 0 & 0 & 1 & 0 & 0 & 0 & 0 & 2 & 2 & & 3 & 1 & 0 & 35 \\
\hline Cx.Sesăo Me & 3 & 9 & 2 & 0 & 0 & 1 & 0 & 1 & 1 & 2 & 0 & 1 & 3 & 0 & & 1 & 9 & 5 & 1 & 0 & 1 & 1 & & 2 & 0 & 0 & 49 \\
\hline Cx.sp* & 0 & 0 & 0 & 0 & 0 & 0 & 0 & 0 & 0 & 0 & 0 & 0 & 0 & 0 & c & 0 & 0 & 1 & 0 & 0 & 0 & 0 & 0 & 0 & 0 & 0 & 1 \\
\hline Limatus & 0 & 0 & 0 & 0 & 0 & 0 & 0 & 0 & 0 & 2 & 0 & 2 & 0 & 0 & c & 0 & 1 & 0 & 0 & 0 & 0 & 0 & c & 0 & 0 & 0 & 5 \\
\hline Mansonia & 0 & 0 & 0 & 0 & 0 & 0 & 0 & 0 & 0 & 0 & 0 & 0 & 1 & 0 & 0 & 0 & 0 & 0 & 0 & 0 & 0 & 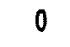 & 0 & 0 & 0 & 0 & 1 \\
\hline Phoniomyia & 70 & 36 & 54 & 46 & 139 & 33 & 182 & 77 & 0 & 627 & 645 & 686 & 348 & 53 & 116 & 51 & 93 & 14 & 24 & 12 & 5 & 67 & 183 & 230 & 48 & 130 & 3969 \\
\hline Psorophora & 0 & 0 & 50 & 3 & 1 & 0 & 4 & 20 & 0 & 534 & 99 & 35 & 35 & 35 & 754 & 92 & 121 & 9 & 0 & 1 & 0 & 0 & 0 & 0 & 0 & 0 & 1793 \\
\hline Runchomyia & 66 & 17 & 27 & 11 & 22 & 19 & 8 & 3 & 8 & 25 & 25 & 5 & 12 & 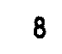 & 18 & 1 & 20 & 23 & 9 & 1 & 1 & 3 & 12 & 36 & 21 & 14 & 415 \\
\hline Sabethes & 0 & 0 & 0 & 0 & 0 & 0 & 1 & 0 & 0 & 0 & 0 & 0 & 0 & 0 & 0 & 0 & 0 & 0 & 0 & 0 & 0 & 0 & 0 & 0 & 0 & 0 & 1 \\
\hline Uranotaeni & 0 & 1 & 0 & 0 & 0 & 0 & 0 & 0 & 0 & 0 & 1 & 0 & 1 & 0 & 0 & 1 & 0 & 0 & 0 & 0 & 0 & 0 & 0 & 0 & 0 & 0 & 4 \\
\hline Wyoomyia & 0 & 0 & 1 & 0 & 0 & 0 & 0 & 0 & 0 & 4 & 1 & 0 & 0 & 0 & 1 & 0 & 0 & 0 & 0 & 0 & 0 & 0 & 1 & 1 & 0 & 1 & 10 \\
\hline Total Kerteszia & 13 & 2 & 27 & 61 & 2 & 1 & 29 & 16 & 101 & 12 & 28 & 59 & 9 & 1 & 40 & 87 & 87 & 4 & 7 & 19 & 17 & 46 & 28 & 26 & 3 & 16 & 741 \\
\hline Total outros & 269 & 110 & 2098 & 1049 & 804 & 202 & 402 & 400 & 43 & 1375 & 1226 & 978 & 707 & 290 & 1043 & 228 & 496 & 142 & 122 & 68 & 39 & 124 & 239 & 297 & 78 & 175 & 13004 \\
\hline Total & 282 & 112 & 2125 & 1110 & 806 & 203 & 431 & 416 & 144 & 1387 & 1254 & 1037 & 716 & 291 & 1083 & 315 & 583 & 146 & 129 & 87 & 56 & 170 & 267 & 323 & 81 & 191 & 13745 \\
\hline
\end{tabular}

"espécimes danificados; 1 - An mediopunctatus/costaiforattini, 2 - Ae. serratus/nubilus, 3- Seçảo Melanoconion 
Tabela 2: Mosquitos capturados a 6 metros do solo, em armadilha luminosa $C D C+\mathrm{CO}_{2}, 17-20 \mathrm{~h}, 18 / 09 / 2001$ a 17/0/2002. IIha Comprida, SP

\begin{tabular}{|c|c|c|c|c|c|c|c|c|c|c|c|c|c|c|c|c|c|c|c|c|c|c|c|c|c|c|c|}
\hline Captura & set & 0 & & $\mathrm{ne}$ & & dez & & jan & & fev & & mar & & $a b r$ & & maic & & & un & & it & as & & & set & & al \\
\hline Táxon & 18 & 9 & 23 & 6 & 20 & 5 & 18 & 8 & 29 & 5 & 19 & 5 & 19 & 2 & 16 & 1 & 14 & 28 & 11 & 25 & 11 & 23 & 6 & 20 & 3 & 17 & \\
\hline An bellator & 0 & 0 & 7 & 6 & 0 & 0 & 13 & 12 & 20 & 3 & 32 & 31 & 13 & 6 & 15 & 18 & 34 & 1 & 2 & 4 & 2 & 18 & 7 & 5 & 1 & 11 & 261 \\
\hline An cruzii & 11 & 3 & 32 & 37 & 4 & 0 & 12 & 46 & 33 & 3 & 66 & 37 & 37 & 22 & 52 & 394 & 94 & 4 & 7 & 18 & 12 & 29 & 18 & 13 & 1 & 47 & 1032 \\
\hline An (Ker) sp* & 0 & 0 & 0 & 1 & 0 & 0 & 0 & 2 & 2 & 0 & 3 & 1 & 0 & 0 & 0 & 16 & 2 & 0 & 0 & 0 & 0 & 2 & 0 & 0 & 0 & 2 & 31 \\
\hline$A \cap(A \cap 0) s p^{1}$ & 0 & 0 & 6 & 4 & 1 & 0 & 0 & 0 & 22 & 3 & 6 & 4 & 11 & 8 & 23 & 17 & 5 & 1 & 5 & 2 & 1 & 1 & 0 & 0 & 0 & 0 & 120 \\
\hline Ae fulvus & 0 & 0 & 0 & 0 & 0 & 0 & 0 & 1 & 0 & 12 & 0 & 1 & 1 & 0 & 46 & 35 & 79 & 20 & 20 & 0 & 0 & 0 & 0 & 0 & 0 & 0 & 215 \\
\hline A $\theta$ hortator & 0 & 0 & 0 & 0 & 0 & 0 & 0 & 1 & 0 & 4 & 1 & 0 & 0 & 0 & 6 & 9 & 1 & 0 & 0 & 0 & 0 & 0 & 0 & 0 & 0 & 0 & 22 \\
\hline Ae scapularis & 1 & 0 & 3 & 2 & 0 & 0 & 1 & 1 & 5 & 1 & 0 & 1 & 3 & 0 & 7 & 6 & 8 & 3 & 1 & 0 & 0 & 1 & 0 & 0 & 1 & 0 & 45 \\
\hline Ae serratus & 0 & 0 & 1 & 0 & 0 & 0 & 0 & 1 & 1 & 0 & 1 & 0 & 0 & 0 & 2 & 1 & 0 & 0 & 0 & 0 & 0 & 0 & 0 & 0 & 0 & 0 & 7 \\
\hline Ae gr Serratus? & 0 & 1 & 1 & 1 & 2 & 0 & 0 & 7 & 15 & 0 & 3 & 4 & 6 & 2 & 9 & 28 & 5 & 3 & 2 & 16 & 3 & 3 & 1 & 0 & 0 & 0 & 112 \\
\hline Coquillettidia & 33 & 26 & 636 & 658 & 370 & 73 & 130 & 253 & 66 & 19 & 593 & 112 & 505 & 196 & 60 & 39 & 23 & 14 & 7 & 1 & 0 & 1 & 0 & 0 & 0 & 34 & 3849 \\
\hline Cx dolosus & 0 & 1 & 0 & 0 & 0 & 0 & 0 & 0 & 0 & 0 & 0 & 0 & 0 & 0 & 0 & 0 & 0 & 0 & 0 & 0 & 0 & 0 & 0 & 0 & 0 & 0 & 1 \\
\hline Cx nigripalpus & 0 & 0 & 0 & 0 & 0 & 0 & 0 & 0 & 0 & 0 & 0 & 0 & 0 & 0 & 1 & 4 & 0 & 0 & 0 & 0 & 0 & 0 & 0 & 0 & 0 & 0 & 5 \\
\hline$C x(\operatorname{Cux}) s p^{*}$ & 0 & 0 & 1 & 0 & 0 & 0 & 0 & 0 & 0 & 0 & 0 & 0 & 0 & 0 & 0 & 0 & 0 & 0 & 0 & 0 & 0 & 0 & 0 & 0 & 0 & 0 & 1 \\
\hline$C \times(M C x) s p$ & 0 & 1 & 0 & 0 & 0 & 0 & 0 & 0 & 0 & 0 & 0 & 0 & 0 & 0 & 0 & 0 & 0 & 0 & 0 & 0 & 0 & 0 & 0 & 0 & 0 & 0 & 1 \\
\hline Cxpedroi & 0 & 0 & 0 & 0 & 0 & 0 & 0 & 0 & 0 & 0 & 0 & 1 & 0 & 0 & 3 & 1 & 0 & 0 & 2 & 0 & 0 & 0 & 0 & 0 & 0 & 0 & 7 \\
\hline Cx ribeirensis & 3 & 6 & 0 & 0 & 0 & 0 & 1 & 2 & 0 & 0 & 2 & 14 & 0 & 2 & 2 & 0 & 1 & 0 & 0 & 1 & 2 & 0 & 0 & 0 & 0 & 2 & 38 \\
\hline CX sacchettae & 13 & 3 & 8 & 2 & 1 & 4 & 4 & 13 & 10 & 1 & 1 & 7 & 15 & 15 & 15 & 21 & 11 & 0 & 8 & 73 & 8 & 10 & 5 & 9 & 1 & 16 & 274 \\
\hline Cx spissipes & 0 & 0 & 0 & 0 & 0 & 0 & 0 & 0 & 0 & 0 & 0 & 0 & 0 & 0 & 0 & 0 & 2 & 0 & 0 & 0 & 3 & 0 & 0 & 0 & 0 & 0 & 5 \\
\hline Cx gr Atratus & 0 & 1 & 1 & 0 & 0 & 1 & 0 & 1 & 5 & 14 & 2 & 0 & 12 & 2 & 7 & 7 & 8 & 2 & 12 & 4 & 8 & 4 & 5 & 0 & 0 & 3 & 99 \\
\hline Cx gr. Pilosus & 0 & 0 & 0 & 0 & 0 & 0 & 0 & 0 & 0 & 0 & 0 & 1 & 0 & 0 & 0 & 0 & 0 & 0 & 0 & 0 & 0 & 0 & 0 & 0 & 0 & 0 & 1 \\
\hline Cx seçăo Mel. & 3 & 6 & 0 & 0 & 0 & 0 & 0 & 1 & 0 & 1 & 0 & 0 & 0 & 1 & 3 & 4 & 9 & 1 & 2 & 1 & 8 & 0 & 1 & 0 & 0 & 1 & 42 \\
\hline $\mathrm{Cx}(\mathrm{Mel}) \mathrm{sp}^{*}$ & 0 & 0 & 0 & 0 & 0 & 0 & 0 & 0 & 0 & 0 & 0 & 0 & 1 & 0 & 0 & 0 & 1 & 0 & 0 & 0 & 0 & 0 & 0 & 0 & 0 & 0 & 2 \\
\hline Limatus & 0 & 1 & 0 & 0 & 0 & 0 & 0 & 0 & 1 & 0 & 0 & 0 & 0 & 0 & 0 & 0 & 0 & 0 & 0 & 0 & 0 & 0 & 0 & 0 & 0 & 0 & 2 \\
\hline Mansonia & 0 & 0 & 0 & 0 & 0 & 0 & 0 & 0 & 0 & 0 & 0 & 0 & 0 & 0 & 0 & 0 & 1 & 2 & 0 & 0 & 0 & 0 & 0 & 0 & 0 & 0 & 3 \\
\hline Phoniomyia & 18 & 20 & 26 & 22 & 65 & 20 & 126 & 30 & 553 & 260 & 356 & 176 & 157 & 35 & 81 & 14 & 40 & 12 & 29 & 5 & 5 & 45 & 50 & 72 & 42 & 99 & 2358 \\
\hline Psorophora & 0 & 0 & 0 & 0 & 0 & 0 & 0 & 1 & 159 & 64 & 7 & 1 & 2 & 22 & 564 & 47 & 20 & 0 & 0 & 0 & 0 & 0 & 0 & 0 & 0 & 0 & 887 \\
\hline Runchomyia & 11 & 5 & 8 & 5 & 16 & 9 & 3 & 1 & 6 & 7 & 9 & 0 & 4 & 10 & 15 & 0 & 8 & 9 & 3 & 0 & 1 & 4 & 9 & 10 & 18 & 13 & 184 \\
\hline Sabethes & 0 & 0 & 0 & 0 & 0 & 0 & 0 & 0 & 5 & 0 & 1 & 0 & 0 & 0 & 0 & 0 & 0 & 0 & 0 & 0 & 0 & 0 & 0 & 0 & 0 & 0 & 6 \\
\hline Uranotaenia & 0 & 1 & 0 & 0 & 0 & 0 & 0 & 0 & 0 & 0 & 0 & 0 & 0 & 0 & 1 & 0 & 0 & 0 & 0 & 0 & 0 & 1 & 0 & 0 & 0 & 0 & 3 \\
\hline Wyeomyia & 0 & 0 & 0 & 0 & 0 & 0 & 0 & 0 & 0 & 1 & 0 & 0 & 0 & 0 & 0 & 0 & 0 & 0 & 0 & 0 & 0 & 0 & 0 & 0 & 0 & 0 & 1 \\
\hline Total Kerteszia & 11 & 3 & 39 & 44 & 4 & 0 & 25 & 60 & 55 & 6 & 101 & 69 & 50 & 28 & 67 & 428 & 130 & 5 & 9 & 22 & 14 & 49 & 25 & 18 & 2 & 60 & 1324 \\
\hline Total outros & 82 & 72 & 691 & 694 & 455 & 107 & 265 & 313 & 848 & 387 & 982 & 322 & 717 & 293 & 845 & 233 & 222 & 67 & 91 & 103 & 39 & 70 & 71 & 91 & 62 & 168 & 8290 \\
\hline Total & 93 & 75 & 730 & 738 & 459 & 107 & 290 & 373 & 903 & 393 & 1083 & 391 & 767 & 321 & 912 & 661 & 352 & 72 & 100 & 125 & 53 & 119 & 96 & 109 & 64 & 228 & 9614 \\
\hline
\end{tabular}


Tabela 3: Mosquitos capturados a 12 metros do solo, em armadilha luminosa $\mathrm{CDC}+\mathrm{CO}_{2}, 17-20 \mathrm{~h}, 1809 / 2001$ a 1710/2002. Illa Comprida, SP.

\begin{tabular}{|c|c|c|c|c|c|c|c|c|c|c|c|c|c|c|c|c|c|c|c|c|c|c|c|c|c|c|c|}
\hline Captura & set & & it & & & & & & & & & $\mathrm{ma}$ & & & & & maio & & N & & it & & $a$ & & & & \\
\hline Taxon & 18 & 9 & 23 & 6 & 20 & 5 & 18 & 8 & 29 & 5 & 19 & 5 & 19 & 2 & 16 & 1 & 14 & 28 & 11 & 25 & 11 & 23 & 6 & 20 & 3 & 17 & lotal \\
\hline Ad squamipennis & 0 & 0 & 0 & 0 & 0 & 0 & 0 & 0 & 0 & 0 & 0 & 0 & 0 & 0 & 0 & 0 & 6 & 0 & 0 & 0 & 0 & 0 & 0 & 0 & 0 & 0 & 6 \\
\hline An bellator & 14 & 5 & 19 & 19 & 3 & 5 & 23 & 77 & 33 & 18 & 47 & 96 & 28 & 11 & 46 & 59 & 83 & 5 & 7 & 12 & 26 & 69 & 29 & 20 & 12 & 36 & 802 \\
\hline An corzii & 30 & 45 & 72 & 36 & 11 & 2 & 47 & 146 & 45 & 22 & 122 & 217 & 119 & 95 & 185 & 2080 & 429 & 25 & 29 & 64 & 61 & 107 & 121 & 71 & 12 & 227 & 4420 \\
\hline An (Ker ) sp* & 4 & 0 & 6 & 3 & 1 & 0 & 2 & 5 & 1 & 0 & 8 & 11 & 5 & 3 & 2 & 51 & 9 & 0 & 0 & 0 & 0 & 1 & 3 & 1 & 0 & 6 & 122 \\
\hline$A \cap(A \cap O) S P^{\prime}$ & 2 & 2 & 21 & 0 & 2 & 0 & 0 & 1 & 29 & 33 & 7 & 4 & 12 & 65 & 73 & 97 & 57 & 2 & 38 & 9 & 6 & 1 & 2 & 0 & 0 & 2 & 465 \\
\hline Ae fulvus & 0 & 0 & 0 & 0 & 0 & 0 & 0 & 0 & 1 & 9 & 2 & 3 & 3 & 1 & 42 & 69 & 54 & 20 & 27 & 6 & 3 & 2 & 0 & 0 & 0 & 0 & 242 \\
\hline Ae hortator & 0 & 1 & 1 & 0 & 0 & 0 & 0 & 3 & 3 & 3 & 1 & 1 & 1 & 0 & 0 & 8 & 3 & 0 & 0 & 0 & 0 & 0 & 0 & 0 & 0 & 0 & 25 \\
\hline A日 scapularis & 0 & 2 & 7 & 2 & 3 & 0 & 4 & 2 & 16 & 0 & 4 & 2 & 4 & 3 & 4 & 14 & 5 & 1 & 3 & 0 & 1 & 8 & 6 & 2 & 2 & 3 & 98 \\
\hline Ae serratus & 0 & 0 & 0 & 0 & 0 & 0 & 0 & 0 & 4 & 3 & 2 & 2 & 0 & 5 & 4 & 1 & 0 & 0 & 1 & 0 & 0 & 0 & 0 & 0 & 0 & 0 & 22 \\
\hline Ae gr Serratus? & 0 & 0 & 2 & 11 & 4 & 0 & 1 & 11 & 14 & 4 & 6 & 18 & 11 & 7 & 16 & 22 & 17 & 2 & 7 & 5 & 3 & 5 & 1 & 0 & 0 & 0 & 167 \\
\hline Coquillettiduia & 273 & 279 & 3610 & 2374 & 2517 & 335 & 375 & 191 & 214 & 188 & 3254 & 573 & 1686 & 3007 & 227 & 504 & 586 & 19 & 30 & 1 & 2 & 0 & 0 & 0 & 0 & 129 & 20374 \\
\hline Cx nigripalpus & 0 & 0 & 0 & 0 & 0 & 0 & 0 & 0 & 0 & 0 & 0 & 1 & 0 & 0 & 2 & 1 & 0 & 0 & 0 & 0 & 0 & 0 & 0 & 0 & 0 & 0 & 4 \\
\hline Cx gr Coronator & 0 & 0 & 0 & 0 & 0 & 0 & 0 & 0 & 0 & 0 & 0 & 0 & 0 & 0 & 0 & 1 & 0 & 0 & 0 & 0 & 0 & 0 & 0 & 0 & 0 & 0 & 1 \\
\hline Cx inadmirabilis & 0 & 0 & 0 & 0 & 0 & 0 & 0 & 0 & 0 & 0 & 0 & 0 & 0 & 0 & 0 & 1 & 0 & 0 & 0 & 0 & 0 & 0 & 0 & 0 & 0 & 0 & 1 \\
\hline Cx.pedroi & 0 & 0 & 0 & 0 & 0 & 0 & 0 & 0 & 0 & 0 & 0 & 2 & 0 & 0 & 2 & 0 & 1 & 0 & 0 & 0 & 0 & 1 & 0 & 1 & 1 & 0 & 8 \\
\hline Cxribeirensis & 1 & 0 & 0 & 0 & 0 & 0 & 0 & 0 & 0 & 0 & 0 & 0 & 0 & 3 & 1 & 1 & 1 & 0 & 1 & 0 & 1 & 0 & 0 & 0 & 1 & 1 & 11 \\
\hline Cx sacchettae & 17 & 33 & 1 & 1 & 0 & 6 & 3 & 15 & 14 & 22 & 4 & 31 & 12 & 14 & 45 & 98 & 43 & 12 & 59 & 216 & 61 & 64 & 171 & 31 & 7 & 25 & 1005 \\
\hline Cx spissipes & 0 & 0 & 0 & 0 & 0 & 0 & 0 & 0 & 0 & 0 & 0 & 0 & 0 & 0 & 0 & 2 & 0 & 0 & 0 & 0 & 0 & 0 & 0 & 0 & 0 & 0 & 2 \\
\hline Cxgr Atratus & 0 & 1 & 0 & 0 & 0 & 0 & 1 & 0 & 1 & 1 & 0 & 0 & 1 & 1 & 2 & 2 & 2 & 3 & 0 & 1 & 0 & 0 & 1 & 0 & 0 & 0 & 17 \\
\hline Cxgr Plosus & 0 & 0 & 0 & 0 & 0 & 0 & 0 & 0 & 0 & 0 & 0 & 0 & 0 & 0 & 0 & 0 & 0 & 1 & 0 & 0 & 0 & 0 & 0 & 1 & 0 & 1 & 3 \\
\hline Cx seçá Mel ${ }^{3}$ & 0 & 0 & 0 & 0 & 0 & 0 & 0 & 0 & 0 & 0 & 0 & 0 & 0 & 0 & 1 & 3 & 0 & 0 & 1 & 0 & 1 & 0 & 0 & 3 & 0 & 0 & 9 \\
\hline Limatus & 0 & 0 & 0 & 0 & 0 & 0 & 0 & 0 & 0 & 0 & 1 & 0 & 0 & 0 & 1 & 0 & 0 & 0 & 0 & 0 & 0 & 0 & 0 & 0 & 0 & 0 & 2 \\
\hline Mansonia & 0 & 0 & 0 & 0 & 0 & 0 & 0 & 0 & 0 & 0 & 0 & 1 & 1 & 1 & 3 & 0 & 0 & 2 & 1 & 0 & 0 & 1 & 0 & 0 & 2 & 0 & 12 \\
\hline Phoniomyia & 15 & 27 & 109 & 37 & 77 & 40 & 248 & 11 & 575 & 599 & 536 & 219 & 167 & 62 & 156 & 20 & 34 & 15 & 52 & 21 & 10 & 157 & 75 & 111 & 62 & 72 & 3507 \\
\hline Psorophora & 0 & 0 & 4 & 0 & 0 & 0 & 0 & 1 & 91 & 28 & 4 & 2 & 3 & 11 & 225 & 32 & 3 & 0 & 0 & 0 & 0 & 0 & 0 & 0 & 0 & 0 & 404 \\
\hline Runchomyia & 0 & 5 & 1 & 2 & 10 & 3 & 4 & 0 & 1 & 2 & 4 & 5 & 2 & 4 & 13 & 0 & 4 & 6 & 4 & 1 & 0 & 6 & 6 & 10 & 8 & 1 & 102 \\
\hline Sabethes & 0 & 1 & 0 & 0 & 0 & 0 & 0 & 0 & 1 & 6 & 4 & 1 & 1 & 0 & 0 & 0 & 0 & 0 & 0 & 0 & 0 & 0 & 0 & 0 & 0 & 0 & 14 \\
\hline Uranotaenia & 1 & 1 & 0 & 0 & 0 & 0 & 0 & 0 & 0 & 0 & 0 & 0 & 0 & 0 & 2 & 0 & 5 & 0 & 0 & 0 & 0 & 0 & 2 & 0 & 0 & 0 & 11 \\
\hline Wyoomyia & 0 & 0 & 4 & 0 & 0 & 0 & 0 & 0 & 0 & 0 & 0 & 0 & 0 & 0 & 0 & 0 & 0 & 0 & 0 & 0 & 0 & 0 & 0 & 0 & 0 & 0 & 4 \\
\hline Total Kerteszia & 48 & 50 & 97 & 58 & 15 & 7 & 72 & 228 & 79 & 40 & 177 & 324 & 152 & 109 & 233 & 2190 & 521 & 30 & 36 & 76 & 87 & 177 & 153 & 92 & 24 & 269 & 5344 \\
\hline Total outros & 309 & 352 & 3761 & 2427 & 2613 & 384 & 636 & 235 & 964 & 898 & 3829 & 865 & 1904 & 3184 & 821 & 880 & 821 & 83 & 224 & 260 & 88 & 245 & 264 & 159 & 83 & 234 & 26523 \\
\hline Total & 357 & 402 & 3858 & 2485 & 2628 & 391 & 708 & 463 & 1043 & 938 & 4006 & 1189 & 2056 & 3293 & 1054 & 3070 & 1342 & 113 & 260 & 336 & 175 & 422 & 417 & 251 & 107 & 503 & 31867 \\
\hline
\end{tabular}

"espécines danificados, 1 - An mediopunctatus/costaiforattini, 2 - Ae serratus/nubilus; 3 - Seçáo Melanoconion; nảo tabulados em em 23/101 Culax sp danificado; e em 1604 Aedes e 1 Cx (Mel) sp., danificados. 
Conforme descrito anteriormente, foi elaborado o gráfico abaixo, onde pode se observar a variação de temperatura e chuva durante o periodo trabalhado. Considerando que a chuva do mês anterior possa ter influenciado a distribuição dos mosquitos, os dados climáticos de agosto de 2001 também foram plotados (Figura 3).

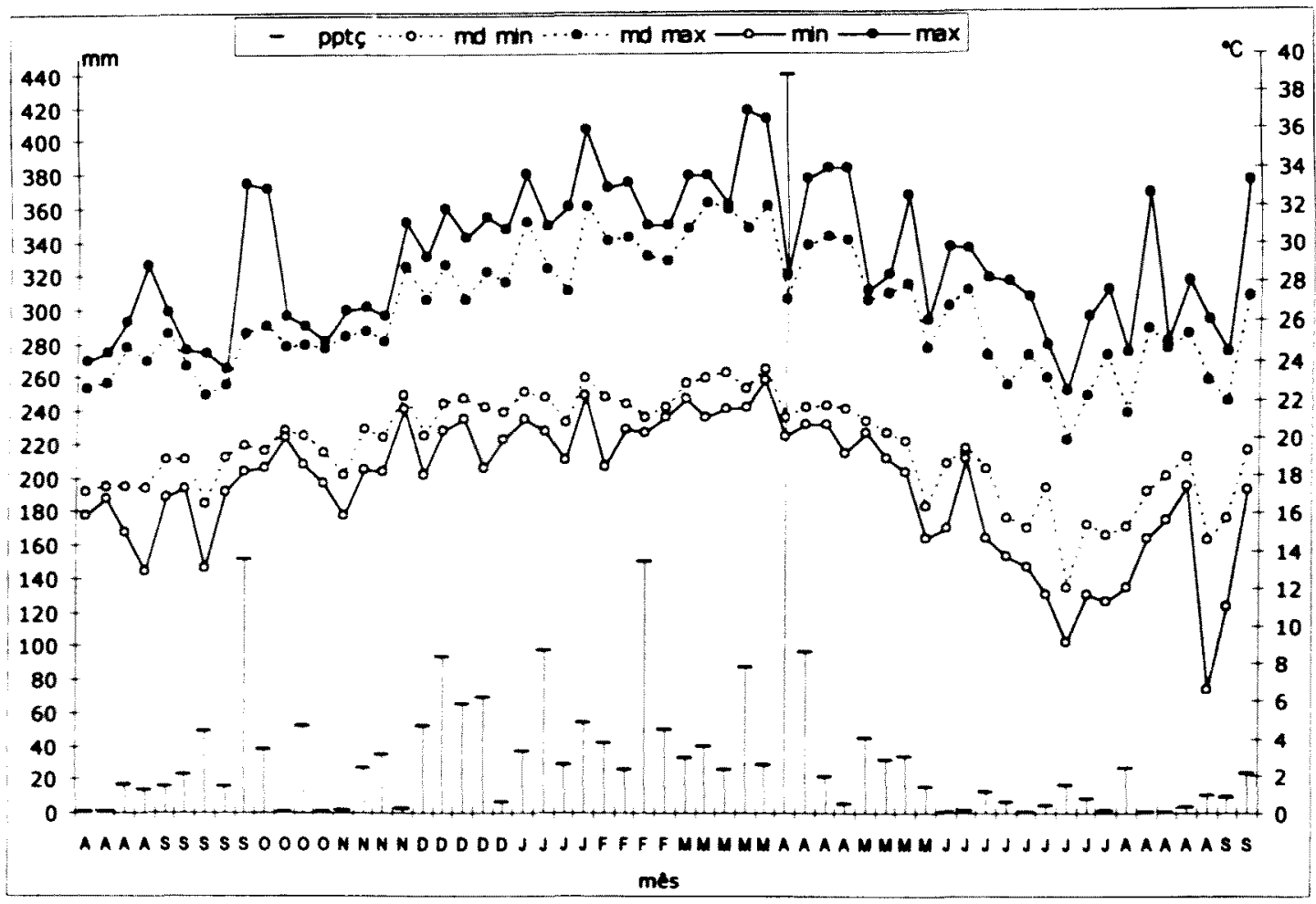

Figura 3: Dados semanais de chuva acumulada (pptç), temperaturas minima (min) e máxima (max) e respectivas médias (md) semanais. Cananéia, SP, agosto/2001 a setembro/2002.

Fonte: Instituto Oceanográfico - USP.

As figuras a seguir ilustram a distribuição da densidade de $A n$. cruzii (Figura 4) e An. bellator (Figura 5) ao longo do periodo trabalhado, em relação à variação de temperatura, mínima e máxima.

A densidade de An. cruzii em 01/05/2002 não foi plotada no gráfico e corresponde à densidade máxima obtido: 2549 indivíduos. Nesta data, a temperatura oscilou entre $20,4^{\circ} \mathrm{C}$ e $27,6^{\circ} \mathrm{C}$, indicando queda em relação ao mês anterior. Nas cinco capturas anteriores, a densidade desta espécie variou de cerca de 100 a não mais do que 300 indivíduos. 
A densidade de $A n$. bellator não excedeu 160 individuos (05/03/2002) e somente em três capturas além desta, foi superior a $100(29 / 01 / 2002$ - 107 indivíduos, 14/05/2002 - 151 e 23/07/2002 - 102). Na captura de 01/05/2002, correspondente à maior densidade de $A n$. cruzii, foram registradas 88 fêmeas de $A n$. bellator.

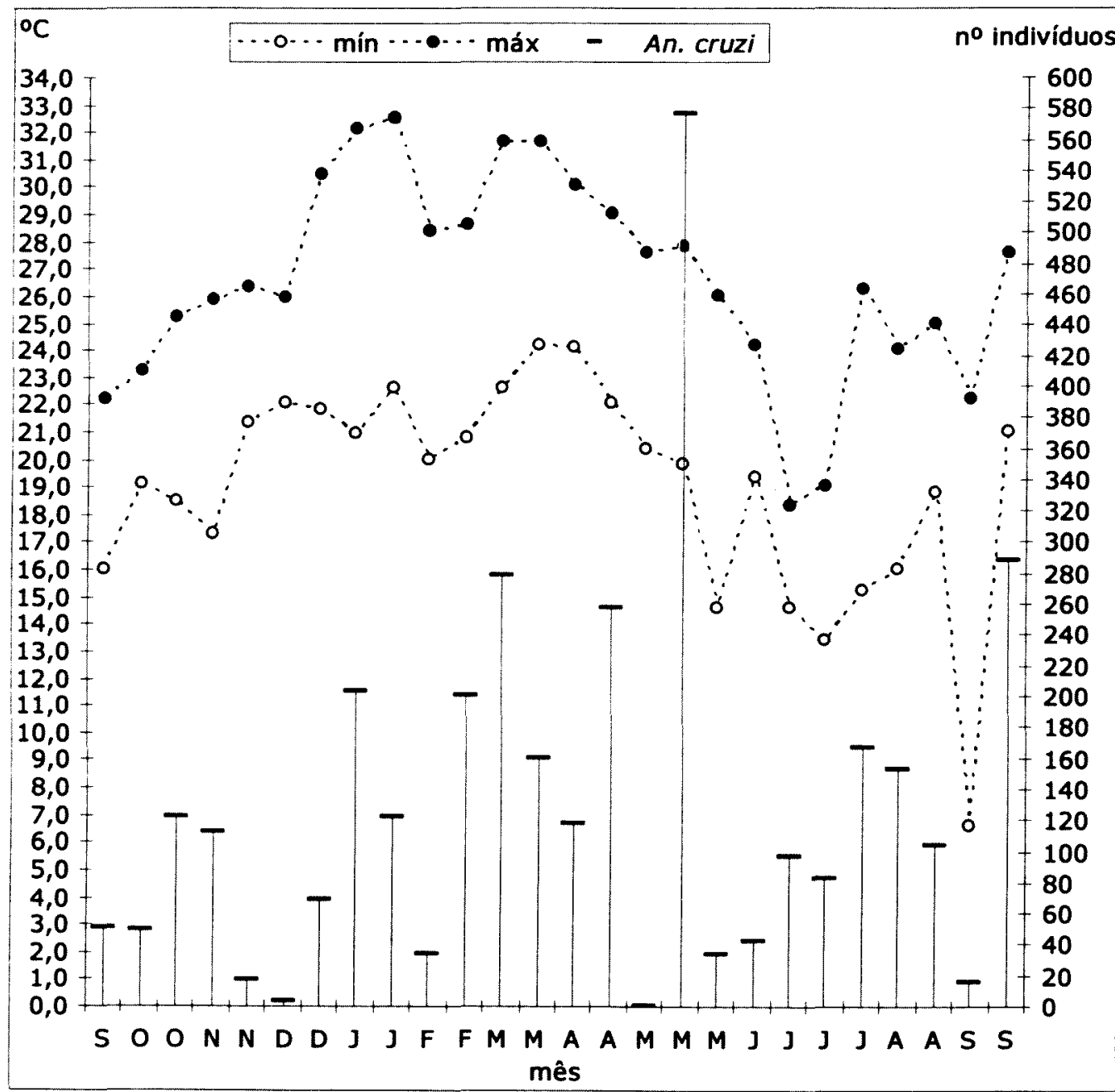

Figura 4: Densidade de An. cruzii capturados em armadilha luminosa $\mathrm{CDC}+\mathrm{CO}_{2}$, das $17-20 \mathrm{~h}$, a $1 \mathrm{~m}$, $6 \mathrm{~m}$, e $12 \mathrm{~m}$ do solo, e temperaturas minima (min) e máxima (máx) registradas nos respectivos dias* Coletas quinzenais, de 18/09/2001 a 17/09/2002. Municipio de llha Comprida, SP.

* Dados climáticos referentes ao municipio de Cananéia. Fonte: Instituto Oceanográfico - USP. 


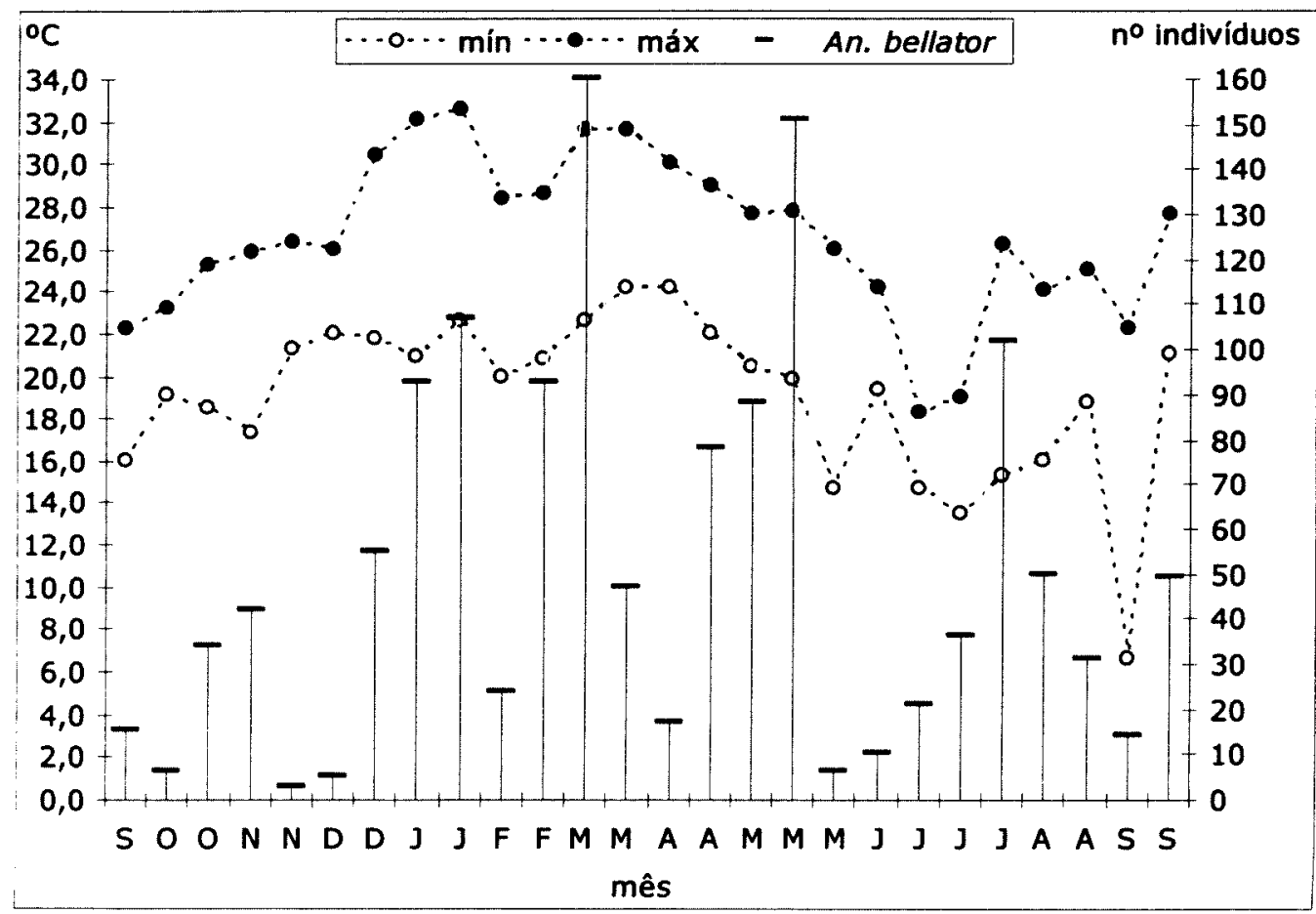

Figura 5: Densidade de An. bellator capturados em armadilha luminosa $\mathrm{CDC}+\mathrm{CO}_{2}$, das $17-20 \mathrm{~h}$, a $1 \mathrm{~m}$, $6 \mathrm{~m}$, e $12 \mathrm{~m}$ do solo, temperaturas minima e máxima registradas nos respectivos dias* Coletas quinzenais, de 18/09/2001 a 17/09/2002. Municipio de llha Comprida, SP.

* Dados climáticos referentes ao municipio de Cananéia. Fonte: Instituto Oceanográfico - USP.

A densidade mais baixa registrada foi de 3 fềmeas de $A n$. bellator em 20/11/2001 e 3 de An. cruzii, em 05/12/2001, sob temperaturas semelhantes à de $01 / 05 / 2002$, com amplitude térmica menor: mínima de $21,3^{\circ} \mathrm{C}$ e máxima de $26,3^{\circ} \mathrm{C}$ em $20 / 11 / 2001$ e , respectivamente, $22,0^{\circ} \mathrm{C}$ e $25,9^{\circ} \mathrm{C}$ em $05 / 12 / 2001$.

$O$ registro da temperatura mais baixa em todo o período trabalhado foi de $6,6^{\circ} \mathrm{C}$, em $03 / 09 / 2002$, quando foram capturadas 15 fêmeas de $A n$. cruzii e 14 de An. bellator. A temperatura mais elevada foi de $32,5^{\circ} \mathrm{C}$, em $29 / 01 / 2002$, quando foram capturadas aproximadamente 100 fêmeas de cada espécie.

A amplitude térmica média das datas de coleta foi de $7,6^{\circ} \mathrm{C}$, variando de $3,7^{\circ} \mathrm{C}(25 / 06 / 2002)$ - ocasião em que foram coletados quase 5 vezes mais $A n$. cruzii do que $A n$. bellator (96 e 21 indivíduos, respectivamente) - a $15,6^{\circ} \mathrm{C}$, em 03/09/2002, coincidindo com a data do registro da temperatura mais baixa, com rendimento de captura inferior a 100 culicídeos.

$\mathrm{O}$ coeficiente de Spearman não indicou correlação entre temperatura mínima e densidade de An. cruzii $\left(r_{s}=0,311 ; \mathrm{p}>0,05\right)$. Pela fórmula de Kendall foi 
obtido valor de $t=1,606$, o qual estabelece nível de significância de $10 \%$. Da mesma forma, para $A n$. bellator, o valor obtido $r_{s}=0,271$ indica não haver associação entre a densidade deste anofelino e a temperatura mínima diária. $O$ valor de $t=1,380$ permite fixar $\alpha=0,10$.

Já a temperatura máxima diária indicou correlações positivas fortes, significativas a $1 \%$. Para a associação entre a densidade de $A n$. cruzii e a variável em questão, o $r_{s}$ obtido foi de 0,489 , com $t=2,743$, confirmando a significância ao nivel de $1 \%$. Contudo, para An. bellator o valor de $t=3,507$ comprovou que o $r_{s}=0,582$ é significativo para $\alpha=0,005$.

O coeficiente de Spearman revelou correlação positiva entre densidade de $A n$. bellator e amplitude térmica diária $\left(r_{s}=0,528 ; \mathrm{p}<0,01\right)$. $\mathrm{O}$ valor de $t=3,045$ calculado permite estabelecer nível de significância de $0,5 \%$. Porém, não houve correlação entre a densidade de $A n$. cruzii e a amplitude térmica diária $\left(r_{s}=0,243 ; \mathrm{p}>0,05\right)$. O valor de $t=1,225$ não atinge o valor crítico $t=1,318$, correspondente ao $\alpha$ de $10 \%$.

Com relação à intensidade de precipitação, o periodo de maio a setembro de 2002 corresponde a chuvas que, em geral, acumularam menos de $20 \mathrm{~mm}$. O valor máximo registrado foi de $561,7 \mathrm{~mm}$ de chuva acumulada nos 15 dias anteriores a 26/04/2002, coleta anterior àquela em que houve uma explosão da população de $A n$. cruzii (01/05/2002 - 2549 individuos). O registro semanal de chuva (Figura 3 ) indica $438,1 \mathrm{~mm}^{3}$ somente na primeira semana de abril. Contudo, os valores de $r_{s}$ obtidos não indicaram correlação entre a densidade de $A n$. cruzii $\left(r_{s}=0,176 ; \mathrm{p}>0,05\right)$ nem de An. bellator $\left(r_{s}=0,191 ; \mathrm{p}>0,05\right)$ e a precipitação acumulada nos 15 dias anteriores. Os valores de $t$ são inferiores a 1, abaixo do valor crítico $t=1,318$, que estabelece $\alpha=0,10$.

Quanto aos resultados de distribuição vertical, o gráfico na página seguinte mostra a freqüência relativa (\%) de An. bellator e An. cruzii nos diferentes estratos, considerando o período total de capturas. 


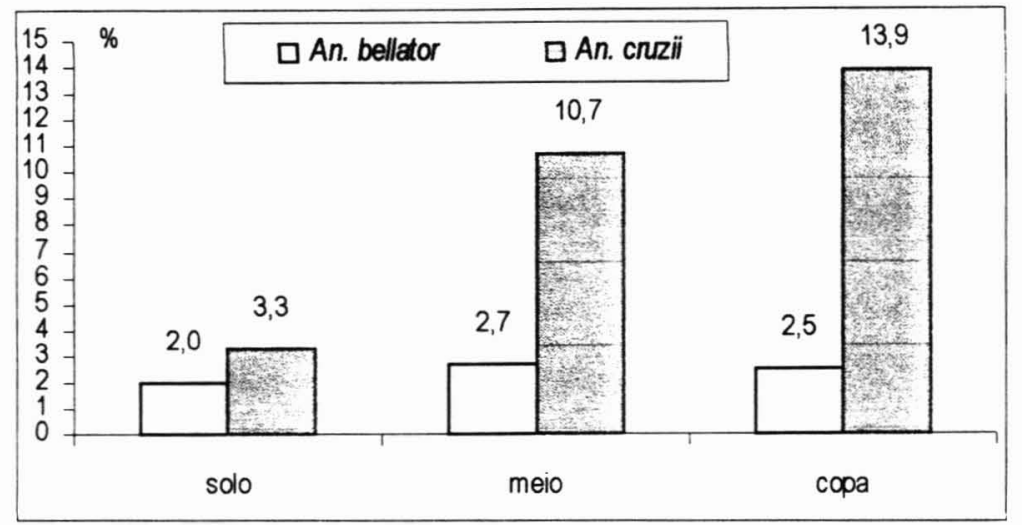

Figura 6: Freqüência relativa de An. bellator e An. cruzii capturados em armadilha luminosa $\mathrm{CDC}+\mathrm{CO}_{2}$, das 17-20h, a 1 (solo), 6 (meio) e 12 (copa) metros de altura. Ilha Comprida, SP, 18/09/2001 a 17/09/2002.

Os gráficos a seguir ilustram a freqüência relativa de Kerteszia e outros culicídeos em cada estrato ao longo do período trabalhado (Figura 7). Próximo ao solo, a população de Kerteszia manteve freqüências baixas, inferiores a $5 \%$, aumentando em direção à copa, onde chega a representar $70 \%$ da fauna culicídea. Entre os meses de maio e setembro de 2002, a freqüência deste subgênero é maior do que nos demais meses. 


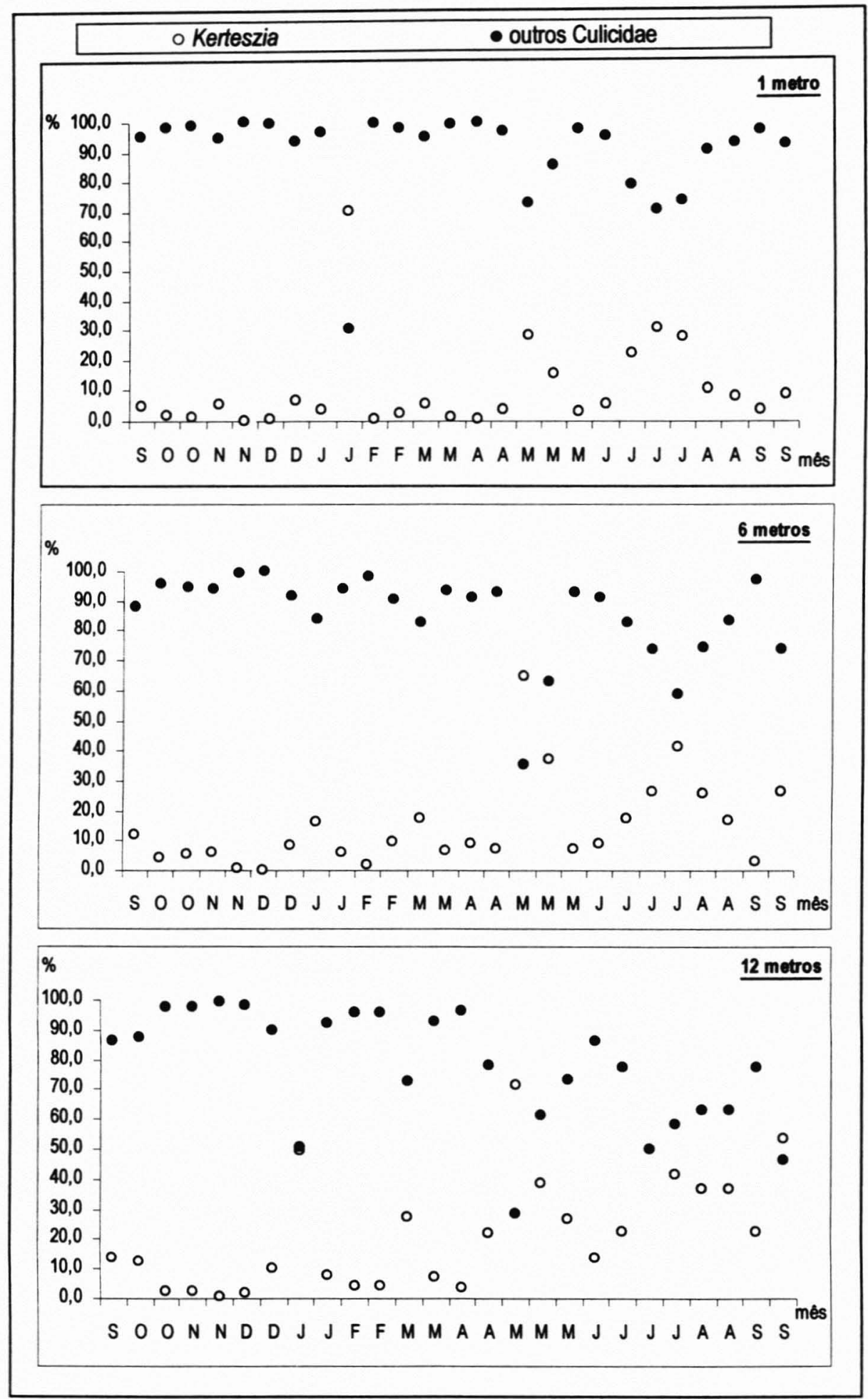

Figura 7: Freqüência de Kerteszia em relação aos demais culicideos capturados em armadilha luminosa $\mathrm{CDC}+\mathrm{CO}_{2}$ a $1 \mathrm{~m}, 6 \mathrm{~m}$ e $12 \mathrm{~m}$ do solo, 17-20h, 18/09/2001 a 17/09/2002. Ilha Comprida, SP. 
$\mathrm{Na}$ tentativa de estabelecer padrão de distribuição vertical, o gráfico abaixo foi construído com base na freqüência de Kerteszia entre os estratos. Observase predomínio de freqüências mais altas no meio e na copa do que próximo ao solo.

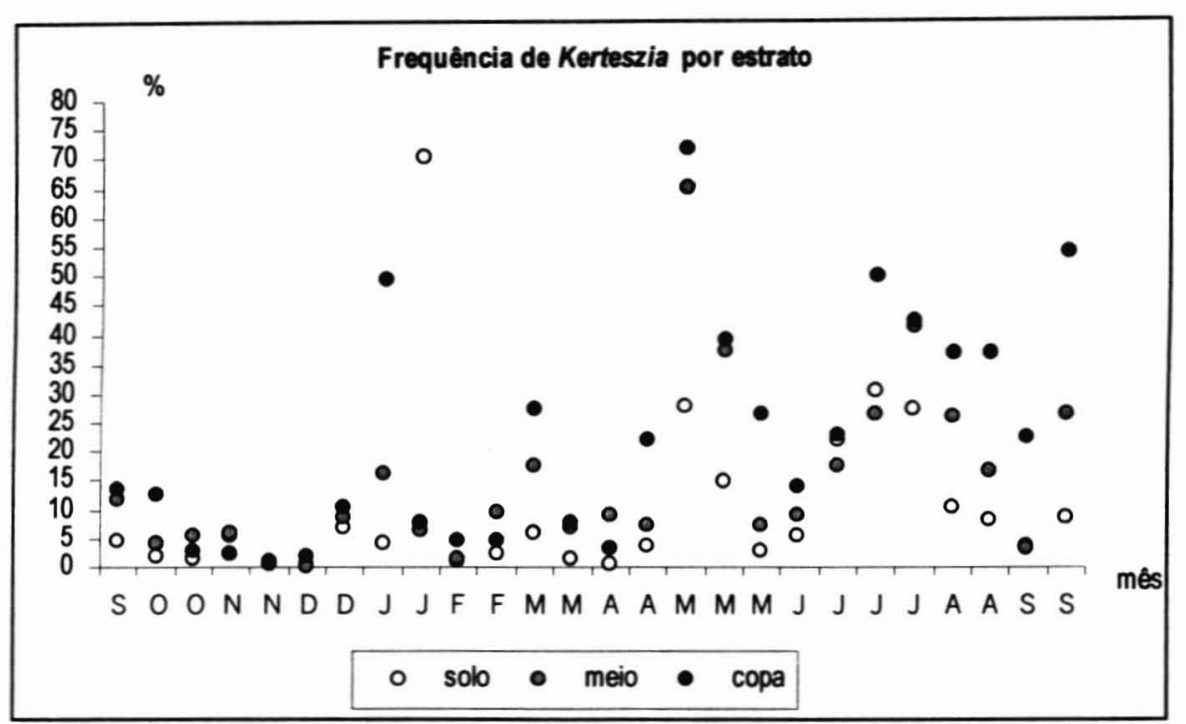

Figura 8 Frequiência de Kerteszia capturados em armadilha luminosa $\mathrm{CDC}+\mathrm{CO}_{2}$, 17$20 \mathrm{~h}$,a em relação aos estratos ( $1 \mathrm{~m}$ - solo, $6 \mathrm{~m}$ - meio e $12 \mathrm{~m}$ - copa). Ilha Comprida, SP, $18 / 09 / 2001$ a $17 / 09 / 2002$.

Analisando-se as espécies de Kerteszia separadamente, por estratos, na figura a seguir observa-se claro predomínio de An. cruzii sobre An. bellator. Observa-se, ainda, que os valores no eixo y dos gráficos aumentam proporcionalmente à altura em que as armadilhas foram instaladas. 


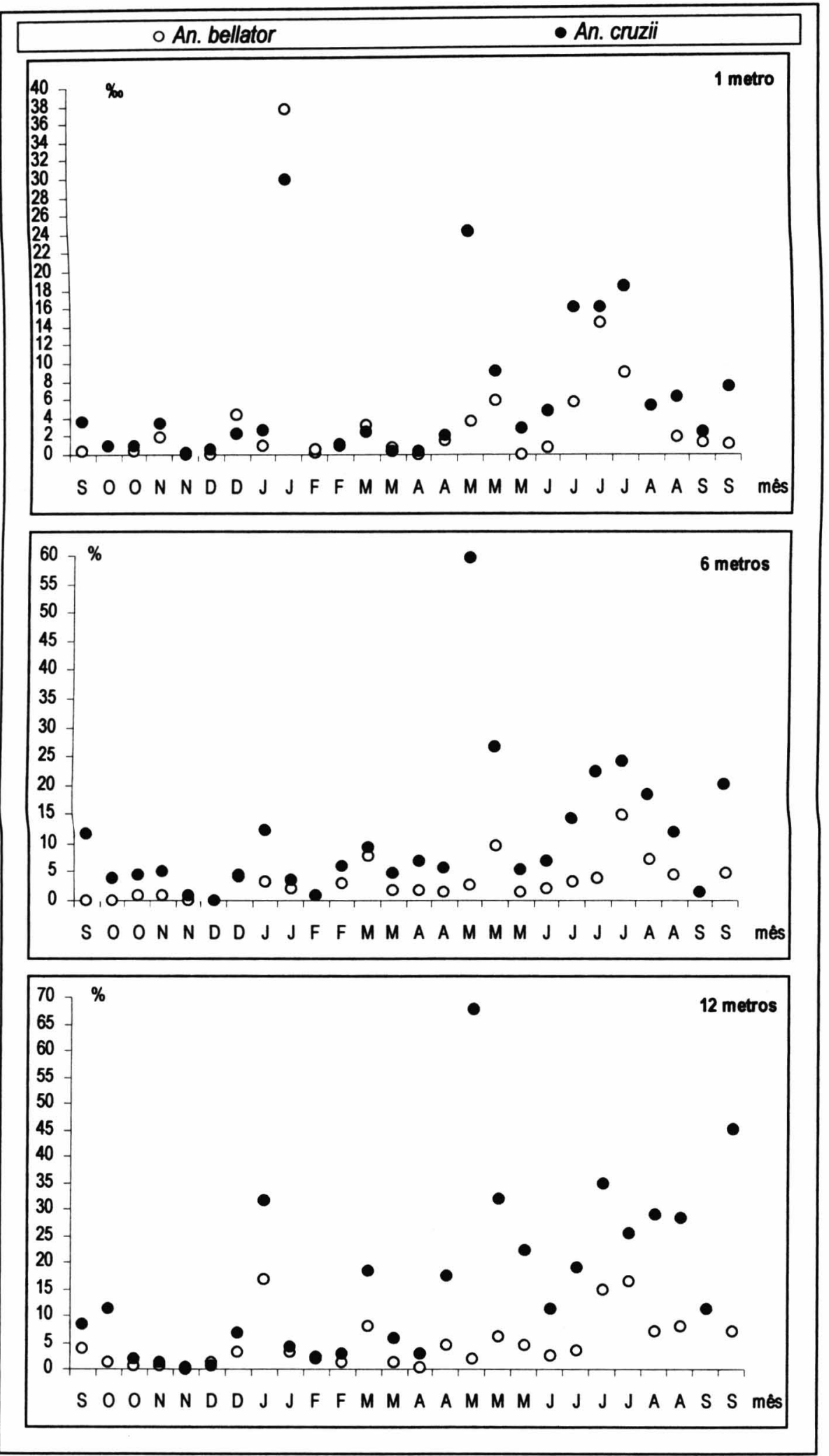

Figura 9: Freqüências (\%) de An. bellator e An. cruzii em relação aos demais culicideos capturados em armadilha luminosa $\mathrm{CDC}+\mathrm{CO}_{2}$, a $1 \mathrm{~m}, 6 \mathrm{~m}$ e $12 \mathrm{~m}$ do solo, das $17-20 \mathrm{~h}$. Iha Comprida, SP, 18/09/2001 a 17/09/2002. 
Conforme descrito em Métodos, a análise estatística foi feita pelo Teste de Mann-Whitney. A tabela abaixo apresenta os valores obtidos nas análises de comparação de cada espécie entre os estratos, bem como a comparação entre as espécies para cada estrato.

\begin{tabular}{|c|c|c|c|c|c|}
\hline Comparação & $U$ & $\mathbf{z}$ & $Z_{\text {comigido }}$ & $p$ & Decisão \\
\hline \multicolumn{6}{|c|}{ Anopheles bellator } \\
\hline solo $\times$ meio & 332 & 0,1098 & 0,1102 & $<0,4562$ & $\mathrm{H}_{0}$ \\
\hline solo $\times$ copa & 143 & 3,569 & 3,572 & $<0,00023$ & $\mathrm{H}_{1}$ \\
\hline meio $\times$ copa & 142 & 3,587 & 3,59 & $<0,00023$ & $\mathrm{H}_{1}$ \\
\hline \multicolumn{6}{|c|}{ Anopheles cruzii } \\
\hline solo $\times$ meio & 257 & 1,482 & 1,483 & $<0,0694$ & $\mathrm{H}_{0}$ \\
\hline solo $\times$ copa & 85 & 4,63 & 4,632 & $<0,00003$ & $\mathrm{H}_{1}$ \\
\hline meio $\times$ copa & 151 & 3,422 & 3,423 & $<0,0003$ & $\mathrm{H}_{1}$ \\
\hline \multicolumn{6}{|c|}{ Anopheles bellator $\times$ Anopheles cruzii } \\
\hline solo & 242 & 1,757 & 1,761 & $<0,0392$ & $\mathrm{H}_{1}$ \\
\hline meio & 181 & 2,873 & 2,877 & $<0,0020$ & $\mathrm{H}_{1}$ \\
\hline copa & 151 & 3,4223 & 3,4233 & $<0,0003$ & $\mathrm{H}_{1}$ \\
\hline
\end{tabular}

$H_{0}=$ as distribuiçōes são iguais; $H_{1}=$ as distribuições são diferentes; $\alpha=0,05$.

Considerando o total de espécimes obtidos em cada estrato, a distribuição de $A n$. bellator, como a de $A n$. cruzii, não difere entre $1 \mathrm{~m}$ e $6 \mathrm{~m}$, mas quando se compara cada um desses estratos com o de $12 \mathrm{~m}$, há diferença estatística para o nivel de significância estabelecido, revelando maior densidade na copa.

Na comparação entre An. bellator e $A n$. cruzii nos estratos, houve diferença significativa em todos eles, com franco predomínio da segunda espécie.

Os gráficos seguintes apresentam, em ordem decrescente, a distribuição de espécies ou gêneros com freqüência relativa superior a $1 \%$ para cada estrato (Figura 10). 


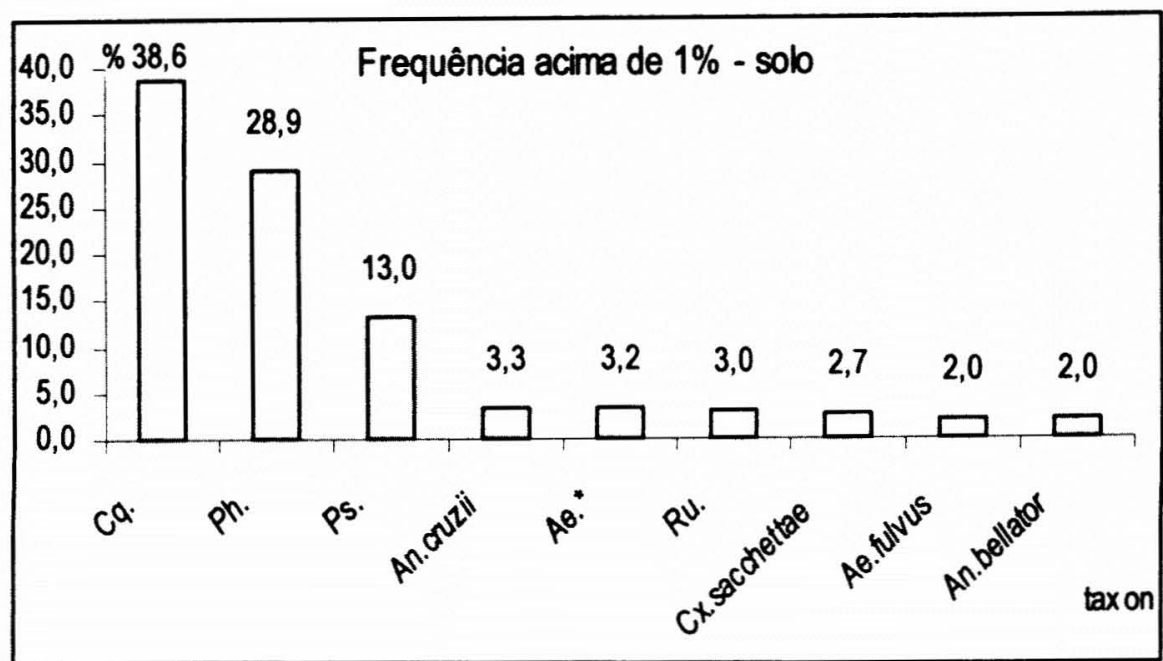

-Aedes serratus/nubilus

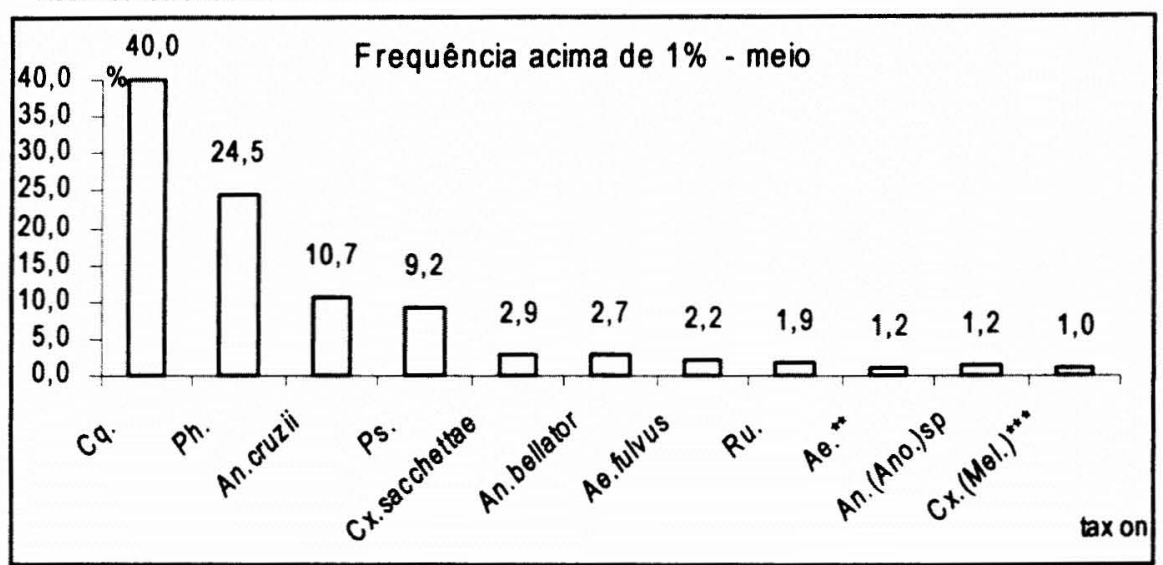

"Aedes serratus/nubilus;"-grupo Atratus:

An.(Ano.)=Anopheles mediopunctatus/costaiforattinii.

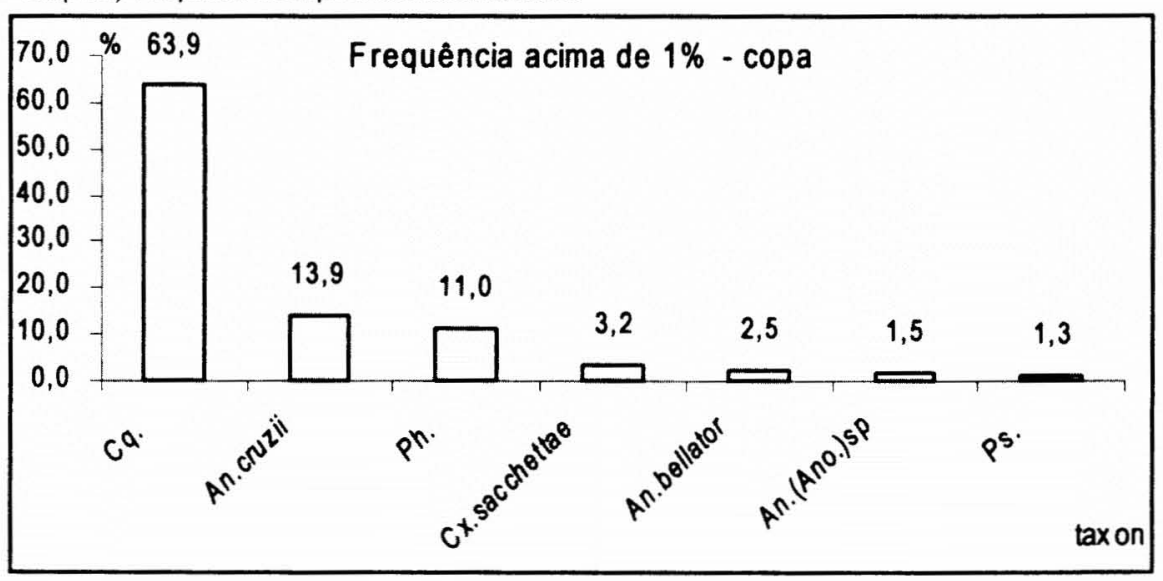

Figura 10: Táxons com frequeência relativa superior a $1 \%$ capturados em armadilha luminosa $\mathrm{CDC}+\mathrm{CO}_{2}, 17-20 \mathrm{~h}$, a $1 \mathrm{~m}, 6 \mathrm{~m}$ e $12 \mathrm{~m}$ do solo. Iha Comprida, SP, 18/09/2001 a 17/09/2002. 
Conforme destacado anteriormente, o gênero Coquillettidia tem domínio expressivo em todos os estratos, tendo representado cerca de $40 \%$ da fauna culicídea a $1 \mathrm{~m}$ e $6 \mathrm{~m}$, e mais de $60 \%$ na copa. Com grau de dominância inferior, espécimes de Phoniomyia mostraram tendência inversa, tendo predominado próximo ao solo e reduzindo sua frequência relativa a $11 \%$ na copa. Psorophora e Runchomyia também têm representatividade maior no solo, diminuindo em direção à copa.

O compartilhamento e a constância de gêneros e espécies estão apresentados na Tabela 5. Vale destacar espécies constantes (presentes em mais de $50 \%$ das capturas) em todos os estratos: An. mediopunctatus/costai/forattinii, Ae. scapularis, Ae. serratus/mubilus e Cx. sacchettae - todos de importância médica; e os gêneros Coquillettidia, Phoniomyia e Runchomyia.

An. mediopunctatus/costai/forattini concentrou sua ocorrência nos estratos de $6 \mathrm{~m}$ e $12 \mathrm{~m}$ e nos meses de fevereiro a junho, apesar de ter sido considerada constante, ou seja, presente em mais da metade das capturas, mas com densidades baixas. Sua freqüência relativa foi de $1,2 \%$ no meio e $1,5 \%$ na copa

As espécies de Culex em geral não foram muito freqüentes, exceto algumas do subgênero Melanoconion (Cx. ribeirensis, grupo Atratus e seção Melanoconion), além de $C x$. sacchettae. Esta espécie representou 2,7\% dos Culicidae capturados próximo ao solo, elevando essa proporção a $2,9 \%$ no meio, e $3,2 \%$ na copa, distribuidos quase que continuamente ao longo do ano, com aumento de densidade em meses variáveis conforme o estrato. A espécie esteve ausente em apenas duas capturas (20/11/2001 na copa e 28/05/2002 no meio)

Dentre as espécies de Aedes, destacou-se Ae. fulvus, cuja freqüência relativa foi de $2,2 \%$ próximo ao solo, $2,0 \%$ no meio e $0,8 \%$ na copa, mas o interessante é assinalar que essa porcentagem se concentrou praticamente nos meses de abril e maio, estendendo-se até a primeira captura de junho, sendo que antes e depois desse periodo a espécie foi capturada esporadicamente

Foi capturada uma única fêmea de Ae. albopictus próximo ao solo $(05 / 03 / 2002)$.

Ad. squamipennis ocorreu somente na copa, na captura de 14/05/2002 ( 3 fềmeas em cada ponto) 
Tabela 5: Compartilhamento e constância de gêneros e espécies de Culicidae capturadas em armadilha luminosa tipo $\mathrm{CDC}+\mathrm{CO}_{2}$, das 17 as $20 \mathrm{~h}$, a $1 \mathrm{~m}, 6 \mathrm{~m}$ e $12 \mathrm{~m}$ do solo. Municipio de llha Comprida, 18/09/2001 a 17/09/2002.

\begin{tabular}{|c|c|c|c|}
\hline ESPÉCIE & SOLO & MEIO & COPA \\
\hline Ad.squamipennis & & & $\mathbf{z}$ \\
\hline An. bellator & $x$ & $x$ & $x$ \\
\hline An.cruzii & $x$ & $x$ & $x$ \\
\hline An.(Ker.)sp danificado & $\mathbf{z}$ & $y$ & $x$ \\
\hline An.mediopunctatus/costai/forattinii & $x$ & $x$ & $x$ \\
\hline Ae.albopictus & $\mathbf{z}$ & & \\
\hline Ae.fulvus & $x$ & y & $x$ \\
\hline Ae.hortator & y & $\mathbf{z}$ & $y$ \\
\hline Ae.scapularis & $x$ & $x$ & $x$ \\
\hline Ae. serratus & y & $\mathbf{z}$ & y \\
\hline Ae.sematus/nubilus & $x$ & $x$ & $x$ \\
\hline Ae.sp danificado & $\mathbf{z}$ & & $\mathbf{z}$ \\
\hline Coquillettidia & $x$ & $x$ & $x$ \\
\hline Cx.dolosus & & $z$ & \\
\hline Cx.nigripalpus & & $z$ & $z$ \\
\hline Cx.(Cux.)grupo Coronator & & & $z$ \\
\hline Cx.(Cux.)sp danificado & & $\mathbf{z}$ & \\
\hline Cx. $(M c x) s p$. & $\mathbf{z}$ & $\mathbf{z}$ & \\
\hline Cx.aureonotatus & $\mathbf{z}$ & & \\
\hline Cx.inadmirabilis & & & z \\
\hline Cx.pedroi & & $\mathbf{z}$ & $\mathbf{z}$ \\
\hline Cx.ribeirensis & $x$ & $y$ & $y$ \\
\hline Cx. sacchettae & $x$ & $x$ & $x$ \\
\hline Cx.spissipes & $\mathbf{z}$ & z & $z$ \\
\hline Cx.(Mel.)grupo Atratus & $x$ & $x$ & $y$ \\
\hline Cx.(Mel.)grupo Pilosus & & $z$ & $z$ \\
\hline Cx.(Mel.)seção Melanoconion & $x$ & $x$ & $z$ \\
\hline Cx.(Mel.)sp danificado & & $z$ & $z$ \\
\hline Cx.sp danificado & $z$ & & $z$ \\
\hline Limatus & $\mathbf{z}$ & $z$ & $z$ \\
\hline Mansonia & $\mathbf{z}$ & $\mathbf{z}$ & y \\
\hline Phoniomyia & $x$ & $x$ & $x$ \\
\hline Psorophora & $x$ & y & y \\
\hline Runchomyia & $x$ & $x$ & $x$ \\
\hline Sabethes & $\mathbf{z}$ & $\mathbf{z}$ & $\mathbf{z}$ \\
\hline Uranotaenia & $z$ & $\mathbf{z}$ & $z$ \\
\hline Wyeomyia & $y$ & $z$ & $z$ \\
\hline
\end{tabular}




\subsection{Imaturos}

De 04/09/2001 a 17/09/2002, foram coletados 34298 imaturos de Culicidae, distribuídos entre 25 espécies. $O$ número de coletas variou conforme o estrato. Na tabela 6 estão apresentados os dados gerais de trabalho de campo. No dia 04/09/2001, foi utilizada bomba tipo fole para aspirar bromélias na restinga. A tabela 6 inclui os dados desta coleta, mas para as análises estatísticas e na tabelas de composição especifica os dados de bromélias de solo (praia e mata) desta data foram excluídos.

Tabela 6: Coletas de larvas de Kerteszia em bromélias. Illha Comprida, SP, 04/092001 a 17/09/2002.

\begin{tabular}{|c|c|c|c|c|}
\hline $\begin{array}{l}\text { Ponto ou } \\
\text { Altura (m) }\end{array}$ & $\begin{array}{c}n^{\circ} \\
\text { coletas }\end{array}$ & $\begin{array}{c}\mathrm{n}^{\circ} \\
\text { bromélias }\end{array}$ & $\begin{array}{r}\text { volume de } \\
\text { água }(\mathrm{ml})\end{array}$ & $\begin{array}{l}\text { larvas de } \\
\text { Kerteszia }\end{array}$ \\
\hline solo-praia & 26 & 730 & 138270 & 15 \\
\hline solo-mata & 26 & 778 & 130400 & 674 \\
\hline $1 \mid-2$ & 23 & 544 & 36930 & 365 \\
\hline $2 \mid-3$ & 26 & 119 & 9580 & 44 \\
\hline $3 \mid-4$ & 25 & 199 & 13360 & 113 \\
\hline $4 \mid-5$ & 27 & 484 & 41780 & 240 \\
\hline $51-6$ & 13 & 62 & 4235 & 8 \\
\hline $61-7$ & 24 & 119 & 6990 & 12 \\
\hline $71-8$ & 18 & 99 & 12020 & 37 \\
\hline $81-9$ & 25 & 230 & 35380 & 331 \\
\hline $9 \mid-10$ & 19 & 147 & 7870 & 17 \\
\hline $10 \mid-11$ & 25 & 182 & 34405 & 278 \\
\hline $11-12$ & 10 & 20 & 9075 & 46 \\
\hline total & 287 & 3713 & 480295 & 2180 \\
\hline
\end{tabular}

Considerando as coletas por estrato, a média variou entre 48 $\mathrm{ml} /$ bromélia a $464 \mathrm{ml} / \mathrm{bromélia}$ na restinga da praia. No solo da mata a média variou entre 82 e $312,5 \mathrm{ml} /$ bromélia. Nos demais estratos, as médias por coleta variaram de $7,5 \mathrm{ml} /$ bromélia na classe $[5,6[\mathrm{~m}$ até $840 \mathrm{ml} /$ bromélia na classe $[10,11] \mathrm{m}$.

Vale lembrar que, por serem menos numerosas e de acesso mais dificil, as bromélias epífitas foram aspiradas repetidamente a cada coleta. A $12 \mathrm{~m}$, por exemplo, foram acessadas apenas duas bromélias, adjacentes. Em todas as coletas foi possivel aspirar água em ambas, comprovando que a reposição de água, cogitada no estudo piloto, foi desnecessária. 
Outro fato que ficou evidente foi a coleta de ovos, já que na água mantida em laboratório foi possivel encontrar larvas de $1^{\circ}$ estadio 13 dias após a coleta.

O subgênero Kerteszia esteve presente em todos os estratos ao longo do periodo de estudo. Destacaram-se as coletas nos estratos $[8,9[\mathrm{~m},[10,11[\mathrm{~m}$ e $[11,12] \mathrm{m}$ devido à quantidade de larvas de Kerteszia em relação ao número de bromélias acessadas.

Nas páginas a seguir estão apresentadas tabelas com os dados gerais de campo, referentes ao número de bromélias aspiradas por estrato a cada coleta. $O$ volume registrado corresponde à somatória do conteúdo aquático de bromélias do mesmo estrato. Apesar das distorções que a média pode sofrer quando os valores são muito díspares, calculou-se o volume médio por bromélia como medida indireta de possivel padrão de distribuição desses vegetais por tamanho em escala vertical. Além disso, registrou-se a positividade das bromélias para imaturos de Kerteszia (Tabelas 7,8 e 9 ).

Ao nível do solo foram coletadas em média $27 \pm 10$ bromélias na restinga e $29 \pm 10$ na mata. Os volumes médios são próximos: $220 \pm 86$ e $190 \pm 70$ $\mathrm{ml} /$ bromélia, respectivamente. $\mathrm{Na}$ mata, freqüentemente foram aspiradas mais bromélias para se atingir o volume estipulado de 5 litros, devido à maior quantidade de folhas caidas no interior dos tanques, o que dificultava a aspiração da água. Ainda assim, em época chuvosa foram necessárias apenas 11 bromélias na praia e 16 na mata para se obter os 5 litros aspirados. Porém, em época de seca, o limite máximo de 50 bromélias aspiradas não somava mais do que 2,4 litros. Convém reforçar que na restinga não foi registrada a presença de imaturos de $A n$. cruzii, mas somente $A n$. bellator. Contudo, na mata (com exceção da coleta de 17/09/2002), todas as coletas foram positivas para imaturos de Kerteszia. 
Tabela 7: Dados referentes ao número de bromélias de solo (brom), volume aquático aspirado (vol, em ml), volume médio por bromélia ( $\mu_{\text {vol, }}$ em ml) e positividade para larvas de Kerteszia (Ker). Ilha Comprida, SP, 04/09/2001 a 17/09/2002.

\begin{tabular}{|c|c|c|c|c|c|c|c|c|}
\hline \multirow{2}{*}{ Data } & \multicolumn{4}{|c|}{ praia } & \multicolumn{4}{|c|}{ mata } \\
\hline & brom & vol & $\mu_{\text {vol }}$ & Ker & brom & vol & $\mu_{\text {vol }}$ & $\mathrm{Ker}$ \\
\hline $04 / 09 / 01$ & 50 & 6100 & 122 & b & 40 & 4950 & 124 & c \\
\hline $18 / 09 / 01$ & 33 & 5200 & 158 & b & 57 & 5000 & 87,7 & c \\
\hline 09/10/01 & 26 & 5000 & 192 & & 25 & 5000 & 200 & $c b$ \\
\hline $23 / 10 / 01$ & 31 & 5000 & 161 & & 42 & 5350 & 127 & $\mathrm{c} / \mathrm{b}$ \\
\hline $06 / 11 / 01$ & 50 & 2400 & 48 & & 44 & 3600 & 81,8 & $\mathrm{c} / \mathrm{b}$ \\
\hline $20 / 11 / 01$ & 26 & 5000 & 192 & & 38 & 5000 & 132 & $\mathrm{c} / \mathrm{b}$ \\
\hline $05 / 12 / 01$ & 44 & 5000 & 114 & & 31 & 5000 & 161 & c \\
\hline $18 / 12 / 01$ & 34 & 5350 & 157 & & 45 & 5000 & 111 & c \\
\hline $08 / 01 / 02$ & 15 & 5400 & 360 & & 24 & 5100 & 213 & $p$ \\
\hline $29 / 01 / 02$ & 18 & 5000 & 278 & & 26 & 5000 & 192 & $c / b$ \\
\hline $05 / 02 / 02$ & 18 & 5000 & 278 & & 17 & 5000 & 294 & $c$ \\
\hline $19 / 02 / 02$ & 21 & 5650 & 269 & & 29 & 2400 & 82,8 & $\mathrm{c} / \mathrm{b}$ \\
\hline $05 / 03 / 02$ & 21 & 4900 & 233 & & 26 & 5000 & 192 & c \\
\hline 19/03/02 & 26 & 5600 & 215 & & 33 & 4000 & 121 & $c / b$ \\
\hline $02 / 04 / 02$ & 11 & 5100 & 464 & & 21 & 5000 & 238 & b \\
\hline $16 / 04 / 02$ & 21 & 5500 & 262 & $b$ & 25 & 5000 & 200 & $p$ \\
\hline $01 / 05 / 02$ & 26 & 5350 & 206 & $p$ & 17 & 5000 & 294 & $c / b$ \\
\hline $14 / 05 / 02$ & 25 & 5000 & 200 & b & 25 & 5100 & 204 & $\mathrm{c} / \mathrm{b}$ \\
\hline $28 / 05 / 02$ & 21 & 5590 & 266 & & 17 & 5000 & 294 & c \\
\hline $11 / 06 / 02$ & 50 & 3300 & 66 & b & 41 & 5000 & 122 & $c / b$ \\
\hline $25 / 06 / 02$ & 23 & 5150 & 224 & & 23 & 5000 & 217 & $c b$ \\
\hline $11 / 07 / 02$ & 28 & 4850 & 173 & & 34 & 5000 & 147 & $\mathrm{c} / \mathrm{b}$ \\
\hline $23 / 07 / 02$ & 20 & 5700 & 285 & $b$ & 18 & 5000 & 278 & $\mathrm{c} / \mathrm{b}$ \\
\hline $06 / 08 / 02$ & 20 & 5350 & 268 & & 17 & 4900 & 288 & $c / b$ \\
\hline $20 / 08 / 02$ & 31 & 6380 & 206 & $b$ & 23 & 5000 & 217 & 0 \\
\hline $03 / 09 / 02$ & 25 & 5300 & 212 & & 24 & 5000 & 208 & $\mathrm{c} / \mathrm{b}$ \\
\hline $17 / 09 / 02$ & 16 & 5100 & 319 & & 16 & 5000 & 313 & \\
\hline Total & 730 & 138270 & 189 & 8 & 778 & 130400 & 168 & 26 \\
\hline
\end{tabular}




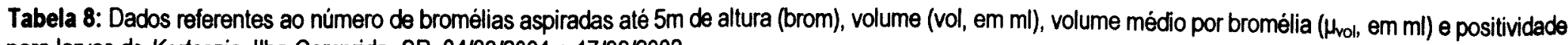
para larvas de Kerteszia. Itha Comprida, SP, 04/09/2001 a 17/09/2002.

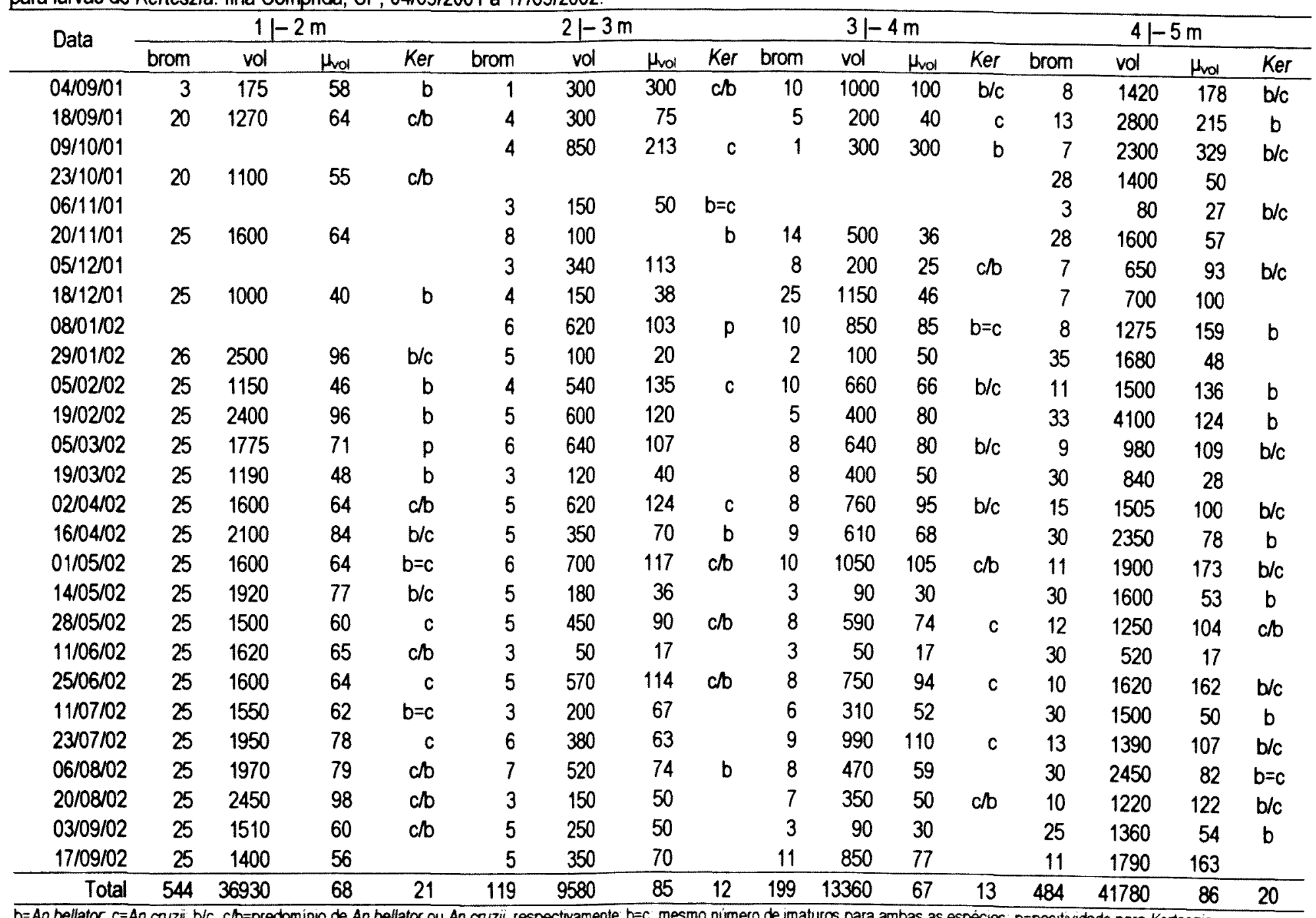




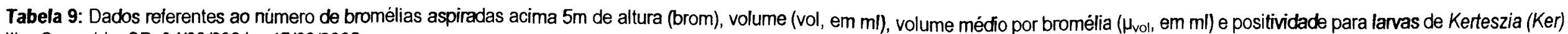
Ilha Comprida, SP, 04/09/2001 a 17/09/2002.

\begin{tabular}{|c|c|c|c|c|c|c|c|c|c|c|c|c|c|c|c|c|c|c|c|c|c|c|c|c|c|c|c|c|}
\hline \multirow{2}{*}{ Data } & \multicolumn{4}{|c|}{$51-6 m$} & \multicolumn{4}{|c|}{$61-7 m$} & \multicolumn{4}{|c|}{$7 \mid-8 m$} & \multicolumn{4}{|c|}{$8 \mid-9 m$} & \multicolumn{4}{|c|}{$9 \mid-10 m$} & \multicolumn{4}{|c|}{$10 \mid-11 m$} & \multicolumn{4}{|c|}{$11 \mid-12 m$} \\
\hline & brom & vol & $\mu_{\mathrm{vol}}$ & Ker & brom & vol & $\mu_{\mathrm{vol}}$ & Ker & brom & vol & $\mu_{\text {vol }}$ & Ker & brom & vol & $\mu_{\text {vol }}$ & $\mathrm{Ker}$ & brom & vol & $\mu_{\mathrm{vol}}$ & Ker & brom & vol & $\mu_{\mathrm{vol}}$ & $\mathrm{Ker}$ & brom & vol & $\mu_{\mathrm{vol}}$ & Ke \\
\hline $04 / 09$ & & & & & & & & & & & & & 12 & 330 & 28 & $\mathrm{~b} / \mathrm{c}$ & 6 & 300 & 50 & & 3 & 150 & 50 & $b$ & & & & \\
\hline $18 / 09$ & 5 & 500 & 100 & & 8 & 300 & 37,5 & & 8 & 770 & 96 & c & & & & & 12 & 390 & 33 & $c$ & & & & & & & & \\
\hline $09 / 10$ & & & & & & & & & 1 & 100 & 100 & & 6 & 1500 & 250 & $\mathrm{~b} / \mathrm{c}$ & 6 & 450 & 75 & & 11 & 1600 & 145 & $b$ & & & & \\
\hline $23 / 10$ & $30^{*}$ & 1600 & 53,3 & & 7 & 250 & 35,7 & c & 7 & 480 & 69 & & 11 & 1400 & 127 & $\mathrm{~b} / \mathrm{c}$ & 12 & 330 & 28 & & 3 & 650 & 217 & $p$ & & & & \\
\hline $06 / 11$ & & & & & 4 & 150 & 37,5 & & & & & & & & & & 3 & 100 & 33 & & & & & & & & & \\
\hline $20 / 11$ & 4 & 550 & 138 & & 5 & 300 & 60 & $b$ & 8 & 1200 & 150 & & 7 & 770 & 110 & $b$ & 9 & 330 & 37 & & 5 & 1350 & 270 & $b$ & & & & \\
\hline $05 / 12$ & & & & & 3 & 100 & 33,3 & & & & & & 11 & 600 & 55 & $\mathrm{clb}$ & 4 & 150 & 38 & & 10 & 580 & 58 & $b$ & 2 & 530 & 265 & $b$ \\
\hline $18 / 12$ & 4 & 280 & 70 & & 7 & 500 & 71,4 & c & 9 & 540 & 60 & & 4 & 440 & 110 & $b$ & 6 & 650 & 108 & $b$ & 2 & 450 & 225 & $b$ & & & & \\
\hline $08 / 01$ & & & & & & & & & & & & & 14 & 2170 & 155 & $b$ & 16 & 560 & 35 & $p$ & 19 & 2040 & 107 & $b / c$ & & & & \\
\hline $29 / 01$ & 2 & 190 & 95 & & 2 & 70 & 35 & & 5 & 870 & 174 & $b$ & 8 & 800 & 100 & $b$ & 6 & 780 & 130 & $b$ & 2 & 680 & 340 & $b$ & & & & \\
\hline $05 / 02$ & & & & & 6 & 300 & 50 & $b$ & & & & & 9 & 1600 & 178 & & 8 & 300 & 38 & $b$ & 12 & 1850 & 154 & & 2 & 1000 & 500 & $b$ \\
\hline $19 / 02$ & 2 & 300 & 150 & & 5 & 450 & 90 & & 10 & 1100 & 110 & $b$ & 9 & 1500 & 167 & $b$ & & & & & 4 & 2000 & 500 & $b$ & & & & \\
\hline $05 / 03$ & & & & & 3 & 250 & 83,3 & & & & & & 11 & 1450 & 132 & $b$ & 6 & 950 & 158 & & 12 & 1350 & 113 & $b$ & 2 & 800 & 400 & $b$ \\
\hline $19 / 03$ & 2 & 15 & 7,5 & & 3 & 80 & 26,7 & $p$ & 6 & 210 & 35 & b & 6 & 400 & 67 & $b$ & & & & & 3 & 950 & 317 & $b$ & & & & \\
\hline $02 / 04$ & & & & & 6 & 400 & 66,7 & & 1 & 100 & 100 & $\mathrm{c}$ & 15 & 3050 & 203 & b & 7 & 300 & 43 & & 14 & 1825 & 130 & $b$ & 2 & 975 & 488 & b \\
\hline $16 / 04$ & 2 & 100 & 50 & & 4 & 200 & 50 & & 7 & 1450 & 207 & $b$ & 7 & 1450 & 207 & $b$ & & & & & 3 & 2100 & 700 & $b$ & & & & \\
\hline $01 / 05$ & & & & & 6 & 400 & 66,7 & & & & & & 13 & 2150 & 165 & $\mathrm{~b} / \mathrm{c}$ & 6 & 350 & 58 & $b$ & 9 & 1500 & 167 & $b$ & 2 & 1300 & 650 & b \\
\hline $14 / 05$ & 2 & 50 & 25 & $b$ & 4 & 200 & 50 & $b$ & 6 & 520 & 87 & $\mathrm{~b} / \mathrm{c}$ & 4 & 530 & 133 & $b$ & & & & & 4 & 1680 & 420 & $b$ & & & & \\
\hline $28 / 05$ & & & & & 3 & 360 & 120 & & 1 & 30 & 30 & & 13 & 1800 & 138 & $\mathrm{~b} / \mathrm{c}$ & 4 & 150 & 38 & & 10 & 1150 & 115 & $b$ & 2 & 1000 & 500 & \\
\hline $11 / 06$ & 1 & 50 & 50 & $b=c$ & 2 & 100 & 50 & & 5 & 270 & 54 & & 4 & 360 & 90 & $b$ & & & & & 3 & 350 & 117 & $b$ & & & & \\
\hline $25 / 06$ & & & & & 7 & 490 & 70 & $b$ & 1 & 40 & 40 & & 12 & 2540 & 212 & $\mathrm{~b} / \mathrm{c}$ & 10 & 370 & 37 & $p$ & 13 & 1880 & 145 & $b$ & 2 & 900 & 450 & \\
\hline $11 / 107$ & 2 & 100 & 50 & b & 3 & 200 & 66,7 & c & 5 & 850 & 170 & $b$ & 4 & 1300 & 325 & $b$ & & & & & 3 & 1850 & 617 & $b$ & & & & \\
\hline $23 / 07$ & & & & & 6 & 350 & 58,3 & & & & & & 11 & 2230 & 203 & $b$ & 10 & 400 & 40 & & 7 & 1300 & 186 & $b$ & 2 & 900 & 450 & $b$ \\
\hline $06 / 08$ & 3 & 300 & 100 & $b$ & 10 & 520 & 52 & c & 10 & 2070 & 207 & $b$ & 9 & 2230 & 248 & bic & & & & & 3 & 2520 & 840 & $b$ & & & & \\
\hline 20108 & & & & & 3 & 300 & 100 & & 1 & 20 & 20 & & 7 & 950 & 136 & $b$ & 7 & 440 & 63 & & 12 & 1000 & 83,3 & $b$ & 2 & 570 & 285 & $b$ \\
\hline $03 / 09$ & 3 & 200 & 66,7 & & 6 & 300 & 50 & $b$ & 8 & 1400 & 175 & $b / c$ & 10 & 1750 & 175 & $b$ & & & & & 3 & 2150 & 717 & $b$ & & & & \\
\hline 17109 & & & & & 6 & 420 & 70 & & & & & & 13 & 2080 & 160 & $b$ & 9 & 570 & 63 & $b$ & 12 & 1450 & 121 & $b$ & 2 & 1100 & 550 & $b$ \\
\hline Total & 62 & 4235 & 68,3 & 4 & 119 & 6990 & 58,7 & 9 & 99 & 12020 & 121 & 10 & 230 & 35380 & 154 & 24 & 147 & 7870 & 54 & 8 & 182 & 34405 & 189 & 24 & 20 & 9075 & 454 & 8 \\
\hline
\end{tabular}

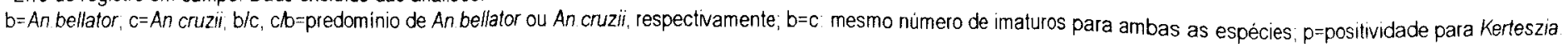


No estrato $[1,2[\mathrm{~m}$ também se trabalhou com o limite de até 25 bromélias ou 2,5 litros. Os dados mostram que foram aspiradas em média $24 \pm 4,6$ bromélias, sempre com volume pequeno (média $67 \pm 16 \mathrm{ml} /$ bromélia). Embora com bromélias menores, neste estrato quase todas as coletas foram positivas para Kerteszia, com predomínio de An. cruzii (21 das 23 coletas nesse estrato).

Nos estratos $[2,3[\mathrm{~m}$ e $[3,4[\mathrm{~m}$ os resultados variaram de coleta para coleta, sobretudo a $[3,4[\mathrm{~m}$, com relação ao número de bromélias aspiradas, sempre baixo: $4,4 \pm 1,3$ bromélias a $[2,3[\mathrm{~m}$ e $8 \pm 4,6$ a $[3,4[\mathrm{~m}$. O volume médio variou ainda mais, o que fica evidente ao se observar os desvios padrão: $90 \pm 60$ e $73 \pm 53 \mathrm{ml} /$ bromélia para $[2,3[\mathrm{~m} \mathrm{e}[3,4[\mathrm{~m}$, respectivamente. Quanto à positividade para Kerteszia, a $[2,3[\mathrm{~m}$ foram registradas 12 e a $[3,4[\mathrm{~m}, 13$ coletas positivas, de um total de 25 para cada estrato. A [2,3[m An. cruzii predominou e a $[3,4[\mathrm{~m}$ ambas ocorrem com frequências semelhantes

Para o estrato [4,5[m também se trabalhou com limite: até 30 bromélias ou 3 litros de água aspirada. Foram aspiradas em média 18 bromélias e o volume médio foi de $108 \pm 68 \mathrm{ml} /$ bromélia. Aqui já se observa claro predomínio de $A n$. bellator na coletas positivas para Kerteszia (18 das 20 coletas positivas para o subgênero; 27 coletas no período de trabalho).

O estrato [5,6[m tinha poucas bromélias, com média de bromélias aspiradas ói de $3 \pm 1$, com $73 \pm 41 \mathrm{ml} /$ bromélia. Apenas 4 coletas foram positivas para Kerteszia, ambém com predomínio de An. bellator (em 1 coleta, ambas espécies foram representadas Jor 1 larva; nas demais havia mais larvas de An.bellator do que de An. cruzii).

Nos estratos $[6,7[\mathrm{~m} \mathrm{e}[7,8[\mathrm{~m}$ o número de bromélias aspiradas foi semelhante, :om respectivas médias de $4,9 \pm 2$ e 5,5 $\pm 3,1$. Quanto ao volume, a média para [7,8[m foi um souco maior - $105 \pm 62 \mathrm{ml} /$ bromélia do que para $[6,7[\mathrm{~m}-60 \pm 23 \mathrm{ml} / \mathrm{bromélia}$, mas não liferem se levarmos em consideração os intervalos de confiança. Os estratos também não liferem quanto à positividade para Kerteszia: 9 de 24 coletas a $[6,7[\mathrm{~m}$ e 10 de 18 coletas a 7,8[m, ambas com predomínio de An. bellator.

O estrato [8,9[m destacou-se pela alta positividade para Kerteszia; das 25 :oletas, 24 foram positivas para o subgênero, com predomínio de An. bellator. O dado se orna mais significativo quando se leva em consideração que foram aspiradas cerca 10 romélias por coleta (média 9,2 $\pm 3,3$ ), com volume médio de $155 \pm 66 \mathrm{ml} / \mathrm{bromélia}$. 
A [9,10[m foram aspiradas em média $7,7 \pm 3,1$ bromélias, com volume médio de $58 \pm 36 \mathrm{ml} /$ bromélia. Aqui, a positividade para Kerteszia foi relativamente baixa: 8 das 19 zoletas continham imaturos desse subgênero, também com predomínio de An. bellator.

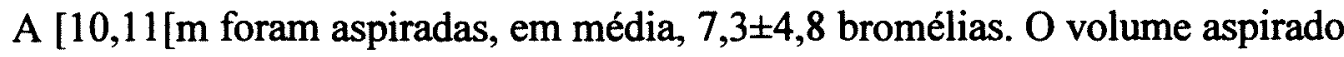
variou entre 50 e $840 \mathrm{ml} /$ bromélia (média $274 \pm 228 \mathrm{ml} /$ bromélia). Ainda assim, a positividade foi de 24 das 25 coletas.

Finalmente, a [11,12]m é importante enfatizar que foram examinadas sempre 2 bromélias, adjacentes e de tamanho semelhante. O volume aspirado variou de 265 $\mathrm{ml} /$ bromélia a $650 \mathrm{ml} /$ bromélia (média $454 \pm 116 \mathrm{ml} /$ bromélia). Das 10 coletas realizadas neste estrato, 8 foram positivas para An. bellator, exclusivamente.

Por entender que a chuva exerça influência direta na manutenção de sriadouros pequenos e transitórios, são apresentados abaixo os dados semanais de rrecipitação acumulada de 2001 e 2002 (Figura 11).

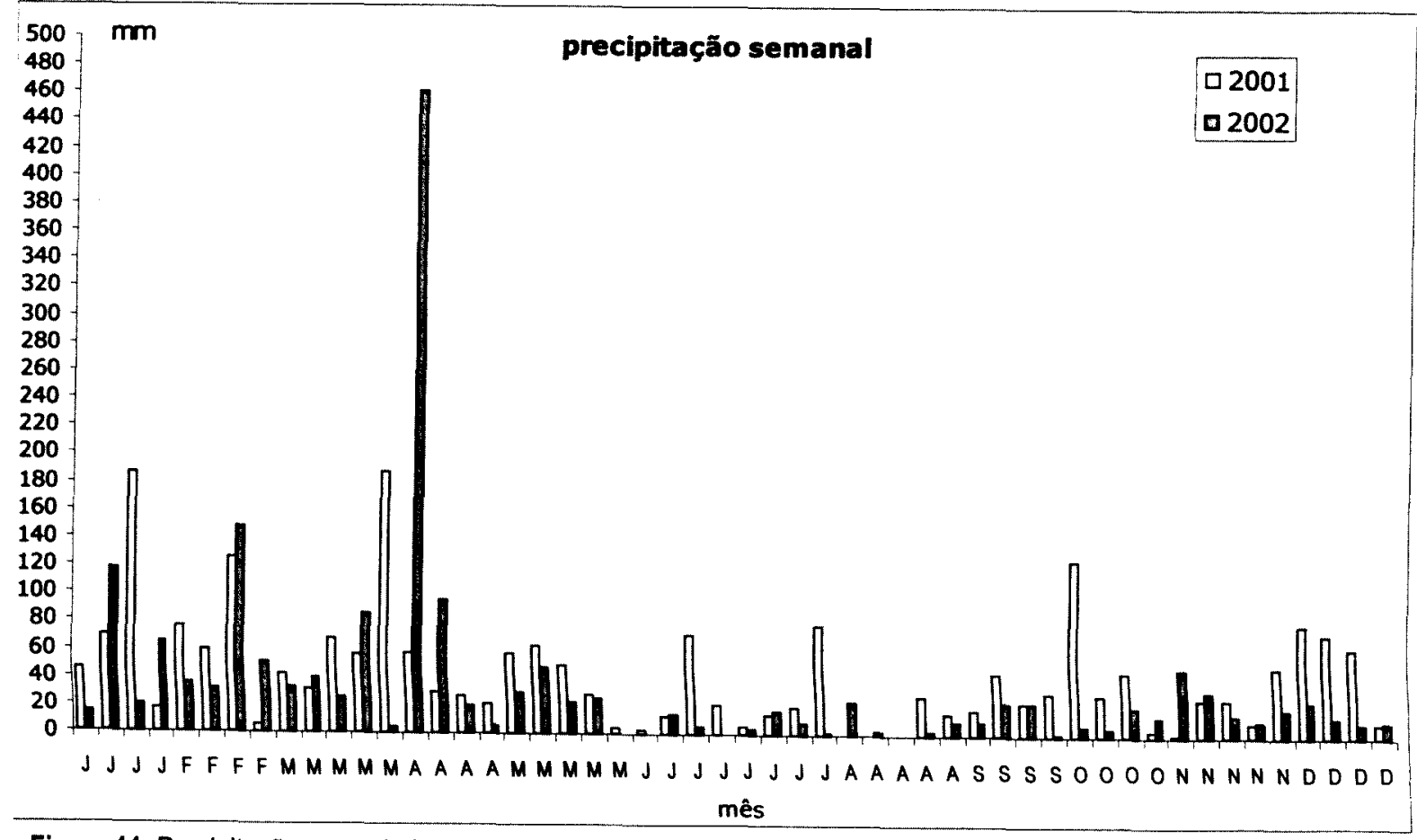

Figura 11: Precipitação acumulada semanal em 2001 e 2002 no municipio de Cananéia, SP.

Fonte: Instituto Oceanográfico - USP. 
Em relação à variação sazonal por estrato, como a densidade das espécies de Kerteszia foi freqüentemente inferior a limaturo $/ 100 \mathrm{ml}$, optou-se por descrever os dados que se destacaram. Conforme citado anteriormente, a restinga apresentou An. bellator esporadicamente, em setembro de 2001 (0,06 imaturos $/ 100 \mathrm{ml})$ e, em 2002, nos meses de abril, maio, julho e agosto, com densidades sempre inferiores ao obtido em setembro de 2001 .

$\mathrm{Na}$ mata, as bromélias de solo apresentaram densidades maiores e mais constantes para An. cruzii do que para An. bellator. A primeira espécie só esteve ausente em uma das coletas de janeiro e no mês de abril de 2002. As maiores densidades foram registradas de maio a setembro (de 2002), periodo no qual os valores oscilaram entre 0,2 e 1,3 imaturos $/ 100 \mathrm{ml}$. An. bellator esteve presente em cerca de $60 \%$ das coletas, mas com densidade sempre baixa (máxima registrada de 0,2 imaturos $/ 100 \mathrm{ml}$, em jun/2002).

No estratos de [1,2[m em set e outubro de 2001 a densidade de An. cruzii foi 1,2 imaturos $/ 100 \mathrm{ml}$. Após esse periodo, a densidade se aproxima de zero, voltando a subir a partir de maio seguinte, com cerca de 0,5 a até 1,7 imaturos $/ 100 \mathrm{ml}$. Quanto a An. bellator, somente no mês de setembro de 2001 e de 2002 a densidade foi mais alta: 0,6 e 1,1 imaturos $/ 100 \mathrm{ml}$, respectivamente. Neste intervalo as densidades são inferiores a 0,5 .

A $[2,3[\mathrm{~m}$ foi registrada a densidade máxima obtida no presente estudo para An. cruzii: 4 imaturos $/ 100 \mathrm{ml}$, em setembro de 2001. Na mesma coleta, An. bellator teve densidade neste estrato $(1,3)$. Nos demais meses, a densidade se mantém baixa para as duas espécies, exceto novembro de 2001 com densidade 0,7 e maio de 2002 , com densidade 0,3 para as duas espécies.

No estrato $[3,4[\mathrm{~m}$ a densidade de An. bellator manteve-se mais alta entre setembro de 2001 e março de 2002 , variando entre 0,7 e 1,3 imaturos $/ 100 \mathrm{ml}$. No período total de estudo, a densidade de $A n$. cruzii variou de 0,3 a 2 .

$\mathrm{Na}$ classe de altura $[4,5[\mathrm{~m}$ An. bellator registrou a densidade máxima da espécie em todo o estudo (estratos e período) : 6,25 imaturos $/ 100 \mathrm{ml}$, em novembro de 2001 . Na mesma coleta, An. cruzii teve densidade 1,25 - a maior neste estrato. Nos demais meses, An. bellator predominou sobre An. cruzii. Outras coletas com densidades de An. bellator superiores a 0,5 ocorreram em setembro $(3,2)$, outubro $(1,1)$ e dezembro $(2,0)$ de 2001 ; e fevereiro $(0,7)$, maio $(0,8)$, junho $(0,5)$, agosto $(1,6)$ e setembro $(0,7)$ de 2002 .

A [5,6[m, a única coleta positiva para An. cruzii foi em julho de 2002, com densidade de 2 imaturos $/ 100 \mathrm{ml}$. Em uma das coletas de maio e de junho do mesmo ano, 
registrou-se densidade igual para An. bellator; em julho, a densidade foi de limaturo/100ml e no mês seguinte, caiu para 0,3 . Nos demais meses, esta espécie também esteve ausente.

A $[6,7[\mathrm{~m}$, apenas 4 coletas foram positivas para $A n$. cruzii: em outubro e dezembro de 2001, e em julho e agosto de 2002. Em todas elas a densidade deste anofelino foi de limaturo/100ml. Em maio de 2002, An. bellator apresentou esta mesma densidade; esteve presente em outras 4 coletas (nov/2001, fev/jun/set/2002), com densidade em torno de 0,3 , e ausente nas demais.

A densidade de $A$. cruzii ainda chegou a 1, a [7,8[m de altura (abr/2002) e a $[9,10[\mathrm{~m}$, na única coleta positiva para esta espécie a densidade foi 0,8 (set/2001). Nas demais coletas e estratos este anofelino praticamente desaparece e sua densidade não ultrapassa o valor de 0,3 imaturos $/ 100 \mathrm{ml}$. Por outro lado, An. bellator apresenta certa constância ao longo dos meses a partir da classe $[7,8[\mathrm{~m}$, com densidades variáveis. Neste estrato, a densidade máxima foi de 1,9 (maio/2002); ficando abaixo de 0,5 nos outros meses positivos para esta espécie. $\mathrm{Na}$ classe seguinte $([8,9[\mathrm{~m})$, a positividade (oito coletas) de An. bellator foi maior do que a de $A n$. cruzii, mas em nenhuma delas a densidade ultrapassou o valor de 0,5 .

O estrato de $[10,11[\mathrm{~m}$ apresentou produção constante de imaturos de $A n$. bellator (apenas 1 coleta negativa), com densidades que variaram de 0,2 (jan/2001) a 2,7 (set/2001). No última estrato estudado, das 10 coletas realizadas, 8 foram positivas, exclusivamente para An. bellator. Em três delas a densidade foi superior a 1 (dez/2001, maio e ago/2002); nas demais, variou de 0,1 a 0,6 imaturos $/ 100 \mathrm{ml}$.

Para a verificar se há associação entre densidade de imaturos e chuva acumulada nos 15 dias anteriores ao de coleta, utilizou-se a densidade diária, ou seja, a soma das densidades nos estratos positivos para $A n$. cruzii e $A n$. bellator. Na página seguinte são apresentados gráficos que ilustram este dado em relação à precipitação (Figura 12).

É interessante destacar que, inversamente ao que foi observado em relação aos adultos, as densidades de $A n$. bellator foram sempre mais altas do que as de $A n$. cruzii, exceto na primeira coleta de setembro de 2001. Porém, em números absolutos, o máximo registrado foi de 92 larvas de An. cruzii (03/09/2002) e 90 de An. bellator (01/05/2002). Nenhuma coleta foi negativa para ambas as espécies, considerando todos os estratos como um todo. $\mathrm{O}$ menor número de larvas coletadas foi 2 , de An. cruzii e 7, de An. bellator. 


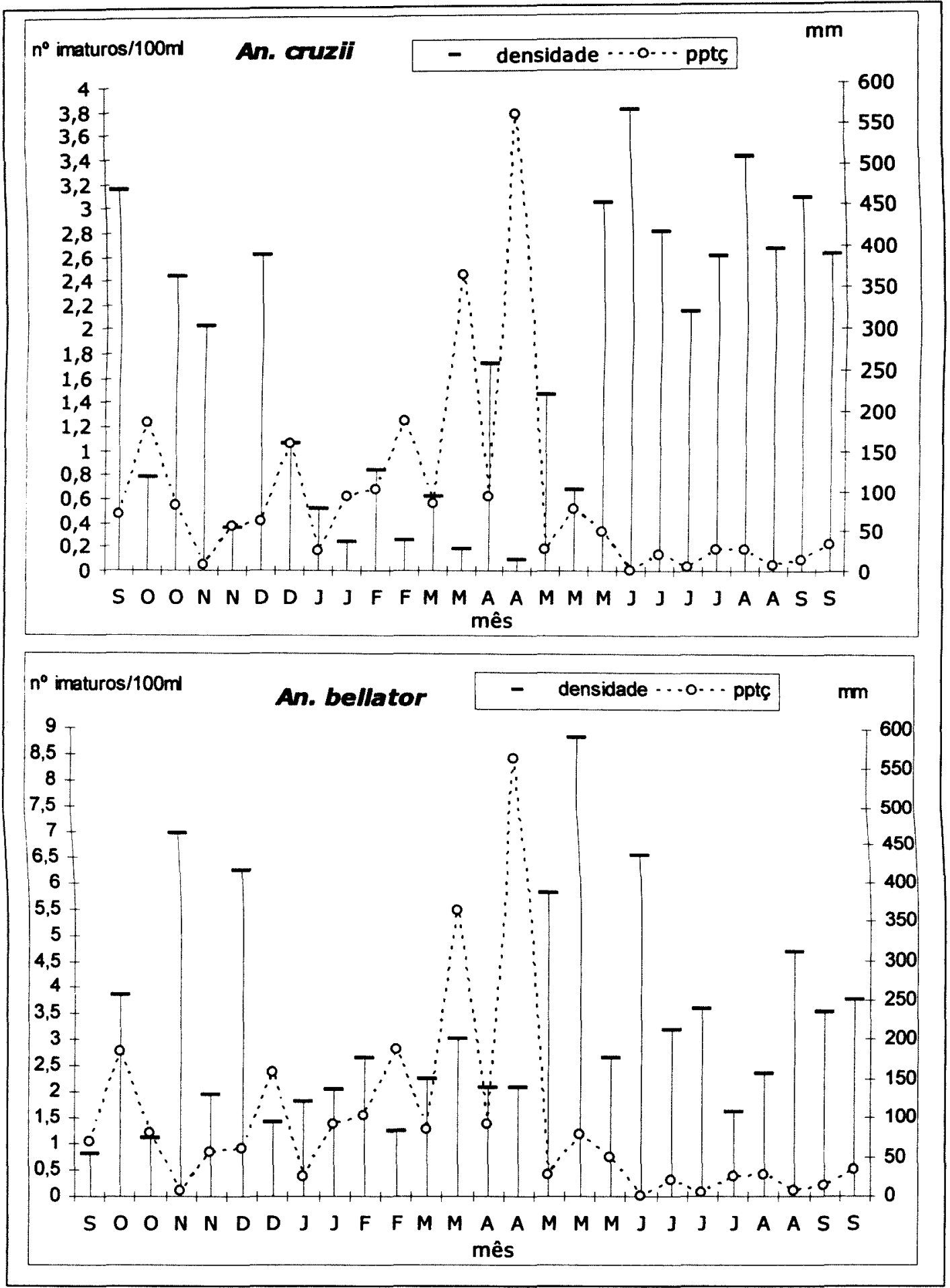

Figura 12: Densidade de An. cruzii e An. bellator em bromélias de mata (de solo e epifitas até $12 \mathrm{~m}$ de altura) e precipitação acumulada* nos 15 dias anteriores ao de coleta (pptç). Coletas quinzenais, de 18/09/2001 a 17/09/2002. Itha Comprida, SP.

"Dados de chuva medidos no municipio de Cananéia e fornecidos pelo Instituto Oceanográfico USP. 
O coeficiente de Spearman calculado para a densidade de An. cruzii em relação à chuva acumulada nos 15 dias anteriores aos de coleta, $r_{s}=-0,657$, indica correlação negativa entre essas variáveis, ao nível de significância de $1 \%$. $O$ valor de $t=6,500$ confirma esta relação e permite estabelecer nível de significância de $0,5 \%$. Em se tratando de $A n$. bellator, foi obtido $r_{s}=-0,444$, singificativo para $\alpha=0,05$; o valor de $t=5,467$ permite reduzir o valor de $\alpha$ para 0,005 . Isso significa que, para ambas as esṕcies, a densidade de imaturos foi maior quando a precipitação no periodo anterior foi mais baixa.

No que diz respeito à distribuição vertical, a figura abaixo ilustra a variação de volumes médios de água aspirada por bromélia para cada estrato.

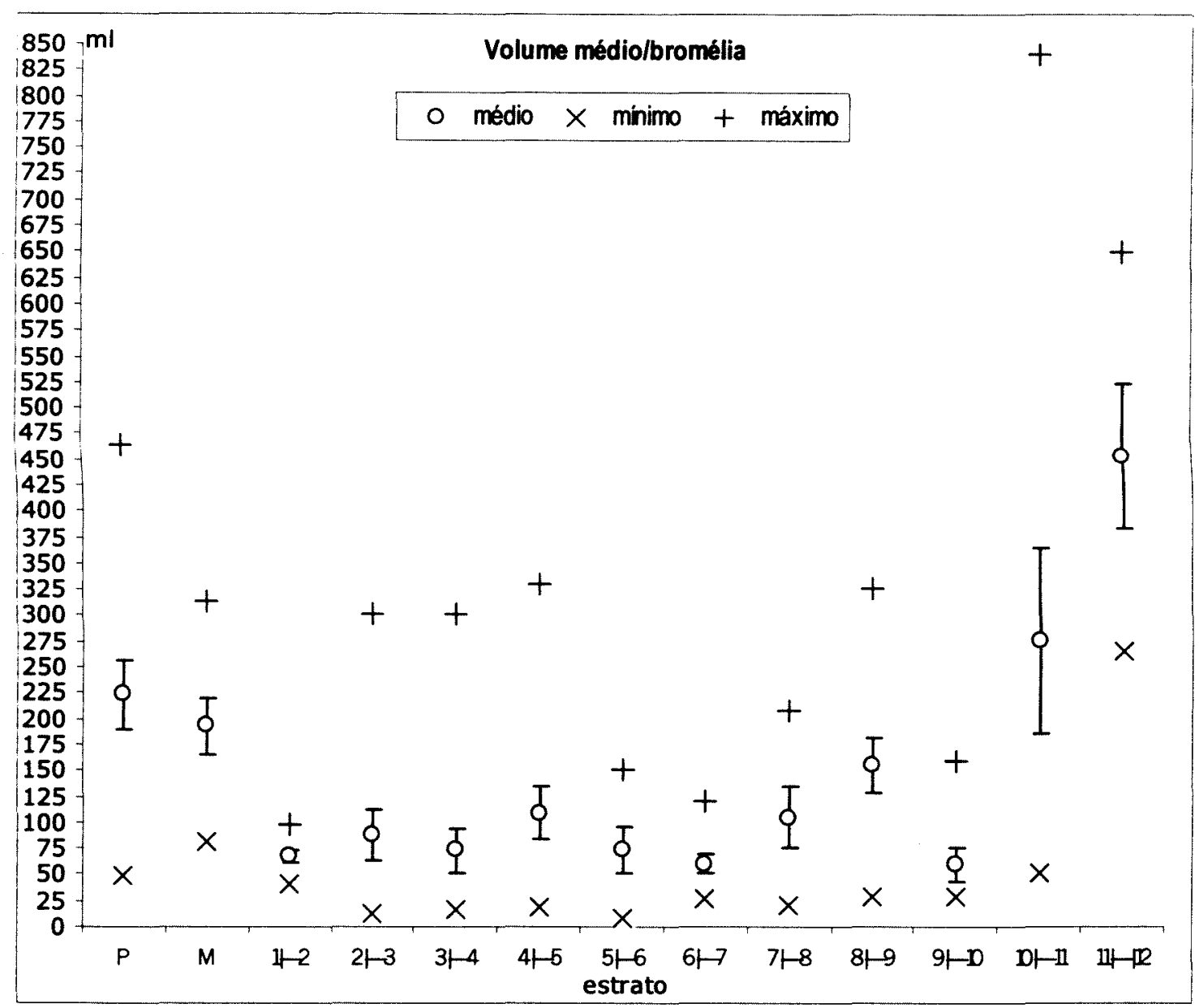

Figura 13: Intervalo de confiança dos volumes médios, mínimos e máximos de água aspirada por bromélia, segundo estrato (no solo, $P=$ praia e $M=$ mata). Ilha Comprida, set/2001 a set/2002. 
Com o intuito de observar se existe correlação entre o volume médio de água nas bromélias de mata, como estimativa indireta de seu tamanho, e a altura em que se encontram, foi calculado o coeficiente de Spearman. $\mathrm{O} r_{\mathrm{s}}$ obtido demonstra que não houve correlação entre o volume médio de água por bromélia e sua altura de fixação nas árvores ( $r_{\mathrm{s}}=0,267 ; \alpha>0,05$; o valor de $t=0,878$ não atinge o valor crítico que estabelece $\alpha=0,10$ ).

Em relação à positividade dos criadouros, isto é, cada estrato por coleta, procurou-se observar a freqüência de ocorrência das espécies de Kerteszia. Na coexistência de ambas, levou-se em consideração sua proporção relativa, conforme se apresenta na tabela a seguir:

Tabela 10: Número de coletas positivas para larvas de An. cruzii (c) e/ou An. bellator (b) em bromélias na mata e proporção relativa na coexistència de ambas as espécies, segundo estratificação vertical. Ilha Comprida, 04/09/2001 a 17/09/2002.

\begin{tabular}{lccccc}
\hline Estrato & $\mathrm{c}$ & $\mathrm{c}>\mathrm{b}$ & $\mathrm{c}=\mathrm{b}$ & $\mathrm{c}<\mathrm{b}$ & $\mathrm{b}$ \\
\hline Solo-praia & - & - & - & - & 7 \\
Solo-mata & 8 & 16 & - & - & 1 \\
$1 \mid-2 \mathrm{~m}$ & 4 & 7 & 2 & 3 & 5 \\
$2 \mid-3 \mathrm{~m}$ & 4 & 3 & 1 & - & 4 \\
$3 \mid-4 \mathrm{~m}$ & 5 & 3 & 1 & 4 & 1 \\
$4 \mid-5 \mathrm{~m}$ & 1 & 1 & 1 & 9 & 9 \\
$5 \mid-6 \mathrm{~m}$ & - & - & 1 & - & 3 \\
$6 \mid-7 \mathrm{~m}$ & 3 & - & - & - & 5 \\
$7 \mid-8 \mathrm{~m}$ & 2 & - & - & 2 & 6 \\
$8 \mid-9 \mathrm{~m}$ & - & 1 & - & 7 & 16 \\
$9 \mid-10 \mathrm{~m}$ & - & 1 & - & - & 5 \\
$10 \mid-11 \mathrm{~m}$ & - & - & - & 1 & 22 \\
$11 \mid-12 \mathrm{~m}$ & - & - & - & - & 8 \\
\hline
\end{tabular}

A tabela acima indica que a praia não se mostrou ambiente favorável ao desenvolvimento de Kerteszia, já que as sete coletas positivas para este subgênero (incluindo a de 04/09/2001) totalizaram 15 larvas de An. bellator e nenhuma de An. cruzii.

$\mathrm{Na}$ mata registrou-se predomínio da $A$ n. cruzii no solo e nas classes de altura até $[3,4[\mathrm{~m}$. A partir de $[4,5[\mathrm{~m}$ a ocorrência de $A n$. cruzii diminuiu, enquanto que a de $A n$. bellator aumentou.

Como o número de bromélias e os volumes de água aspirada variaram consideravelmente entre os estratos, e mesmo entre as coletas, calculou-se a densidade de imaturos de An. bellator e An. cruzii por estrato. O coeficiente de Spearman revelou 
:orrelação positiva para An. bellator, ou seja, quanto mais alto o ponto de fixação da romélia, maior a densidade de imaturos desta espécie; o $r_{\mathrm{s}}$ obtido foi de 0,566 , significativo $15 \%$, cujo valor associado de $t=2,174$ confirma esta significância, mas se aproxima do valor sítico que estabelece $\alpha=2,5 \%\left(t_{\text {critico }}=2,228\right)$. Para $A n$. cruzii o coeficiente revelou correlação fortemente negativa, isto é, quanto mais baixo o estrato, maior foi a densidade de imaturos da zspécie, com $r_{\mathrm{s}}=-0,874$ e $\alpha=0,01$, reduzido para 0,005 quando associado ao valor $t=5,691$ obtido pela fórmula de Kendall.

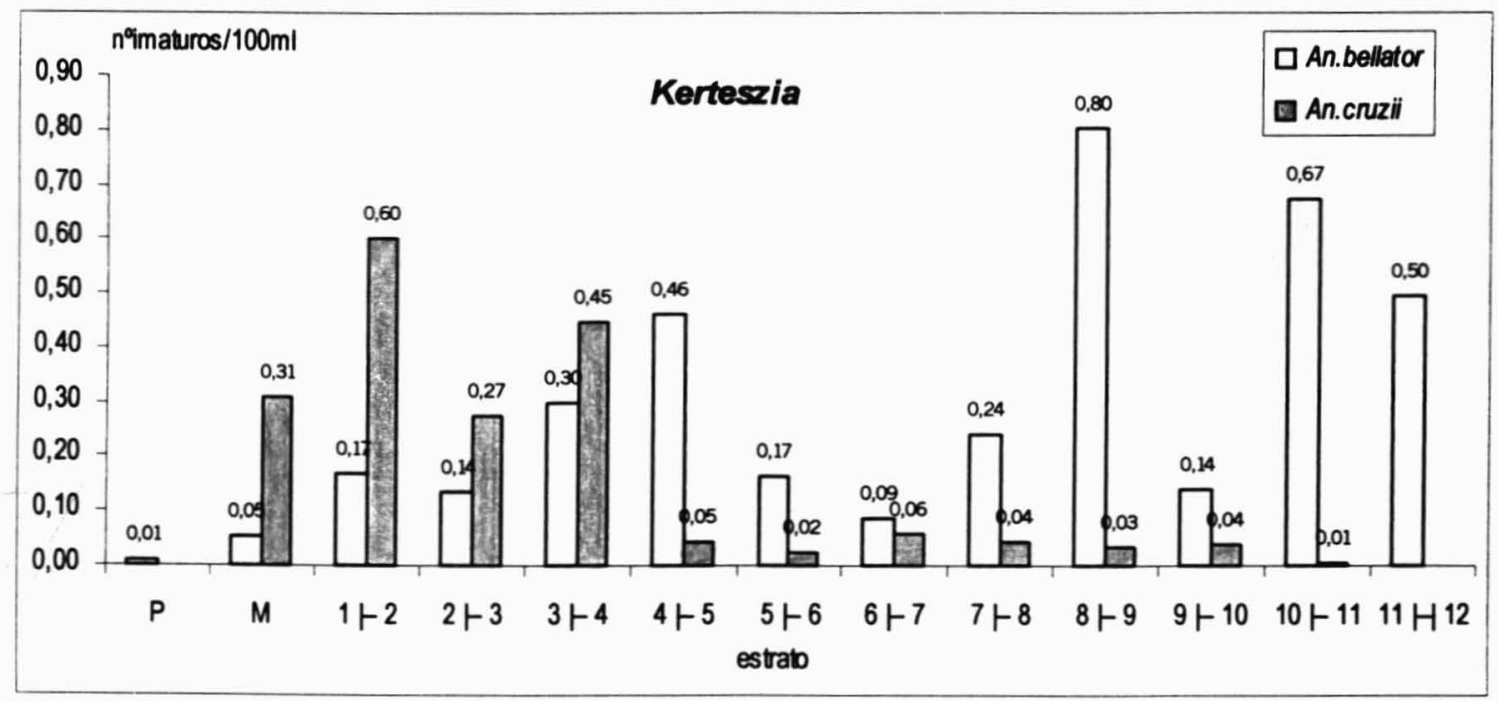

Figura 14: Densidades de imaturos de An. bellator e An. cruzii em bromélias de solo e epifitas, segundo classes de altura (no solo, $\mathrm{P}=$ praia e M=mata). Ilha Comprida, set/2001 a set/2002.

As larvas de Kerteszia coletadas foram criadas em laboratório. Ao todo, foram criadas 2180 larvas, das quais 2119 (97\%) desenvolveram-se até a fase adulta, sendo 754 (34\%) An. cruzii e 1002 (46\%) An. bellator (em 363 (16,7\%) dos indivíduos não foi possível determinar a espécie). A razão sexual (machos/fêmeas) foi próxima a 1 para as duas espécies: 0,87 para An. cruzii e 1,1 para An. bellator.

O volume total de cada estrato por coleta representou um criadouro em laboratório. Em 52\% deles todas as larvas chegaram até a fase adulta, o que levou de 31 a 108 dias. Os períodos mais longos justificam-se em função da retirada de larvas de $1^{\circ}$ estadio no $13^{\circ}$ dia após a coleta e baixas temperaturas (coletas de inverno). Apenas em $0,4 \%$ dos 
criadouros não houve a produção do adulto, independentemente do número de larvas. Nos demais, a mortalidade foi variável. O maior registro de Kerteszia foi de 95 larvas (03/09/02), coletadas nas bromélias de solo na mata, das quais 71 chegaram até a fase adulta.

Para imaturos de Culicidae, considerados em conjunto, não houve correlação entre a altura de fixação das bromélias e a densidade encontrada, de acordo com o coeficiente de Spearman $\left(r_{\mathrm{s}}=0,077 ; \mathrm{p}>0,05\right)$. A figura abaixo ilustra as densidades de larvas de Culicidae (número de imaturos $/ 100 \mathrm{ml}$ ) em cada estrato.

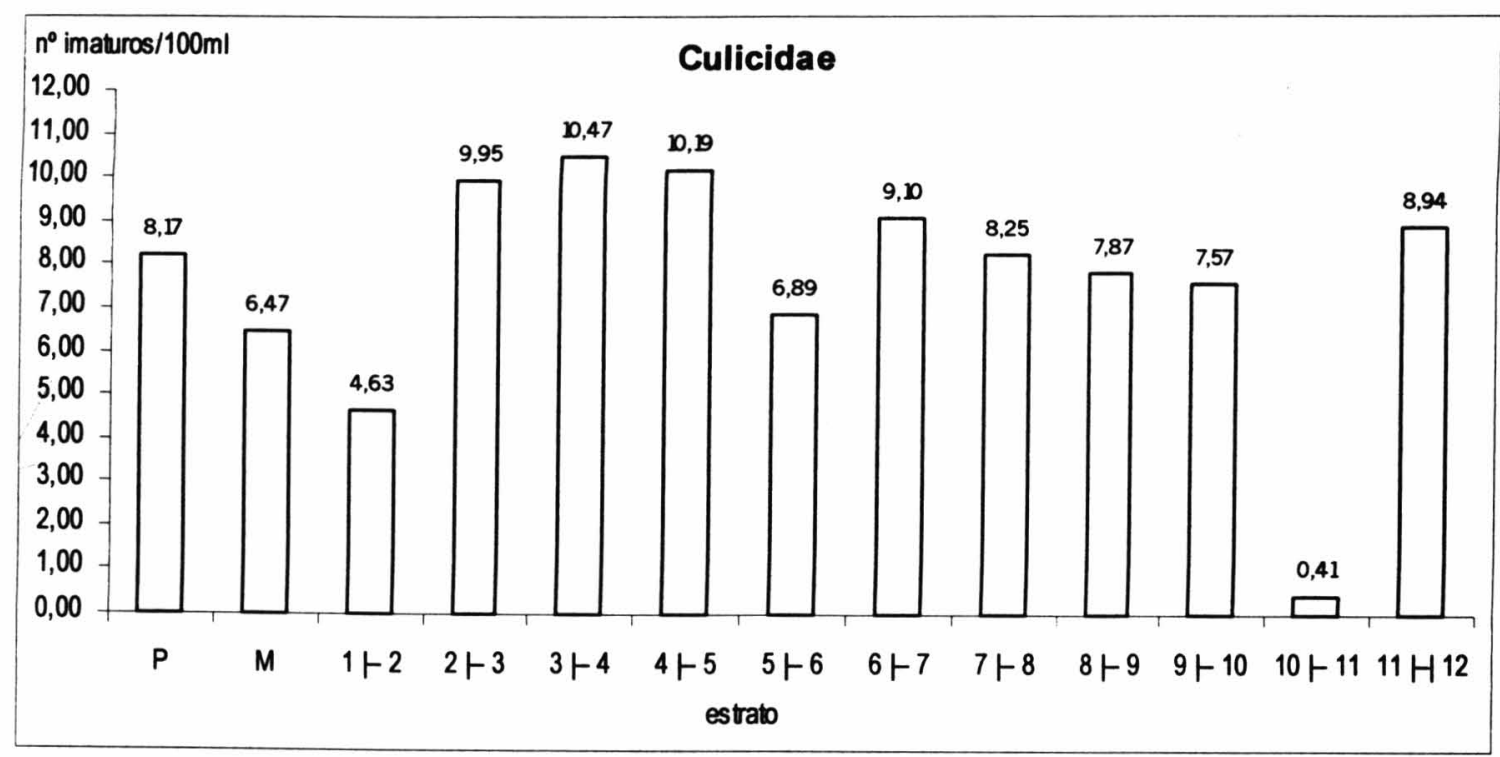

Figura 15: Densidades de imaturos de Culicidae em bromélias de solo e epífitas, segundo classes de altura (no solo, $P=$ praia e $M=$ mata). Ilha Comprida, set/2001 a set/2002.

A composição específica da fauna de mosquitos coletados nas bromélias apresenta-se nas Tabelas 11 a 23. 
Tabela 11: Larvas de Culicidae coletadas em bromélias de solo na praia. Ilha Comprida, SP, 18/09/2001 a 17/09/2002.

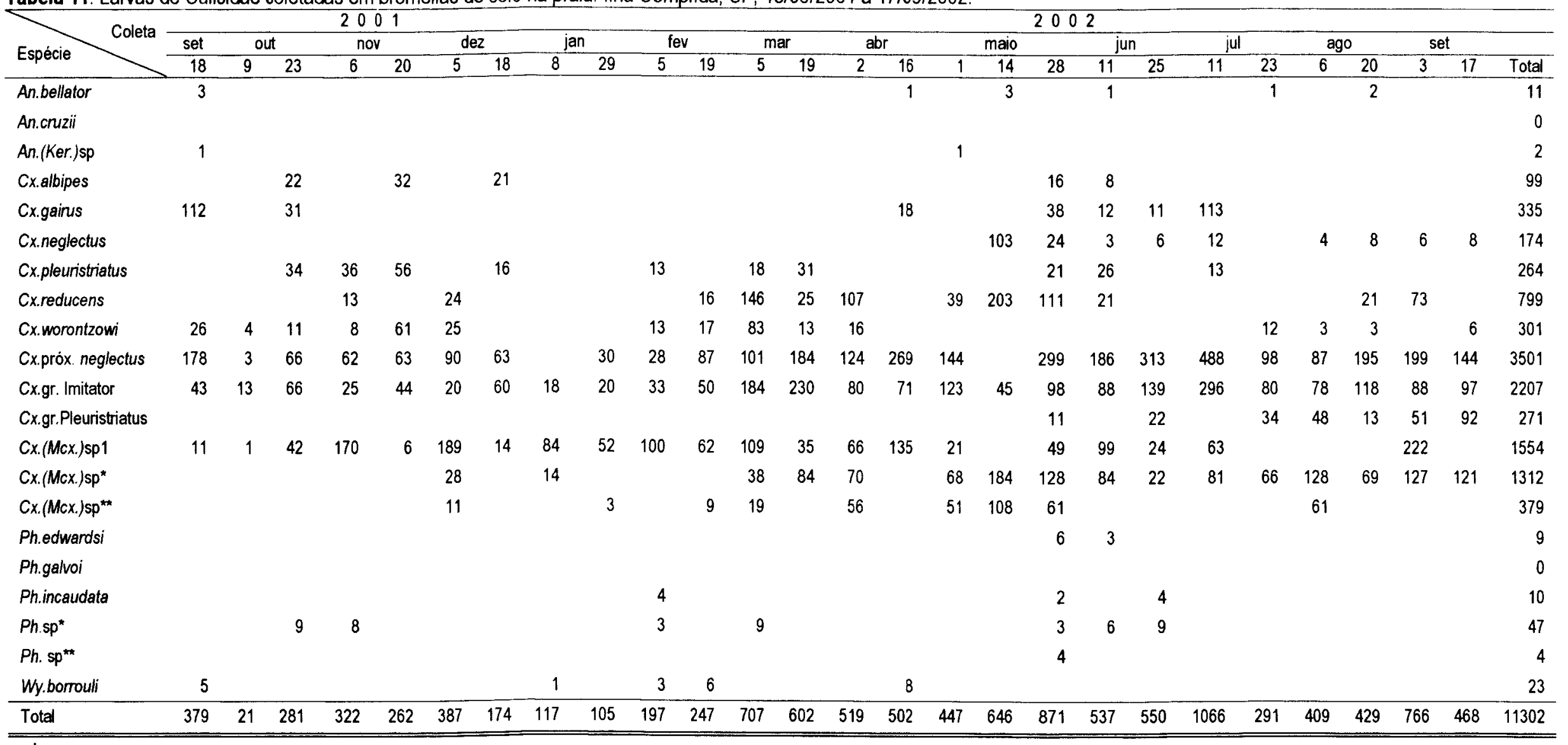

* larvas em estágios iniciais, não identificáveis; " espécimes danificados 
Tabela 12: Larvas de Culicidae coletadas em bromélias de solo na mata. Ilha Comprida, SP, 18/09/2001 a 17/09/2002.

\begin{tabular}{|c|c|c|c|c|c|c|c|c|c|c|c|c|c|c|c|c|c|c|c|c|c|c|c|c|c|c|c|}
\hline \multirow{3}{*}{ Espécie } & \multicolumn{7}{|c|}{2001} & \multicolumn{19}{|c|}{2002} & \multirow{3}{*}{ Total } \\
\hline & \multirow{2}{*}{$\begin{array}{c}\text { set } \\
18 \\
\end{array}$} & \multicolumn{2}{|c|}{ out } & \multicolumn{2}{|c|}{ nov } & \multicolumn{2}{|c|}{ dez } & \multicolumn{2}{|c|}{ jan } & \multicolumn{2}{|c|}{ fev } & \multicolumn{2}{|c|}{ mar } & \multicolumn{2}{|c|}{$a b r$} & \multicolumn{3}{|c|}{ maio } & \multicolumn{2}{|c|}{ jun } & \multicolumn{2}{|c|}{ jul } & \multicolumn{2}{|c|}{ ago } & \multicolumn{2}{|c|}{ set } & \\
\hline & & 9 & 23 & 6 & 20 & 5 & 18 & 8 & 29 & 5 & 19 & 5 & 19 & 2 & 16 & 1 & 14 & 28 & 11 & 25 & 11 & 23 & 6 & 20 & 3 & 17 & \\
\hline An.bellator & & 2 & 3 & 1 & 5 & & & & 1 & & 5 & & 2 & 2 & & 3 & 8 & & 12 & 1 & 15 & 1 & 3 & & 5 & & 69 \\
\hline An.cruzii & 22 & 14 & 6 & 4 & 11 & 6 & 3 & & 2 & 2 & 6 & 2 & 7 & & & 17 & 9 & 32 & 18 & 33 & 37 & 21 & 26 & 34 & 66 & 22 & 400 \\
\hline An.(Ker.)sp & 2 & 2 & & 1 & 1 & 1 & & 4 & & & 2 & & & 1 & 2 & 2 & 1 & 3 & 16 & 11 & 34 & & 5 & 11 & 24 & 6 & 129 \\
\hline Cx.albipes & 1 & & & 44 & 42 & & & & & & & & & & & & & & & & & & & & & & 87 \\
\hline Cx.gainus & & & & & 14 & & & 153 & & & & & & & & & & & & & & & & & & & 167 \\
\hline Cxintermedius & & & & & & & & 46 & & & & & & & & & & & & & & & & & & & 46 \\
\hline Cx.neglectus & & & & & & & & & & & & 62 & & & & & & & 5 & 2 & 3 & 1 & 2 & 5 & 2 & 2 & 84 \\
\hline Cx.pleuristriatus & & & & 18 & 21 & & & 18 & & 10 & & & & & & & & 5 & & & & & & & & & 72 \\
\hline Cx.reducens & 3 & 1 & 57 & 56 & & 21 & 24 & 21 & 24 & 40 & 67 & 118 & & 97 & 38 & 20 & 55 & 19 & 42 & 21 & 11 & 12 & & 11 & 18 & & 776 \\
\hline Cx.worontzowi & 22 & 3 & 76 & & 63 & 48 & & & & 23 & & 93 & 31 & & 11 & & & 3 & & & 3 & & & 12 & 1 & 1 & 390 \\
\hline Cx.próx.neglectus & 96 & 5 & 178 & 177 & 102 & 188 & 214 & 146 & 74 & 94 & 29 & 62 & 109 & 61 & 75 & 31 & 194 & 26 & 185 & 105 & 189 & 63 & 144 & 38 & 128 & 77 & 2790 \\
\hline Cx. inimitabilisffuscatus & 1 & & & & & & & & & & & & & & & & & & & & & & & & & & 1 \\
\hline Cx.Grupo Imitator & 60 & & 69 & 54 & 147 & 51 & 106 & & 13 & 103 & 91 & 249 & 289 & 36 & 63 & 16 & 31 & 11 & 12 & 28 & 5 & 22 & 43 & 68 & 69 & 40 & 1676 \\
\hline Cx.Grupo pleuristriatus & & & & & & & & & & & & & & & & & & & & & & & & 21 & 23 & 9 & 53 \\
\hline$C x .(M c x) s p 1$, & & & & 171 & 22 & & & 128 & & & 71 & & & & & & & & 68 & & 18 & & 31 & & & & 509 \\
\hline$C_{x .}(M c x.) \mathrm{sp}^{*}$ & & & & & & & & 44 & & & 30 & 75 & 101 & 38 & & 24 & 20 & 42 & 29 & 68 & 98 & & 70 & 54 & 68 & 15 & 776 \\
\hline$C_{x} .(M c x) s p *$. & & & & & & 44 & & 28 & & & & 45 & 26 & 64 & & 11 & 88 & 6 & & & & & & 3 & & & 315 \\
\hline Ph.edwardsi & 3 & & & & 13 & & & & 4 & & 4 & & & & 3 & & & & & 1 & 3 & & & & 2 & & 33 \\
\hline Ph.incaudata & & & & & & & 6 & & & & & & & & & & & & 11 & & & & & & & & 17 \\
\hline Ph.sp* & & & & & & & & & & & & & & & & & & & 10 & 2 & 4 & & & & 5 & & 21 \\
\hline Ph.sp ** & & & 1 & & & & & & & & 3 & & & & & & & & 8 & & & & & & & & 12 \\
\hline Ru.reversa & & & & & & & 1 & & & & & & & & & & & & & & & & & & & & 1 \\
\hline Wy.borrouli & & & & & & 14 & & & & & & & & & & & & & & & & & & & & & 14 \\
\hline Total & 210 & 27 & 390 & 526 & 441 & 373 & 354 & 588 & 118 & 272 & 308 & 706 & 565 & 299 & 192 & 124 & 406 & 147 & 416 & 272 & 420 & 120 & 324 & 257 & 411 & 172 & 8438 \\
\hline
\end{tabular}

* larvas em estágios iniciais, nåo identificáveis; "*espécimes danificados 
Tabela 13: Larvas de Culicidae coletadas em bromélias a [1, 2[m do solo na mata. Ilha Comprida, SP, 04/09/2001 a 17/09/2002.

\begin{tabular}{|c|c|c|c|c|c|c|c|c|c|c|c|c|c|c|c|c|c|c|c|c|c|c|c|c|}
\hline \multirow{3}{*}{ Espécie Coleta } & \multicolumn{5}{|c|}{2001} & \multicolumn{19}{|c|}{2002} \\
\hline & \multicolumn{2}{|c|}{ set } & \multirow{2}{*}{$\begin{array}{l}\text { out } \\
23\end{array}$} & \multirow{2}{*}{$\begin{array}{r}\text { nov } \\
20\end{array}$} & \multirow{2}{*}{$\begin{array}{r}\frac{d e z}{18} \\
\end{array}$} & \multirow{2}{*}{$\begin{array}{l}\mathrm{jan} \\
29 \\
\end{array}$} & \multicolumn{2}{|c|}{ fev } & \multicolumn{2}{|c|}{ mar } & \multicolumn{2}{|c|}{$a b r$} & \multicolumn{3}{|c|}{ maio } & \multicolumn{2}{|c|}{ jun } & \multicolumn{2}{|c|}{ jul } & \multicolumn{2}{|c|}{ ago } & \multicolumn{2}{|c|}{ set } & \multirow{2}{*}{ Total } \\
\hline & 4 & 18 & & & & & 5 & 19 & 5 & 19 & 2 & 16 & 1 & 14 & 28 & 11 & 25 & 11 & 23 & 6 & 20 & 3 & 17 & \\
\hline An.bellator & 1 & 1 & 3 & & 2 & 6 & 4 & 5 & & 1 & 1 & 6 & 1 & 7 & & 1 & & 6 & & 1 & 1 & 16 & & 63 \\
\hline An.cnuzii & & 15 & 13 & 1 & & 5 & & & & & 2 & 2 & 1 & 6 & 9 & 23 & 16 & 6 & 17 & 34 & 25 & 25 & 22 & 222 \\
\hline An.(Ker.)sp & & 0 & 4 & & & 2 & 2 & 3 & 1 & & & & & 1 & & 16 & & & 4 & 4 & 33 & 12 & & 82 \\
\hline Cx.albipes & & & & & & & & & 11 & & & & & & 3 & & & & & & & & & 14 \\
\hline Cx.davisi & & & & & & & & & & 4 & & & & & & & & & & & & & & 4 \\
\hline Cx.gairus & & & & & & & 10 & 10 & & 4 & & & & & 3 & & & & & & & & & 27 \\
\hline Cx.lanei & & & & & & & & & & 4 & & & & & & & & & & & & & & 4 \\
\hline Cx.neglectus & & & & & & & & & & & & & & 1 & & & & & & 1 & & & 4 & 6 \\
\hline Cx.pleuristriatus & & & & & 14 & & & 2 & 16 & 11 & & & & & & & & & & & & & & 43 \\
\hline Cx.reducens & & 5 & & & 8 & 22 & 11 & & 13 & 5 & 3 & & 3 & & 14 & 18 & & 11 & 4 & 46 & 2 & & & 165 \\
\hline Cx.worontzowi & & 6 & 21 & & & & & & & & 3 & & & & & & & & & & & & & 30 \\
\hline Cx.próx.neglectus & & 2 & 33 & 2 & 12 & 36 & 13 & 26 & 13 & 19 & 16 & 38 & 10 & 40 & 45 & 64 & & 31 & 20 & & 21 & 24 & & 465 \\
\hline Cx.Grupo Imitator & 38 & 73 & 18 & & 9 & 24 & 22 & 16 & 11 & & & 16 & 6 & 3 & 6 & 24 & 21 & 10 & 10 & & 19 & 4 & 33 & 363 \\
\hline Cx.Grupo Pleuristriatus & & & & & & & & & & & & & & & & & 3 & & & & & & 3 & \\
\hline$C x .(M c x) s p 1$. & & & 6 & & & & & & & 16 & & & & & & & & 8 & & & & & & 30 \\
\hline$C_{x} .(M c x.) s^{*}$ & & & & & & & 3 & & & & & 16 & & & 12 & 31 & & & & & 22 & 10 & & 94 \\
\hline$C x .(M c x)$ sp $\#$ & & & & & & 19 & & & & & 4 & & & 8 & 2 & & & & & & & & & 33 \\
\hline Ph.edwardsi & & & 1 & 1 & & & & & & & & & & & 2 & 1 & & & & & & & 1 & 6 \\
\hline Ph.galvoi & & & & & & & & & & & & & & & 1 & & & & & & & & & 1 \\
\hline Phincaudata & & & & & & & 9 & & & & 5 & & 1 & & 4 & 3 & & & & & & & & 22 \\
\hline Ph.sp* & & & & & 1 & & & & & & & & & & & & & & & & 5 & 3 & & 9 \\
\hline Ph.sp ** & & & & & & & & & & 20 & & & & & 1 & & & & & & & & & 21 \\
\hline Wy. borrouli & & & & & & & & & & & & & & & & & & & & & 1 & & & 1 \\
\hline$W y \cdot s p$ * & & & & & & 1 & & & & & & & & & & & & & & & & & & 1 \\
\hline Total & 39 & 102 & 99 & 4 & 46 & 115 & 74 & 62 & 65 & 84 & 34 & 78 & 22 & 66 & 102 & 181 & 37 & 75 & 55 & 86 & 129 & 94 & 60 & 1709 \\
\hline
\end{tabular}

* larvas em estágios iniciais, não identificáveis, "espécimes danificados 
Tabela 14: Larvas de Culicidae coletadas em bromélias a [2, 3/m do solo na mata. Ilha Comprida, SP, 04/09/2001 a 17/09/2002.

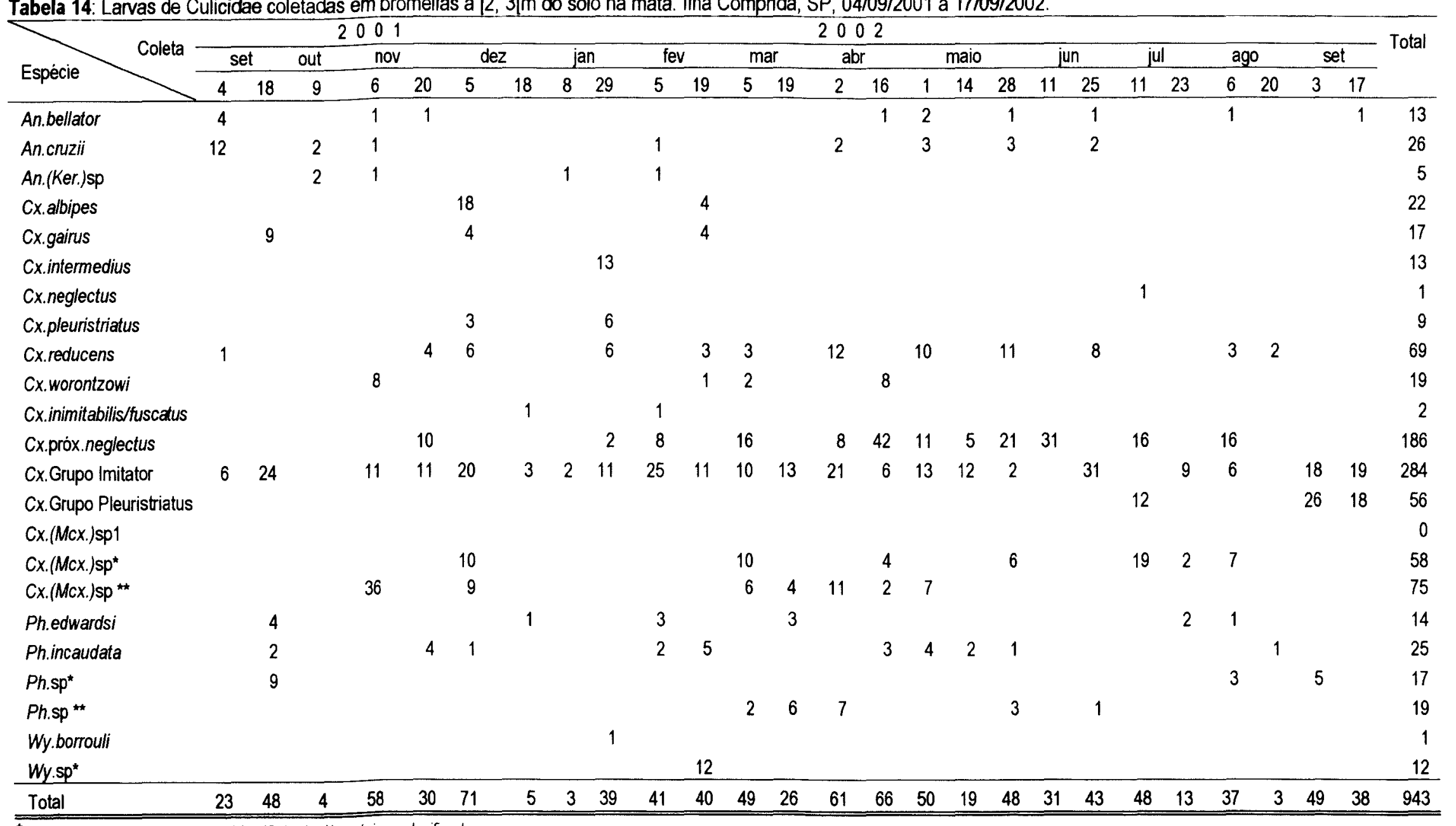

* larvas em estágios iniciais, não identificáveis; "espécimes danificados 
Tabela 15: Larvas de Culicidae coletadas em bromélias a [3, 4[m do solo na mata. Itha Comprida, SP, 04/09/2001 a 17/09/2002

\begin{tabular}{|c|c|c|c|c|c|c|c|c|c|c|c|c|c|c|c|c|c|c|c|c|c|c|c|c|c|c|}
\hline & \multicolumn{6}{|c|}{2001} & \multicolumn{19}{|c|}{2002} & \multirow{3}{*}{ Total } \\
\hline & \multicolumn{2}{|c|}{ set } & \multirow{2}{*}{$\frac{\text { out }}{9}$} & \multirow{2}{*}{$\frac{\text { nov }}{20}$} & \multicolumn{2}{|c|}{ dez } & \multicolumn{2}{|c|}{ jan } & \multicolumn{2}{|c|}{ fev } & \multicolumn{2}{|c|}{ mar } & \multicolumn{2}{|c|}{$a b r$} & \multicolumn{3}{|c|}{ maio } & \multicolumn{2}{|c|}{ jun } & \multicolumn{2}{|c|}{ jul } & \multicolumn{2}{|c|}{ ago } & \multicolumn{2}{|c|}{ set } & \\
\hline & \multirow{2}{*}{$\frac{4}{13}$} & \multirow[t]{2}{*}{18} & & & 5 & 18 & 8 & 29 & 5 & 19 & 5 & 19 & 2 & 16 & 1 & 14 & 28 & 11 & 25 & 11 & 23 & 6 & 20 & 3 & 17 & \\
\hline Espécie Coleta & & & 3 & & 2 & & 6 & & 5 & & 5 & & 3 & & 2 & & & & & & & & 1 & & & 40 \\
\hline An.cnuzii & 8 & 1 & & & 4 & & 4 & & 4 & & 3 & & 2 & & 5 & & 5 & & 5 & & 12 & & 3 & & 4 & 60 \\
\hline An.(Ker.)sp & & & & & 4 & & & & 2 & & 5 & & 2 & & 4 & & & & & & 1 & & & & & 18 \\
\hline Cx.albipes & & & & 2 & & 19 & & & & & & & & & & & & & & & & & & & & 21 \\
\hline Cx.gairus & & 6 & & 1 & 1 & 6 & & & 1 & & 24 & & & 6 & & & & & & & & & & & & 45 \\
\hline Cx.neglectus & & & & & & & & & & & & & & & & & 1 & & & & & & & & & 1 \\
\hline Cx.pleuristriatus & & & & 2 & 5 & & & & & & & & & 4 & & & & & & & & & & & & 11 \\
\hline Cx.reducens & 8 & & & & & & 15 & 8 & 14 & & 68 & & 26 & 30 & 48 & & 2 & 1 & & 22 & 12 & & 13 & & & 267 \\
\hline Cx.worontzowi & 7 & & & & 5 & & & & & & & & & & & & & & & & & & & & & 12 \\
\hline Cx.próx.neglectus & & & & 16 & 16 & 9 & & & & & & & 18 & & & 7 & 24 & & & & 22 & & 15 & & & 127 \\
\hline Cx.Grupo Imitator & 49 & 14 & & 52 & 13 & 12 & 12 & 10 & 53 & 28 & 35 & 7 & 36 & 11 & 21 & 1 & & 10 & & 1 & & 14 & & & 15 & 394 \\
\hline Cx.Grupo Pleuristriatus & & & & & & & & & & & & & & & & & & & & & & 4 & & & & 4 \\
\hline$C x .(M c x) s p 1$. & & & & & & & & & & & & & & & & & & & & & 1 & & & & & 1 \\
\hline$C x .(M c x). s p^{*}$ & & & & & & & 32 & & & & 28 & & & 10 & 13 & & 3 & 16 & & 28 & 3 & 2 & 9 & 10 & 48 & 202 \\
\hline$C x .(M c x) s$,$p **$ & & & & & & & & & & 9 & & 11 & & 5 & 9 & & & & & & & & & & & 34 \\
\hline Ph.edwardsi & & 3 & & & & & 5 & & 2 & & & & & 2 & & & 15 & & & & & & & & & 27 \\
\hline Ph.galvoi & & & & 1 & & & & & & & & & & & & & & & & & & & & & & 1 \\
\hline Phincaudata & & 11 & & 13 & 2 & 3 & 4 & 4 & & 21 & 6 & & & 3 & & & & & & & & & & & & 67 \\
\hline Ph.palmata & & 2 & & & & & 1 & 1 & & & & & & & & & & & & & & & & & & 4 \\
\hline$P h . \mathrm{sp}^{*}$ & 1 & 7 & & 6 & & 3 & 6 & 1 & & & & & & & & 1 & & 3 & & & & & & 3 & 3 & 34 \\
\hline$P h . s p$ * & & & & & & & & & & 11 & & 9 & & 2 & & 1 & 1 & & & & & & & & & 24 \\
\hline Ru.reversa & & & & & & 5 & & & & & & & & & & & & & & & & & & & & 5 \\
\hline Total & 86 & 44 & 3 & 93 & 52 & 57 & 85 & 24 & 81 & 69 & 174 & 27 & 87 & 73 & 102 & 10 & 51 & 30 & 5 & 51 & 51 & 20 & 41 & 13 & 70 & 1399 \\
\hline
\end{tabular}

* larvas em estágios iniciais, não identificáveis, "espécimes danificados 
Tabela 16: Lanas de Culicidae coletadas em bromélias a 14,5/m do solo na mata. Itha Comprida, SP, 04/09/2001 a 17/09/2002

\begin{tabular}{|c|c|c|c|c|c|c|c|c|c|c|c|c|c|c|c|c|c|c|c|c|c|c|c|c|c|c|c|c|}
\hline \multirow{2}{*}{ Espécie Coleta } & \multicolumn{8}{|c|}{2001} & \multicolumn{20}{|c|}{2002} \\
\hline & \multicolumn{2}{|c|}{ set } & \multicolumn{2}{|c|}{ out } & \multicolumn{2}{|c|}{ nov } & \multicolumn{2}{|c|}{$\operatorname{dez}$} & \multicolumn{2}{|c|}{ jan } & \multicolumn{2}{|c|}{ fev } & \multicolumn{2}{|c|}{ mar } & \multicolumn{2}{|c|}{$\mathrm{abr}$} & \multicolumn{3}{|c|}{ maio } & \multicolumn{2}{|c|}{ jun } & \multicolumn{2}{|l|}{ jul } & \multicolumn{2}{|c|}{ ago } & \multicolumn{2}{|c|}{ set } & Total \\
\hline An bellator & 45 & 6 & 26 & & 5 & & 13 & & 5 & & 10 & 3 & 2 & & 6 & 2 & 15 & 4 & 1 & & 8 & 2 & 4 & 2 & 20 & 1 & 13 & 193 \\
\hline An cruzii & 2 & & 3 & & 1 & & 1 & & & & & & 1 & & & & 2 & & 2 & & 1 & & 1 & 2 & 1 & & 2 & 19 \\
\hline An (Ker)sp & 1 & 3 & 13 & & & & 4 & & 2 & & 2 & & 1 & & 2 & & & & & & & 1 & 1 & & & & & 30 \\
\hline Cx albipes & 32 & 7 & & 64 & & & & 8 & & & & & 18 & & & & & & & & & & & & & & & 129 \\
\hline Cx gairus & 16 & 13 & & 36 & & & 20 & & 16 & 8 & 18 & & 61 & & & 51 & & & & 9 & & & & & & & & 248 \\
\hline Cx neglectus & & & & & & & & & & & & & & & & & & & & & 1 & 1 & & & & & & 2 \\
\hline Cxpleuristriatus & & & & 31 & & & 19 & 3 & 15 & & 8 & & 26 & & 4 & 41 & & & & 19 & & & & & & & & 166 \\
\hline Cx reducens & 31 & 3 & & 10 & & & 18 & & 8 & 11 & 11 & & 44 & & 56 & & 49 & 41 & 18 & & 6 & 16 & 11 & & 7 & & 9 & 349 \\
\hline Cxworontzowi & 34 & 1 & & 23 & & & & & 7 & & & 10 & & & & & & & & & & & 2 & & & & & 77 \\
\hline Cx próx neglectus & 136 & 2 & & 92 & & & & 11 & & 29 & 27 & 27 & 33 & 12 & 16 & 19 & 39 & 114 & 75 & 28 & 16 & 26 & 22 & 81 & 39 & 101 & 51 & 996 \\
\hline Cxgr Imitator & 109 & 180 & 3 & 75 & 1 & 9 & 42 & 6 & 65 & 19 & 65 & 65 & 107 & 71 & 103 & 68 & 28 & 11 & & 21 & 15 & 11 & 12 & 46 & 16 & 21 & 19 & 1186 \\
\hline Cx gr Pleuristralus & & & & & & & & & & & & & & & & & & 18 & & & & 6 & & 4 & & 12 & & 40 \\
\hline Cx (Mcx) sp1 1 & & 1 & & & & & & 2 & & & & & & 8 & & & & & 11 & & & 9 & & 11 & & & 21 & 63 \\
\hline$C \times(M c x) s p^{*}$ & & 35 & & & & & & & 30 & 3 & & & & & 26 & 21 & & 39 & 21 & & 20 & 24 & 59 & & 11 & 26 & 28 & 343 \\
\hline$C \times(M c x) s p=$ & & & & & & & 9 & & & & & & 13 & 6 & 14 & 13 & 6 & 16 & 6 & & & & & & & & & 83 \\
\hline Phedwardsi & & & & 8 & & & & & 3 & 2 & & 10 & & 2 & & & & 6 & 2 & 1 & & & 4 & 2 & & 8 & 8 & 56 \\
\hline Ph gatvoi & & 1 & & & & & & & & & & & & & & & & & & & & & & & & & & 1 \\
\hline Phincaudata & & 18 & & 17 & & 26 & 15 & & 12 & 18 & 3 & 10 & & & & & 8 & 1 & 7 & 3 & & & & 1 & & 4 & 10 & 153 \\
\hline Ph palmata & & & & 1 & & & 3 & & & & & & & & & & & & & & & & & & & & & 4 \\
\hline$P h \mathrm{sp}^{*}$ & & 1 & & 12 & & & 6 & & 6 & & & & & & & & & 3 & 3 & & & & & 1 & & 16 & 12 & 60 \\
\hline$P h s p * *$ & & 2 & & & & & 1 & & & & 1 & 6 & 3 & 2 & 8 & 8 & 3 & 1 & 4 & & & & & & & & & 39 \\
\hline Ph theobaldi & & & & & & & & & & & & & & & & & 1 & & & & & & & & & & & 1 \\
\hline Ru cerqueirai & & 1 & & & & & & & & & & & & & & & & & & & & & & & & & & 1 \\
\hline Ru reversa & 1 & & & 1 & & & & & & & & & & 1 & & & & & & & 2 & & & & & & & 5 \\
\hline Wy borrouli & & & & & & & & & & & & & & 1 & & & & & & & & & 1 & & & & & 2 \\
\hline Wysp & & & & & & & & & & 5 & & 5 & & & & & & & & & & & & & & & & 10 \\
\hline Total & 407 & 274 & 45 & 370 & 7 & 35 & 151 & 30 & 169 & 95 & 145 & 136 & 309 & 103 & 235 & 223 & 149 & 254 & 150 & 81 & 69 & 96 & 117 & 150 & 94 & 189 & 173 & 4256 \\
\hline
\end{tabular}

* larvas em estágios iniciais, não identificáveis, "especimes danificados 
Tabela 17: Larvas de Culicidae coletadas em bromelias a $[5,6[\mathrm{~m}$ do solo na mata. Itha Comprida, SP, 18/09/2001 a 17/09/2002.

\begin{tabular}{|c|c|c|c|c|c|c|c|c|c|c|c|c|c|c|}
\hline \multirow[b]{2}{*}{ Espécie } & \multirow[t]{2}{*}{ Coleta } & \multicolumn{3}{|c|}{2001} & \multicolumn{10}{|c|}{2002} \\
\hline & & $18 / 9$ & $20 / 11$ & $18 / 12$ & $29 / 1$ & $19 / 2$ & $19 / 3$ & $16 / 4$ & $14 / 5$ & $11 / 6$ & $11 / 7$ & $6 / 8$ & $3 / 9$ & Total \\
\hline An bellator & & & & & & & & & 1 & 1 & 1 & 4 & & 7 \\
\hline An.cruzii & & & & & & & & & & 1 & & & & 1 \\
\hline Cx.davisi & & & & 4 & & & & & & & & & & 4 \\
\hline Cxintermedius & & & 2 & 3 & & & & & & & & & & 5 \\
\hline Cx.lanei & & & 5 & & & & & & & & & & & 5 \\
\hline Cx.pleuristriatus & & & 15 & 1 & & & & & & & & & & 16 \\
\hline Cx.reducens & & 3 & 3 & 4 & 3 & & & 2 & & & & 27 & & 42 \\
\hline Cx.próx.neglectus & & & & & & & & 18 & 6 & 16 & 12 & & & 52 \\
\hline Cx.Grupo Imitator & & 24 & & 32 & 3 & 3 & 18 & & & & & & 11 & 91 \\
\hline CX. (McX.)sp* & & & & & & & 5 & & & 14 & 5 & 9 & 25 & 58 \\
\hline$C x .(M c x$.$) sp **$ & & & & & & & & 4 & & & & & & 4 \\
\hline Ph.edwardsi & & & & & & & & & & & 2 & & & 2 \\
\hline Ph.palmata & & 1 & & & & & & & & & & & & 1 \\
\hline Ph.sp * & & & & & & & & & & & & 2 & & 2 \\
\hline Ph.sp.** & & 1 & & & & & & & & & & & & 1 \\
\hline Ru.reversa & & & & & & & & & & & & & 1 & 1 \\
\hline Total & & 29 & 25 & 44 & 6 & 3 & 23 & 24 & 7 & 32 & 20 & 42 & 37 & 292 \\
\hline
\end{tabular}

* larvas em estágios inclais, não identficicaveis, "espécimes dan nificados 
Tabela 18: Larvas de Culicidae coletadas em bromélias a [6, 7[m do solo na mata. llha Comprida, SP, 18/09/2001 a 17/09/2002.

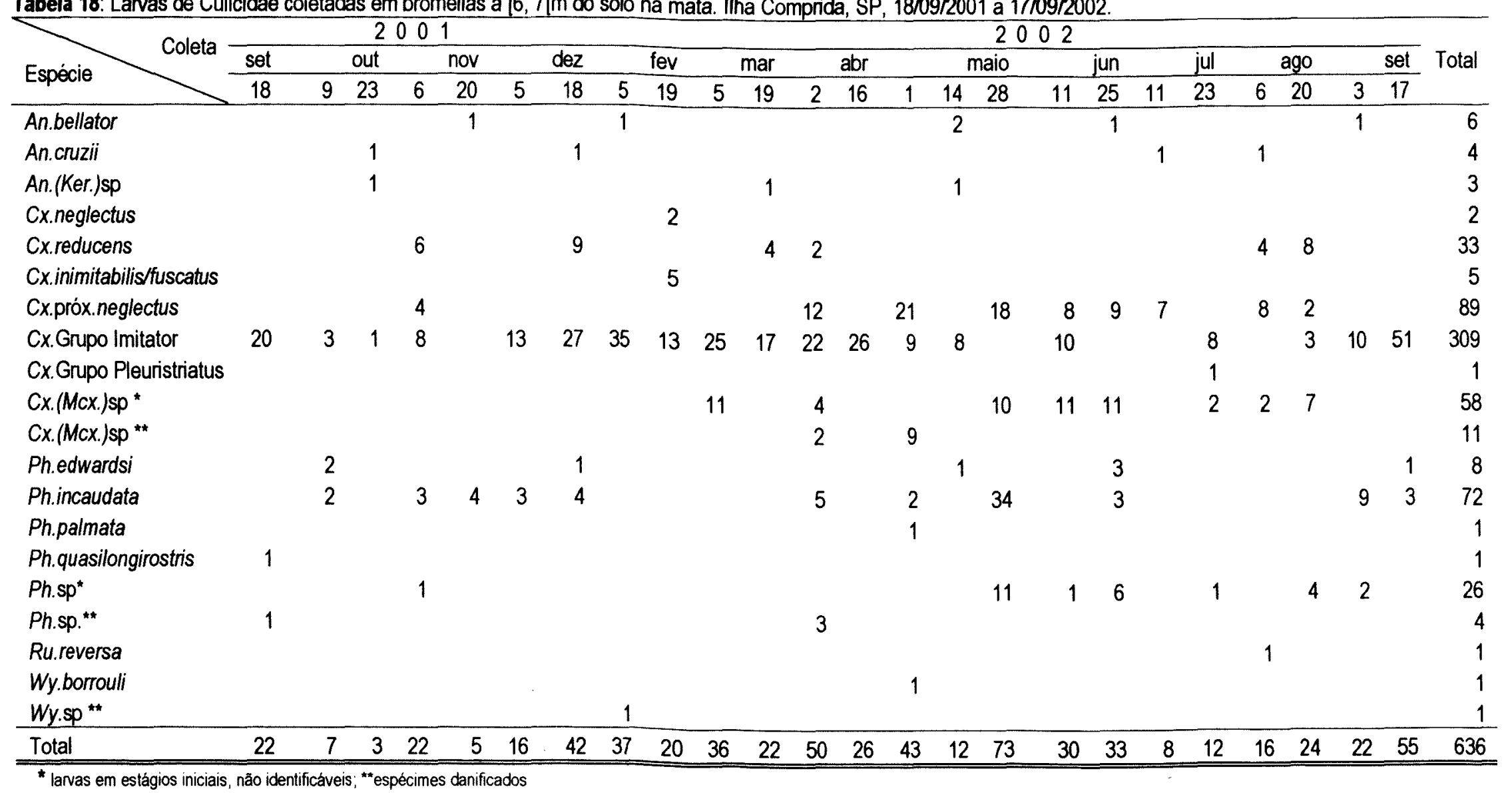


Tabela 19: Larvas de Culicidae coletadas em bromélias a $\rceil, 8[m$ do solo na mata. Itha Comprida, SP, 18/09/2001 a 18/09/2002.

\begin{tabular}{|c|c|c|c|c|c|c|c|c|c|c|c|c|c|c|c|c|c|}
\hline \multirow{2}{*}{ Espécie Coleta } & \multicolumn{3}{|c|}{2001} & \multicolumn{13}{|c|}{2002} & \multirow{2}{*}{ Total } \\
\hline & $18 / 9$ & $20 / 11$ & $18 / 12$ & $29 / 1$ & $19 / 2$ & $19 / 3$ & $2 / 4$ & $16 / 4$ & $14 / 5$ & $28 / 5$ & $11 / 6$ & $25 / 6$ & $11 / 7$ & $6 / 8$ & $20 / 8$ & $3 / 9$ & \\
\hline An.bellator & & & & 2 & 1 & 1 & & 4 & 10 & & & & 4 & 1 & & 6 & 29 \\
\hline An.cruzii & 2 & & & & & & 1 & & 1 & & & & & & & 1 & 5 \\
\hline An.(Ker.)sp & & & & 1 & & & & 1 & 1 & & & & & & & & 3 \\
\hline Cx.albipes & 20 & 1 & 6 & & & & & & & & & & & & & & 27 \\
\hline Cx.gairus & & & & & 10 & 4 & & 12 & & & & & & & & & 26 \\
\hline Cx.pleuristriatus & 2 & & 3 & & 1 & & & & & & & & & & & & 6 \\
\hline Cx.reducens & 3 & & 4 & 18 & 31 & 16 & & 11 & 3 & & & & & & & 9 & 95 \\
\hline Cx.worontzowi & 19 & & & & & & & & & & & & & & & & 19 \\
\hline Cx.próx.neglectus & 3 & & & & & 44 & & 5 & 43 & 1 & 34 & & 13 & 69 & & 31 & 243 \\
\hline Cx.Grupo Imitator & 101 & 10 & 66 & 62 & 27 & 35 & 2 & 6 & 1 & & 17 & & 8 & 16 & & 7 & 358 \\
\hline Cx.Grupo Pleuristriatus & & & & & & & & & & & & & & 6 & & & 6 \\
\hline Cx. (Mcx.)sp1 & & 7 & & & & & & & & & & & 28 & & & & 35 \\
\hline$C x .(M c x.) s^{*}$ & & & & 3 & 3 & & & & & & 12 & 18 & & 21 & & & 57 \\
\hline$C_{x}(M C X) s$.$p **$ & & & & 2 & & 11 & & & & & & & & & & & 13 \\
\hline Ph.edwardsi & 1 & 1 & & & 2 & 8 & & & & & & & 1 & & & & 13 \\
\hline Ph.galvoi & & & & & & & & & & 2 & & & & & & & 2 \\
\hline Phincaudata & 2 & & & & 4 & & 2 & & & & 2 & & 1 & 1 & 1 & 4 & 17 \\
\hline Ph.palmata & 2 & & & & & & & & & & & & & & & & 2 \\
\hline Ph.sp* & 1 & & & & & & & & & & 6 & & 2 & 4 & 1 & 5 & 19 \\
\hline Ph.sp."** & 3 & & & & & 8 & 3 & & & 1 & & & & & & & 15 \\
\hline Ru.reversa & & & & & & & & & & & & & & & 1 & & 1 \\
\hline Wy.borrouli & & & & & & & & & & & & & & & & 1 & 1 \\
\hline Total & 159 & 19 & 79 & 88 & 79 & 127 & 8 & 39 & 59 & 4 & 71 & 18 & 57 & 118 & 3 & 64 & 992 \\
\hline
\end{tabular}

* larvas em estágios iniciais, não identifićáveis; " "espécimes danificados 
Tabela 20: Larvas de Culicidae coletadas em bromélias a 18, 9[m do solb na mata. Itha Comprida, SP, 04/09/2001 a 17/09/2002

\begin{tabular}{|c|c|c|c|c|c|c|c|c|c|c|c|c|c|c|c|c|c|c|c|c|c|c|c|c|c|c|}
\hline \multirow{3}{*}{ Espécie Coleta } & \multicolumn{6}{|c|}{2001} & \multirow{2}{*}{\multicolumn{2}{|c|}{ jan }} & \multicolumn{17}{|c|}{2002} & \multirow{3}{*}{ Total } \\
\hline & \multirow{2}{*}{$\begin{array}{r}\text { set } \\
4 \\
\end{array}$} & \multicolumn{2}{|c|}{ out } & \multirow{2}{*}{$\begin{array}{r}\text { nov } \\
20\end{array}$} & \multicolumn{2}{|c|}{ dez } & & & \multicolumn{2}{|c|}{ fev } & \multicolumn{2}{|c|}{ mar } & \multicolumn{2}{|c|}{$a b r$} & \multicolumn{3}{|c|}{ maio } & \multicolumn{2}{|c|}{ jun } & \multicolumn{2}{|c|}{ jul } & \multicolumn{2}{|c|}{ ago } & \multicolumn{2}{|c|}{ set } & \\
\hline & & 9 & 23 & & 5 & 18 & 8 & 29 & 5 & 19 & 5 & 19 & 2 & 16 & 1 & 14 & 28 & 11 & 25 & 11 & 23 & 6 & 20 & 3 & 17 & \\
\hline An.bellator & 18 & 10 & 11 & 1 & 1 & 3 & 5 & 7 & & 7 & 10 & 5 & 16 & 13 & 23 & 15 & 14 & 7 & 26 & 7 & 25 & 14 & 7 & 17 & 22 & 284 \\
\hline An.cruzii & 1 & 2 & 2 & & 2 & & & & & & & & & & 1 & & 2 & & 1 & & & 1 & & & & 12 \\
\hline An. (Ker.)sp & 2 & 2 & & & 1 & 1 & 1 & 1 & & 2 & 3 & 1 & 8 & 2 & 1 & 1 & 1 & 1 & 3 & 1 & 1 & 1 & & & 2 & 36 \\
\hline Cx.albipes & & & 51 & & & & & & & & & & & & & & & & & & & & & & & 51 \\
\hline Cx.gainus & & & 32 & & 11 & & & & & & & & & & & 14 & & & 10 & & & & & & & 67 \\
\hline Cx.neglectus & & & & & & & & & & & & & & & & & 3 & & & & & 1 & & & & 4 \\
\hline Cx.pleuristriatus & & & 45 & 1 & & & & & 2 & & & & & & & & & & & & & & & & & 48 \\
\hline Cx.reducens & & & & 6 & 9 & 3 & & 13 & 42 & 5 & 8 & & 91 & 140 & 68 & 8 & 28 & 11 & & 11 & 6 & 38 & 9 & 10 & & 506 \\
\hline Cx.worontzowi & 6 & & 11 & & & & & & 4 & & & & 9 & 8 & & & & & & & & & & & & 38 \\
\hline Cx.próx.neglectus & 32 & & 41 & & & & & 3 & 9 & & 16 & & 61 & & & 12 & 18 & 26 & 86 & 41 & & 43 & & 60 & 85 & 533 \\
\hline Cx.Grupo Imitator & 10 & 2 & 63 & 8 & 16 & 16 & & 23 & 33 & 30 & 11 & 55 & 32 & & 2 & 26 & 36 & 31 & 98 & 18 & 30 & 44 & 8 & 21 & 23 & 636 \\
\hline Cx.Grupo Pleuristriatus & & & & & & & & & & & & & & & & & & & & & & & 18 & & & 18 \\
\hline$C \times .(M c x) s p 1$. & & & 10 & & & & & & & & & & & & & & 13 & & & & & & & & & 23 \\
\hline$C \times .(M c x.) s^{*}$ & & & & & & & & 11 & & & 16 & 8 & & 4 & 9 & 31 & 31 & & 31 & 21 & & 39 & 34 & 16 & 47 & 298 \\
\hline$C x .(M c x$,$) sp *$ & & & & & & & & 5 & & & 9 & 4 & 18 & 11 & & & 10 & & & & & & & & & 57 \\
\hline Ph.edwardsi & & & & & 4 & & & & 2 & & & 3 & 1 & 3 & 1 & 4 & & & 1 & 1 & & 1 & & 1 & 5 & 27 \\
\hline Ph.galvoi & 1 & & & & & & & & & & & & & & & & & & & & & & & & & 1 \\
\hline Ph.incaudata & 1 & & & 15 & 2 & & & & 1 & 8 & 3 & & 9 & 3 & & & 7 & & 4 & 1 & & & 1 & & 3 & 58 \\
\hline Ph.sp* & 1 & & & 12 & 2 & & & 10 & & & & 11 & & & & & & & 2 & & & 6 & 3 & 3 & 4 & 54 \\
\hline Ph.sp & & & & & & & & & & & & & 6 & 3 & 1 & 2 & 2 & & & & & & & & & 14 \\
\hline Ru.reversa & & & & & & & & & 1 & & & & & & & & & & & & & & & & & 1 \\
\hline$W y \cdot s p$ & & & & & & & & & & & 3 & & & & & & & & & & & & & & & 3 \\
\hline Total & 72 & 16 & 266 & 43 & 48 & 23 & 6 & 73 & 94 & 52 & 79 & 87 & 251 & 187 & 106 & 113 & 165 & 76 & 262 & 101 & 62 & 188 & 80 & 128 & 191 & 2769 \\
\hline
\end{tabular}

" larvas em estágios iniciais, não identificáveis, "espécimes danificados 
Tabela 21: Lanvas de Culicidae coletadas em bromélias a $19,10[\mathrm{~m}$ do solo na mata. Ilha Comprida, SP, 04/09/2001 a 17/09/2002

\begin{tabular}{|c|c|c|c|c|c|c|c|c|c|c|c|c|c|c|c|c|c|c|c|c|}
\hline \multirow{2}{*}{ Espécie Coleta } & \multicolumn{6}{|c|}{20001} & \multicolumn{13}{|c|}{2002} & \multirow[b]{2}{*}{ Total } \\
\hline & $4 / 9$ & $18 / 9$ & $9 / 10$ & $6 / 11$ & $20 / 11$ & $5 / 12$ & $18 / 12$ & $8 / 1$ & $29 / 1$ & $5 / 2$ & $5 / 3$ & $2 / 4$ & $16 / 4$ & $1 / 5$ & $28 / 5$ & $25 / 6$ & $23 \pi$ & $20 / 8$ & $17 / 9$ & \\
\hline An.bellator & & 2 & & & & & 2 & & 4 & 1 & & & & 1 & & & & & 1 & 11 \\
\hline An.cruzii & & 3 & & & & & & & & & & & & & & & & & & 3 \\
\hline An. (Ker.)sp & & & & & & & & 1 & & & & & & 1 & & 1 & & & & 3 \\
\hline Cx.albipes & & & & & 1 & & & & & & & & & & & & & & & 1 \\
\hline Cx.gairus & & & & & & & & 7 & & & & & & & & & & & & 7 \\
\hline Cx.neglectus & & & & & & & & & & & & & & 12 & 1 & & & & & 13 \\
\hline Cx.pleuristriatus & & & & & & & & 2 & & & & & & & & & & & & 2 \\
\hline Cx,reducens & & 1 & 2 & & 4 & & 9 & 7 & 8 & & & & & 10 & & 6 & 6 & & & 53 \\
\hline Cx.worontzowi & & & & & & & & & 9 & & & & & 8 & & & & & & 17 \\
\hline Cx.próx.neglectus & & & & & 7 & 4 & 4 & & 14 & & 11 & & & & 19 & & 2 & 6 & & 67 \\
\hline Cx.Grupo Imitator & 38 & 11 & 22 & 14 & 10 & 8 & 7 & 13 & 18 & 18 & 20 & 20 & & 28 & & 16 & 6 & 12 & 31 & 292 \\
\hline$C x .(M c x) s p 1$. & & & & & 2 & & & & & & & & & & & & & & & 2 \\
\hline$C_{X} .(M c X) s p *$. & & & & & & & & 7 & & & & & & & & 3 & & 14 & 20 & 44 \\
\hline$C_{X}(M C X)$ sp "* & & & & & & & & & & & & 2 & & & & & & & & 2 \\
\hline Ph.edwardsi & 2 & 2 & & & & & & 1 & & 8 & & 1 & & & & & & 2 & 3 & 19 \\
\hline Ph.galvoi & 1 & & 1 & & & & 2 & 1 & & & 1 & & & & & & & & & 6 \\
\hline Ph.incaudata & & 1 & 5 & & 4 & 1 & 9 & 6 & 10 & 2 & & 2 & & & & 1 & 1 & & 1 & 43 \\
\hline Ph.palmata & & & & & & & & 2 & & & & & & & & & & & & 2 \\
\hline Ph.sp* & 2 & 2 & & & & & & & & & & 3 & & & & & 1 & & 2 & 10 \\
\hline Ph.sp ** & & & & & & & & & & & 4 & 1 & & 4 & & & & & & 9 \\
\hline Ru.reversa & & & & & & & & & & & & & & & & 2 & & 1 & & 3 \\
\hline Wy.borrouli & & & & & & & & & & & & & & & & 1 & & & & 1 \\
\hline Total & 43 & 22 & 30 & 14 & 28 & 13 & 33 & 47 & 63 & 29 & 36 & 29 & 0 & 64 & 20 & 30 & 16 & 35 & 58 & 610 \\
\hline
\end{tabular}

* larvas em estágios iniciais, não identificáveis; "*espécimes danificados 
Tabela 22: Larvas de Culicidae coletadas em bromélias a [10, 11[m do solo na mata. Ilha Comprida, SP, 04/09/2001 a 17/09/2002.

\begin{tabular}{|c|c|c|c|c|c|c|c|c|c|c|c|c|c|c|c|c|c|c|c|c|c|c|c|c|c|c|}
\hline \multirow{3}{*}{ Espécie } & \multicolumn{6}{|c|}{2001} & \multicolumn{19}{|c|}{2002} & \multirow{3}{*}{ Total } \\
\hline & \multirow{2}{*}{$\begin{array}{r}\text { set } \\
\end{array}$} & \multirow{2}{*}{\multicolumn{2}{|c|}{$\begin{array}{l}\text { out } \\
9 \quad 23\end{array}$}} & \multirow{2}{*}{$\begin{array}{r}\text { nov } \\
20\end{array}$} & \multicolumn{2}{|c|}{ dez } & \multicolumn{2}{|c|}{ jan } & \multicolumn{2}{|c|}{ fev } & \multicolumn{2}{|c|}{ mar } & \multicolumn{2}{|c|}{$a b r$} & \multicolumn{3}{|c|}{ maio } & \multicolumn{2}{|c|}{ jun } & \multicolumn{2}{|c|}{$\mathrm{jul}$} & \multicolumn{2}{|c|}{ ago } & \multicolumn{2}{|c|}{ set } & \\
\hline & & & 23 & & 5 & 18 & 8 & 29 & 5 & 19 & 5 & 19 & 2 & 16 & 1 & 14 & 28 & 11 & 25 & 11 & 23 & 6 & 20 & 3 & 17 & \\
\hline An.bellator & 4 & 16 & & 5 & 10 & 1 & 10 & 1 & & 4 & 1 & 11 & 8 & 5 & 26 & 5 & 18 & 8 & 24 & 14 & 1 & 24 & 9 & 12 & 14 & 231 \\
\hline An.cruzii & & & & 1 & & & 1 & & & & & & & & & & & & & & & & & & & 2 \\
\hline An. (Ker.)sp & 1 & 2 & 1 & 1 & & & 4 & & & 3 & 2 & 2 & 7 & 1 & 5 & & 8 & & 4 & 5 & & 1 & & 1 & & 48 \\
\hline Cx.albipes & & & 4 & & & & & & & & & & & & & & & & & & & & & & & 4 \\
\hline Cx.davisi & & & & & & 10 & & & & & & & & & & & & & & & & & & & & 10 \\
\hline Cx.gainus & & & & & & & & & 6 & & & & & & & & & & & & & & & & & 6 \\
\hline Cx.intermedius & & & & 4 & & & & & & & & & & & & & & & & & & & & & & 4 \\
\hline Cx.lanei & & & & & & 8 & & & & & & & & & & & & & & & & & & & & 8 \\
\hline Cx.pleuristriatus & & 2 & 2 & & & 17 & & & 21 & & 13 & & & & & & & & & & & & & & & 55 \\
\hline Cx.neglectus & & & & & & & & & & & & & & & & 3 & & & & 1 & & 1 & 1 & & 2 & 8 \\
\hline Cx.reducens & & & 4 & 41 & 8 & 19 & & 4 & 11 & & 24 & 63 & & & 25 & 6 & 21 & 21 & 8 & 16 & 6 & 31 & 13 & 94 & 33 & 448 \\
\hline Cx.worontzowi & & & 2 & 21 & & 4 & & & 4 & & & & & 9 & & & & & & 2 & & & 4 & & & 46 \\
\hline Cx.próx.neglectus & & & 5 & & 30 & 11 & & 17 & 32 & & 18 & 17 & 41 & 39 & 28 & 81 & 19 & 10 & 22 & 29 & 31 & 27 & 30 & 96 & 36 & 619 \\
\hline Cx.Grupo Imitator & & & & 43 & 14 & 21 & & 29 & 22 & 7 & 39 & 11 & 36 & & 19 & 12 & 18 & 12 & 18 & 10 & 1 & 24 & 20 & 28 & 2 & 386 \\
\hline Cx.Grupo Pleuristriatus & & & & & & & & & & & & & & & & & & 11 & & & & & & & & 11 \\
\hline$C x .(M c x) s p 1$. & & & & & & & & & & & & 4 & & & & & & & & & & & & & & 4 \\
\hline$C_{x}($ Mcx.)sp* & & & & & & & & & 16 & & & & 12 & & 31 & & & 16 & 31 & 31 & 3 & 63 & 49 & 61 & 28 & 341 \\
\hline$C_{x}(M c x$.$) sp **$ & & & & & & & & & 3 & & 8 & & 9 & & 8 & 26 & 9 & & & & & & & & & 63 \\
\hline Ph.edwardsi & & & 2 & 6 & & 4 & & 10 & 4 & 8 & 6 & 1 & 4 & & & & & & & 1 & & & 2 & 3 & 2 & 53 \\
\hline Ph.galvoi & & & & & & 1 & & & & & & 2 & & & & & & & & & & & & & & 3 \\
\hline Phincaudata & & & 3 & 7 & 5 & 6 & & & 8 & 5 & & 2 & & & & & & & 3 & & 1 & 2 & 1 & & 13 & 56 \\
\hline Ph.palmata & & & & & & & & & & & 1 & & & & & & & & & & & & & & & 1 \\
\hline Ph.sp* & & & & & & & & & & 7 & & & & & & & 3 & & 1 & 1 & 1 & 3 & 2 & 9 & 11 & 38 \\
\hline$P h . s p$ ** & 3 & & & & & & & & & & & 2 & & & 3 & 1 & & 1 & & & & & & & & 10 \\
\hline Ru.reversa & & & & & & & & & & & & & 2 & & & & & & & & & & & & & 2 \\
\hline Wy.sp * & & & & & & & & & 2 & & & & & & & & & & & & & & & & & 2 \\
\hline Total & 8 & 20 & 23 & 129 & 67 & 102 & 15 & 61 & 129 & 34 & 112 & 115 & 119 & 54 & 145 & 134 & 96 & 79 & 111 & 110 & 44 & 176 & 131 & 304 & 141 & 2459 \\
\hline
\end{tabular}


Tabela 23: Larvas de Culicidae coletadas em bromélias a [11, 12[m do solo na mata. Iha Comprida, SP, 05/12/2001 a 17/09/2002.

\begin{tabular}{|c|c|c|c|c|c|c|c|c|c|c|c|}
\hline Espécie Coleta & $5 / 12$ & $5 / 2$ & $5 / 3$ & $2 / 4$ & $1 / 5$ & $28 / 5$ & $25 / 6$ & $23 / 7$ & $20 / 8$ & $17 / 9$ & Total \\
\hline An.bellator & 7 & 2 & 4 & 2 & 17 & & & 1 & 6 & 6 & 45 \\
\hline Cx.albipes & & & & & 1 & & 19 & & & & 20 \\
\hline Cx.gainus & & & & & 9 & & & & & & 9 \\
\hline Cx.neglectus & & & & & & 1 & & & & & 1 \\
\hline Cx.pleuristriatus & & & & & 11 & & 1 & & & & 12 \\
\hline Cx.reducens & 4 & & & & 11 & 8 & & 26 & 8 & & 57 \\
\hline Cx.próx.neglectus & 18 & 8 & 24 & 37 & 64 & 16 & & & & & 167 \\
\hline Cx.Grupo Imitator & 15 & 13 & 31 & 15 & 48 & & 77 & 19 & 38 & 30 & 286 \\
\hline$C \times .(M c x) s p 1$. & & & & & & 11 & & & & & 11 \\
\hline$C X .(M c x.) \mathrm{sp}^{*}$ & & & & & 18 & 13 & 61 & 8 & 23 & 40 & 163 \\
\hline$C x .(M c x) s p *$. & & & & & 8 & 9 & & & & & 17 \\
\hline Ph.edwardsi & 4 & & & & & & 1 & & & 3 & 8 \\
\hline Phincaudata & & 2 & 3 & 2 & & & & & & 2 & 9 \\
\hline Ph.sp* & & & & & & & & & & 1 & 1 \\
\hline Ru.reversa & & & & & & & & & 1 & & 1 \\
\hline Wy.borrouli & & & & & & & & & 4 & & 4 \\
\hline Total & 48 & 25 & 62 & 56 & 187 & 58 & 159 & 54 & 80 & 82 & 811 \\
\hline
\end{tabular}

Como um dos objetivos era apresentar a composição específica de Culicidae por estrato, cabem aqui algumas considerações em relação à dificuldades de identificação. Além da coleta de larvas danificadas e larvas nos primeiros estágios de desenvolvimento, o que impossibilitou identificação específica, algumas situações repetitivas permitiram estabelecer alguns padrões.

"Cx. próximo a neglectus" pode se referir a $C x$. microphyllus/aphylactus ou $C x$. neglectus. As duas primeiras não são distinguiveis, pois ambas possuem a cerda $8 \mathrm{P}$ simples. Porém, em algumas larvas a $8 \mathrm{P}$ apresentouse simples de um lado, e sua correspondente, dupla, que é característica de $C x$. neglectus. Assim, quando nas tabelas, "Cx. próximo a neglectus" provavelmente é Cx. microphyllus/aphylactus, podendo incluir alguns individuos com características de $C x$. microphyllus/aphylactus e de Cx. neglectus. Situação semelhante foi verificada para o chamado grupo Pleuristriatus; e, algumas larvas, a cerda $4 \mathrm{C}$ era simples de um lado, e sua correspondente, dupla. Assim, quando se refere grupo Pleuristriatus, pode ser $C x$. pleuristriatus (4C simples) ou $C x$. albipes (4C dupla). 
Cx. grupo Imitator, em principio, estava sendo identificado como $C x$. imitator. Porém, a coleta de pupas, identificadas pelo adulto, revelou a presença de Cx. carioca. Como não é possivel distingui-las na fase larvária, considerou-se grupo Imitator, porém, com claro predominio de $C x$. imitator. Situação semelhante foi verificada para Ph. pilicauda/incaudata. Após a criação de várias larvas de Phoniomyia sp em laboratório, verificou-se por meio da identificação de machos, a presença exclusiva de $P h$. incaudata. Deste modo, embora se saiba que as larvas de $P h$. pilicauda e $P$ h. incaudata não são distinguiveis, a primeira espécie foi descartada com base em identificação de machos. Está sendo verificado se, entre os adultos coletados há machos deste gênero, para complementação desta informação. E quanto a $C x$. (Mcx.) spl, refere-se a um padrão morfológico repetitivo, cujos caracteres não se encaixam à descrição de nenhuma das espécies descritas até o momento.

Ainda sobre a fauna culicídea, o número de espécies variou pouco entre os estratos. A tabela a seguir mostra o compartilhamento e a constância das espécies de Culicidae nos diferentes estratos estudados (Tabela 24)

Como citado anteriormente, as espécies de Kerteszia estiveram presentes em todos os estratos, com exceção das bromélias da restinga da praia, onde não foi registrada a presença de $A \boldsymbol{n}$. cruzii. No mais, apenas espécies do subgênero Microculex apresentaram maior constância entre os estratos. Várias delas, acessórias ou mesmo acidentais, foram compartilhadas entre todos os estratos, além de Phoniomyia edwardsi, Cx. davisi, Cx. lanei, Ph. palmata, Ph. quasilongirostris, Ph. theobaldi e $R$ u. cerqueirai foram coletadas raramente, em densidades baixas e sempre em bromélias epifitas (a partir de $1 \mathrm{~m}$ ). Nenhuma espécie foi exclusiva da restinga. 
Tabela 24: Compartilhamento e constância de espécies de Culicidae coletadas em bromélias, segundo estratos. Ilha Comprida, 04/09/2001 a 17/09/2002.

\begin{tabular}{|c|c|c|c|c|c|c|c|c|c|c|c|c|c|}
\hline \multirow[b]{2}{*}{ Espécie } & \multicolumn{2}{|c|}{ solo } & \multicolumn{11}{|c|}{ Classe de Altura (metros) } \\
\hline & praia & mata & $1-2$ & $2-3$ & $3-4$ & $4-5$ & $5-6$ & 67 & $7-8$ & 8.9 & 910 & $10-11$ & $11-12$ \\
\hline An bellator & $z$ & $x$ & $x$ & $y$ & $y$ & $x$ & $y$ & $z$ & $x$ & $x$ & $y$ & $x$ & $x$ \\
\hline Ancruzii & & $x$ & $x$ & $y$ & $x$ & $y$ & $z$ & $\mathbf{z}$ & $y$ & $y$ & $z$ & $z$ & \\
\hline An (Ker) sp & $z$ & $x$ & $x$ & $z$ & $z$ & $y$ & & $z$ & $z$ & $x$ & $z$ & $x$ & \\
\hline Cx.albipes & $z$ & $z$ & $z$ & $z$ & $z$ & $z$ & & & $z$ & $z$ & $z$ & $z$ & $z$ \\
\hline Cx.davisi & & & $z$ & & & & $z$ & & & & & $z$ & \\
\hline Cx.gairus & $y$ & $z$ & $z$ & $z$ & $y$ & $y$ & & & $z$ & $z$ & $z$ & $z$ & $z$ \\
\hline Cx.intermedius & & $z$ & & $z$ & & & $z$ & & & & & $z$ & \\
\hline Cxlanei & & & $z$ & & & & $\mathbf{z}$ & & & & & $z$ & \\
\hline Cx.neglectus & $y$ & $y$ & $z$ & $z$ & $z$ & $z$ & & $z$ & & $z$ & $z$ & $z$ & $z$ \\
\hline Cx.pleuristriatus & $y$ & $z$ & $z$ & $z$ & $z$ & $y$ & $z$ & & $z$ & $z$ & $z$ & $z$ & $z$ \\
\hline Cx.reducens & $y$ & $x$ & $x$ & $y$ & $x$ & $x$ & $y$ & $y$ & $x$ & $x$ & $x$ & $x$ & $y$ \\
\hline Cx.worontzowi & $x$ & $x$ & $z$ & $z$ & $z$ & z & & & $z$ & $z$ & $z$ & $y$ & \\
\hline Cx. inimitabilis/fuscatus & & $z$ & & $z$ & & & & $z$ & & & & & \\
\hline Cx.próx. neglectus & $x$ & $x$ & $x$ & $y$ & $y$ & $\mathrm{x}$ & $y$ & $y$ & $x$ & $x$ & $y$ & $x$ & $x$ \\
\hline Cx.gr. Imitator & $x$ & $x$ & $x$ & $x$ & $x$ & $x$ & $y$ & $x$ & $x$ & $x$ & $x$ & $x$ & $x$ \\
\hline Cx.gr.Pleuristriatus & $y$ & $z$ & $z$ & $z$ & $z$ & $z$ & & $z$ & $z$ & 2 & & $z$ & \\
\hline CX. (Mcx.)sp1 & $x$ & $y$ & z & & $z$ & $y$ & & & $z$ & $z$ & $z$ & $z$ & $z$ \\
\hline$C_{x}(M c x) s p^{*}$ & $x$ & $x$ & $y$ & $y$ & $y$ & $y$ & $y$ & $y$ & $y$ & $x$ & $z$ & $y$ & $x$ \\
\hline$C x .(M c x) s p^{* t}$ & $y$ & $y$ & $z$ & $y$ & $z$ & $y$ & $z$ & $z$ & $z$ & $z$ & $z$ & $z$ & $z$ \\
\hline Ph. edwardsi & $z$ & $y$ & $z$ & $z$ & $z$ & $y$ & $z$ & z & $y$ & $y$ & $y$ & $x$ & $y$ \\
\hline Ph.galvoi & & & $z$ & & $z$ & $z$ & & & $z$ & $z$ & $y$ & $z$ & \\
\hline Phincaudata & $z$ & $z$ & $z$ & $y$ & $y$ & $x$ & & $y$ & $x$ & $x$ & $x$ & $y$ & $y$ \\
\hline Phpalmata & & & & & z & z & $z$ & $z$ & $z$ & & $z$ & $z$ & \\
\hline Ph quasilongirostris & & & & & & & & $z$ & & & & & \\
\hline Ph.sp* & $y$ & $z$ & $z$ & $z$ & $y$ & $y$ & $z$ & $y$ & $y$ & $y$ & $y$ & $y$ & $z$ \\
\hline Ph. sp & $z$ & $z$ & $z$ & $z$ & $z$ & $y$ & $z$ & $z$ & $y$ & $z$ & $z$ & z & \\
\hline Ph theobaldi & & & & & & $z$ & & & & & & & \\
\hline Ru.cerqueirai & & & & & & $z$ & & & & & & & \\
\hline Ru reversa & & $z$ & & & $z$ & $z$ & $z$ & $z$ & $z$ & $z$ & $z$ & $z$ & $z$ \\
\hline Wy.borrouli & $z$ & 2 & $z$ & $z$ & & $z$ & & $z$ & $z$ & & $z$ & & $z$ \\
\hline$W y \cdot s p$ & & & & z & & $z$ & & & & & & $z$ & \\
\hline Wy sp danificado & 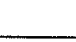 & 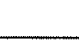 & $z$ & 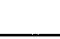 & 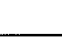 & & & $z$ & & $z$ & & & \\
\hline
\end{tabular}

As figuras que seguem apresentam as espécies com freqüências relativas superiores a $1 \%$ e as do subgênero Kerteszia (exceto na praia), independentemente da porcentagem que representaram, segundo cada estrato estudado. Tais figuras complementam os dados apresentados na tabela acima, pois a constância de espécies considera apenas a positividade de coletas para as espécies, ao 
passo que a freqüência relativa das espécies dá idéia do grau de dominância das espécies, independentemente da constância.

$\mathrm{Na}$ restinga, o subgênero Microculex domina, sobretudo se for considerado que as bromélias deste ambiente foram as mais produtivas, totalizando 11302 larvas. As espécies destacadas somam 95\% dos Culicidae coletados, sem contar os espécimes danificados deste grupo, que totalizaram 3,4\%. Não foi coletado An. cruzii e An. bellator representou $0,1 \%$ dos larvas.

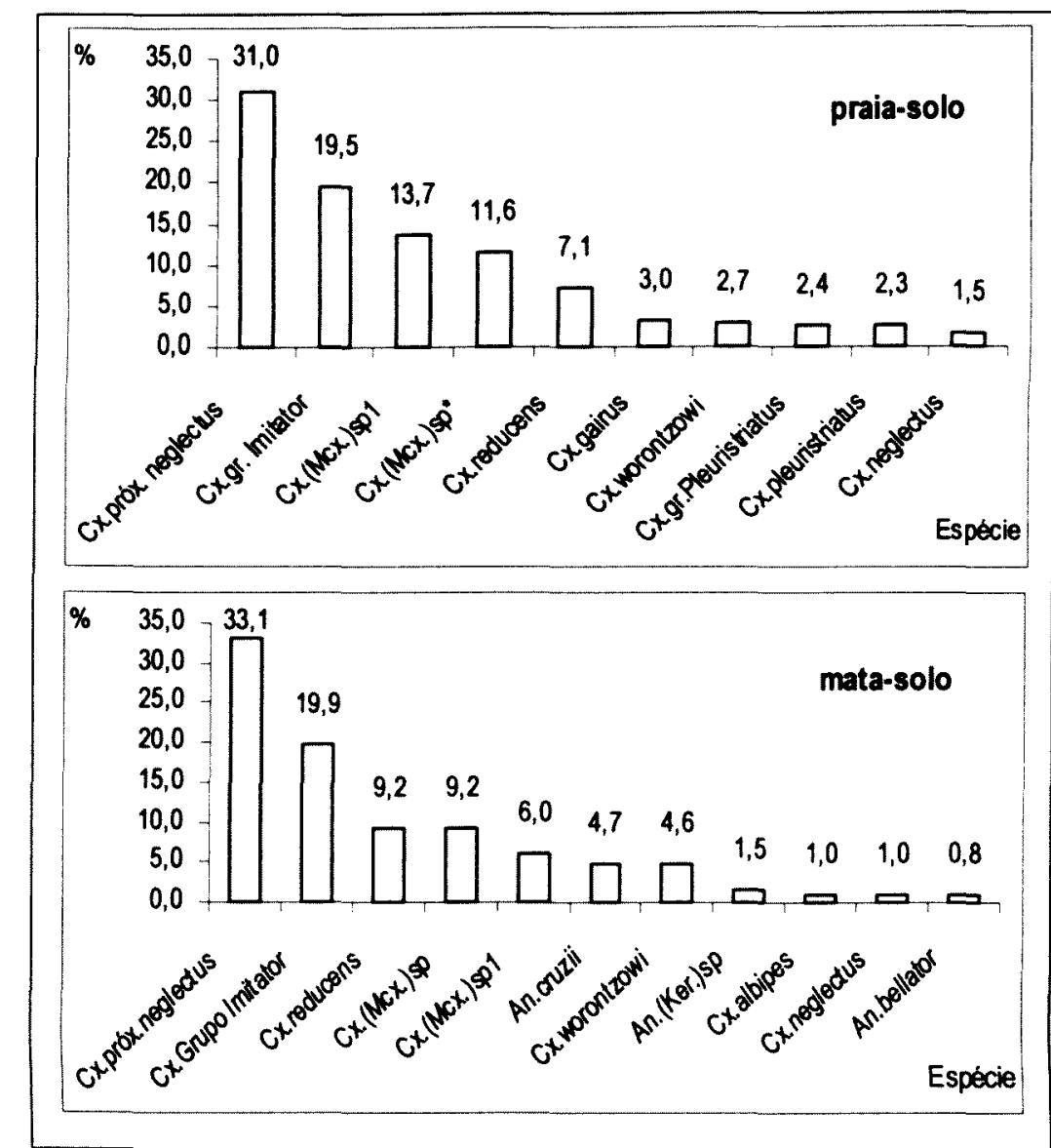

Figura 16: Espécies de Culicidae com freqüência relativa superiores a $1 \%$. Larvas coletadas em bromélias de solo, na praia e na mata. Itha Comprida, 18/09/2001 a 17/09/2002.

Este predomínio de Microculex se mantém nas bromélias de solo no ambiente de mata, mas aqui o subgênero Kerteszia representa 6,8\% das quase 8500 larvas coletadas. 
A [1,2[m. o subgênero Kerteszia tem sua freqüência relativa mais alta registrada em todo o estudo, contribuindo com 34,5\% das 1709 larvas coletadas. $A n$. cruzii contribuiu com $13 \%$ dos espécimes. Ainda há predomínio de Microculex, mas $P h$. incaudata tem freqüência relativa semelhante à de algumas espécies deste subgênero.

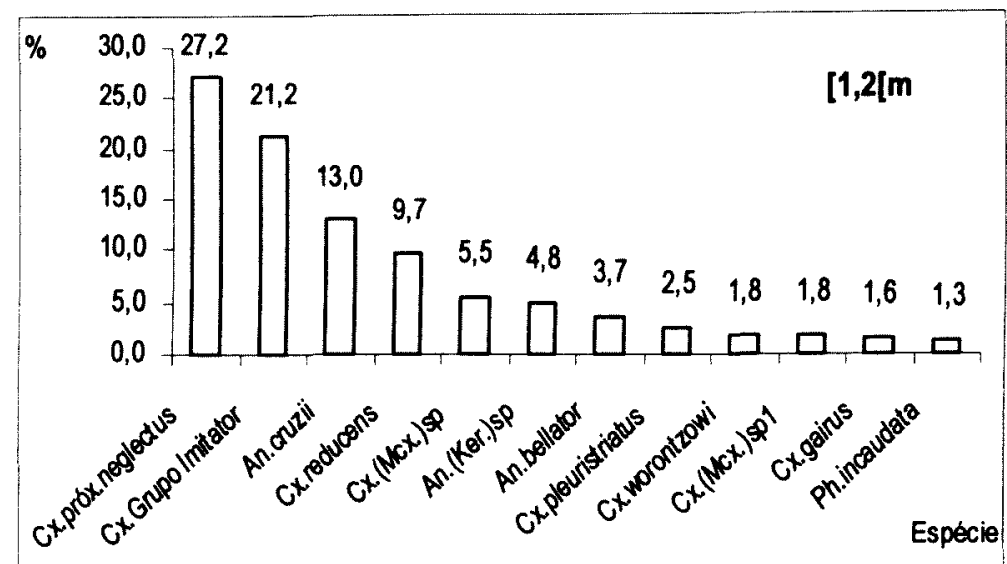

Figura 17: Espécies de Culicidae com freqüência relativa superiores a $1 \%$ e do subgênero Kerteszia. Larvas coletadas em bromélias a [1,2[m solo, na mata. Itha Comprida, 04/09/2001 a 17/09/2002

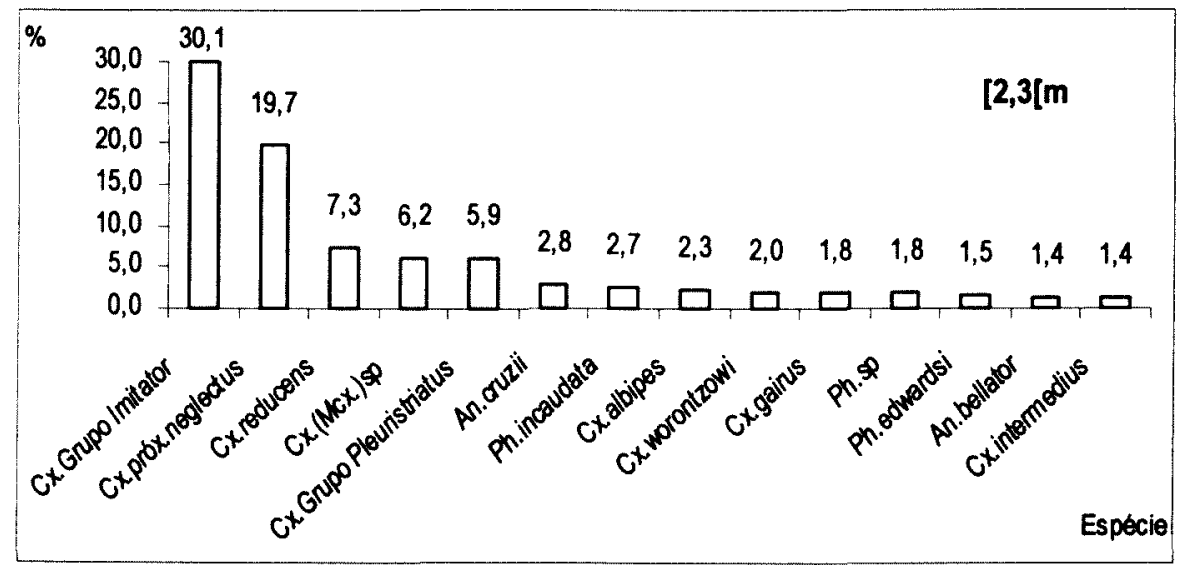

Figura 18: Espécies de Culicidae com freqüência relativa superiores a 1\% e do subgênero Kerteszia. Larvas coletadas em bromélias a [2,3[m do solo, na mata. Itha Comprida, 04/09/2001 a 17/09/2002.

Nas bromélias a [2,3[m do solo, Microculex, especialmente grupo Imitator e $C x$. próximo a neglectus, prevalece e o subgênero Kerteszia, com predomínio de An. cruzii, passa a representar menos de 5\% das quase 1000 larvas coletadas. 
Nas bromélias a [3,4[m, o subgênero Kerteszia aumenta novamente sua freqüência relativa, com 8,5\% das 1399 larvas, contribuindo com pouco menos do que espécies de Phoniomyia.

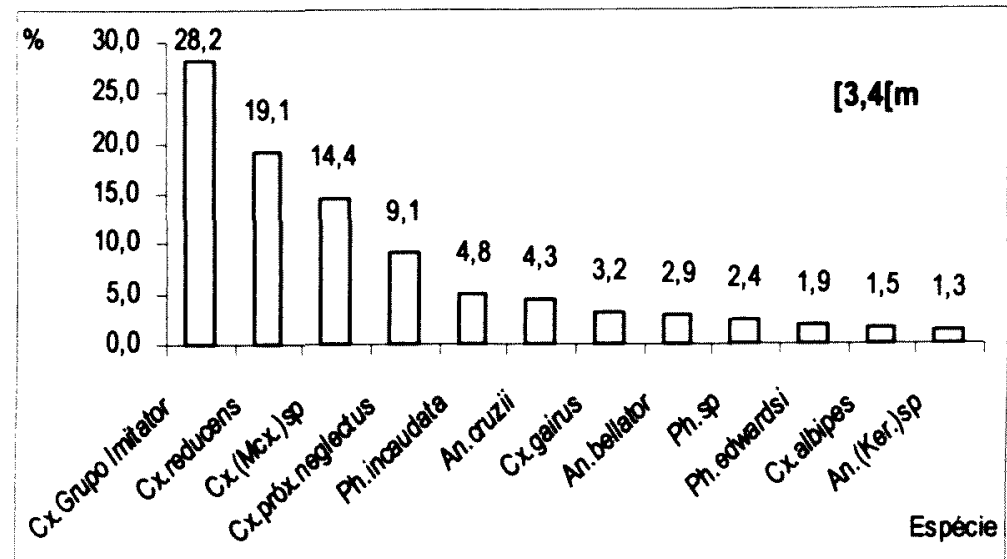

Figura 19: Espécies de Culicidae com freqüência relativa superiores a $1 \% \mathrm{e}$ do subgènero Kerteszia. Larvas coletadas em bromélias a [3,4[m do solo, na mata. Ilha Comprida, 04/09/2001 a 17/09/2002.

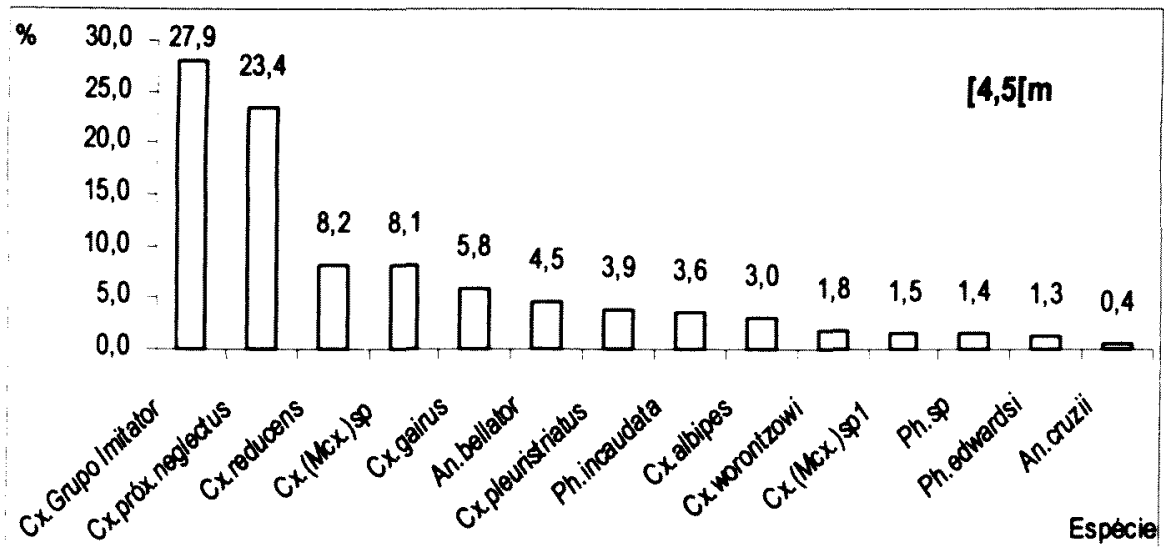

Figura 20: Espécies de Culicidae com freqüència relativa superiores a $1 \%$ e do subgènero Kerteszia. Larvas coletadas em bromélias a [4,5[m do solo, na mata. Itha Comprida, 04/09/2001 a 17/09/2002.

No estrato $[4,5[\mathrm{~m} A n$. bellator tem frequiência relativa mais alta do que $A n$. cruzii, que até então havia predominado sobre a aquela espécie $(4,5$ e $0,4 \%$ de 4256 larvas, respectivamente). 
Neste estrato as espécies de Kerteszia, com predomino de An. bellator, não chegam a representar $3 \%$ do Culicidae e nenhuma espécie de Phoniomyia chega atingir 1\% das 292 larvas coletadas. Foi o menor registro de indivíduos coletados, porém, deve se ter em mente que o número de bromélias aspiradas inferior e a densidade de larvas por volume foi semelhante à dos demais estratos.

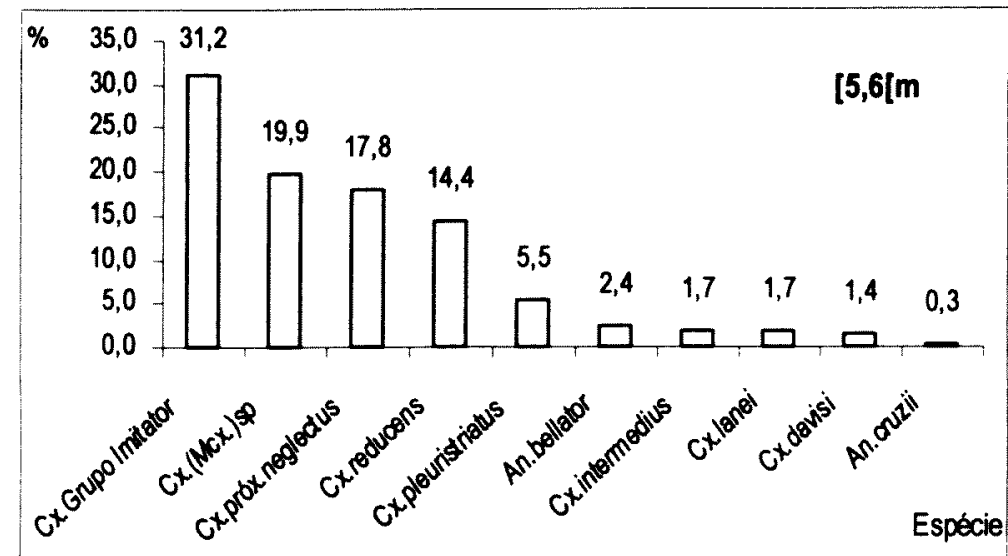

Figura 21: Espécies de Culicidae com freqüência relativa superiores a 1\%. e do subgénero Kerteszia Larvas coletadas em bromélias a [5,6[m do solo, na mata. Itha Comprida, 04/09/2001 a 17/09/2002.

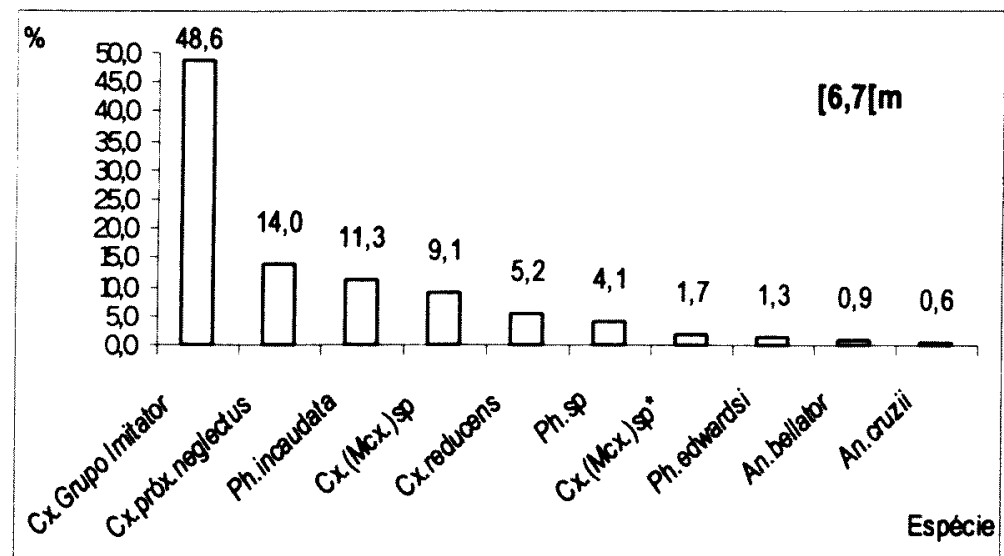

Figura 22: Espécies de Culicidae com freqüência relativa superiores a $1 \%$. e do subgênero Kerteszia. Larvas coletadas em bromélias a [6,7[m do solo, na mata. Itha Comprida, 04/09/2001 a 17/09/2002.

Neste estrato, o Grupo Imitator atinge seu maior grau de dominância, contribuindo com quase $50 \%$ dos espécimes coletados. Isso, obviamente, reduz a frequêencia relativa de todas as outras espécies, mas como o total de imaturos foi 
baixo (cerca de 600 larvas), a contribuição de cada espécie se torna relativamente maior. Ainda assim, Ph. incaudata teve freqüência de 11,3\%. As espécies de Kerteszia somaram 1,5\%.

A [7,8[m Kerteszia tem freqüência relativa pouco maior do que no estrato anterior, mais ainda baixa (3,7\%). O total coletado foi de 992 larvas.

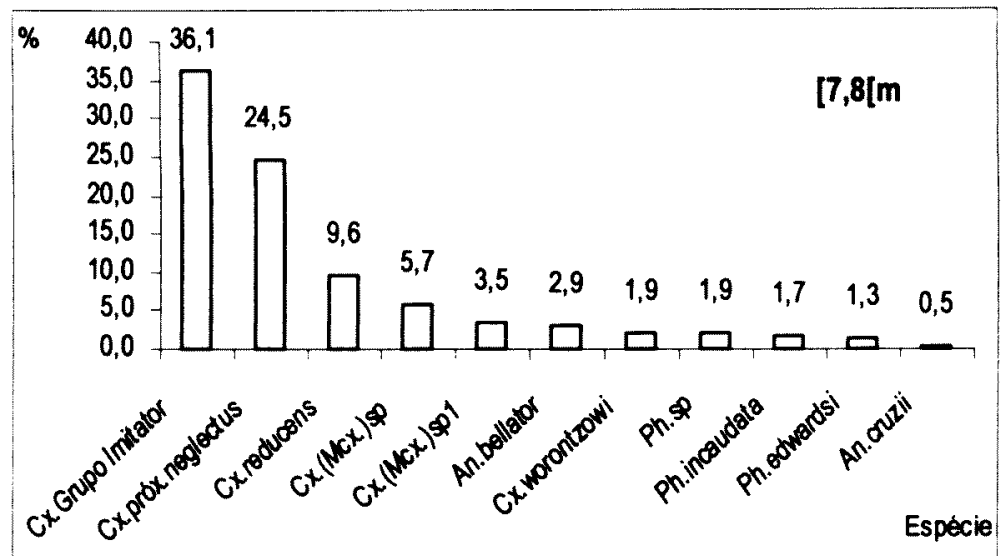

Figura 23: Espécies de Culicidae com freqüência relativa superiores a $1 \%$ e do subgénero Kerteszia. Larvas coletadas em bromélias a $77,8[\mathrm{~m}$ do solo, na mata. Itha Comprida, 04/09/2001 a 17/09/2002.

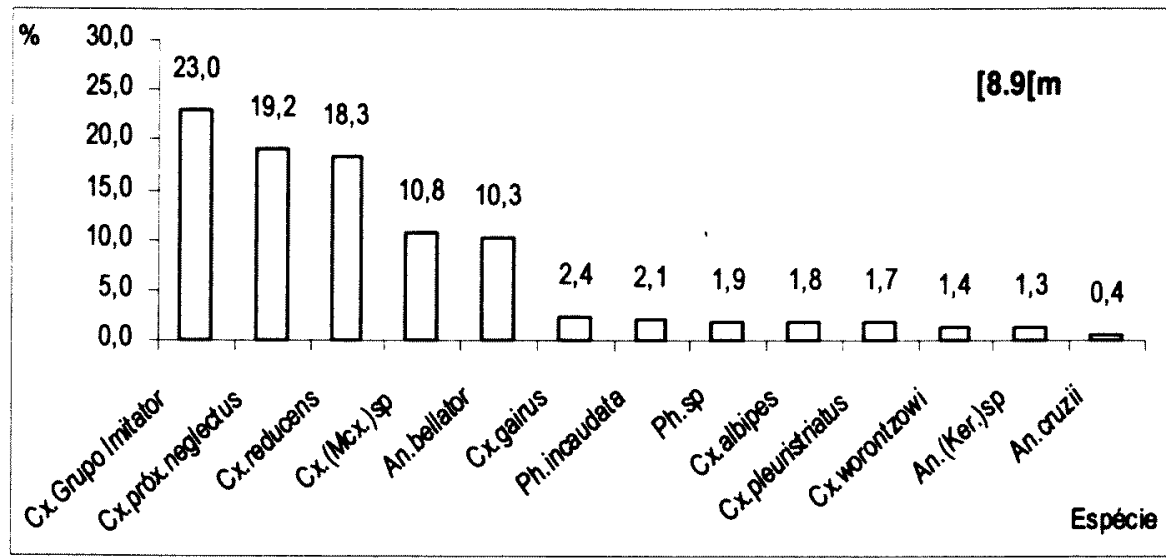

Figura 24: Espécies de Culicidae com freqüência relativa superiores a $1 \%$ e do subgênero Kerteszia. Larvas coletadas em bromélias a [8,9[m do solo, na mata. llha Comprida, 04/09/2001 a 17/09/2002.

Neste estrato, An. bellator atingiu sua maior freqüência, com mais de $10 \%$ das 2769 larvas de Culicidae e o grupo Imitator, sua freqüência mais baixa (23\%), embora ainda com alto grau de dominância. 
A $[9,10$ [m o grupo Imitator novamente contribui com quase $50 \%$ das 610 larvas, semelhantemente ao que ocorreu no estrato $[6,7[\mathrm{~m}$.

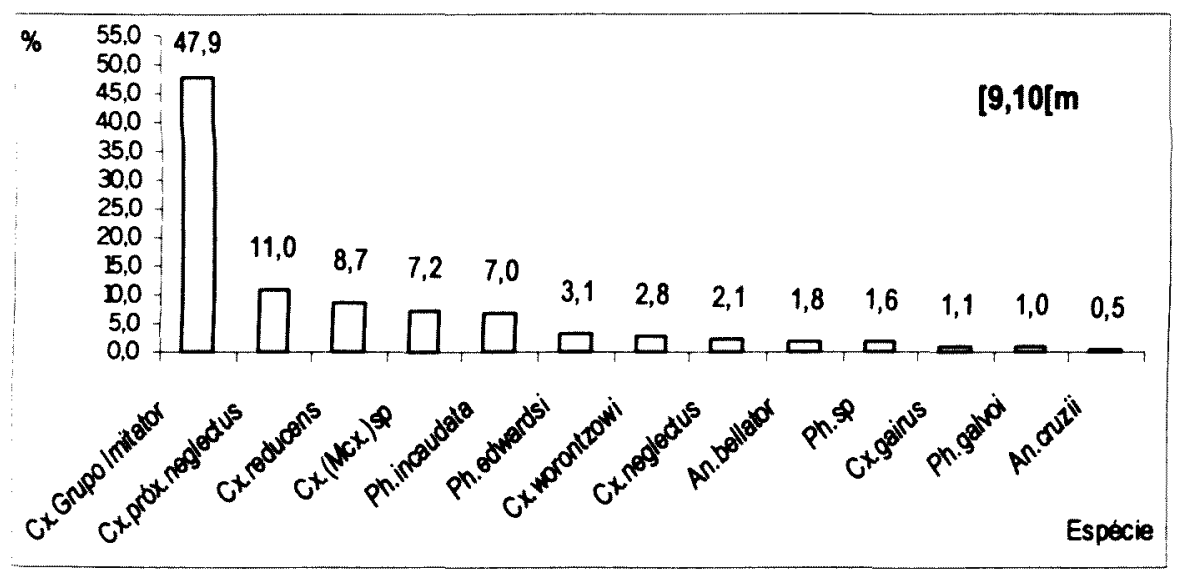

Figura 25: Espécies de Culicidae com frequeência relativa superiores a $1 \%$ e do subgênero Kerteszia. Larvas coletadas em bromélias a [9,10[m do solo, na mata. Itha Comprida, 04/09/2001 a 17/09/2002.

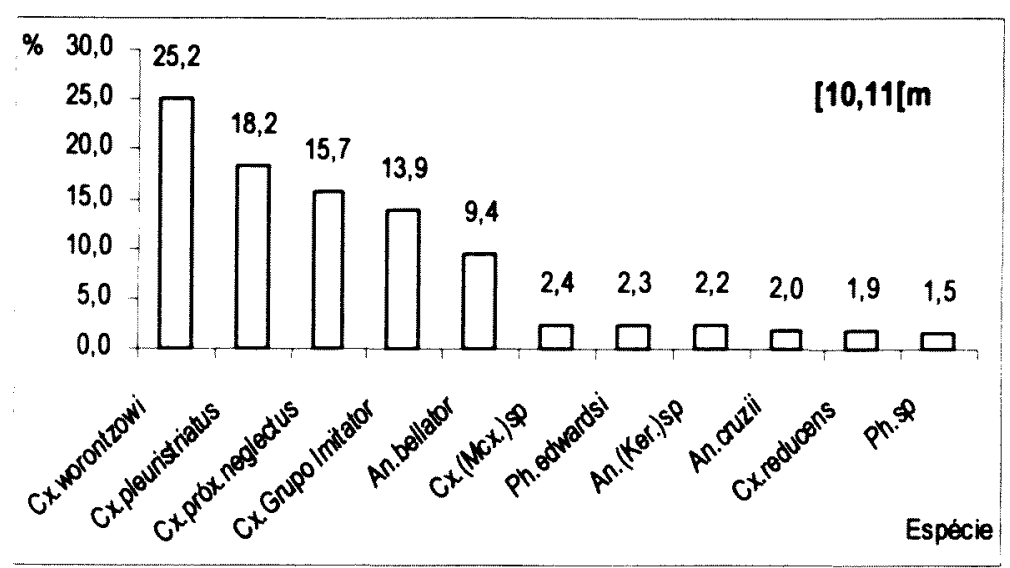

Figura 26: Espécies de Culicidae com freqüência relativa superiores a $1 \%$ e do subgênero Kerteszia. Larvas coletadas em bromélias a [10,11[m do solo, na mata. Itha Comprida, 04/09/2001 a 17/09/2002.

Neste estrato ocorreu situação semelhante à encontrada a $[8,9[\mathrm{~m}$, quanto ao total de larvas coletas - quase 2500; quanto ao grau de dominância de espécie com maior frequiência relativa - cerca de $25 \%$, porém aqui não se trata do grupo Imitator, mas de $C x$. worontzowi; e An. bellator contribuiu com quase $10 \%$ dos culicídeos coletados. Aqui An. cruzii ainda esteve presente, mas no estrato seguinte, a 
espécie foi ausente. An. bellator contribuiu com 5,5\% das 811 larvas coletadas. Neste caso, vale lembrar que esse foi o rendimento de apenas duas bromélias, visitadas mensalmente, totalizando 10 coletas, 8 das quais positivas para este anofelino.

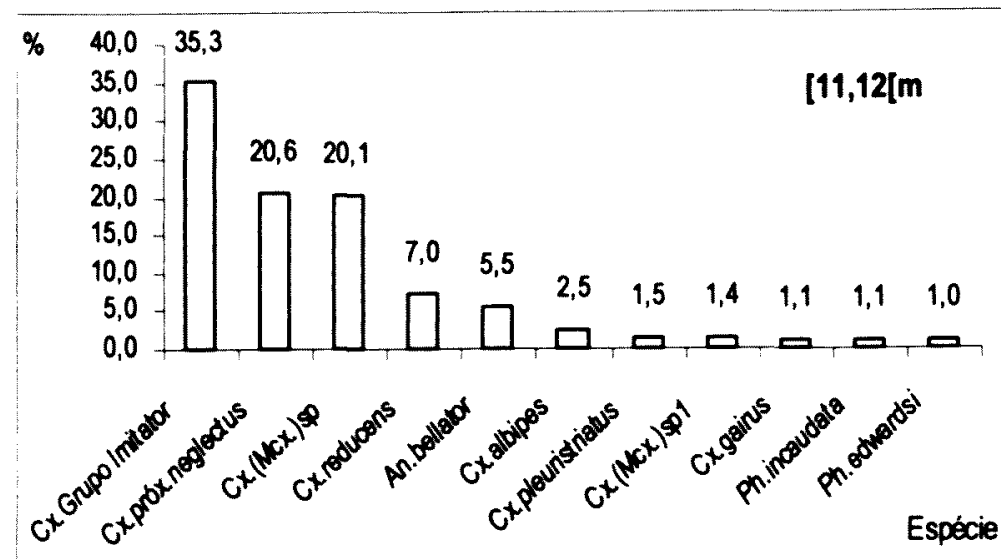

Figura 27: Espécies de Culicidae com frequência relativa superiores a $1 \% \mathrm{e}$ do subgênero Kerteszia. Larvas coletadas em bromélias a [11,12[m do solo, na mata. Itha Comprida, 04/09/2001 a 17/09/2002.

O gráfico abaixo ilustra a flutuação da densidade de Culicidae em bromélias de solo, ao longo do ano trabalhado, segundo os ambientes estudados. A densidade máxima obtida foi de 22 larvas $/ 100 \mathrm{ml}$, no inverno, na praia, e a densidade mínima registrada foi de 0,4 , também na praia, em outubro de 2001 . Este mês correspondeu à densidade mínima calculada para as bromélias de mata, onde a densidade máxima não ultrapassa 15 larvas $/ 100 \mathrm{ml}$. A produtividade de imaturos não zera, embora oscile consideravelmente e em ritmos diferentes no ambiente de mata e restinga da praia, com pico de densidade entre novembro e março, e março e junho, respectivamente. 


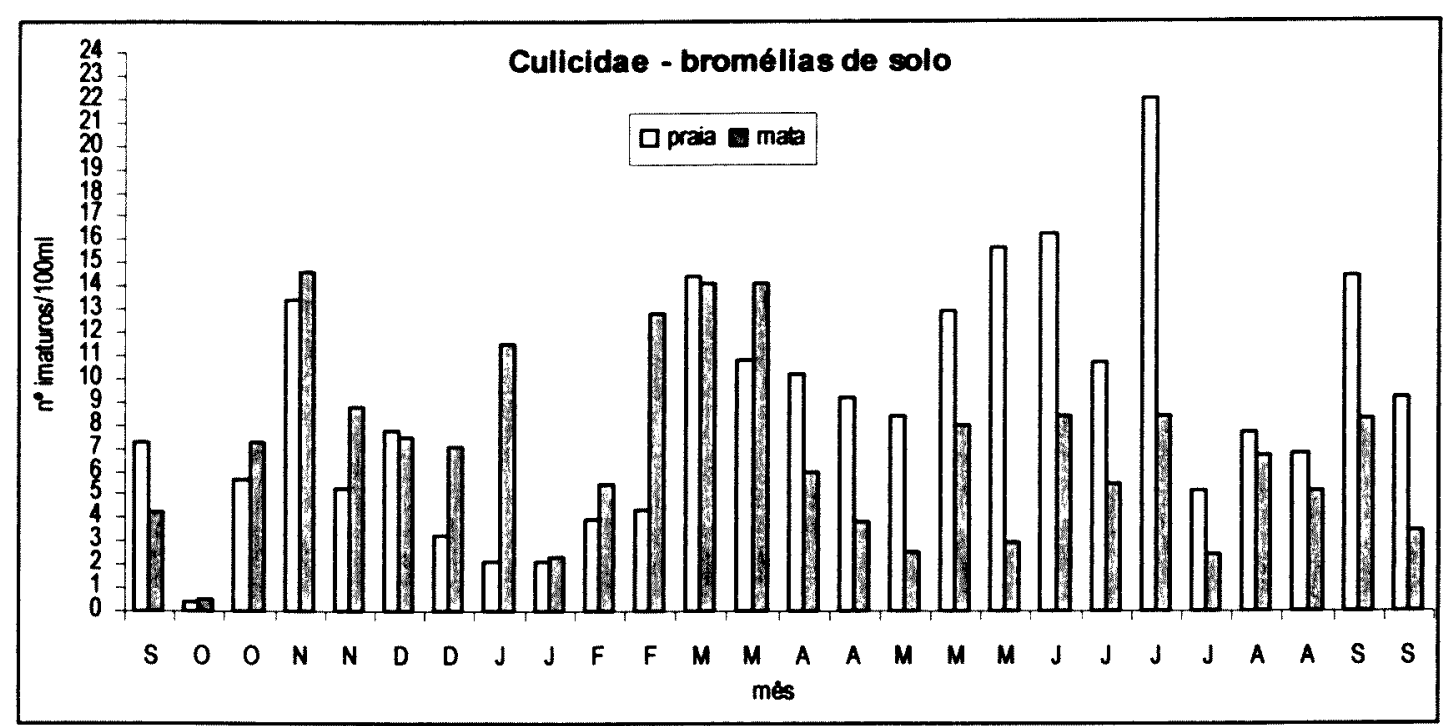

Figura 28: Densidade de larvas de Culicidae em bromélias de solo ao longo dos meses trabalhados. Itha Comprida, 18/09/2001 a 17/09/2002.

Densidades máximas, considerando todos os estratos foram registradas nas classes $[2,3[\mathrm{~m},[3,4[\mathrm{~m},[5,6[$ e $[7,8[\mathrm{~m}$, com valores em torno de 60 imaturos/100ml, em junho de 2002 para os três primeiros, e março de 2002 para $[7,8[\mathrm{~m}$. Nas classes $[4,5[\mathrm{~m}$ e $[6,7[\mathrm{~m}$ as densidades mais altas foram de cerca de 30 imaturos $/ 100 \mathrm{ml}$, em março e janeiro de 2002, respectivamente. Nas outras classes, as densidades máximas foram em torno de $20 \mathrm{imaturos} / 100 \mathrm{ml}$, em meses variáveis, de modo que não parece haver um padrão de flutuação populacional para as bromélias de um modo geral. 


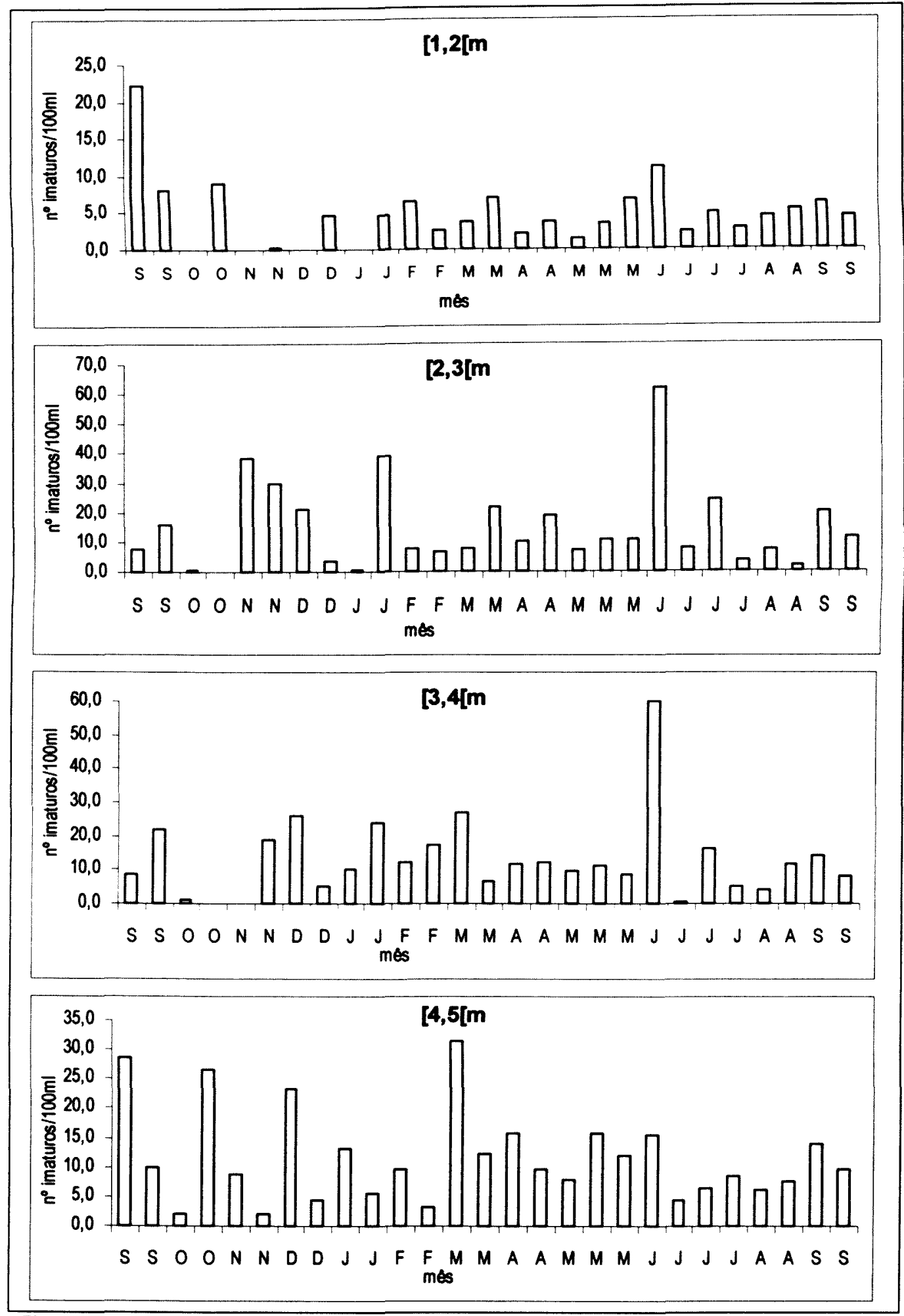

Figura 29: Densidade de larvas de Culicidae em bromélias a até $5 \mathrm{~m}$ do solo, em ambiente de mata. Ilha Comprida, 04/09/201 a 17/09/2002. 


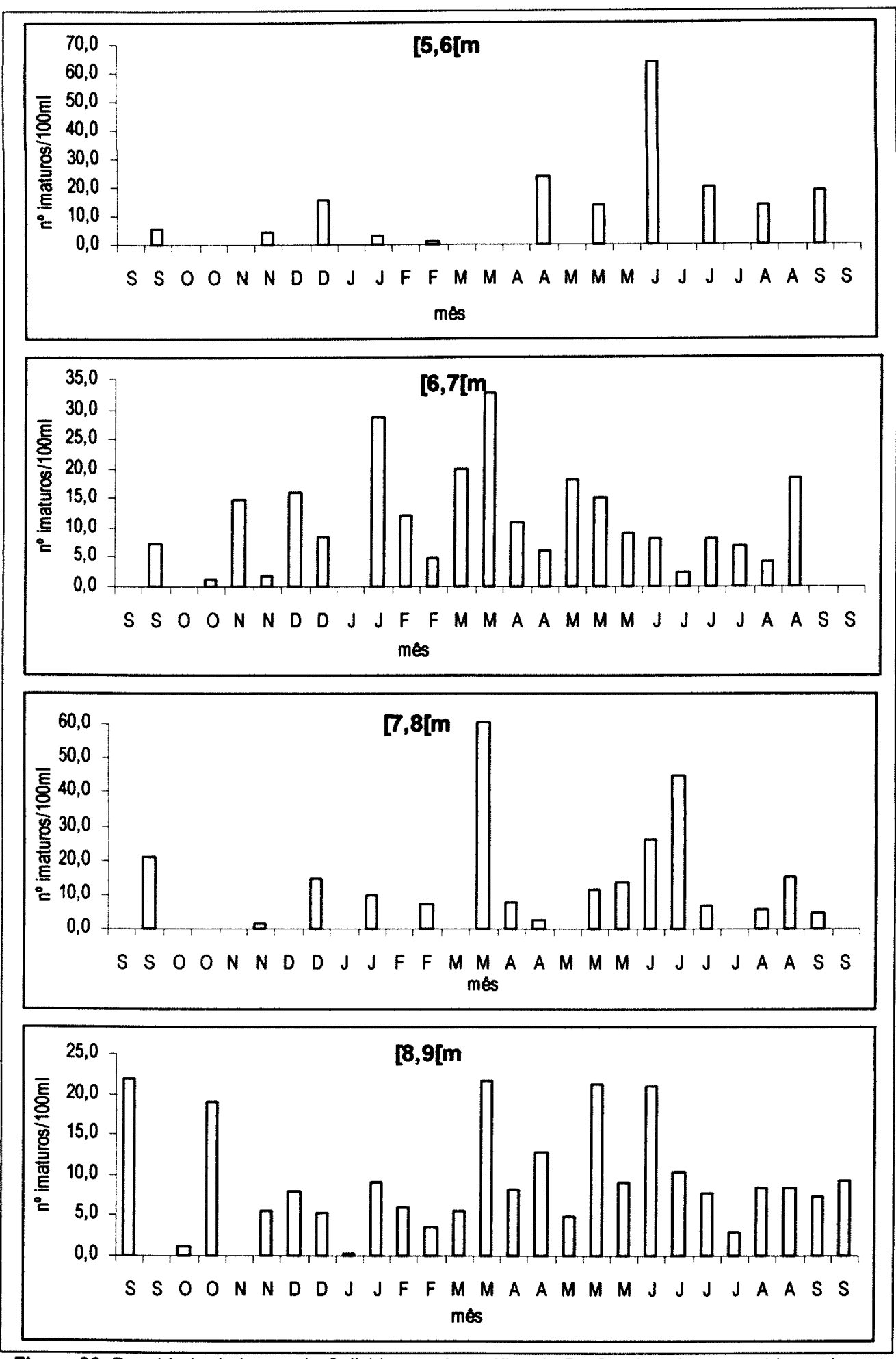

Figura 30: Densidade de larvas de Culicidae em bromélias de 5 a $9 \mathrm{~m}$ do solo, em ambiente de mata. Ilha Comprida, 04/09/201 a 17/09/2002 

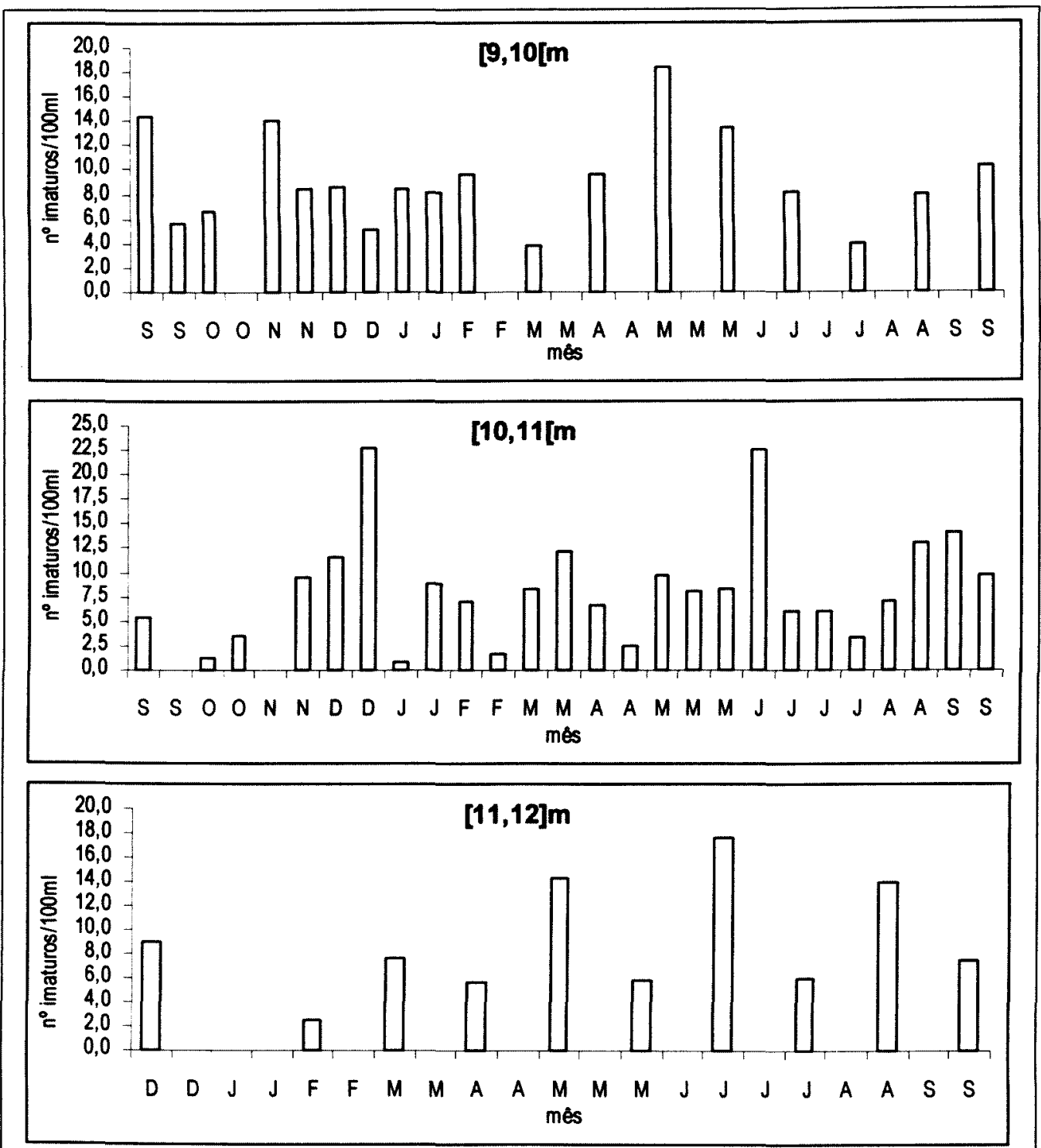

Figura 31:Densidade de larvas de Culicidae em bromélias de 9 a $12 \mathrm{~m}$ do solo, em ambiente de mata. Itha Comprida, 04/09/201 a 17/09/2002. 


\section{DISCUSSÃO}

Desde meados dos anos 70 tem se tornado cada vez mais freqüente o uso de dióxido de carbono $\left(\mathrm{CO}_{2}\right)$ associado a armadilhas luminosas, aumentando o rendimento das capturas de mosquitos (SEVICE 1993). A proporção de machos nas capturas é baixa e a maior parte das fêmeas não está ingurgitada, sendo atraída pelo $\mathrm{CO}_{2}$ na procura por fonte para realizar repasto sangüíneo. As fontes de $\mathrm{CO}_{2}$ mais comuns são cilindros, com a principal vantagem de possuírem sistemas que regulam a liberação do gás. Porém, são caros, grandes e podem conter impurezas repelentes aos mosquitos. Como alternativa, o uso do gelo seco tem se consagrado devido à sua praticidade e baixo custo, apesar de não permitir controle sobre a taxa de liberação de $\mathrm{CO}_{2}$ e de reduzir a temperatura próximo à armadilha (SERVICE 1977).

Como método de levantamento de fauna, armadilhas luminosas tipo CDC permitem a captura de mosquitos menos antropofilicos, além de evitar a exposição humana e reduzir tanto o fator de erro humano no uso de aspiradores ou tubos coletores, quanto as diferenças individuais de atratividade sobre mosquitos (DAVIS et al 1995).

Vários pesquisadores têm tentado correlacionar dados obtidos por diferentes técnicas e atrativos com capturas por isca humana. Os resultados variam de acordo com o tipo de luz, tipo e dosagem de atrativo, entre outros fatores, mas em geral, as capturas em armadilhas tipo CDC tendem a subestimar as densidades de mosquitos antropofilicos em relação à isca humana (RUBIO-PALIS e CURTIS 1992; DAVIS et al 1995; RUBIO-PALIS 1996; HII et al 2000). REISEN et al (2000) discutem especificamente o uso de diferentes fontes e concentrações de $\mathrm{CO}_{2}$.

A possibilidade de operar armadilhas tipo CDC em gradiente vertical, com várias capturas simultâneas padronizadas, constitui vantagem sobre a isca humana. Além disso, a captura de mosquitos zoofilicos na mata e, particularmente, ornitofilicos em copa arbórea, representa dado importante da estimativa de risco de transmissão de arbovírus. A subestimação das densidades de mosquitos vetores de doença humana deve ser levada em consideração, sobretudo em áreas de transmissão e é, sem dúvida, desvantagem da técnica, pois acaba por subestimar o risco de transmissão de doenças veiculadas por mosquitos vetores. 
No presente estudo, um dos objetivos foi estimar as densidades das populações de $A n$. bellator e $A n$. cruzii, procurando relacioná-las a alguns de seus determinantes. Por representarem fases do ciclo de vida com biologia e função distintas, as análises foram realizadas separadamente, para adultos e imaturos.

Temperaturas extremas podem levar os insetos a procurarem abrigos. Em se tratando de hematófagos, o comportamento das fontes para repasto sangüíneo também exerce influência direta sobre a atividade das fềmeas de mosquitos. Além disso, variações de temperatura podem alterar o ciclo de patógenos em vetores.

De acordo com GITHEKO et al (2000), mudanças climáticas devem interferir nos limites extremos da faixa de temperatura em que ocorre transmissão de doenças como malária, arboviroses e outras que envolvam a participação de artrópodes. Elevação do limite inferior de temperatura exerce impacto significativo sobre o periodo extrínseco de incubação, ao passo que elevação do limite superior, tende a interromper a transmissão. Entre esses extremos, sob temperaturas entre 30 a $32^{\circ} \mathrm{C}$, a capacidade vetora tende a aumentar, devido ao desenvolvimento mais rápido de larvas e à redução do período extrínseco de incubação de patógenos.

O clima tropical é bastante favorável ao desenvolvimento de insetos e a hipótese inicial era que a temperatura não seria fator limitante da atividade de mosquitos. Se fosse, o seria em seus limites, razão pela qual não foi utilizada a temperatura média, mas a temperatura mínima e máxima diária, bem como a amplitude térmica, que indica a diferença entre esses dois valores.

A ausência de associação entre temperatura minima e densidade de adultos de Kerteszia sugere que sua variação não influencia a atividade desses mosquitos, até porque o horário de registro da primeira variável se dá no início da manhã. Já o registro da temperatura máxima ocorre por volta das $15 \mathrm{~h}$, horário mais próximo do início das capturas. Assim, tanto para An. cruzii quanto para An. bellator, houve correlação positiva entre suas densidades e a temperatura máxima. Contudo, somente esta espécie demonstrou associação com a amplitude térmica. $\mathrm{O}$ ritmo e a intensidade das variações na densidade de $A n$. bellator e foram menores do que de An. cruzii, o que poderia explicar este resultado, uma vez que a amplitude térmica também não sofreu flutuações tão acentuadas quanto a densidade de $A n$. cruzii (Figuras 4 e 5). 
No que diz respeito à precipitação, segundo WALLNER (1987), insetos de zonas tropicais e temperadas, em geral, estão sujeitos a variações sazonais equivalentes. No entanto, populações de áreas secas, sejam tropicais ou temperadas, tendem a sofrer maiores flutuações do que as de áreas úmidas. A região do Vale do Ribeira é caracteristicamente úmida; durante o periodo estudado, a URA média foi superior a $94 \%$.

Não houve associação entre chuva acumulada em período anterior de 15 dias e densidade dos anofelinos estudados. A chuva poderia justificar densidades inferiores nos dias de captura, na dependência do horário e intensidade da precipitação, enquanto que a chuva nos dias anteriores poderia explicar aumento na densidade, em função da emergência de adultos.

No Pantanal, SORIANO e GALDINO (2002) estudaram o padrão diário de chuvas de 1977 a 2000. Os autores estabeleceram uma classificação da intensidade de precipitação, segundo intervalos de classe de $5 \mathrm{~mm}$ : muito fraca, fraca, moderadamente fraca, moderada, moderadamente forte, forte e muito forte (esta última classe implica em precipitação superior a $30 \mathrm{~mm}$ ). Com base nesta classificação, concluiu-se que dias com precipitação muito fraca $(0,1$ a $5 \mathrm{~mm})$ predominam e o que caracteriza a estação chuvosa, de outubro a março, é o número de dias com chuva.

Neste trabalho, a foi chuva moderadamente forte apenas nas coletas de 08/01/2002 e 02/04/2002 (22,2 e 23,8mm, respectivamente). Das 26 capturas, 13 ocorreram em dias sem chuva, com as respectivas densidades de An. bellator e $A n$. cruzii variáveis. Nos demais, a intensidade de precipitação foi muito fraca, fraca ou moderadamente fraca, correspondente a até $15 \mathrm{~mm}$, também com densidades variáveis, de modo que não foi possível estabelecer padrão que relacionasse esses dois parâmetros, chuva e densidade de anofelinos.

Em relação à distribuição vertical, tanto $A n$. bellator e $A n$. cruzii apresentaram maiores densidades na copa do que próximo ao solo ou a $6 \mathrm{~m}$. Embora DEANE et al (1984) tenham demonstrado mobilidade de An. cruzii no sentido copasolo e vice-versa, a espécie predominou em estrato arbóreo, ainda que em diferentes proporções, em vários estudos anteriores. 
Na região da Serra da Cantareira, DEANE et al (1967) capturaram. próximo ao solo e em plataformas em árvores a 10 e $15 \mathrm{~m}$ de altura, 3887 mosquitos, distribuídos entre mais de 30 espécies, das quais $\mathrm{An}$. cruzii representou quase $30 \%$ do total de culicídeos. Em relação à distribuição por estrato, $99 \%$ dos indivíduos da espécie foram capturados nas plataformas. Em outra pesquisa, 99,3\% dos espécimes de An. cruzii foram capturados em copa arbórea, no então chamado Horto Florestal da Cantareira (atualmente Parque Estadual). Aliás, foi o único anofelino obtido em maior densidade na copa. Comparativamente, no Estado do Espirito Santo (Santa Leopoldina), a densidade desta espécie foi bem inferior à registrada na Cantareira, mas também houve predomínio de individuos em copa arbórea $(99,4 \%)$. Já no Sul do Brasil, o comportamento acrodendrófilo de An. cruzii foi menos marcante. No Estado de Santa Catarina, em Campo Alegre, ainda houve predomínio da espécie na copa de árvore (89,3\%); já em Joinvile, a freqüência ao estrato arbóreo caiu para $58 \%$ e, no Rio Grande do Sul (Guaiba), para 56\%. Em todas essas localidades, An. cruzii foi o mais abundante dos anofelinos (DEANE et al 1971).

Anos depois, MONTES (2003) não encontrou Kerteszia na Serra da Cantareira. Ao longo de um ano de trabalho, com capturas em armadilhas CDC com gelo seco, foram capturados mais de 2000 mosquitos de quase 30 espécies, porém, nenhuma do subgênero mencionado, apesar de ainda existirem muitas bromélias no local. Segunda a autora, a ausência de espécies de Kerteszia sugere que a região da Cantareira não oferece mais condições para a manutenção do grupo, devido à especulação imobiliária, devastação da mata, proximidade com área urbana, entre outros fatores. Isso pode justificar também a baixa densidade de Culicidae em geral.

No nordeste do Estado de São Paulo, FORATTINI et al (1968) estudaram a distribuição vertical de Culicidae, tendo registrado $74,4 \%$ dos 3310 mosquitos da espécie $A n$. cruzii a $12 \mathrm{~m}$ e $83,3 \%$ dos 13900 individuos desta espécie a $15 \mathrm{~m}$, em duas localidade distintas. Dentre os culicideos, este anofelino foi a espécie mais abundante, com freqüências superiores a $60 \%$.

Recentemente. GUIMARÃES et al (2000a) conduziram levantamento de fauna de Culicidae no Núcleo de Picinguaba, no Parque Estadual da Serra do Mar, próximo à área onde foi realizado o estudo de FORATTINI et al (1968). Foram estudados vários ambientes, inclusive o florestal. Em dois anos de coleta (jan/1991 a 
dez/1992) foram capturados 24943 mosquitos, correspondentes a 57 espécies. Dentre esses, 5,7\% eram anofelinos, sendo que $\mathrm{An}$. cruzii foi a espécie mais abundante $(40 \%$ dos Anopheles; 2,3\% dos Culicidae).

No sudeste do Estado de São Paulo, DUTRA et al (1996) realizaram levantamento de culicídeos na Reserva Estadual de Pedro de Toledo, município de Juquitiba. No período de agosto de 1990 e julho de 1992, das 17 às 20h, em armadilhas CDC com gelo seco, isca humana e armadilha de Shannon, An. cruzii foi a espécie mais freqüente, representando de 46 a $98 \%$ dos mosquitos. Houve claro predomínio da espécie no ambiente de mata, sobretudo na copa, mas é importante assinalar a presença da espécie em ambiente domiciliar. Quanto ao rendimento das capturas pelas diferentes técnicas, em isca humana na mata e em armadilha de Shannon no peridomicílio, foram capturados mais de 4000 mosquitos, segundo cada técnica, enquanto que nas CDCs - solo e copa da mata - 997 e 1520 culicídeos, respectivamente.

O horário e a técnica empregada foram os mesmos adotados nesta pesquisa, porém o predomínio de $A n$. cruzii nas matas de Juquitiba é muito maior do que o encontrado na Ilha Comprida. Tal domínio pode justificar a ausência de $A n$. bellator. Outra informação importante do levantamento dos autores é a comparação entre o rendimento de capturas com o emprego de diferentes técnicas, indicando que a isca humana e a armadilha de Shannon propiciaram a captura de cerca de 2,5 vezes mais An. cruzii do que as CDCs. Contudo, essa referência não pode ser adotada como parâmetro de adaptação da estimativa de tamanho populacional, pois conforme discutido no início desta seção, algumas espécies são mais atraídas por um tipo de armadilha do que por outro, de modo que os resultados podem variar muito de acordo com a técnica, espécie alvo, local, horário, condições climáticas no momento da captura, entre outras variáveis.

Mais ao sul, no Estado de São Paulo, na região do Vale do Ribeira, vários estudos sobre Culicidae foram realizados. De abril de 1980 a abril de 1982, FORATTINI et al (1986a) coletaram 138383 mosquitos, em coletas de 25 horas ininterruptas e armadilha de Shannon, dentro e fora da mata de encosta, no município de Cananéia. $81 \%$ desses mosquitos pertenciam ao subgênero Kerteszia, sendo que $77 \%$ da espécie An. cruzii e o restante, An. bellator. É interessante assinalar que nas 
demais localidades citadas até agora nesta discussão esta espécie esteve ausente, tanto em estudos antigos quanto nos mais recentes. Ainda assim, com baixa representatividade, quando comparada com a de $A$ n. cruzii.

No mesmo município, de fevereiro de 1983 a fevereiro de 1984, mas em mata de planicie, o emprego das mesmas técnicas obteve 37533 mosquitos, mais de $50 \%$ dos quais representados por Kerteszia, com predomino de An. cruzii (46,9\%). No horário das 18 às $23 \mathrm{~h}$, a freqüência de Kerteszia em relação aos demais culicídeos oscilou entre 85 e 92\%. Os autores justificam a maior freqüência de Kerteszia na mata de encosta em função do seu acentuado aclive, possibilitando, mesmo ao nível do solo, coletar mosquitos abrigados em copa arbórea. Por outro lado, An. bellator não apresentou diferença de comportamento em mata de encosta ou planície (FORATTINI et al 1986b).

Ainda na mata de planície em Cananéia, GOMES et al (1987) utilizaram CDCs sem e com isca animal (ave ou roedor), próximo ao solo e em copa arbórea $(11 \mathrm{~m})$, no interior e margem da mata, e ambiente domiciliar. Foram capturados 18393 mosquitos (mar/1983-jan/1984), dos quais 10,5\% eram An. cruzii.

Recentemente CURADO (2003) realizou capturas de anofelinos no Vale do Ribeira, nos parques estaduais de Intervales e o Turístico do Alto Ribeira (PETAR), empregando armadilhas CDC (18-6h) e armadilha tipo Shannon (18-22h), em áreas de mata. Foram capturados, ao longo de um ano (abr/2001 a abr/2002) 9 espécies de Anopheles, sendo que An. cruzii representou $79 \%$ dos anofelinos, com 794 indivíduos no PETAR e 135 (de um total de 179) fềmeas em Intervales.

Há três questões distintas que merecem ser discutidas: a densidade de Culicidae; a freqüência das espécies de Kerteszia, em relação aos demais culicídeos; e a freqüência relativa desses anofelinos nos estratos. Claro que essas questões devem considerar o protocolo de campo, principalmente o ambiente estudado, a técnica empregada e o horário de captura. Diferenças nesses fatores impossibilitam comparações diretas, mas permitem algumas inferências.

O comportamento acrodendrófilo parece ser característica das espécies de Kerteszia que não sofreu alteração nesses últimos anos, diferentemente da 
frequêencia relativa desses anofelinos em relação aos culicideos em geral. $75 \%$ dos espécimes de $A n$. cruzii e $60 \%$ dos de $A n$. bellator foram capturados em copa arbórea.

No presente trabalho, Kerteszia representou $36 \%$ dos 55226 Culicidae capturados. O horário de trabalho inclui o pico dos anofelinos de interesse, e pode ter excluído espécies diurnas, alterando a composição específica. A instalação de armadilhas em copa arbórea aumenta o número de espécies e o número de mosquitos com um todo, conforme observado neste trabalho e em outros, citados nos parágrafos anteriores.

A freqüência de $A n$. bellator em relação aos demais culicídeos não variou muito entre os estratos, ficando em torno de 2,5\%. Esse valor passa a ser mais importante e merece atenção diante da ausência da espécie em outros trabalhos, em áreas próximas e semelhantes. Já $A n$. cruzii tem sua freqüência relativa crescente no sentido copa-solo: $3,3 \%$ no solo, $10,7 \%$ no meio e $13,9 \%$ na copa. Porém, o grau de dominância da espécie foi menor do que o de trabalhos desenvolvidos na região: cerca de $80 \%$ em mata de encosta, e cerca de $50 \%$ em mata de planicie (FORATTINI et al 1986a; FORATTINI et al 1986b). Embora o protocolo tenha sido diferente, o estudo piloto deste trabalho incluiu visita a esses locais, descartados por dificuldades operacionais de acesso ao local, por aparente baixa densidade de anofelinos e pela relativa escassez de bromélias acessiveis no fragmento de mata, em comparação com as da Ilha Comprida. Deve-se ter cuidado na interpretação deste dado, pois a espécie pode ter sofrido redução do tamanho da população, ou pode ter se deslocado (e não desaparecido).

Embora DORVILÉ (1996) tenha apontado Kerteszia como grupo bioindicador de ambientes inalterados, é importante mencionar que este subgênero tem alta antropofilia (CORREA 1943; DEANE 1986; GUIMARÃES et al 1987; FORATTINI et al 1990) e tem sido registrado em ambiente domiciliar na proximidades de áreas de mata primitiva (RACHOU 1958, DUTRA 1996; GUIMARÃES et al 2000b). An. bellator tem sido mais freqüente em ambiente domiciliar do que An. cruzii (FORATTINI et al 1961; FORATTINI et al 1999; SANTOS 2001)

A freqüência ao ambiente domiciliar deve ser vista com cuidado, pois há situações em que, na verdade, o domicílio se encontra praticamente dentro da mata 
ou em sua margem. Descartado esse tipo de situação, a capacidade de freqüentar o ambiente domiciliar e, ao mesmo tempo, ser dominante nas matas é indissociável do alcance de vôo da espécie. CORREA et al (1961) demonstraram para An. cruzii e An. bellator alcance de vôo de cerca de $700 \mathrm{~m}$, cruzando, inclusive, braço de mar entre a Ilha Comprida e Cananéia. Não se pode descartar a influência de correntes de vento, transportando passivamente adultos em vôo e, na atualidade, transporte de adultos e imaturos por meios propiciados pelo homem

Por outro lado, a intensificação de atividades de ecoturismo incentiva a conservação de áreas de mata e admite que o homem vá até esses locais, propiciando outra via de contato entre homem e mosquitos. Deste modo, o risco de desmatamento e degradação de áreas de Mata Atlântica remanescentes é mais baixo, mas não se pode dizer o mesmo a respeito do risco epidemiológico da inserção do homem em ciclos zoonóticos de transmissão de doenças.

Particularmente na região do Vale do Ribeira, ainda é comum a freqüência humana ao ambiente de mata para atividade de extrativismo e caça. Apesar de envolver outros vetores, ANDRADE et al (1986) relataram surto epidêmico de malária por Plasmodium falciparum no oeste do Estado, com provável transmissão por An. darlingi e An. albitarsis. Os autores atribuíram a ocorrência do surto a movimentos populacionais, alertando sobre a vulnerabilidade da região e esta doença.

A região da Serra do Mar é receptiva à malária em função das altas densidades de vetores e população suscetivel, de modo que a introdução de fonte de infecção pode deflagrar surto de casos. Considerada área hipoendêmica da doença, a epidemiologia dos casos autóctones nesta região, onde os casos são atípicos, vem sendo debatida. BRANQUINHO et al (1997) encontrou An. cruzii infectados por $P$. vivax clássico e variante VK247 em São Vicente e Juquitiba, sugerindo que a forma variante do plasmódio possa explicar os casos brandos da doença na região. Nestes mesmos municipios, CURADO et al (1997) demonstraram soroprevalência de anticorpos anti-esporozoítos contra $P$. vivax e $P$. malariae/brasiliamum, e anticorpos contra formas sangüineas de $P$. vivax e $P$. basilianum, sugerindo a possibilidade de circulação de plasmódios simianos entre humanos, os quais não haviam referido acometimento por malária. 
Seguindo essa linha de investigação, CURADO (2003) encontrou alta prevalência de anticorpos contra $P$. vivax e $P$. malariae nos Parques Estaduais abertos à visitação, no Vale do Ribeira (Parque Estadual Intervales e Parque Estadual do Alto Ribeira - PETAR). Semelhantemente, nestas localidades as pessoas não haviam relatado malária. Complementando a investigação, a autora demonstrou positividade para anticorpos contra esses plasmódios em soro de macacos, porém, não conseguiu diagnosticar anofelinos infectados.

Essa malária residual e persistente na região deve ser acompanhada com atenção, pois as investigações citadas evidenciam subestimação da doença. Historicamente, a chamada bromélia-malária foi problema de saúde pública alarmante na década de 40. Especificamente na região estudada, GUARITA e COSTA (1965) relataram que em Cananéia a doença foi considerada endêmica entre 1940 e 1956, chegando a atingir $10 \%$ da população, com picos epidêmicos de dezembro a abril, causada por $P$. vivax ( $99 \%$ dos casos) e de transmissão autóctone e extradomiciliar, atribuida a $A n$. cruzii e $A n$. bellator (esporadicamente por An. albitarsis). Os autores referiram preocupação com a população vetora na Ilha Comprida, que poderia voar até o continente. Esforços da campanha antimalárica levaram à interrupção da transmissão da doença, em abril de 1964. Porém, desde o início dos anos 80 têm ocorrido casos esporádicos, autóctones, naquele município.

Se diante de medidas tão intensas como as adotadas nas décadas de 60 e 70, que incluiam destruição de bromélias e aplicação de larvicidas e inseticidas nas matas, as espécies do subgênero foram capazes de persistir na região, é possível que as populações de Kerteszia estejam se restabelecendo, já que não há mais controle específico desses mosquitos.

Apesar da especificidade desses mosquitos quanto ao criadouro, característica da espécie, larvas de Kerteszia já foram registradas em criadouros "não bromélia", demonstrando certo grau de adaptabilidade. LUZ et al (1987) encontraram larvas de $A n$. cruzii em vasos de barro, em localidade onde não existiam bromélias. FORATTINI et al (1998b) registraram An. bellator em caixa d'água na llha Comprida, onde a oferta de bromélias é grande. MARQUES (2001) estudou situação um pouco diferente, mas que requer monitoramento: estudou bromélias em gradiente ambiental, segundo impacto antrópico. Como era de se esperar, An. bellator e $A n$. 
cruzii foram encontradas em bromélias de mata, porém, como não havia sido registrado antes, a autora coletou essas larvas em bromélias de ambiente periurbano e urbano, em Ilhabela.

O'MEARA et al (2003) demonstraram diferenças na composição especifica de culicídeos em bromélias nativas e exóticas. $\mathrm{Na}$ região estudada, sul da Flórida, os pesquisadores encontraram mosquitos de espécies nativas em bromélias nativas, mas também em exóticas. Porém, mosquitos cujos criadouros típicos são outros que não bromélias, são incapazes de colonizar bromélias nativas. Possivelmente, a colonização de bromélias exóticas por mosquitos como Ae. aegypti, Ae. albopictus e $C x$. quinquefasciatus, tenha se dado em função da maior capacidade de retenção de água desses vegetais, introduzidos para fins ornamentais, com axilas grandes e regas constantes.

Diga-se de passagem, tem sido cada vez mais comum o uso de bromélias para fins ornamentais, que podem ser encontradas em grandes centros urbanos, tanto em áreas comerciais como residenciais, em ambiente interno e externo. A falta de informações sobre o uso desses vegetais como criadouros por mosquitos acaba por propagar o uso desses vegetais.

$\mathrm{Na}$ Colômbia, OLANO et al (1997) realizaram estudo entomológico para investigação de epidemiologia da malária urbana local, cujo número de casos tem aumentado recentemente. $\mathrm{O}$ estudo incluiu levantamento e adultos e imaturos Em relação a estes, foram inspecionados 469 criadouros, incluindo 27 bromélias, uma das quais foi positiva para $A n$. neivai, espécie vetora na região.

O acompanhamento do desenvolvimento das larvas coletadas, em condições de laboratório, revelou boa adaptabilidade das espécies a condições artificiais, já que os as larvas foram mantidas em água destilada e alimentada com ração para peixe, microhabitat seguramente diferente do encontrado nas bromélias. Durante os meses mais frios, as larvas tiveram desenvolvimento bastante lento, porém, geralmente com baixa mortalidade. Aliás, o transporte das larvas de llha Comprida a São Paulo, onde foram criadas, também produziu baixa mortalidade. A associação desse dado com o encontro de larvas em recipientes artificiais requer 
atenção, pois isso abre precedente para sugerir boas chances de sucesso na colonização de novos criadouros e ambientes.

Registrou-se periodo de mais de 100 dias para o desenvolvimento das larvas. Além de denotar resistência a condições desfavoráveis, o fato revelou, na verdade, a coleta de ovos nas bromélias, pois a contagem do periodo se iniciou na data da coleta, mas a água das bromélias foi mantida em laboratório por mais 13 dias, quando em algumas vezes, foram retiradas larvas de primeiro estadio. Indiretamente, isso sugere a coexistência das diferentes fases do ciclo de vida desses anofelinos. Como estratégia evolutiva, parece ser interessante cada fềmea colocar poucos ovos em diferentes bromélias, uma vez que nestes criadouros as larvas são sujeitas a predação e competição, em níveis variáveis de uma bromélia para outra. Além disso, o próprio criadouro é instável, pois depende dos níveis de precipitação para sua manutenção; pode secar, na ausência de chuva por periodos prolongados, ou pode ser "lavado" por chuvas intensas.

MAHARAJ (2003) simulou condições sazonais sob as quais construiu tábuas de vida de An. arabiensis. As temperaturas de referência são as típicas da África do Sul: $17,9^{\circ} \mathrm{C}, 23,2^{\circ} \mathrm{C}, 26,1^{\circ} \mathrm{C}$ e $21,4^{\circ} \mathrm{C}$, representando inverno, primavera, verão e outono, respectivamente. De acordo com a pesquisa, durante o inverno simulado, fềmeas grávidas não ovipuseram até que houvesse aumento da temperatura. Sabe-se que em condições de campo é possível a oviposição durante o inverno, mas deve ocorrer aumento brusco no número de ovos no início da primavera e, conseqüentemente, aumento da densidade de adultos.

No trabalho, MAHARAJ (2003) levantou a hipótese de ocorrência de discordância gonotrófica durante o inverno. No verão, apesar do aumento de competição intra-especifica por causa da alta densidade de larvas, a produção de adultos também é alta, como decorrência do número de ovos postos, ainda maior. $\mathrm{A}$ duração média do estágio larval foi de 11 a 32 dias, respectivamente, no verão e inverno. Na primavera, o número de ovos é maior do que no verão, porém, a viabilidade dos mesmos é menor. No outono, registrou-se menor número de ovos, mas a maior porcentagem de sobrevivência até a fase adulta $(85,8 \%)$. Esses dados demonstram regulação precisa do ciclo de vida da espécie estudada. Há um balanço entre longevidade e duração de ciclo gonotrófico, inversamente proporcionais. 
BAYOH e LINDSAY (2004) acompanharam o desenvolvimento de larvas de $A n$. gambiae sob temperaturas de 10 a $40^{\circ} \mathrm{C}$. A mortalidade de larvas foi alta sob temperaturas inferiores a $18^{\circ} \mathrm{C}$ e superiores a $32^{\circ} \mathrm{C}$, embora entre 14 e $20^{\circ} \mathrm{C}$ algumas larvas tenham sobrevivido por mais de 40 dias. Isso indica que pode haver manutenção da espécie em estágio larval, com desenvolvimento lento durante a estação fria, com rápido aumento da abundância de adultos logo após elevação da temperatura em decorrência da aceleração do desenvolvimento das larvas.

Evidentemente, os dados sobre desenvolvimento de larvas em laboratório apresentados aqui são empíricos e não foi possível controlar parâmetros conforme as pesquisas descritas nos parágrafos anteriores. Estudos posteriores poderão fornecer dados mais precisos sobre como a temperatura influencia o desenvolvimento de larvas de Kerteszia. Tais informações, aliadas a estudos de idade fisiológica e sobrevivência desses anofelinos em campo constituirão contribuições importantes para o entendimento da biologia dessas espécies. Sabe-se que anofelinos Kerteszia são longevos, conforme SANTOS (2001) demonstrou - 59 dias em campo, corroborando dados obtidos por FERREIRA et al (1969b): sobrevivência de $A n$. cruzii por 56 dias em campo e de An. bellator, 55 dias.

CLEMENTS (1999) assinala que condições climáticas extremas afetam o comportamento de insetos de maneira previsível. Contudo, em condições intermediárias, associações estabelecidas entre dados de campo sobre a atividade de insetos e fatores climáticos não podem ser interpretadas como relação de causa-efeito. Fatores climáticos sob os quais as larvas são sujeitas podem interferir no tamanho, sobrevivência e fertilidade do adulto, que por sua vez pode, dentro de certos limites, responder a pressões ambientais como $r$-estrategistas ou $K$-estrategistas (CLEMENTS 1992).

Além da temperatura, a precipitação é fator importante, sobretudo quando se trata e criadouros do tipo recipiente. O coeficiente de Spearman indicou correlação negativa significativa entre a chuva acumulada nos 15 dias anteriores aos de coleta e densidade de imaturos dos anofelinos estudados. De maio a setembro de 2002 os nível de precipitação acumulada em 15 dias não ultrapassaram 50mm (exceto no período anterior a 14/05/2002, com acúmulo de $77,4 \mathrm{~mm}$ de chuva). A alta umidade relativa do ar pode manter o criadouro relativamente estável, condição 
favorável ao desenvolvimento das larvas. De julho a setembro de 2002 , An. cruzii manteve densidade de aproximadamente 2 a 4 imaturos $/ 100 \mathrm{ml}$, ao passo que $A n$. bellator atingiu densidades superiores a 2 imaturos $/ 100 \mathrm{ml}$ a partir de abril, com densidade máxima registrada de 8,8 imaturos/100ml em 14/05/2002, exatamente a coleta com maior precipitação acumulada nos dias anteriores, durante o período "seco".

A associação deste dado com a correlação positiva entre densidade de An. bellator e altura de fixação das bromélias e, inversamente, correlação negativa entre densidade de $A n$. cruzii e altura, requer explicações diferentes para a correlação negativa entre chuva acumulada em periodo anterior e densidade de larvas. A maior exposição de bromélias em copa arbórea ao sol submete-as a maior variação de temperatura diária e maior taxa de evaporação nos dias quentes e, sob chuva forte, maior chance de transbordamento da água do criadouro. Talvez por esta razão, pouca chuva tenha propiciado maior densidade de $A n$. bellator, já que temperaturas mais altas tende a acelerar o ciclo das larvas.

Por outro lado, as bromélias de solo (na mata) são sombreadas e com microclima mais estável. Neste caso, chuvas fortes são parcialmente retidas nas copas das árvores, de onde caem folhas que acabam formando cobertura sobre as bromélias. Tal situação pôde ser observada durante o trabalho de campo. Após chuvas fortes, as bromélias de solo ficavam com a água bastante "suja" e com muitas folhas, condição possivelmente desfavorável ao desenvolvimento de $A n$. cruzii.

No entanto, quando se trata de utilizar essas informações para explicar os resultados de captura de adultos, surgem mais perguntas do que respostas. Se a densidade de larvas de An. cruzii foi menor do que a de $A \boldsymbol{n}$. bellator e, em laboratório as duas espécies se desenvolveram bem, pergunta-se porque a densidade de adultos desta espécie foi tão inferior ao daquela. As correlações obtidas com dados climáticos também não ajudam a esclarecer os dados.

Uma possível explicação seria o horário de captura. Contudo, o horário estabelecido baseou-se em FORATTINI et al (1986a) que demonstram claramente o mesmo horário de atividade para An. cruzii e An. bellator, embora com diferenças acentuadas entre suas densidades, também com claro predomínio daquela. No crepúsculo matutino, An. bellator apresentou pico um pouco maior, segundo a média 
de Williams. É possivel que a densidade desta espécie oscile menos ao longo do dia, mantendo-se mais elevada do que a de $A n$. cruzii em durante a manhã, tarde, fim de noite e madrugada. Apesar da dificuldade operacional, essa questão só poderia ser respondida com novo trabalho de captura de 24 horas.

Direcionando a discussão para a distribuição vertical de imaturos, a questão inicial que norteou esta pesquisa era a aparente não correspondência entre a densidade de adultos e imaturos das espécies de Kerteszia. Os adultos são abundantes e freqüentemente se destacam entre os culicídeos em áreas de mata. Estudos de criadouros (que, aliás, são escassos) demonstram baixas freqüências relativas para larvas deste subgênero e geralmente se referem a bromélias de solo. A hipótese era de que as larvas pudessem estar distribuidas em gradiente vertical.

VELOSO (1956) colheu 120000 bromélias em matas nos Estados do Paraná e Rio Grande do Sul, encontrando positividade de $20 \%$ para o subgênero Kerteszia, totalizando 60000 larvas, cujo desenvolvimento foi acompanhado em laboratório até a fase adulta ( $20 \%$ de emergência de adultos). $\mathrm{O}$ autor considerou como bromélias de "pequeno porte" aquelas cujo volume de água coletado foi de até $300 \mathrm{ml}$, e "grandes" aquelas com mais de $1000 \mathrm{ml}$. Comparando-se os dados dessa pesquisa com os apresentados aqui, não existem bromélias de grande porte na região estudada. $\mathrm{O}$ autor concluiu que não há relação espécie-específica entre bromélias e anofelinos, e que $A n$. cruzii parece ser indiferente ao tamanho e posição das bromélias, ao passo que An. bellator parece estar mais associado a bromélias maiores e expostas ao sol. $\mathrm{O}$ autor encontrou maiores densidades larvárias em bromélias de grande porte, apesar delas serem bem menos numerosas do que as pequenas. Evidentemente, os números absolutos de bromélias examinadas e de larvas coletadas impressionam bastante, como a própria densidade de bromélias nas áreas de mata. Todavia, vale lembrar que o trabalho foi desenvolvido em período anterior ao processo de desbromelização das matas, estratégia do Programa de Erradicação da Malária.

No presente trabalho, como foi constituído lote de bromélias por estrato, não é possivel dizer com exatidão a positividade para Culicidae ou Kerteszia por bromélia, mas sim por estrato. Alternativamente, utilizou-se a densidade larvária 
por volume de água aspirada e a freqüência relativa, de modo a permitir comparações entre os estratos e coletas, entre os quais houve variação de número de bromélias acessadas e volume aspirado

A associação entre de An. bellator e bromélias mais expostas ao sol foi corroborada por este estudo. Esta espécie apresentou correlação positiva com a altura de fixação de bromélias, tendo sido registrada com maiores densidades em bromélias epifitas de estratos mais elevados. $O$ estrato de $[11,12] \mathrm{m}$ deixou isso evidente: as bromélias continham quase sempre mais de $500 \mathrm{ml}$ cada (consideradas grandes quanto comparadas com as demais) e bem expostas ao sol. A ocorrência desta espécie nas bromélias da restinga também confirma esse dado.

Em Cananéia, FORATTINI et al (1961) trabalharam com lotes de 10 bromélias, registrando $58,3 \%$ de positividade, com densidades de 2,6 An. cruzii e 1,3 An. bellator por lote. Devido às diferenças de protocolo de campo, a comparação desses resultados com os aqui obtidos é dificil, mas como os trabalhos são da mesma região, é possível fazer algumas inferências. $O$ volume médio geral por bromélia na Ilha Comprida foi de aproximadamente $130 \mathrm{ml}$. Trabalhou-se com densidade de imaturos por $100 \mathrm{ml}$. Se considerarmos que os lotes de 10 bromélias possam ser equivalentes a $1000 \mathrm{ml}$, então, pode-se estimar, grosseiramente, que a densidade de larvas por $100 \mathrm{ml}$ em Cananéia tenha sido de 0,26 para $A n$. cruzii e 0,13 para $A n$. bellator. Estes valores não diferem muito dos obtidos na Ilha Comprida (ver Figura 15). Considerando o periodo total de estudo, as densidades por estrato e por espécie foram inferiores a 1 . Na avaliação mês a mês, a densidade máxima registrada foi de 6,25 para An. bellator e 4 para An. cruzii.

Próximo a Cananéia, em Peruibe, SETO (1992) encontrou 58,5\% (69 bromélias) de positividade para Kerteszia, representado por An. cruzii e An. homunculus. A autora pesquisou 492 bromélias individualizadas, a até $12 \mathrm{~m}$ de altura, das quais aspirou cerca de $30000 \mathrm{ml}$, volume que continha 2160 larvas de mosquitos. $\mathrm{O}$ volume médio geral foi de $62,5 \mathrm{ml} /$ bromélia. $\mathrm{O}$ máximo e o mínimo registrados foram $485 \mathrm{ml}$ e $10 \mathrm{ml}$, respectivamente. Nesta pesquisa, embora se tenha trabalhado com lotes de bromélias, os volumes médios foram semelhantes: mínimo médio de $12,5 \mathrm{ml}$ e máximo de $650 \mathrm{ml} /$ bromélia. Na Ilha Comprida, as larvas de Kerteszia tiveram praticamente a mesma freqüência relativa registrada em Peruíbe $-6,5 \%$ 
nesta, e 6,4\% naquela. No entanto, os valores absolutos diferiram consideravelmente, tendo sido coletadas 140 larvas do subgênero em Peruibe e 2180 na Ilha Comprida. Da mesma forma que encontrado na presente pesquisa, SETO (1992) não encontrou correlação entre volume médio por bromélia e número de larvas de mosquitos.

Em Ilhabela, litoral norte do Estado de São Paulo, MARQUES (2001) trabalhou com bromélias de solo, individualizadas, estabelecendo número limite de vegetais aspirados (30 os cinco primeiros meses e 50 ao longo de um ano, quinzenalmente), em ambiente de mata, periurbano e urbano. No total, foram coletadas 31134 larvas, sendo 5572 em bromélias da mata. As comparações discutidas aqui se referem ao ambiente de mata em Ilhabela e às bromélias de solo na mata em Ilha Comprida. Em Ilhabela a frequêencia relativa de $A$ n. cruzii foi de $2,9 \% \mathrm{e}$ a de An. bellator, 0,04\%, valores inferiores aos registrados na Ilha Comprida, onde apenas em bromélias de solo foram coletadas 8438 larvas, sendo que 4,7\% delas pertenciam a $A n$. cruzii e $0,8 \%, A n$. bellator.

Em relação ao volume de água, a autora concluiu que $A n$. cruzii ocorreu em bromélias com capacidade volumétrica igual ou inferior a $170 \mathrm{ml}$. Esse valor é condizente com volumes registrados em bromélias deste estudo. Quanto à estimativa de densidade, a autora trabalhou com número médio de larvas por bromélia, tendo obtido os valores 1,81 larvas de An. cruzii por bromélia na mata, 1,45 na ambiente periurbano e 1,03 no ambiente urbano. Esses valores diferem estatisticamente entre si e são relativamente altos, se comparados com os registrados por SETO (1992) e FORATTINI et al (1961). Isso sem mencionar a importância do registro da espécie em ambiente urbano.

Se por um lado o número de larvas coletadas por MARQUES (2001) foi inferior ao obtido na Ilha Comprida, por outro, a riqueza de espécies de culicideos na Ilhabela foi maior; na Ilha Comprida (bromélias de solo, na mata) foram identificadas 18 espécies e na Ilhabela, 37. Nesta localidade, Cx. ocellatus foi a espécie mais freqüente e contribuiu com $31 \%$ da fauna culicidea. Outra espécie que se destacou foi $C x$. imitator, com freqüência de $14,7 \%$. As demais espécies não atingem a freqüência de $10 \%$. Na Ilha Comprida, o padrão de diversidade difere em algumas características. Além da riqueza de espécies, chamou a atenção a ausência de $C x$. ocellatus, que não foi encontrado nem em bromélias de solo, nem em epífitas. Nesta 
localidade, a espécie mais freqüente - $C \boldsymbol{x}$. próximo a neglectus (com predomínio de Cx. microphyllus/aphylactus) - teve o mesmo grau e dominância, 31\%. Além desta, $C x$. grupo Imitator (com predomínio de $C x$. imitator) teve frequência de $19,5 \%$. Aliás, estes dois grupos dominaram em praticamente todos os estratos. $\mathrm{O}$ grupo Imitator chegou a representar quase $50 \%$ das larvas coletadas nos estratos $[6,7[\mathrm{~m} \mathrm{e}[9,10[\mathrm{~m}$.

Outra diferença importante, sobretudo do ponto de vista epidemiológico, foi o registro de Ae. albopictus nas bromélias de mata na Ilhabela. LOUNIBOS (2002) cita este mosquito como exemplo de invasor bem sucedido e alerta para o fato de que as recentes invasões por mosquitos têm resultado do transporte de imaturos pelo homem. Na Ilha Comprida esta espécie não foi encontrada em bromélias. Houve apenas o registro de uma fềmea, capturadas em armadilha CDC próximo ao solo. Por ter sido evento único, é possivel que esta fêmea tenha sido transportada de carro, pela própria equipe, durante os trabalhos de campo, já que nas proximidades, fora da área de mata é espécie bastante comum. Sabe-se que esta espécie é diurna, o que poderia explicar sua ausência nas capturas. Contudo, sua freqüência à mata da região poderia ser confirmada pelo encontro de imaturos em bromélias, fato não registrado (o que não significa que não possa ter ocorrido). 


\section{CONCLUSÕES}

Em relação à população adulta de Kerteszia, o estudo revelou maior densidade de An. cruzii do que de An. bellator. Houve correlação entre a densidade desses anofelinos e temperatura máxima, como era de se esperar, mas não com a chuva acumulada nos dias anteriores. Houve também correlação entre amplitude térmica diária e densidade de An. bellator, mas não de $A n$. cruzii. É possível que essa diferença expresse mais relação numérica e estatística, do que biológica.

Confirmou-se o comportamento acrodendrófilo de ambas as espécies, cujas densidades foram significativamente mais altas na copa das árvores (12m), embora tenham sido freqüentes e constantes próximo ao solo e a $6 \mathrm{~m}$.

Em relação aos imaturos, houve correlação negativa entre densidade de An. bellator e An. cruzii e precipitação nos dias anteriores. Chuvas muito intensas, de fato, devem fazer transbordar a água (e conseqüentemente as larvas) de bromélias epífitas, enquanto que as bromélias de solo podem receber menos água proveniente da chuva, mas recebem grande quantidade de folhas caidas das copas, que podem aumentar o teor de matéria orgânica e estabelecer condições menos favoráveis ao desenvolvimento de larvas desses anofelinos

O estudo em gradiente vertical revelou maiores densidades de $A n$. cruzii em bromélias próximas ao solo, enquanto que para An. bellator, verificou-se correlação positiva entre densidade e altura das bromélias. Este fato pode estar associado à maior exposição ao sol, o que poderia explicar também a ocorrência de An. bellator em bromélias de restinga, ainda que em baixas densidades.

Considerando os imaturos independentemente de gradiente vertical, a densidade de An. bellator foi mais elevada do que a de An. cruzii durante o ano todo, situação inversa ao que ocorreu com os adultos. Os dados deste trabalho não são suficientes para explicar tal diferença. 
Bromélias da praia produziram muitas larvas de culicídeos, mas não parece ser ambiente favorável às espécies de Kerteszia. Tanto neste ambiente quanto na mata, em todos os estratos, houve predomínio de espécies do subgênero Microculex, que parecem ser indiferentes quanto à estratificação vertical e volume de água nas bromélias, já que não houve correlação entre volume médio de água por bromélia e densidade de imaturos de Culicidae.

A riqueza de espécies de Culicidae em bromélias não indicou a presença de outras espécies além de importância para a saúde humana, além de $A n$. bellator e An. cruzii. Espécies de Sabethini, que podem estar envolvidas na transmissão de arboviroses, estiveram presentes em densidade baixas e sem padrão bem definido de distribuição vertical. 


\section{CONSIDERAÇÕES FINAIS}

A estratificação vertical, como forma de amostragem de fauna culicídea, mostrou-se importante para o conhecimento das espécies, permitindo a obtenção de espécies com freqüência maior em estrato arbóreo. $O$ uso de armadilhas tipo CDC permitiu capturas simultâneas e padronizadas em pontos diferentes, e o rendimento obtido mediante o uso de gelo seco foi até superior aos obtidos em estudos que empregaram outras técnicas, em horários semelhantes.

A representatividade de $A n$. bellator e An. cruzii, expressa em porcentagem, revelou-se inferior à registrada em estudos anteriores, porém, em números absolutos, a quantidade de mosquitos capturados neste estudo foi grande. Portanto, não se pode afirmar que a população de Kerteszia diminuiu nos últimos anos. $\mathrm{Na}$ verdade, essas espécies resistiram a um ambiente que sofreu medidas drásticas de controle, na tentativa de eliminá-las. Deste modo, é possivel que essas populações estejam ainda se restabelecendo no ambiente, podendo aumentar ainda sua abundância.

Embora não fosse objetivo do trabalho, a criação de larvas de Kerteszia em laboratório revelou que as espécies se desenvolvem bem em condições artificiais, porém nos meses mais frios, parecem ter praticamente parado $o$ desenvolvimento, chegando a levar até cerca de 100 dias para a emergência do adulto. A mortalidade foi baixa $\mathrm{e}$, ainda que em campo isso seja pouco provável, a aparente não correspondência entre as populações de larvas e adultos pode ser explicada pela associação deste dado a outras características de Kerteszia. O desenvolvimento lento das larvas produz adultos na mesma velocidade, porém a alta longevidade nesta fase sobrepõe "gerações" desses anofelinos, cujas fềmeas parecem pôr poucos ovos por bromélia. A alta densidade desses vegetais nas áreas de mata pode compensar a baixa densidade das larvas por bromélia. Certamente em condições naturais, vários fatores podem acelerar o desenvolvimento de ovos, aumentar as taxas de eclosão e acelerar o desenvolvimento de larvas, o que explicaria aumentos súbitos de densidade. Resta saber quais seriam esses fatores e como atuam. 
A preservação legal de áreas de mata, o incremento de atividades de ecoturismo, a verificação da presença de Kerteszia em bromélias de ambiente urbano e até em criadouros artificiais, a alta densidade desses mosquitos e a persistência de transmissão de casos autóctones de malária (ainda que com baixa incidência) justificam a importância de monitoramento desses anofelinos. 


\section{REFERÊNCIAS}

Andrade JCR, Anjos CFD, Wanderley DMV, Alves MJCP, Campos PC. Foco de malária no Estado de São Paulo (Brasil). Rev Saúde Pública. 1986; 20(4):323-6.

Bayoh MN. Lindsay SW. Temperature-related duration of aquatic stages of the Afrotropical malaria vector mosquito Anopheles gambiae in the laboratory. Med Vet Entomol 2004; 18:174-9

Branquinho MS, Marrelli MT, Curado I, Natal D, Barata JMS, Tubaki R et al. Infecção do Anpheles (Kerteszia) cruzii por Plasmodium vivax e Plasmodium vivax variante VK247 nos municipios de São Vicente e Juquitiba, São Paulo. Rev Panam Salud Publica; 1997 2(3): 189-93.

Carvalho-Pinto, Lourenço-de-Oliveira R. Isoenzimatic analysis of four Anopheles (Kerteszia) cruzii (Diptera: Culicidae) populations of Brazil. Mem Inst Oswaldo Cruz 2004, 99(5):471-5

Clements AN. The biology of mosquitoes vol 1- Development, nutrition and reproduction. London: Chapman \& Hall; 1992.

Clements AN. The biology of mosquitoes vol 2- Sensory reception and behaviour. London: Chapman \& Hall; 1999.

Consoli RAGB, Lourenço-de-Oliveira R. Principais mosquitos de importância sanitária no Brasil. Rio de Janeiro: Editora Fiocruz; 1994.

Correa RR. Os vetores de malária no Estado de São Paulo. Arq Hyg Saúde Pública $1943,19: 119-32$.

Correa RR, Ramalho GR. Revisão de Phoniomyia. Folia Clin Biol 1956; 25(1/6):460

Correa RR, Forattini OP, Guarita OF, Rabello EX. Observações sobre o vòo do Anopheles (Kerteszia) cruzii e do $A$. (K.) bellator, vetores de malária (Diptera, Culicidae). Arq Hig Saúde Pública 1961; 26:333-42.

Cotgreave $P$, Hill MJ, Middleton DAJ. The relationship between body size and population size in bromeliad tank faunas. Biol $\mathbf{J}$ Linnean Soc 1993; 49:367-80.

Curado I, Duarte AMRC, Lal AA, Oliveira SG, Kloetzel JK. Antibodies anti bloodstream and circumsporozoite antigens (Plasmodium vivax and Plasmodium malaria P.brasiliamum) in áreas of very low malaria endemicity in Brazil. Mem Inst Oswaldo Cruz 1997; 92:235-43. 
Curado I. Estudo epidemiológico sobre a malária humana e simiana e infecção de anofelinos em áreas de baixa endemicidade no Estado de São Paulo. São Paulo; 2003. [Tese de Doutorado - Faculdade de Saúde Pública da Universidade de São Paulo]

Dajoz R. Ecologia geral. Trad. Guimarães FM. Petrópolis: Ed. Vozes/Ed. da USP; 1973.

Davis JR, Hall T, Chee EM, Majala A, Minjas J. Shiff CJ. Comparison of sampling anopheline mosquitoes by light-trap and human-bait collections indoors at Bagamoyo, Tanzania. Med Vet Entomol 1995; 9:249-55.

Deane LM, Deane MP, Ferreira Neto J. Estúdios sobre la transmision de la malaria simica y sobre uma infeccion natural del hombre por Plasmodium simium en el Brasil. Bol Oficina Sanitária Panamericana 1967; 8(2):100-5.

Deane LM, Ferreira Neto JA, Deane MP, Silveira IPS. Anopheles (Kerteszia) cruzii, a natural vector of the monkey malaria parasites, Plasmodium simium and Plasmodium brasilianum. Tans R S Trop Méd Hyg 1970; 64:647.

Deane LM, Deane MP, Ferreira Neto J, de Almeida FB. On the transmission of simian malaria in Brazil. Rev Inst Med Trop São Paulo 1971; 13(5):311-9.

Deane LM, Ferreira Neto JA, Lima MM. The vertical transmission of Anopheles (Kerteszia) cruzii in a forest in southern Brazil suggests that human cases of malaria of simian origin might be expected. Mem Inst Oswaldo Cruz 1984; 79:461-3.

Deane LM. Malaria vectors in Brazil. Mem Inst Oswaldo Cruz 1986; 81(suppl.II):5-14. [Intern Symp on Malaria].

Deane LM. Malaria studies and control in Brazil. Am J Trop Med Hyg 1988; 38:223-30.

Dorvillé LFM. Mosquitoes as bioindicators of forest degradation in southeastern Brazil, a statistical evaluation of published data in the literature. Stud Neotrop Fauna \& Environm 1996; 31:68-78.

Dutra AP, Natal D, Tubaki RM, Barata JMS, Menezes RMT, Urbinatti PR, Costa AIP. Mosquitos (Diptera, Culicidae) da Reserva Estadual de Pedro de Toledo (Juquitiba, SP, Brasil). Rev Bras Ent 1996; 40(3/4):375-8.

Ferreira E, Correa RR, Tomich A, Sá FT. Estudo sobre o vôo do Anopheles (Kerteszia) cruzii e do Anopheles (Kerteszia) bellator em Guaratuba, litoral do Estado do Paraná, Brasil. Rev Bras Malariol Doenças Trop 1969a; 21:819-22.

Ferreira E, Castro Filho J, Tomich A, Sá FT. Estudo da longevidade do Anopheles (Kerteszia) cruzii e do Anopheles (Kerteszia) bellator em condições naturais. Rev Bras Malariol Doenças Trop 1969b; 21:823-7. 
Forattini OP, Correa RR, Rabello EX, Guarita O. Algumas observações sobre a densidade de anofelinos Kerteszia no Estado de São Paulo, Brasil. Arq Hig e Saúde Pública 1961; 26:249-56.

Forattini OP, Lopes OS, Rabello EX. Investigações sobre o comportamento de formas adultas de mosquitos silvestres no Estado de São Paulo, Brasil. Rev Saúde Pública 1968; 2:111-73.

Forattini OP, Gomes AC, Galati EAB, Rabello EX, Iverson LB. Estudos ecológicos sobre mosquitos Culicidae no Sistema Serra do Mar, Brasil. 1 - Observações no ambiente extradomiciliar. Rev Saúde Púbica 1978; 12:297-325.

Forattini OP, Gomes AC, Natal D, Santos JLF. Observações sobre a atividade de mosquitos Culicidae em mata primitiva da encosta no Vale do Ribeira, São Paulo, Brasil. Rev Saúde Pública 1986a; 20:1-20.

Forattini OP, Gomes AC, Natal D, Santos JLF. Observações sobre a atividade de mosquitos Culicidae em matas primitivas de planície e perfis epidemiológicos de vários ambientes no Vale do Ribeira, São Paulo, Brasil. Rev Saúde Pública 1986b; 20:178-203.

Forattini OP, Gomes AC, Santos JLF, Kakitani I, Marucci D. Frequência ao ambiente humano e dispersão de mosquitos Culicidae em área adjacente à mata atlântica primitiva da planície. Rev Saúde Pública 1990; 24:101-7.

Forattini OP, Kakitani I, Massad E, Gomes AC. Studies on mosquitoes (Diptera: Culicidae) and anthropic environment. 1 - parity of blood seeking Anopheles (Kerteszia) in South-Eastern Brazil. Rev Saúde Pública 1993; 27:1-8.

Forattini OP, Kakitani I, Massad E, Marucci D. Studies on mosquitoes (Diptera: Culicidae) and anthropic environment. 11 - biting activity and blood-seeking parity of Anopheles (Kerteszia) in South-Eastern Brazil. Rev Saúde Pública 1996; 30:10714.

Forattini OP, Massad E. Culicidae vectors and anthropic changes in a southern Brazil natural ecosystem. Ecosyst Health 1998; 4(1):9-19.

Forattini OP, Marques GRAM, Kakitani I, Brito M, Sallum MAM. Significado epidemiológico dos criadouros de Aedes albopictus em bromélias. Rev Saúde Pública 1998a; 32:186-8

Forattini OP, Kakitani I, Marques GRAM, Brito M. Formas imaturas e anofelíneos em recipiente artificiais. Rev Saúde Pública 1998b; 32:189-91.

Forattini OP. Mosquitos Culicidae como vetores emergentes de infecções. Rev Saúde Pública 1998; 32:497-502. 
Forattini OP, Kakitani I, Santos RLC, Ueno HM, Kobayashi KM. Role of Anopheles (Kerteszia) bellator as malaria vector in southern Brazil (Diptera: Culicidae). Mem Inst Oswaldo Cruz 1999; 94:715-8.

Forattini OP e Marques GRAM. Nota sobre o encontro de Aedes aegypti em bromélias. Rev Saúde Pública 2000; 34:543-4.

Forattini OP, Kakitani I, Santos RLC, Kobayashi KM, Ueno HM, Fernandez Z. Potencial sinantrópico de mosquitos Kerteszia e Culex (Diptera: Culicidae) no Sudeste do Brasil. Rev Saúde Pública 2000; 34:565-9.

Forattini OP. Culicidologia Médica vol.2: identificação, biologia e epidemiologia. São Paulo: Edusp, 2002.

Fundação Sistema Estadual de Análise de Dados - SEADE. Informações municipais - perfil municipal. Disponivel em: URL: <http:www. seade.gov.nr/perfil/index.html>. [2004 Ago 20].

Ghiteko AK, Lindsay SW, Confalonieri EU, Patz A .Climate change and vectorborne diseases: a reagional analysis. Bull WHO 2000; 78(9):1136-47.

Gomes AC, Forattini OP, Natal D. Composição e atividade de mosquitos Culicidae. Emprego de armadilha CDC no Vale do Ribeira, Estado de São Paulo, Brasil. Rev Saúde Pública 1987; 21(5):363-70.

Guarita OF, Costa FDA. Interrupção da transmissão da malária no município de Cananéia. Arq Hig Saúde Pública 1965;30/1(103/10):47-58.

Guimarães EA, Arlé M, Machado RNM. Mosquitos no Parque Nacional da Serra dos Órgãos, Estado do Rio de Janeiro, Brasil. II. Distribuição vertical. Mem Inst Oswaldo Cruz 1985; 80:171-85.

Guimarães AE, Arlé M, Machado RNM. Mosquitos no Parque Nacional da Serra dos Orgãos, Estado do Rio de Janeiro, Brasil. IV. Preferência Alimentar. Mem Inst Oswaldo Cruz 1987; 82:277-85.

Guimarães AE, de Mello RP, Lopes CM, Gentile C. Ecology of mosquitoes (Díptera: Culicidae) in áreas of Serra do Mar State Park, State of São Paulo, Brazil. I monthly frequency and climatic factors. Mem Inst Oswaldo Cruz 2000a; 95(1):116.

Guimarães AE, Gentile C, Lopes CM, Mello RP. Ecology of mosquitoes (Diptera: Culicidae) in areas of Serra do Mar State Park, State of São Paulo, Brazil. II - habitat distribution. Mem Inst Oswaldo Cruz 2000b; 95(1):17-28.

Hii JLK, Smith T, Mai A, Ibam E, Alpers MP. Comparison between anopheline mosquitoes (Diptera: Culicidae) caught using different methods in a malaria endemic area of Papua New Guinea. Bull Entomol Res 2000; 90:211-9 
Judd DD. Review of a bromeliad-ovipositing lineage in Wyeomyia and the resurrection of Hystatomyia (Diptera: Culicidae). Annals Entomol Soc Am 1998; 91:572-89.

Lane J. Neotropical Culicidae, vol.II. São Paulo: Universidade de São Paulo; 1953.

Lounibos LP. Invasions by insect vectors of human disease. Annu Rev Entomol 2002; 47:233-66.

Luz E, Consolim J, Vieira AM, Borba AM. Alguns aspectos epidemiológicos da persistência de transmissão de malária no litoral paranaense. I - Idade fisiológica de Anopheles cruzii (Diptera: Culicidae). Arq Biol Tecnol 1979; 22: 63-88.

Luz E, Consolim J, Barbosa OC, Torres PB. Larvas de Anopheles (subgênero Kerteszia) Theobald 1905 encontradas em criadouros artificiais, no Estado do Paraná, Brasil. Rev Saúde Pública 1987; 21:466-8.

Maharaj R.Life tabel characteristics of Anopheles arabiensis (Diptera:Culicidae) under simulated seasonal conditions. J Med Entomol 2003; 40 (6):737-42.

Maretti CC, Filet M. Ilha Comprida: um desafio ao planejamento ambiental. Ambiente 1988; 2:66-73.

Marques GRAM. Aedes albopictus e outros mosquitos (Diptera: Culicidae) em bromélias terrestres em Ilhabela, litoral do Estado de São Paulo, Brasil. São Paulo; 2001 [Tese de Doutorado - Faculdade de Saúde Pública da Universidade de São Paulo].

Montes J. Levantamento da fauna Culicidae (Diptera) utilizando armadilha luminosa CDC-CD , no Parque Estadual da Serra da Cantareira, Estado de São Paulo. São Paulo, 2003. [Dissertação de mestrado - Faculdade de Saúde Pública da Universidade de São Paulo].

Olano V, Carrasquilla G, Méndez F. Transmisión de la malaria urbana em Buenaventura, Colômbia: aspectos entomológicos. Rev Panam Salud Publica 1997; 1(4):287-94

O'Meara GF, Cutwa MM, Evans Jr LF. Bromeliad-inhabiting mosquitoes in south Florida: native and exotic plants differ in species composition. J Vector Ecol 2003; 28(1):37-46.

Perry DR. A method of access into de crowns of emergent and canopy trees. Biotropica 1978; 10(2):155-7

Rachou RG. Anofelinos do Brasil: comportamento das espécies vetoras de malária. Rev Bras Malariol Doenças Trop 1958; 10:145-81. 
Rachou RG, Lima MM, Ferreira Neto JA, Martins CM. Alguns dados sobre o comportamento de mosquitos de Ponta Grossa (Florianópolis, Santa Catarina). Rev Bras Malariol Doenças Trop 1958; 10:417-27.

Reinert JF. New classification for the composite genus Aedes (Díptera: Culicidae: Aedini), elevation of subgenus Ochlerotatus to generic rank, reclassification of the other subgenera, and notes on certain subgenera and species. J Am Mosq Control Assoc 2000; 16(3):175-88.

Reinert JF. Revised list of abbreviations for genera and subgenera of Culicidae (Diptera) and notes on generic and subgeneric changes. J Am Mosq Control Assoc $2001 ; 17(1): 51-5$.

Reisen WK, Meyer RP, Cummings RF, Delgado O. Effects of trap design and $\mathrm{CO}_{2}$ presentation on the measurement of adult mosquito abundance using centers for disease control-style miniature ligh traps. J Am Mosq Control Assoc 2000; 16(1):13-8.

Richardson BA. The bromeliad microcosm and the assessment of faunal diversity in a neotropical forest. Biotropica 1999; 31(2):321-36.

Richardson BA, Rogers C, Richardson MJ. Nutrients, diversity, and community structure of two phytotelm systems in a lower montane forest, Puerto Rico. Ecol Entomol 2000; 25:348-56.

Rubio-Palis Y, Curtis CF. Evaluation of different methods of catching anopheline mosquitoes in western Venezuela. J Am Mosq Contol Assoc 1992; 8(3):261-7

Rubio-Palis Y. Evaluation of light traps combined with carbon dioxide and 1-octen3-ol to collect anophelines in Venezuela. J Am Mosq Control Assoc 1996; 12(1):91-6.

Sallum MAM, Forattini OP. Review of the Spissipes section fo Culex (Melanoconion). J. Am Mosq Control Assoc 1996; 12(3):517-600.

Santos RLC. Medida da capacidade vetorial de Anopheles albitarsis e de Anopheles (Kerteszia) da região Sudeste do Brasil. São Paulo; 2001. [Tese de Doutorado - Faculdade de Saúde Pública da Universidade de São Paulo].

Service MW. A critical review of procedures for sampling populations of adult mosquitoes. Bull Ent Res 1977; 67:343-82.

Service MW. Mosquito ecology - field sampling methods. 2nd ed. London: Elsevier Applied Science; 1993.

Seto MI. Ocorrência de mosquitos (Diptera: Culicidae) em bromélias da localidade de Aldeia dos Índios, área endêmica de malária, no município de Peruíbe (SP), no periodo de julho de 1985 a julho de 1987. São Paulo; 1992. 
[Dissertação de Mestrado - Instituto de Ciências Biomédicas da Universidade de São Paulo]

Siegel S. Estatística não-paramética para as ciências do comportamento. Trad. Farias AA. São Paulo: McGraw-Hill do Brasil; 1975.

Soriano BMA, Galdino S. Análise da distribuição da freqüência mensal de precipitação para a sub-região da Nhecolândia, Pantanal, Mato Grosso do Sul, Brasil. Bol Pesq 2002; 34-1-23.

Veloso HP, Moura JV, Klein RM. Delimitação ecológica dos anofelinos do subgênero Kerteszia na região costeira do sul do Brasil. Mem Inst Oswaldo Cruz $1956 ; 54: 517-41$.

Veloso HP. Considerações gerais sobre os biótopos e habitats dos anofelineos do sub-gênero Kerteszia. Mem Inst Oswaldo Cruz 1958; 56:163-79.

Wilkerson RC, Peyton EL. The Brazilian malaria vector Anopheles (Kerteszia) cruzii: life stages and biology (Diptera: Culicidae). Mosq Syst 1991; 23(2):110-22.

Zavortink TJ. Mosquito studies (Diptera, Culicidae). XXIX A review of the subgenus Kerteszia of Anopheles. Contrib Amer Ent Inst 1973; 9:1-54 
Anexos 


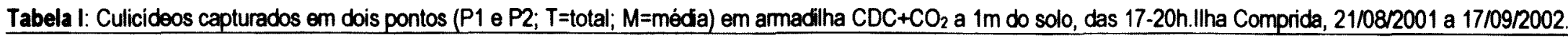

\begin{tabular}{|c|c|c|c|c|c|c|c|c|c|c|c|c|c|c|c|c|c|c|c|c|c|c|c|c|}
\hline \multirow[b]{2}{*}{ ESPÉCIE } & \multicolumn{4}{|c|}{$21 / 08101$} & \multicolumn{4}{|c|}{$04 / 09 / 01$} & \multicolumn{4}{|c|}{$18 / 09 / 01$} & \multicolumn{4}{|c|}{$09 / 10 / 01$} & \multicolumn{4}{|c|}{$23 / 10 / 01$} & \multicolumn{4}{|c|}{$06 / 11 / 01$} \\
\hline & P1 & $\mathrm{P} 2$ & $T$ & $M$ & P1 & P2 & $T$ & $M$ & $P 1$ & P2 & $T$ & $M$ & $\mathrm{P1}$ & $\mathrm{P} 2$ & $T$ & $M$ & P1 & P2 & $T$ & $M$ & $\mathrm{P} 1$ & P2 & $T$ & $M$ \\
\hline An.bellator & 0 & 1 & 1 & 0,5 & 1 & 0 & 1 & 0,5 & 0 & 1 & 1 & 0.5 & 0 & 1 & 1 & 0,5 & 1 & 7 & 8 & 4 & 17 & 3 & 20 & 10 \\
\hline An.cruzii & 0 & 2 & 2 & 1 & 20 & 0 & 20 & 10 & 1 & 9 & 10 & 5 & 1 & 0 & 1 & 0,5 & 8 & 11 & 19 & 9,5 & 31 & 7 & 38 & 19 \\
\hline An.(Ker.)sp danificado & 0 & 0 & 0 & 0 & 4 & 0 & 4 & 2 & 0 & 2 & 2 & 1 & 0 & 0 & 0 & 0 & 0 & 0 & 0 & 0 & 2 & 1 & 3 & 1,5 \\
\hline An.mediopunctatus/costaifforattinll & & 1 & 1 & 0.5 & & & 0 & 0 & & & 0 & 0 & & & 0 & 0 & 2 & & 2 & 1 & 1 & & 1 & 0,5 \\
\hline Ae.albopictus & & & 0 & 0 & & & 0 & 0 & & & 0 & 0 & & & 0 & 0 & & & 0 & 0 & & & 0 & 0 \\
\hline Ae.fulvus & & & 0 & 0 & & & 0 & 0 & & & 0 & 0 & & & 0 & 0 & & & 0 & 0 & & & 0 & 0 \\
\hline Ae.hortator & & & 0 & 0 & & & 0 & 0 & & & 0 & 0 & & & 0 & 0 & 1 & 6 & 7 & 3,5 & 1 & 2 & 3 & 1,5 \\
\hline Ae.sceppularis & & & 0 & 0 & 1 & & 1 & 0.5 & & 1 & 1 & 0,5 & & & 0 & 0 & 2 & 8 & 10 & 5 & 2 & 1 & 3 & 1.5 \\
\hline Ae.serratus & & & 0 & 0 & & & 0 & 0 & & 1 & 1 & 0,5 & & & 0 & 0 & & & 0 & 0 & & & 0 & 0 \\
\hline Ae.serratus/nubilus & & 3 & 3 & 1,5 & 1 & & 1 & 0,5 & & 3 & 3 & 1,5 & 1 & 1 & 2 & 1 & 9 & 11 & 20 & 10 & 2 & & 2 & 1 \\
\hline Ae.sp danificado & & & 0 & 0 & & & 0 & 0 & & & 0 & 0 & & & 0 & 0 & & & 0 & 0 & & & 0 & 0 \\
\hline Coquillettidia & & & 0 & 0 & 6 & 2 & 8 & 4 & 20 & 51 & 71 & 35,5 & 11 & 29 & 40 & 20 & 28 & 1874 & 1902 & 951 & 469 & 501 & 870 & 485 \\
\hline$C x .(M c x) s p$. & & & 0 & 0 & & & 0 & 0 & & & 0 & 0 & & & 0 & 0 & 1 & & 1 & 0,5 & & & 0 & 0 \\
\hline CX. aureonotatus & & & 0 & 0 & & & 0 & 0 & & 1 & 1 & 0,5 & & & 0 & 0 & & & 0 & 0 & & & 0 & 0 \\
\hline Cx.nbeirensis & & 2 & 2 & 1 & 1 & & 1 & 0,5 & 2 & 2 & 4 & 2 & & 2 & 2 & 1 & 2 & & 2 & 1 & & 1 & 1 & 0,5 \\
\hline Cx.sacchettee & 3 & 1 & 4 & 2 & 4 & 2 & 6 & 3 & 30 & 19 & 49 & 24.5 & 2 & 1 & 3 & 1,5 & 12 & 6 & 18 & 9 & 8 & 1 & 9 & 4.5 \\
\hline Cx.spissipes & & & 0 & 0 & & & 0 & 0 & & & 0 & 0 & & & 0 & 0 & & & 0 & 0 & & & 0 & 0 \\
\hline Cx.(Mel.)grupo Atratus & & & 0 & 0 & & & 0 & 0 & & & 0 & 0 & & & 0 & 0 & 1 & 1 & 2 & 1 & & & 0 & 0 \\
\hline CX.(Mel.)grupo Pilosus & & & 0 & 0 & & & 0 & 0 & & & 0 & 0 & & & 0 & 0 & & & 0 & 0 & & & 0 & 0 \\
\hline Cx.(Mel.)seçăo Melanoconion & & 10 & 10 & 5 & & & 0 & 0 & 2 & 1 & 3 & 1,5 & & 9 & 9 & 4,5 & 2 & & 2 & 1 & & & 0 & 0 \\
\hline Cx.sp danificado & & & 0 & 0 & & & 0 & 0 & & & 0 & 0 & & & 0 & 0 & & & 0 & 0 & & & 0 & 0 \\
\hline Limatus & & & 0 & 0 & & & 0 & 0 & & & 0 & 0 & & & 0 & 0 & & & 0 & 0 & & & 0 & 0 \\
\hline Mansonia & & & 0 & 0 & & & 0 & 0 & & & 0 & 0 & & & 0 & 0 & & & 0 & 0 & & & 0 & 0 \\
\hline Phoniomyia & & 3 & 3 & 1,5 & 20 & & 20 & 10 & 41 & 29 & 70 & 35 & 27 & 9 & 36 & 18 & 27 & 27 & 54 & 27 & 16 & 30 & 46 & 23 \\
\hline Psorophora & & & 0 & 0 & & & 0 & 0 & & & 0 & 0 & & & 0 & 0 & 11 & 39 & 50 & 25 & & 3 & 3 & 1,5 \\
\hline Runchomyia & & & 0 & 0 & 5 & & 5 & 2,5 & 32 & 34 & 66 & 33 & 9 & 8 & 17 & 8,5 & 14 & 13 & 27 & 13,5 & 9 & 2 & 11 & 5,5 \\
\hline Sabethes & & & 0 & 0 & & & 0 & 0 & & & 0 & 0 & & & 0 & 0 & & & 0 & 0 & & & 0 & 0 \\
\hline Uranotaenia & & 2 & 2 & 1 & & & 0 & 0 & & & 0 & 0 & 1 & & 1 & 0,5 & & & 0 & 0 & & & 0 & 0 \\
\hline Wyeomyia & & & 0 & 0 & & & 0 & 0 & & & 0 & 0 & & & 0 & 0 & 1 & & 1 & 0,5 & & & 0 & 0 \\
\hline
\end{tabular}


(cont) Tabela I: Culicideos capturados em dois pontos (P1 e P2; T=total; $\mathrm{M}=$ =média) em armadilha $\mathrm{CDC}+\mathrm{CO}_{2}$ a $1 \mathrm{~m}$ do solo, das 17-20h.Ilha Comprida, $21 / 08 / 2001$ a $17 / 09 / 2002$.

\begin{tabular}{|c|c|c|c|c|c|c|c|c|c|c|c|c|c|c|c|c|c|c|c|c|c|c|c|c|}
\hline \multirow[b]{2}{*}{ ESPECCIE } & \multicolumn{4}{|c|}{$20 / 11 / 01$} & \multicolumn{4}{|c|}{$05 / 12 / 201$} & \multicolumn{4}{|c|}{$18 / 12 / 02$} & \multicolumn{4}{|c|}{$08 / 01 / 02$} & \multicolumn{4}{|c|}{$29 / 01 / 02$} & \multicolumn{4}{|c|}{$05 / 02 / 02$} \\
\hline & P1 & $\mathrm{P} 2$ & $\mathrm{~T}$ & $M$ & P1 & P2 & $T$ & $M$ & $P 1$ & P2 & $T$ & $M$ & P1 & $\mathrm{P} 2$ & $T$ & $M$ & $\mathrm{P1}$ & $\mathrm{P} 2$ & $T$ & $M$ & P1 & P2 & $T$ & M \\
\hline An.bellator & 0 & 0 & 0 & 0 & 0 & 0 & 0 & 0 & 4 & 15 & 19 & 9,5 & 1 & 3 & 4 & 2 & 3 & 51 & 54 & 27 & 1 & 2 & 3 & 1,5 \\
\hline An.cnuzii & 2 & 0 & 2 & 1 & 1 & 0 & 1 & 0,5 & 5 & 5 & 10 & 5 & 2 & 9 & 11 & 5,5 & 2 & 41 & 43 & 21,5 & 7 & 2 & 9 & 4,5 \\
\hline An.(Ker.)sp danificado & 0 & 0 & 0 & 0 & 0 & 0 & 0 & 0 & 0 & 0 & 0 & 0 & 1 & 0 & 1 & 0.5 & 1 & 3 & 4 & 2 & 0 & 0 & 0 & 0 \\
\hline An.mediopunctatus/costaifforattinii & & & 0 & 0 & & & 0 & 0 & & & 0 & 0 & 1 & & 1 & 0,5 & 1 & 3 & 4 & 2 & 1 & 8 & 9 & 4,5 \\
\hline Ae.albopictus & & & 0 & 0 & & & 0 & 0 & & & 0 & 0 & & & 0 & 0 & & & 0 & 0 & & & 0 & 0 \\
\hline Ae.fulvus & & 1 & 1 & 0,5 & & & 0 & 0 & & & 0 & 0 & 1 & 1 & 2 & 1 & 1 & 2 & 3 & 1,5 & 10 & 11 & 21 & 10,5 \\
\hline Ae. hortator & & & 0 & 0 & & & 0 & 0 & & & 0 & 0 & 2 & 5 & 7 & 3.5 & 5 & & 5 & 2,5 & 4 & 13 & 17 & 8.5 \\
\hline Ae.scapularis & & & 0 & 0 & & & 0 & 0 & & 7 & 7 & 3,5 & 1 & 3 & 4 & 2 & & & 0 & 0 & 1 & 2 & 3 & 1,5 \\
\hline Ae.serratus & 1 & & 1 & 0,5 & & & 0 & 0 & 1 & 1 & 2 & 1 & 1 & 6 & 7 & 3,5 & & & 0 & 0 & 1 & 4 & 5 & 2,5 \\
\hline Ae.serratus/nubilus & 1 & & 1 & 0,5 & 1 & 1 & 2 & 1 & 1 & 6 & 7 & 3.5 & 44 & 37 & 81 & 40,5 & & & 0 & 0 & 4 & 29 & 33 & 16,5 \\
\hline Ae.sp danificado & & & 0 & 0 & & & 0 & 0 & & & 0 & 0 & & & 0 & 0 & & 1 & 1 & 0,5 & & & 0 & 0 \\
\hline Coquillettidia & 41 & 595 & 636 & 318 & 48 & 94 & 142 & 71 & 25 & 154 & 179 & 90 & 42 & 141 & 183 & 91,5 & & & 0 & 0 & 20 & 63 & 83 & 41,5 \\
\hline$C_{x}(M c x) s p$. & & & 0 & 0 & & & 0 & 0 & & & 0 & 0 & & & 0 & 0 & & & 0 & 0 & & & 0 & 0 \\
\hline Cx.aureonotatus & & & 0 & 0 & & & 0 & 0 & & & 0 & 0 & & & 0 & 0 & & & 0 & 0 & & & 0 & 0 \\
\hline Cx.ribeirensis & & & 0 & 0 & & & 0 & 0 & & & 0 & 0 & & & 0 & 0 & & & 0 & 0 & & & 0 & 0 \\
\hline Cx.secchettae & 3 & & 3 & 1.5 & & 5 & 5 & 2,5 & 7 & 5 & 12 & 6 & 7 & 4 & 11 & 5,5 & 16 & 3 & 19 & 9,5 & 2 & 6 & 8 & 4 \\
\hline Cx.spissipes & & & 0 & 0 & & & 0 & 0 & & & 0 & 0 & & & 0 & 0 & & & 0 & 0 & & & 0 & 0 \\
\hline Cx.(Mel.)grupo Atratus & & & 0 & 0 & & & 0 & 0 & & & 0 & 0 & 2 & 1 & 3 & 1,5 & 1 & 1 & 2 & 1 & & 2 & 2 & 1 \\
\hline Cx.(Mel.)grupo Pilosus & & & 0 & 0 & & & 0 & 0 & & & 0 & 0 & & & 0 & 0 & & & 0 & 0 & & & 0 & 0 \\
\hline CX.(Mel.)seçăo Melanoconion & & & 0 & 0 & & 1 & 1 & 0,5 & & & 0 & 0 & 1 & & 1 & 0,5 & 1 & & 1 & 0,5 & & 2 & 2 & 1 \\
\hline CX.sp danificado & & & 0 & 0 & & & 0 & 0 & & & 0 & 0 & & & 0 & 0 & & & 0 & 0 & & & 0 & 0 \\
\hline Limatus & & & 0 & 0 & & & 0 & 0 & & & 0 & 0 & & & 0 & 0 & & & 0 & 0 & 2 & & 2 & 1 \\
\hline Mansonia & & & 0 & 0 & & & 0 & 0 & & & 0 & 0 & & & 0 & 0 & & & 0 & 0 & & & 0 & 0 \\
\hline Phoniomyia & 68 & 71 & 139 & 69,5 & 10 & 23 & 33 & 16,5 & 67 & 115 & 182 & 91 & 58 & 19 & 77 & 38,5 & & & 0 & 0 & 249 & 378 & 627 & 313,5 \\
\hline Psorophora & 1 & & 1 & 0,5 & & & 0 & 0 & 2 & 2 & 4 & 2 & 5 & 15 & 20 & 10 & & & 0 & 0 & 300 & 234 & 534 & 267 \\
\hline Runchomyia & 5 & 17 & 22 & 11 & 7 & 12 & 19 & 9,5 & 1 & 7 & 8 & 4 & 1 & 2 & 3 & 1,5 & 1 & 7 & 8 & 4 & 13 & 12 & 25 & 12,5 \\
\hline Sabethes & & & 0 & 0 & & & 0 & 0 & & 1 & 1 & 0,5 & & & 0 & 0 & & & 0 & 0 & & & 0 & 0 \\
\hline Uranotaenia & & & 0 & 0 & & & 0 & 0 & & & 0 & 0 & & & 0 & 0 & & & 0 & 0 & & & 0 & 0 \\
\hline Wyeomyia & & & 0 & 0 & & & 0 & 0 & & & 0 & 0 & & & 0 & 0 & & & 0 & 0 & 2 & 2 & 4 & 2 \\
\hline
\end{tabular}


(cont) Tabela I: Culicideos capturados em dois pontos (P1 e P2; $T=$ total; $M=$ média) em armadilha $C D C+\mathrm{CO}_{2}$ a 1m do solo, das 17-20h.llha Comprida, 21/08/2001 a 17/09/2002.

\begin{tabular}{|c|c|c|c|c|c|c|c|c|c|c|c|c|c|c|c|c|c|c|c|c|}
\hline \multirow[b]{2}{*}{ ESPÉCIE } & \multicolumn{4}{|c|}{$19 / 02 / 02$} & \multicolumn{4}{|c|}{$05103 / 02$} & \multicolumn{4}{|c|}{ 19/03/02 } & \multicolumn{4}{|c|}{02104102} & \multicolumn{4}{|c|}{$16 / 04 / 02$} \\
\hline & P1 & P2 & $T$ & $M$ & $\mathrm{P} 1$ & $\mathrm{P} 2$ & $\mathrm{~T}$ & $M$ & P1 & $\mathrm{P} 2$ & $T$ & $M$ & P1 & $\mathrm{P} 2$ & $\mathrm{~T}$ & $M$ & $\mathrm{P1}$ & P2 & $T$ & $M$ \\
\hline An bellator & 1 & 13 & 14 & 7 & 12 & 22 & 34 & 17 & 3 & 3 & 6 & 3 & 0 & 0 & 0 & 0 & 7 & 10 & 17 & 8,5 \\
\hline An.cruzii & 4 & 9 & 13 & 6,5 & 10 & 15 & 25 & 12,5 & 0 & 3 & 3 & 1.5 & 0 & 1 & 1 & 0,5 & 12 & 11 & 23 & 12 \\
\hline An.(Ker.)sp danificado & 0 & 1 & 1 & 0,5 & 0 & 0 & 0 & 0 & 0 & 0 & 0 & 0 & 0 & 0 & 0 & 0 & 0 & & 0 & 0 \\
\hline An.mediopunctatus/costai/forattinii & 1 & 4 & 5 & 2,5 & 1 & & 1 & 0,5 & & 1 & 1 & 0.5 & 1 & 2 & 3 & 1.5 & 3 & 9 & 12 & 6 \\
\hline Ae.albopictus & & & 0 & 0 & 1 & & 1 & 0,5 & & & 0 & 0 & & & 0 & 0 & & & 0 & 0 \\
\hline Ae.fulvus & 5 & 4 & 9 & 4,5 & 2 & 3 & 5 & 2,5 & & 1 & 1 & 0,5 & & 1 & 1 & 0,5 & 12 & 10 & 22 & 11 \\
\hline Ae.hortator & 3 & 1 & 4 & 2 & & & 0 & 0 & 1 & & 1 & 0,5 & & & 0 & 0 & 5 & 10 & 15 & 7.5 \\
\hline Ae.scapularis & & 1 & 1 & 0.5 & 2 & 1 & 3 & 1,5 & 1 & 4 & 5 & 2,5 & & 1 & 1 & 0,5 & 4 & 15 & 19 & 9,5 \\
\hline Ae.serratus & 1 & 4 & 5 & 2,5 & 1 & 3 & 4 & 2 & & & 0 & 0 & & 3 & 3 & 1,5 & 1 & & 1 & 0,5 \\
\hline Ae.serratus/nubilus & 5 & 18 & 23 & 11,5 & 11 & 22 & 33 & 16,5 & 5 & 17 & 22 & 11 & 1 & 3 & 4 & 2 & 1 & 12 & 13 & 6,5 \\
\hline Ae.sp danificado & & & 0 & 0 & & & 0 & 0 & & & 0 & 0 & 1 & & 1 & 0,5 & & & 0 & 0 \\
\hline Coquillettidia & 52 & 328 & 380 & 190 & 43 & 113 & 156 & 78 & 113 & 141 & 254 & 127 & 29 & 121 & 150 & 75 & 17 & 49 & 66 & 33 \\
\hline$C x,(M c x) s p$. & 1 & & 1 & 0,5 & & & 0 & 0 & & & 0 & 0 & & & 0 & 0 & & & 0 & 0 \\
\hline Cx.aureonotatus & & & 0 & 0 & & & 0 & 0 & & & 0 & 0 & & & 0 & 0 & & & 0 & 0 \\
\hline Cx.nibeirensis & 1 & 3 & 4 & 2 & 1 & & 1 & 0,5 & 2 & & 2 & 1 & 1 & 16 & 17 & 8.5 & & & 0 & 0 \\
\hline Cx.sacchettee & 11 & 9 & 20 & 10 & 23 & 17 & 40 & 20 & 4 & 10 & 14 & 7 & 1 & 13 & 14 & 7 & 1 & 5 & 6 & 3 \\
\hline Cx.spissipes & 1 & & 1 & 0.5 & & & 0 & 0 & & & 0 & 0 & & & 0 & 0 & & & 0 & 0 \\
\hline Cx.(Mel.)grupo Atratus & & 2 & 2 & 1 & 4 & 1 & 5 & 2,5 & 2 & 5 & 7 & 3,5 & & & 0 & 0 & & & 0 & 0 \\
\hline CX.(Mel.)grupo Pilosus & & & 0 & 0 & & & 0 & 0 & & & 0 & 0 & & & 0 & 0 & & & 0 & 0 \\
\hline Cx.(Mel.)seçáo Melanoconion & & & 0 & 0 & 1 & & 1 & 0,5 & 1 & 2 & 3 & 1.5 & & & 0 & 0 & & & 0 & 0 \\
\hline Cx.sp danificado & & & 0 & 0 & & & 0 & 0 & & & 0 & 0 & & & 0 & 0 & & & 0 & 0 \\
\hline Limatus & & & 0 & 0 & 2 & & 2 & 1 & & & 0 & 0 & & & 0 & 0 & & & 0 & 0 \\
\hline Mansonia & & & 0 & 0 & & & 0 & 0 & 1 & & 1 & 0.5 & & & 0 & 0 & & & 0 & 0 \\
\hline Phoniomyia & 360 & 285 & 645 & 322,5 & 430 & 256 & 686 & 343 & 84 & 264 & 348 & 174 & 29 & 24 & 53 & 26,5 & 80 & 36 & 116 & 58 \\
\hline Psorophora & 57 & 42 & 99 & 49.5 & 19 & 16 & 35 & 17,5 & 10 & 25 & 35 & 17.5 & 18 & 17 & 35 & 17,5 & 354 & 400 & 754 & 377 \\
\hline Runchomyia & 9 & 16 & 25 & 12,5 & 5 & & 5 & 2,5 & 1 & 11 & 12 & 6 & 2 & 6 & 8 & 4 & 14 & 4 & 18 & 9 \\
\hline Sabethes & & & 0 & 0 & & & 0 & 0 & & & 0 & 0 & & & 0 & 0 & & & 0 & 0 \\
\hline Uranotaenia & 1 & & 1 & 0.5 & & & 0 & 0 & 1 & & 1 & 0,5 & & & 0 & 0 & & & 0 & 0 \\
\hline Wyeomyia & & 1 & 1 & 0,5 & & & 0 & 0 & & & 0 & 0 & & & 0 & 0 & 1 & & 1 & 0.5 \\
\hline
\end{tabular}


(cont.) Tabela l: Culicideos capturados em dois pontos (P1 e P2; $T=$ total; $M=$ =média) em armadilha $C D C+\mathrm{CO}_{2}$ a $1 \mathrm{~m}$ do solo, das 17-20h.llha Comprida, $21 / 08 / 2001$ a 17/09/2002.

\begin{tabular}{|c|c|c|c|c|c|c|c|c|c|c|c|c|c|c|c|c|c|c|c|c|c|c|c|c|}
\hline \multirow[b]{2}{*}{ ESPÉCIE } & \multicolumn{4}{|c|}{$01 / 05 / 02$} & \multicolumn{4}{|c|}{$14 / 05 / 02$} & \multicolumn{4}{|c|}{$28 / 05 / 02$} & \multicolumn{4}{|c|}{$11 / 06 / 02$} & \multicolumn{4}{|c|}{$25 / 06 / 02$} & \multicolumn{4}{|c|}{$11 / 07 / 02$} \\
\hline & P1 & $\mathrm{P} 2$ & $T$ & $M$ & $P_{1}$ & $\mathrm{P} 2$ & $T$ & $M$ & P1 & $\mathrm{P} 2$ & $\mathrm{~T}$ & $M$ & P1 & $\mathrm{P} 2$ & $T$ & $M$ & $\mathrm{P1}$ & $\mathrm{P} 2$ & $T$ & $M$ & P1 & $\mathrm{P} 2$ & $T$ & $M$ \\
\hline An bellator & 11 & 0 & 11 & & 14 & 20 & 34 & 17 & 0 & 0 & 0 & 0 & 1 & 0 & 1 & 0,5 & 2 & 3 & 5 & 2,5 & 0 & 8 & 8 & 4 \\
\hline An.cruzii & 76 & 0 & 76 & & 29 & 24 & 53 & 26,5 & 2 & 2 & 4 & 2 & 2 & 4 & 6 & 3 & 6 & 8 & 14 & 7 & 1 & 8 & 9 & 4,5 \\
\hline An.(Ker.)sp danificado & 0 & 0 & 0 & & 0 & 0 & 0 & 0 & 0 & & 0 & 0 & 0 & & 0 & 0 & 0 & & 0 & 0 & 0 & & 0 & 0 \\
\hline An.mediopunctatus/costaifforattinii & 4 & & 4 & & & & 0 & 0 & & 1 & 1 & 0,5 & 1 & 1 & 2 & 1 & & & 0 & 0 & & & 0 & 0 \\
\hline Ae.albopictus & & & 0 & & & & 0 & 0 & & & 0 & 0 & & & 0 & 0 & & & 0 & 0 & & & 0 & 0 \\
\hline Ae.fulvus & 8 & & 8 & & 26 & 103 & 129 & 64,5 & 13 & 25 & 38 & 19 & 7 & 18 & 25 & 12,5 & 4 & 2 & 6 & 3 & 1 & 1 & 2 & 1 \\
\hline Ae.hortator & 7 & & 7 & & 3 & 5 & 8 & 4 & & & 0 & 0 & 1 & 2 & 3 & 1,5 & & & 0 & 0 & & & 0 & 0 \\
\hline Ae.scapularis & 1 & & 1 & & 4 & 24 & 28 & 14 & & 1 & 1 & 0,5 & & 2 & 2 & 1 & & & 0 & 0 & & & 0 & 0 \\
\hline Ae.serratus & & & 0 & & & 1 & 1 & 0,5 & 2 & & 2 & 1 & & 4 & 4 & 2 & & & 0 & 0 & & & 0 & 0 \\
\hline Ae.serratus/nubilus & 41 & & 41 & & 18 & 25 & 43 & 21.5 & 9 & 8 & 17 & 8,5 & 6 & 17 & 23 & 11,5 & 9 & 24 & 33 & 17 & 1 & 12 & 13 & 6.5 \\
\hline Ae.sp danificado & & & 0 & & & 1 & 1 & 0,5 & & & 0 & 0 & & & 0 & 0 & & & 0 & 0 & & & 0 & 0 \\
\hline Coquillettidia & 11 & & 11 & & 9 & 27 & 36 & 18 & 10 & 13 & 23 & 11,5 & 2 & 10 & 12 & 6 & 2 & 1 & 3 & 1,5 & & 1 & 1 & 0,5 \\
\hline$C x .(M c x) s p$. & & & 0 & & & & 0 & 0 & & & 0 & 0 & & & 0 & 0 & & & 0 & 0 & & & 0 & 0 \\
\hline Cx. aureonotatus & & & 0 & & & & 0 & 0 & & & 0 & 0 & & & 0 & 0 & & & 0 & 0 & & & 0 & 0 \\
\hline Cx.ribeirensis & & & 0 & & & & 0 & 0 & & & 0 & 0 & & 3 & 3 & 1,5 & & 1 & 1 & 0,5 & 1 & 1 & 2 & 1 \\
\hline Cx.sacchettae & 9 & & 9 & & 2 & 4 & 6 & 3 & 4 & 4 & 8 & 4 & 7 & 7 & 14 & 7 & 5 & 6 & 11 & 5,5 & 3 & 9 & 12 & 6 \\
\hline Cx.spissipes & & & 0 & & & & 0 & 0 & & & 0 & 0 & & & 0 & 0 & & & 0 & 0 & & & 0 & 0 \\
\hline Cx.(Mel.)grupo Atratus & 1 & & 1 & & & & 0 & 0 & & & 0 & 0 & & & 0 & 0 & & & 0 & 0 & 2 & & 2 & 1 \\
\hline CX.(Mel.)grupo Pilosus & & & 0 & & & & 0 & 0 & & & 0 & 0 & & & 0 & 0 & & & 0 & 0 & & & 0 & 0 \\
\hline Cx.(Mel.)seçăo Melanoconion & 1 & & 1 & & 4 & 5 & 9 & 4,5 & 3 & 2 & 5 & 2,5 & 1 & & 1 & 0,5 & & & 0 & 0 & 1 & & 1 & 0.5 \\
\hline Cx.sp danificado & & & 0 & & & & 0 & 0 & & 1 & 1 & 0,5 & & & 0 & 0 & & & 0 & 0 & & & 0 & 0 \\
\hline Limatus & & & 0 & & & 1 & 1 & 0,5 & & & 0 & 0 & & & 0 & 0 & & & 0 & 0 & & & 0 & 0 \\
\hline Mansonia & & & 0 & & & & 0 & 0 & & & 0 & 0 & & & 0 & 0 & & & 0 & 0 & & & 0 & 0 \\
\hline Phoniomyia & 51 & & 51 & & 45 & 48 & 93 & 46,5 & 6 & 8 & 14 & 7 & & 24 & 24 & 12 & 5 & 7 & 12 & 6 & 2 & 3 & 5 & 2,5 \\
\hline Psorophora & 92 & & 92 & & 42 & 79 & 121 & 60,5 & 4 & 5 & 9 & 4,5 & & & 0 & 0 & & 1 & 1 & 0.5 & & & 0 & 0 \\
\hline Runchomyia & 1 & & 1 & & 6 & 14 & 20 & 10 & 2 & 21 & 23 & 11,5 & 4 & 5 & 9 & 4,5 & & 1 & 1 & 0.5 & & 1 & 1 & 0,5 \\
\hline Sabethes & & & 0 & & & & 0 & 0 & & & 0 & 0 & & & 0 & 0 & & & 0 & 0 & & & 0 & 0 \\
\hline Uranotaenia & 1 & & 1 & & & & 0 & 0 & & & 0 & 0 & & & 0 & 0 & & & 0 & 0 & & & 0 & 0 \\
\hline Wyeomyia & & & 0 & & & & 0 & 0 & & & 0 & 0 & & & 0 & 0 & & & 0 & 0 & & & 0 & 0 \\
\hline
\end{tabular}


(cont) Tabela I: Culicideos capturados em dois pontos (P1 e P2; T=total; $M=$ =média) em armadilha $C D C+\mathrm{CO}_{2}$ a 1m do solo, das 17-20h.llha Comprida, 21/08/2001 a 17/09/2002.

\begin{tabular}{|c|c|c|c|c|c|c|c|c|c|c|c|c|c|c|c|c|c|c|c|c|}
\hline \multirow[b]{2}{*}{ ESPÉCIE } & \multicolumn{4}{|c|}{$23 / 07 / 02$} & \multicolumn{4}{|c|}{$06 / 08 / 02$} & \multicolumn{4}{|c|}{$20 / 08 / 02$} & \multicolumn{4}{|c|}{$03109 / 02$} & \multicolumn{4}{|c|}{$17 / 09 / 02$} \\
\hline & P1 & P2 & $T$ & $M$ & P1 & $\mathrm{P} 2$ & $T$ & $M$ & P1 & P2 & $T$ & $M$ & $\mathrm{P} 1$ & $\mathrm{P} 2$ & $T$ & $M$ & P1 & P2 & $T$ & $M$ \\
\hline An.bellator & 9 & 6 & 15 & 7,5 & 2 & 12 & 14 & 7 & 4 & 2 & 6 & 3 & 1 & 0 & 1 & 0,5 & 0 & 2 & 2 & 1 \\
\hline An.cruzii & 23 & 8 & 31 & 16 & 4 & 10 & 14 & 7 & 17 & 3 & 20 & 10 & 0 & 2 & 2 & 1 & 7 & 7 & 14 & 7 \\
\hline An.(Ker.)sp danificado & & & 0 & 0 & & & 0 & 0 & & & 0 & 0 & & & 0 & 0 & & & 0 & 0 \\
\hline An.mediopunctatus/costaiforattinit & 5 & & 5 & 2,5 & & & 0 & 0 & & & 0 & 0 & & & 0 & 0 & & & 0 & 0 \\
\hline Ae. albopictus & & & 0 & 0 & & & 0 & 0 & & & 0 & 0 & & & 0 & 0 & & & 0 & 0 \\
\hline Ae.fulvus & & & 0 & 0 & & & 0 & 0 & & & 0 & 0 & & & 0 & 0 & & & 0 & 0 \\
\hline Ae.hortator & & & 0 & 0 & & & 0 & 0 & & & 0 & 0 & & & 0 & 0 & & & 0 & 0 \\
\hline Ae.scapularis & 3 & 7 & 10 & 5 & & 1 & 1 & 0,5 & & 2 & 2 & 1 & 4 & 1 & 5 & 2,5 & & & 0 & 0 \\
\hline Ae.serratus & & & 0 & 0 & & & 0 & 0 & & & 0 & 0 & & & 0 & 0 & & & 0 & 0 \\
\hline Ae.serratus/nubilus & 3 & 20 & 23 & 12 & 2 & 1 & 3 & 1,5 & & 2 & 2 & 1 & & & 0 & 0 & & & 0 & 0 \\
\hline Ae.sp danificado & & & 0 & 0 & & & 0 & 0 & & & 0 & 0 & & & 0 & 0 & & & 0 & 0 \\
\hline Coquillettidia & & & 0 & 0 & & & 0 & 0 & & & 0 & 0 & & & 0 & 0 & 1 & 12 & 13 & 6,5 \\
\hline$C x .(M c x) s p$. & & & 0 & 0 & & & 0 & 0 & & & 0 & 0 & 1 & & 1 & 0,5 & & & 0 & 0 \\
\hline Cx.aureonotetus & & & 0 & 0 & & & 0 & 0 & & & 0 & 0 & & & 0 & 0 & & & 0 & 0 \\
\hline Cx.ribeirensis & & & 0 & 0 & & 1 & 1 & 0,5 & 2 & & 2 & 1 & & & 0 & 0 & & 2 & 2 & 1 \\
\hline Cx.secchettee & 6 & 7 & 13 & 6,5 & 14 & 15 & 29 & 14,5 & 16 & 3 & 19 & 9,5 & 1 & 1 & 2 & 1 & 5 & 10 & 15 & 7.5 \\
\hline Cx.spissipes & & & 0 & 0 & & & 0 & 0 & & & 0 & 0 & & & 0 & 0 & & & 0 & 0 \\
\hline Cx.(Mel.)grupo Atratus & & 2 & 2 & 1 & 1 & 2 & 3 & 1,5 & 2 & 1 & 3 & 1,5 & 1 & & 1 & 0,5 & & & 0 & 0 \\
\hline CX.(Mel.)grupo Pilosus & & & 0 & 0 & & & 0 & 0 & & & 0 & 0 & & & 0 & 0 & & & 0 & 0 \\
\hline Cx.(Mel.)seçæo Melanoconion & & 1 & 1 & 0,5 & 3 & 3 & 6 & 3 & 2 & & 2 & 1 & & & 0 & 0 & & & 0 & 0 \\
\hline Cx.sp danificado & & & 0 & 0 & & & 0 & 0 & & & 0 & 0 & & & 0 & 0 & & & 0 & 0 \\
\hline Lmatus & & & 0 & 0 & & & 0 & 0 & & & 0 & 0 & & & 0 & 0 & & & 0 & 0 \\
\hline Mansonia & & & 0 & 0 & & & 0 & 0 & & & 0 & 0 & & & 0 & 0 & & & 0 & 0 \\
\hline Phoniomyia & 30 & 37 & 67 & 34 & 55 & 128 & 183 & 91,5 & 161 & 69 & 230 & 115 & 26 & 22 & 48 & 24 & 43 & 87 & 130 & 65 \\
\hline Psorophora & & & 0 & 0 & & & 0 & 0 & & & 0 & 0 & & & 0 & 0 & & & 0 & 0 \\
\hline Runchomyia & 1 & 2 & 3 & 1.5 & 4 & 8 & 12 & 6 & 16 & 20 & 36 & 18 & 13 & 8 & 21 & 10,5 & 5 & 9 & 14 & 7 \\
\hline Sabethes & & & 0 & 0 & & & 0 & 0 & & & 0 & 0 & & & 0 & 0 & & & 0 & 0 \\
\hline Uranotaenia & & & 0 & 0 & & & 0 & 0 & & & 0 & 0 & & & 0 & 0 & & & 0 & 0 \\
\hline Wyeanyia & & & 0 & 0 & 1 & & 1 & 0.5 & & 1 & 1 & 0.5 & & & 0 & 0 & & 1 & 1 & 0,5 \\
\hline
\end{tabular}


Tabela II: Culicideos capturados em dois pontos (P1 e P2; $T=$ total; $M=$ =média) em armadilha $C D C+\mathrm{CO}_{2}$ a $6 \mathrm{~m}$ do solo, das 17-20h.llha Comprida, 21/08/2001 a 17/09/2002.

\begin{tabular}{|c|c|c|c|c|c|c|c|c|c|c|c|c|c|c|c|c|c|c|c|c|c|c|c|c|}
\hline \multirow[b]{2}{*}{ ESPECIE } & \multicolumn{4}{|c|}{$21 / 08 / 01$} & \multicolumn{4}{|c|}{$04 / 09 / 01$} & \multicolumn{4}{|c|}{$18 / 09 / 01$} & \multicolumn{4}{|c|}{$09 / 10 / 01$} & \multicolumn{4}{|c|}{$23 / 10 / 01$} & \multicolumn{4}{|c|}{$06 / 111 / 01$} \\
\hline & $\mathrm{P1}$ & P2 & $T$ & $M$ & $\mathrm{P1}$ & $\mathrm{P} 2$ & $T$ & $M$ & $P 1$ & $\mathrm{P} 2$ & $T$ & $M$ & P1 & $\mathrm{P} 2$ & $T$ & $M$ & $P 1$ & P2 & $T$ & $M$ & P1 & $\mathrm{P} 2$ & $T$ & $M$ \\
\hline An. bellator & 1 & 2 & 3 & 1,5 & 0 & 0 & 0 & 0 & 0 & 0 & 0 & 0 & 0 & 0 & 0 & 0 & 3 & 4 & 7 & 3,5 & 5 & 1 & 6 & 3 \\
\hline An.cruzii & 0 & 3 & 3 & 1,5 & 12 & 0 & 12 & 6 & 2 & 9 & 11 & 5,5 & 3 & 0 & 3 & 1,5 & 19 & 13 & 32 & 16 & 22 & 15 & 37 & 18,5 \\
\hline An.mediopunctatus/costailforattinii & & & 0 & 0 & & & 0 & 0 & & & 0 & 0 & & & 0 & 0 & 3 & 3 & 6 & 3 & 4 & & 4 & 2 \\
\hline Ae.fulvus & & & 0 & 0 & & & 0 & 0 & & & 0 & 0 & & & 0 & 0 & & & 0 & 0 & & & 0 & 0 \\
\hline Ae.hortator & & & 0 & 0 & & & 0 & 0 & & & 0 & 0 & & & 0 & 0 & & & 0 & 0 & & & 0 & 0 \\
\hline Ae.scapularis & & & 0 & 0 & & & 0 & 0 & & 1 & 1 & 0,5 & & & 0 & 0 & 1 & 2 & 3 & 1,5 & 1 & 1 & 2 & 1 \\
\hline Ae.serratus & & 2 & 2 & 1 & & & 0 & 0 & & & 0 & 0 & & & 0 & 0 & & 1 & 1 & 0.5 & & & 0 & 0 \\
\hline Ae.serratus/nubilus & & 6 & 6 & 3 & & & 0 & 0 & & & 0 & 0 & & 1 & 1 & 0,5 & & 1 & 1 & 0,5 & 1 & & 1 & 0,5 \\
\hline Coquillettidia & & 1 & 1 & 0,5 & 2 & 1 & 3 & 1,5 & 21 & 12 & 33 & 16,5 & 22 & 4 & 26 & 13 & 42 & 594 & 636 & 318 & 403 & 255 & 658 & 329 \\
\hline Cx.dolosus & & & 0 & 0 & & & 0 & 0 & & & 0 & 0 & 1 & & 1 & 0,5 & & & 0 & 0 & & & 0 & 0 \\
\hline Cx.nigripalpus & & 1 & 1 & 0,5 & & & 0 & 0 & & & 0 & 0 & & & 0 & 0 & & & 0 & 0 & & & 0 & 0 \\
\hline Cx.(Cux.)sp danificado & & & 0 & 0 & & & 0 & 0 & & & 0 & 0 & & & 0 & 0 & 1 & & 1 & 0,5 & & & 0 & 0 \\
\hline$C \times .(M c x) s p$. & 1 & & 1 & 0,5 & & & 0 & 0 & & & 0 & 0 & 1 & & 1 & 0,5 & & & 0 & 0 & & & 0 & 0 \\
\hline Cx.pedroi & & & 0 & 0 & & & 0 & 0 & & & 0 & 0 & & & 0 & 0 & & & 0 & 0 & & & 0 & 0 \\
\hline Cx.secchettee & 3 & 3 & 6 & 3 & 1 & & 1 & 0,5 & 6 & 7 & 13 & 6.5 & 3 & & 3 & 1.5 & 7 & 1 & 8 & 4 & 1 & 1 & 2 & 1 \\
\hline Cx.spissipes & & & 0 & 0 & & & 0 & 0 & & & 0 & 0 & & & 0 & 0 & & & 0 & 0 & & & 0 & 0 \\
\hline CX.(Mel.)grupo Atratus & & & 0 & 0 & & & 0 & 0 & & & 0 & 0 & & 1 & 1 & 0,5 & 1 & & 1 & 0,5 & & & 0 & 0 \\
\hline CX.(Mel.)gupo Pilosus & & & 0 & 0 & & & 0 & 0 & & & 0 & 0 & & & 0 & 0 & & & 0 & 0 & & & 0 & 0 \\
\hline Cx.(Mel.)seçăo Melanoconion & & 1 & 1 & 0,5 & & & 0 & 0 & 1 & 2 & 3 & 1.5 & & 6 & 6 & 3 & & & 0 & 0 & & & 0 & 0 \\
\hline Cx.(Mel.)sp danificado & & & 0 & 0 & & & 0 & 0 & & & 0 & 0 & & & 0 & 0 & & & 0 & 0 & & & 0 & 0 \\
\hline Limatus & & & 0 & 0 & & & 0 & 0 & & & 0 & 0 & 1 & & 1 & 0,5 & & & 0 & 0 & & & 0 & 0 \\
\hline Mansonia & 1 & & 1 & 0,5 & 1 & & 1 & 0,5 & & & 0 & 0 & & & 0 & 0 & & & 0 & 0 & & & 0 & 0 \\
\hline Phoniomyia & & 18 & 18 & 9 & & & 0 & 0 & 5 & 13 & 18 & 9 & 17 & 3 & 20 & 10 & & 26 & 26 & 13 & 8 & 14 & 22 & 11 \\
\hline Psorophora & & & 0 & 0 & & & 0 & 0 & & & 0 & 0 & & & 0 & 0 & & & 0 & 0 & & & 0 & 0 \\
\hline Runchomyia & & 1 & 1 & 0,5 & & & 0 & 0 & 2 & 9 & 11 & 5,5 & 4 & 1 & 5 & 2,5 & & 8 & 8 & 4 & 2 & 3 & 5 & 2,5 \\
\hline Sabethes & & & 0 & 0 & & & 0 & 0 & & & 0 & 0 & & & 0 & 0 & & & 0 & 0 & & & 0 & 0 \\
\hline Uranotaenia & & & 0 & 0 & & & 0 & 0 & & & 0 & 0 & 1 & & 1 & 0.5 & & & 0 & 0 & & & 0 & 0 \\
\hline Wyeamyia & & & 0 & 0 & & & 0 & 0 & & & 0 & 0 & & & 0 & 0 & & & 0 & 0 & & & 0 & 0 \\
\hline
\end{tabular}


(cont.) Tabela II: Culicideos capturados em dois pontos ( $\mathrm{P} 1$ e P2; T=total; $\mathrm{M}=$ média) em armadilha $\mathrm{CDC}+\mathrm{CO}_{2}$ a $6 \mathrm{~m}$ do solo, das 17-20h.llha $\mathrm{Comprida}, 21 / 08 / 2001$ a $17 / 09 / 2002$.

\begin{tabular}{|c|c|c|c|c|c|c|c|c|c|c|c|c|c|c|c|c|c|c|c|c|c|c|c|c|}
\hline & \multicolumn{4}{|c|}{$20 / 11 / 01$} & \multicolumn{4}{|c|}{$05 / 12 / 01$} & \multicolumn{4}{|c|}{$18 / 12 / 01$} & \multicolumn{4}{|c|}{$08 / 01 / 02$} & \multicolumn{4}{|c|}{$29 / 01 / 02$} & \multicolumn{4}{|c|}{$05 / 02 / 02$} \\
\hline ESPÉCIE & P1 & $\mathrm{P} 2$ & $\mathrm{~T}$ & $M$ & P1 & $\mathrm{P} 2$ & $T$ & $M$ & P1 & P2 & $T$ & $M$ & P1 & $\mathrm{P} 2$ & $T$ & $M$ & P1 & $\mathrm{P} 2$ & $T$ & $M$ & P1 & $\mathbf{P} 2$ & $T$ & $M$ \\
\hline An.bellator & 0 & 0 & 0 & 0 & 0 & 0 & 0 & 0 & 4 & 9 & 13 & 6,5 & 11 & 1 & 12 & 6 & 8 & 12 & 20 & 10 & 3 & 0 & 3 & 1,5 \\
\hline An.cruzii & 3 & 1 & 4 & 2 & 0 & 0 & 0 & 0 & 5 & 7 & 12 & 6 & 40 & 6 & 46 & 23 & 7 & 26 & 33 & 16,5 & 2 & 1 & 3 & 1,5 \\
\hline An.(Ker.)sp danificado & 0 & 0 & 0 & 0 & 0 & 0 & 0 & 0 & 0 & 0 & 0 & 0 & 2 & 0 & 2 & 1 & 0 & 2 & 2 & 1 & 0 & 0 & 0 & 0 \\
\hline An.mediopunctatus/costaiforattinii & 1 & & 1 & 0.5 & & & 0 & 0 & & & 0 & 0 & & & 0 & 0 & 13 & 9 & 22 & 11 & 3 & & 3 & 1,5 \\
\hline Ae.futvus & & & 0 & 0 & & & 0 & 0 & & & 0 & 0 & 1 & & 1 & 0,5 & & & 0 & 0 & 7 & 5 & 12 & 6 \\
\hline Ae.hortator & & & 0 & 0 & & & 0 & 0 & & & 0 & 0 & 1 & & 1 & 0,5 & & & 0 & 0 & 3 & 1 & 4 & 2 \\
\hline Ae.scapularis & & & 0 & 0 & & & 0 & 0 & 1 & & 1 & 0.5 & 1 & & 1 & 0,5 & 2 & 3 & 5 & 2,5 & & 1 & 1 & 0,5 \\
\hline Ae.serratus & & & 0 & 0 & & & 0 & 0 & & & 0 & 0 & & 1 & 1 & 0,5 & & 1 & 1 & 0,5 & & & 0 & 0 \\
\hline Ae.serratus/nubilus & 1 & 1 & 2 & 1 & & & 0 & 0 & & & 0 & 0 & 2 & 5 & 7 & 3,5 & 12 & 3 & 15 & 7,5 & & & 0 & 0 \\
\hline Coquillettidia & 114 & 256 & 370 & 185 & 59 & 14 & 73 & 36,5 & 92 & 38 & 130 & 65 & 112 & 141 & 253 & 126,5 & 55 & 11 & 66 & 33 & 13 & 6 & 19 & 9,5 \\
\hline Cx.dolosus & & & 0 & 0 & & & 0 & 0 & & & 0 & 0 & & & 0 & 0 & & & 0 & 0 & & & 0 & 0 \\
\hline Cx.nigripalpus & & & 0 & 0 & & & 0 & 0 & & & 0 & 0 & & & 0 & 0 & & & 0 & 0 & & & 0 & 0 \\
\hline Cx.(Cux.)sp danificado & & & 0 & 0 & & & 0 & 0 & & & 0 & 0 & & & 0 & 0 & & & 0 & 0 & & & 0 & 0 \\
\hline$C \times .(M c x) s p$. & & & 0 & 0 & & & 0 & 0 & & & 0 & 0 & & & 0 & 0 & & & 0 & 0 & & & 0 & 0 \\
\hline Cx.pedroi & & & 0 & 0 & & & 0 & 0 & & & 0 & 0 & & & 0 & 0 & & & 0 & 0 & & & 0 & 0 \\
\hline Cx.nibeirensis & & & 0 & 0 & & & 0 & 0 & & 1 & 1 & 0,5 & 1 & 1 & 2 & 1 & & & 0 & 0 & & & 0 & 0 \\
\hline Cx.secchetteo & & 1 & 1 & 0,5 & 4 & & 4 & 2 & 2 & 2 & 4 & 2 & 10 & 3 & 13 & 6,5 & 7 & 3 & 10 & 5 & & 1 & 1 & 0,5 \\
\hline Cx.spissipes & & & 0 & 0 & & & 0 & 0 & & & 0 & 0 & & & 0 & 0 & & & 0 & 0 & & & 0 & 0 \\
\hline CX.(Mel.)grupo Atratus & & & 0 & 0 & & 1 & 1 & 0,5 & & & 0 & 0 & & 1 & 1 & 0,5 & 2 & 3 & 5 & 2,5 & 9 & 5 & 14 & 7 \\
\hline Cx.(Mel.)grupo Pilosus & & & 0 & 0 & & & 0 & 0 & & & 0 & 0 & & & 0 & 0 & & & 0 & 0 & & & 0 & 0 \\
\hline Cx.(Mel.)seçăo Melanoconion & & & 0 & 0 & & & 0 & 0 & & & 0 & 0 & 1 & & 1 & 0,5 & & & 0 & 0 & & 1 & 1 & 0,5 \\
\hline Cx.(Mel.)sp danificado & & & 0 & 0 & & & 0 & 0 & & & 0 & 0 & & & 0 & 0 & & & 0 & 0 & & & 0 & 0 \\
\hline Limatus & & & 0 & 0 & & & 0 & 0 & & & 0 & 0 & & & 0 & 0 & 1 & & 1 & 0,5 & & & 0 & 0 \\
\hline Mansonia & & & 0 & 0 & & & 0 & 0 & & & 0 & 0 & & & 0 & 0 & & & 0 & 0 & & & 0 & 0 \\
\hline Phoniomyia & 21 & 44 & 65 & 32,5 & 10 & 10 & 20 & 10 & 59 & 67 & 126 & 63 & 25 & 5 & 30 & 15 & 191 & 362 & 553 & 276,5 & 80 & 180 & 260 & 130 \\
\hline Psorophora & & & 0 & 0 & & & 0 & 0 & & & 0 & 0 & 1 & & 1 & 0,5 & 84 & 75 & 159 & 79,5 & 47 & 17 & 64 & 32 \\
\hline Runchomyia & 9 & 7 & 16 & 8 & 4 & 5 & 9 & 4,5 & & 3 & 3 & 1,5 & 1 & & 1 & 0,5 & 3 & 3 & 6 & 3 & 4 & 3 & 7 & 3,5 \\
\hline Sabethes & & & 0 & 0 & & & 0 & 0 & & & 0 & 0 & & & 0 & 0 & 4 & 1 & 5 & 2,5 & & & 0 & 0 \\
\hline Uranotaenia & & & 0 & 0 & & & 0 & 0 & & & 0 & 0 & & & 0 & 0 & & & 0 & 0 & & & 0 & 0 \\
\hline Wyeomyia & & & 0 & 0 & & & 0 & 0 & & & 0 & 0 & & & 0 & 0 & & & 0 & 0 & & 1 & 1 & 0,5 \\
\hline
\end{tabular}


(cont.) Tabela II: Culicideos capturados em dois pontos (P1 e P2; T=total; $M=$ =média) em armadilha $C D C+\mathrm{CO}_{2}$ a $6 \mathrm{~m}$ do solo, das 17-20h. Ilha Comprida, 21/08/2001 a 17/09/2002.

\begin{tabular}{|c|c|c|c|c|c|c|c|c|c|c|c|c|c|c|c|c|c|c|c|c|}
\hline \multirow[b]{2}{*}{ ESPÉCIE } & \multicolumn{4}{|c|}{$19 / 02 / 02$} & \multicolumn{4}{|c|}{$05 / 03 / 02$} & \multicolumn{4}{|c|}{ 19/03/02 } & \multicolumn{4}{|c|}{$02 / 04 / 02$} & \multicolumn{4}{|c|}{$16 / 04 / 02$} \\
\hline & P1 & $\mathrm{P} 2$ & $\mathrm{~T}$ & M & P1 & $\mathrm{P} 2$ & $T$ & $M$ & P1 & $\mathrm{P} 2$ & $T$ & $M$ & P1 & P2 & $T$ & M & P1 & P2 & $T$ & $M$ \\
\hline An.bellator & 8 & 24 & 32 & 16 & 14 & 17 & 31 & 15,5 & 9 & 4 & 13 & 6,5 & 1 & 5 & 6 & 3 & 10 & 5 & 15 & 7,5 \\
\hline An.cruzil & 31 & 35 & 66 & 33 & 19 & 18 & 37 & 18,5 & 31 & 6 & 37 & 18,5 & 13 & 9 & 22 & 11 & 38 & 14 & 52 & 26 \\
\hline An.(Ker.)sp danificado & 1 & 2 & 3 & 1,5 & 1 & 0 & 1 & 0,5 & 0 & 0 & 0 & 0 & 0 & 0 & 0 & 0 & & & 0 & 0 \\
\hline An.mediopunctatus/costai/forattinil & 3 & 3 & 6 & 3 & 3 & 1 & 4 & 2 & 10 & 1 & 11 & 5,5 & 5 & 3 & 8 & 4 & 9 & 14 & 23 & 11,5 \\
\hline Ae.fulvus & & & 0 & 0 & 1 & & 1 & 0,5 & & 1 & 1 & 0,5 & & & 0 & 0 & 33 & 13 & 46 & 23 \\
\hline Ae.hortator & 1 & & 1 & 0,5 & & & 0 & 0 & & & 0 & 0 & & & 0 & 0 & 4 & 2 & 6 & 3 \\
\hline Ae.scapularis & & & 0 & 0 & 1 & & 1 & 0,5 & 3 & & 3 & 1.5 & & & 0 & 0 & 3 & 4 & 7 & 3,5 \\
\hline Ae.serratus & & 1 & 1 & 0,5 & & & 0 & 0 & & & 0 & 0 & & & 0 & 0 & 1 & 1 & 2 & 1 \\
\hline Ae.serratus/nubilus & & 3 & 3 & 1,5 & 3 & 1 & 4 & 2 & 5 & 1 & 6 & 3 & 1 & 1 & 2 & 1 & 8 & 1 & 9 & 4,5 \\
\hline Coquillettidia & 213 & 380 & 593 & 296,5 & 18 & 94 & 112 & 56 & 347 & 158 & 505 & 252,5 & 80 & 116 & 196 & 98 & 9 & 51 & 60 & 30 \\
\hline Cx.dolosus & & & 0 & 0 & & & 0 & 0 & & & 0 & 0 & & & 0 & 0 & & & 0 & 0 \\
\hline Cx.nigripalpus & & & 0 & 0 & & & 0 & 0 & & & 0 & 0 & & & 0 & 0 & & 1 & 1 & 0,5 \\
\hline CX.(Cux.)sp danificado & & & 0 & 0 & & & 0 & 0 & & & 0 & 0 & & & 0 & 0 & & & 0 & 0 \\
\hline$C x .(M c x) s p$. & & & 0 & 0 & & & 0 & 0 & & & 0 & 0 & & & 0 & 0 & & & 0 & 0 \\
\hline Cx.pedroi & & & 0 & 0 & & 1 & 1 & 0,5 & & & 0 & 0 & & & 0 & 0 & 3 & & 3 & 1,5 \\
\hline Cx.ribeirensis & 1 & 1 & 2 & 1 & 10 & 4 & 14 & 7 & & & 0 & 0 & & 2 & 2 & 1 & 2 & & 2 & 1 \\
\hline Cx.sacchettee & 1 & & 1 & 0,5 & 2 & 5 & 7 & 3,5 & 11 & 4 & 15 & 7,5 & 10 & 5 & 15 & 7,5 & 12 & 3 & 15 & 7,5 \\
\hline Cx.spissipes & & & 0 & 0 & & & 0 & 0 & & & 0 & 0 & & & 0 & 0 & & & 0 & 0 \\
\hline Cx.(Mel.)grupo Atratus & 1 & 1 & 2 & 1 & & & 0 & 0 & 4 & 8 & 12 & 6 & 1 & 1 & 2 & 1 & 4 & 3 & 7 & 3.5 \\
\hline Cx.(Mel.)grupo Pilosus & & & 0 & 0 & & 1 & 1 & 0,5 & & & 0 & 0 & & & 0 & 0 & & & 0 & 0 \\
\hline CX.(Mel.)seçăo Melanoconion & & & 0 & 0 & & & 0 & 0 & & & 0 & 0 & 1 & & 1 & 0,5 & 2 & 1 & 3 & 1,5 \\
\hline Cx.(Mel.)sp danificado & & & 0 & 0 & & & 0 & 0 & 1 & & 1 & 0,5 & & & 0 & 0 & & & 0 & 0 \\
\hline Limatus & & & 0 & 0 & & & 0 & 0 & & & 0 & 0 & & & 0 & 0 & & & 0 & 0 \\
\hline Mansonia & & & 0 & 0 & & & 0 & 0 & & & 0 & 0 & & & 0 & 0 & & & 0 & 0 \\
\hline Phoniomyia & 91 & 265 & 356 & 178 & 79 & 97 & 176 & 88 & 106 & 51 & 157 & 78.5 & 11 & 24 & 35 & 17,5 & 52 & 29 & 81 & 40,5 \\
\hline Psorophora & 1 & 6 & 7 & 3,5 & & 1 & 1 & 0,5 & & 2 & 2 & 1 & 16 & 6 & 22 & 11 & 294 & 270 & 564 & 282 \\
\hline Runchomyia & 2 & 7 & 9 & 4,5 & & & 0 & 0 & & 4 & 4 & 2 & 8 & 2 & 10 & 5 & 10 & 5 & 15 & 7,5 \\
\hline Sabethes & & 1 & 1 & 0,5 & & & 0 & 0 & & & 0 & 0 & & & 0 & 0 & & & 0 & 0 \\
\hline Uranotaenia & & & 0 & 0 & & & 0 & 0 & & & 0 & 0 & & & 0 & 0 & 1 & & 1 & 0,5 \\
\hline Wyeomyia & & & 0 & 0 & & & 0 & 0 & & & 0 & 0 & & & 0 & 0 & & & 0 & 0 \\
\hline
\end{tabular}


(cont) Tabela Il: Culicideos capturados em dois pontos (P1 e P2; $T=$ total; $M=$ =média) em armadilha $C D C+\mathrm{CO}_{2}$ a $6 \mathrm{~m}$ do solo, das 17-20h.llha Comprida, 21/08/2001 a 17/09/2002.

\begin{tabular}{|c|c|c|c|c|c|c|c|c|c|c|c|c|c|c|c|c|c|c|c|c|c|c|c|c|}
\hline \multirow[b]{2}{*}{ ESPECIE } & \multicolumn{4}{|c|}{$01 / 05 / 02$} & \multicolumn{4}{|c|}{$14 / 05 / 02$} & \multicolumn{4}{|c|}{$28 / 05102$} & \multicolumn{4}{|c|}{$11 / 06 / 02$} & \multicolumn{4}{|c|}{$25 / 08 / 02$} & \multicolumn{4}{|c|}{$11 / 107 / 02$} \\
\hline & P1 & P2 & $T$ & $M$ & P1 & $\mathrm{P} 2$ & $T$ & $M$ & $\mathrm{P1}$ & $\mathrm{P} 2$ & $T$ & $M$ & P1 & $P 2$ & $T$ & $M$ & P1 & $\mathrm{P} 2$ & $\mathrm{~T}$ & $M$ & P1 & $\mathrm{P} 2$ & $T$ & $M$ \\
\hline An.bellator & 8 & 10 & 18 & 9 & 26 & 8 & 34 & 17 & 0 & 1 & 1 & 0,5 & 1 & 1 & 2 & 1 & 1 & 3 & 4 & 2 & 0 & 2 & 2 & 1 \\
\hline An.cruzij & 154 & 240 & 394 & 197 & 74 & 20 & 94 & 47 & 2 & 2 & 4 & 2 & 4 & 3 & 7 & 3,5 & 12 & 6 & 18 & 9 & 5 & 7 & 12 & 6 \\
\hline An.(Ker.)sp danificado & 1 & 15 & 16 & 8 & & 2 & 2 & 1 & & 0 & 0 & 0 & & 0 & 0 & 0 & & 0 & 0 & 0 & & 0 & 0 & 0 \\
\hline An.mediopunctatus/costaiforattinil & 7 & 10 & 17 & 8,5 & 3 & 2 & 5 & 2,5 & & 1 & 1 & 0.5 & 4 & 1 & 5 & 2,5 & 2 & & 2 & 1 & 1 & & 1 & 0,5 \\
\hline Ae.fulvus & 11 & 24 & 35 & 17,5 & 30 & 49 & 79 & 39,5 & 8 & 12 & 20 & 10 & 11 & 9 & 20 & 10 & & & 0 & 0 & & & 0 & 0 \\
\hline Ae.hortator & 1 & 8 & 9 & 4,5 & 1 & & 1 & 0,5 & & & 0 & 0 & & & 0 & 0 & & & 0 & 0 & & & 0 & 0 \\
\hline Ae.scapularis & 1 & 5 & 6 & 3 & 4 & 4 & 8 & 4 & 3 & & 3 & 1,5 & & 1 & 1 & 0,5 & & & 0 & 0 & & & 0 & 0 \\
\hline Ae.serratus & & 1 & 1 & 0,5 & & & 0 & 0 & & & 0 & 0 & & & 0 & 0 & & & 0 & 0 & & & 0 & 0 \\
\hline Ae.serratus/nubilus & 8 & 20 & 28 & 14 & 1 & 4 & 5 & 2,5 & 3 & & 3 & 1,5 & 1 & 1 & 2 & 1 & 4 & 12 & 16 & 8 & & 3 & 3 & 1,5 \\
\hline Coquillettidia & 17 & 22 & 39 & 19,5 & 14 & 9 & 23 & 11,5 & 6 & 8 & 14 & 7 & 3 & 4 & 7 & 3,5 & 1 & & 1 & 0,5 & & & 0 & 0 \\
\hline Cx.dolosus & & & 0 & 0 & & & 0 & 0 & & & 0 & 0 & & & 0 & 0 & & & 0 & 0 & & & 0 & 0 \\
\hline CX.nigripalpus & & 4 & 4 & 2 & & & 0 & 0 & & & 0 & 0 & & & 0 & 0 & & & 0 & 0 & & & 0 & 0 \\
\hline Cx.(Cux.)sp danificado & & & 0 & 0 & & & 0 & 0 & & & 0 & 0 & & & 0 & 0 & & & 0 & 0 & & & 0 & 0 \\
\hline$C_{x}(M c x) s p$. & & & 0 & 0 & & & 0 & 0 & & & 0 & 0 & & & 0 & 0 & & & 0 & 0 & & & 0 & 0 \\
\hline Cx.pedroi & & 1 & 1 & 0,5 & & & 0 & 0 & & & 0 & 0 & 1 & 1 & 2 & 1 & & & 0 & 0 & & & 0 & 0 \\
\hline Cx.nibeirensis & & & 0 & 0 & 1 & & 1 & 0,5 & & & 0 & 0 & & & 0 & 0 & & 1 & 1 & 0,5 & & 2 & 2 & 1 \\
\hline Cx.sacchettee & 6 & 15 & 21 & 10,5 & 9 & 2 & 11 & 5,5 & & & 0 & 0 & 4 & 4 & 8 & 4 & 58 & 15 & 73 & 36,5 & 6 & 2 & 8 & 4 \\
\hline Cx.spissipes & & & 0 & 0 & & 2 & 2 & 1 & & & 0 & 0 & & & 0 & 0 & & & 0 & 0 & & 3 & 3 & 1,5 \\
\hline Cx.(Mel.)grupo Atratus & & 7 & 7 & 3,5 & 3 & 5 & 8 & 4 & 1 & 1 & 2 & 1 & 7 & 5 & 12 & 6 & & 4 & 4 & 2 & 8 & & 8 & 4 \\
\hline Cx.(Mel.)grupo Pilosus & & & 0 & 0 & & & 0 & 0 & & & 0 & 0 & & & 0 & 0 & & & 0 & 0 & & & 0 & 0 \\
\hline CX.(Mel.)seçăo Melanoconion & 2 & 2 & 4 & 2 & 7 & 2 & 9 & 4.5 & & 1 & 1 & 0.5 & & 2 & 2 & 1 & 1 & & 1 & 0,5 & 3 & 5 & 8 & 4 \\
\hline Cx.(Mel.)sp danificado & & & 0 & 0 & & 1 & 1 & 0,5 & & & 0 & 0 & & & 0 & 0 & & & 0 & 0 & & & 0 & 0 \\
\hline Limetus & & & 0 & 0 & & & 0 & 0 & & & 0 & 0 & & & 0 & 0 & & & 0 & 0 & & & 0 & 0 \\
\hline Mansonia & & & 0 & 0 & & 1 & 1 & 0,5 & 1 & 1 & 2 & 1 & & & 0 & 0 & & & 0 & 0 & & & 0 & 0 \\
\hline Phoniomyis & 2 & 12 & 14 & 7 & 14 & 26 & 40 & 20 & 3 & 9 & 12 & 6 & 10 & 19 & 29 & 14,5 & 1 & 4 & 5 & 2,5 & & 5 & 5 & 2,5 \\
\hline Psorophora & 15 & 32 & 47 & 23,5 & 9 & 11 & 20 & 10 & & & 0 & 0 & & & 0 & 0 & & & 0 & 0 & & & 0 & 0 \\
\hline Runchomyia & & & 0 & 0 & 3 & 5 & 8 & 4 & 1 & 8 & 9 & 4,5 & 1 & 2 & 3 & 1,5 & & & 0 & 0 & & 1 & 1 & 0,5 \\
\hline Sabethes & & & 0 & 0 & & & 0 & 0 & & & 0 & 0 & & & 0 & 0 & & & 0 & 0 & & & 0 & 0 \\
\hline Uranotaenia & & & 0 & 0 & & & 0 & 0 & & & 0 & 0 & & & 0 & 0 & & & 0 & 0 & & & 0 & 0 \\
\hline Wyeomyia & & & 0 & 0 & & & 0 & 0 & & & 0 & 0 & & & 0 & 0 & & & 0 & 0 & & & 0 & 0 \\
\hline
\end{tabular}


(cont.) Tabela II: Culicideos capturados em dois pontos (P1 e P2; $T=$ total; $M=$ média) em armadilha $C D C+\mathrm{CO}_{2}$ a $6 \mathrm{~m}$ do solo, das 17-20h.llha $\mathrm{Comprida}, 21 / 08 / 2001$ a $17 / 09 / 2002$.

\begin{tabular}{|c|c|c|c|c|c|c|c|c|c|c|c|c|c|c|c|c|c|c|c|c|}
\hline & \multicolumn{4}{|c|}{$23 / 07 / 02$} & \multicolumn{4}{|c|}{$06 / 08 / 02$} & \multicolumn{4}{|c|}{$20 / 08 / 02$} & \multicolumn{4}{|c|}{$03 / 09 / 02$} & \multicolumn{4}{|c|}{$17 / 09 / 02$} \\
\hline ESPECIE & $\overline{P 1}$ & P2 & $T$ & $\bar{M}$ & $\overline{\mathrm{P} 1}$ & P2 & $T$ & $M$ & P1 & $\mathrm{P} 2$ & $T$ & $M$ & $P 1$ & P2 & $T$ & $\bar{M}$ & $\mathrm{P1}$ & P2 & $T$ & $\bar{M}$ \\
\hline An.bellator & 7 & 11 & 18 & 9 & 2 & 5 & 7 & 3,5 & 2 & 3 & 5 & 2,5 & 0 & 1 & 1 & 0,5 & 2 & 9 & 11 & 5,5 \\
\hline An.cruzii & 7 & 22 & 29 & 14,5 & 5 & 13 & 18 & 9 & 8 & 5 & 13 & 6.5 & 0 & 1 & 1 & 0,5 & 21 & 26 & 47 & 24 \\
\hline An.(Ker.)sp danificado & & 2 & 2 & 1 & & 0 & 0 & 0 & & 0 & 0 & 0 & 0 & 0 & 0 & 0 & 1 & 1 & 2 & 1 \\
\hline An.mediopunctatus/costailforattinil & & 1 & 1 & 0,5 & & & 0 & 0 & & & 0 & 0 & & & 0 & 0 & & & 0 & 0 \\
\hline Ae.futurs & & & 0 & 0 & & & 0 & 0 & & & 0 & 0 & & & 0 & 0 & & & 0 & 0 \\
\hline Ae.hortator & & & 0 & 0 & & & 0 & 0 & & & 0 & 0 & & & 0 & 0 & & & 0 & 0 \\
\hline Ae.scøpularis & 1 & & 1 & 0,5 & & & 0 & 0 & & & 0 & 0 & 1 & & 1 & 0,5 & & & 0 & 0 \\
\hline Ae.serratus & & & 0 & 0 & & & 0 & 0 & & & 0 & 0 & & & 0 & 0 & & & 0 & 0 \\
\hline Ae.serratus/nubilus & 2 & 1 & 3 & 1,5 & & 1 & 1 & 0,5 & & & 0 & 0 & & & 0 & 0 & & & 0 & 0 \\
\hline Coquillettidia & & 1 & 1 & 0,5 & & & 0 & 0 & & & 0 & 0 & & & 0 & 0 & 4 & 30 & 34 & 17 \\
\hline Cx.dolosus & & & 0 & 0 & & & 0 & 0 & & & 0 & 0 & & & 0 & 0 & & & 0 & 0 \\
\hline Cx.nigripalpus & & & 0 & 0 & & & 0 & 0 & & & 0 & 0 & & & 0 & 0 & & & 0 & 0 \\
\hline Cx.(Cux.)sp danificado & & & 0 & 0 & & & 0 & 0 & & & 0 & 0 & & & 0 & 0 & & & 0 & 0 \\
\hline$C x .(M c x) s p$. & & & 0 & 0 & & & 0 & 0 & & & 0 & 0 & & & 0 & 0 & & & 0 & 0 \\
\hline Cx.pedroi & & & 0 & 0 & & & 0 & 0 & & & 0 & 0 & & & 0 & 0 & & & 0 & 0 \\
\hline Cx.ribeirensis & & & 0 & 0 & & & 0 & 0 & & & 0 & 0 & & & 0 & 0 & 1 & 1 & 2 & 1 \\
\hline Cx.sacchettae & 2 & 8 & 10 & 5 & 2 & 3 & 5 & 2,5 & 3 & 6 & 9 & 4,5 & 1 & & 1 & 0,5 & 6 & 10 & 16 & 8 \\
\hline Cx.spissipes & & & 0 & 0 & & & 0 & 0 & & & 0 & 0 & & & 0 & 0 & & & 0 & 0 \\
\hline Cx.(Mel.)grupo Atratus & 3 & 1 & 4 & 2 & 3 & 2 & 5 & 2,5 & & & 0 & 0 & & & 0 & 0 & 2 & 1 & 3 & 1,5 \\
\hline CX.(Mel.)grupo Pilosus & & & 0 & 0 & & & 0 & 0 & & & 0 & 0 & & & 0 & 0 & & & 0 & 0 \\
\hline CX.(Mel.)seçăo Melanoconion & & & 0 & 0 & & 1 & 1 & 0.5 & & & 0 & 0 & & & 0 & 0 & & 1 & 1 & 0,5 \\
\hline CX.(Mel.)sp danificado & & & 0 & 0 & & & 0 & 0 & & & 0 & 0 & & & 0 & 0 & & & 0 & 0 \\
\hline Limatus & & & 0 & 0 & & & 0 & 0 & & & 0 & 0 & & & 0 & 0 & & & 0 & 0 \\
\hline Mansonia & & & 0 & 0 & & & 0 & 0 & & & 0 & 0 & & & 0 & 0 & & & 0 & 0 \\
\hline Phoniomyia & 8 & 37 & 45 & 22,5 & 6 & 44 & 50 & 25 & 41 & 31 & 72 & 36 & 22 & 20 & 42 & 21 & 21 & 78 & 99 & 50 \\
\hline Psorophora & & & 0 & 0 & & & 0 & 0 & & & 0 & 0 & & & 0 & 0 & & & 0 & 0 \\
\hline Runchomyia & 1 & 3 & 4 & 2 & 4 & 5 & 9 & 4,5 & 6 & 4 & 10 & 5 & 10 & 8 & 18 & 9 & 5 & 8 & 13 & 6,5 \\
\hline Sabethes & & & 0 & 0 & & & 0 & 0 & & & 0 & 0 & & & 0 & 0 & & & 0 & 0 \\
\hline Uranotaenia & & 1 & 1 & 0,5 & & & 0 & 0 & & & 0 & 0 & & & 0 & 0 & & & 0 & 0 \\
\hline Wyeomyia & & & 0 & 0 & & & 0 & 0 & & & 0 & 0 & & & 0 & 0 & & & 0 & 0 \\
\hline
\end{tabular}


Tabela III: Culicideos capturados em dois pontos (P1 e P2; $T=$ total; $M=$ =média) em armadilha $C D C+\mathrm{CO}_{2}$ a 12m do solo, das 17-20h.llha Comprida, $21 / 08 / 2001$ a $17 / 09 / 2002$.

\begin{tabular}{|c|c|c|c|c|c|c|c|c|c|c|c|c|c|c|c|c|c|c|c|c|c|c|c|c|}
\hline \multirow[b]{2}{*}{ ESPÉCIE } & \multicolumn{4}{|c|}{$21 / 08 / 01$} & \multicolumn{4}{|c|}{$04 / 09 / 01$} & \multicolumn{4}{|c|}{ 18/09/01 } & \multicolumn{4}{|c|}{$09 / 10 / 01$} & \multicolumn{4}{|c|}{$23 / 10 / 01$} & \multicolumn{4}{|c|}{$06 / 11 / 01$} \\
\hline & $\mathrm{P} 1$ & $\mathrm{P} 2$ & $T$ & $M$ & P1 & P2 & $T$ & $M$ & $\mathrm{P1}$ & $\mathbf{P 2}$ & $T$ & $M$ & P1 & $\mathrm{P} 2$ & $T$ & $M$ & $\mathrm{P1}$ & $\mathrm{P} 2$ & $T$ & $M$ & $\mathrm{P} 1$ & P2 & $T$ & $M$ \\
\hline \multicolumn{25}{|l|}{ Ad.squamipennis } \\
\hline An. bellator & 0 & 2 & 2 & 1 & 1 & 0 & 1 & 0,5 & 0 & 14 & 14 & 7 & 4 & 1 & 5 & 2,5 & 9 & 10 & 19 & 9,5 & 10 & 9 & 19 & 9,5 \\
\hline An.cruzii & 0 & 20 & 20 & 10 & 3 & 1 & 4 & 2 & 4 & 26 & 30 & 15 & 41 & 4 & 45 & 22,5 & 39 & 33 & 72 & 36 & 22 & 14 & 36 & 18 \\
\hline An.(Ker.)sp danificado & 0 & 4 & 4 & 2 & 0 & 0 & 0 & 0 & 2 & 2 & 4 & 2 & 0 & 0 & 0 & 0 & 2 & 4 & 6 & 3 & 3 & 0 & 3 & 1,5 \\
\hline An.mediopunctatus/costaifforattinii & & 1 & 1 & 0.5 & & & 0 & 0 & & 2 & 2 & 1 & 2 & & 2 & 1 & 8 & 13 & 21 & 10,5 & & & 0 & 0 \\
\hline Ae.fulvus & & & 0 & 0 & & & 0 & 0 & & & 0 & 0 & & & 0 & 0 & & & 0 & 0 & & & 0 & 0 \\
\hline Ae.hortator & & & 0 & 0 & & & 0 & 0 & & & 0 & 0 & 1 & & 1 & 0,5 & & 1 & 1 & 0,5 & & & 0 & 0 \\
\hline Ae.scapularis & & & 0 & 0 & & & 0 & 0 & & & 0 & 0 & 1 & 1 & 2 & 1 & & 7 & 7 & 3,5 & 1 & 1 & 2 & 1 \\
\hline Ae.serratus & & & 0 & 0 & & & 0 & 0 & & & 0 & 0 & & & 0 & 0 & & & 0 & 0 & & & 0 & 0 \\
\hline Ae. serratus/nubilus & & 2 & 2 & 1 & & & 0 & 0 & & & 0 & 0 & & & 0 & 0 & 1 & 1 & 2 & 1 & 11 & & 11 & 5,5 \\
\hline Ae.sp danificado & & & 0 & 0 & & & 0 & 0 & & & 0 & 0 & & & 0 & 0 & & & 0 & 0 & & & 0 & 0 \\
\hline Coquillettidia & & 1 & 1 & 0,5 & 4 & & 4 & 2 & 93 & 180 & 273 & 136,5 & 269 & 10 & 279 & 139,5 & 767 & 2843 & 3610 & 1805 & 1093 & 1281 & 2374 & 1187 \\
\hline Cx.nignipalpus & 1 & 1 & 2 & 1 & & & 0 & 0 & & & 0 & 0 & & & 0 & 0 & & & 0 & 0 & & & 0 & 0 \\
\hline \multicolumn{25}{|l|}{ CX.(Cux.)grupo Coronator } \\
\hline \multicolumn{25}{|l|}{ Cx.inadmirabilis } \\
\hline Cx.pedroi & & & 0 & 0 & & & 0 & 0 & & & 0 & 0 & & & 0 & 0 & & & 0 & 0 & & & 0 & 0 \\
\hline Cx,ribeirensis & & 1 & 1 & 0,5 & & & 0 & 0 & & 1 & 1 & 0,5 & & & 0 & 0 & & & 0 & 0 & & & 0 & 0 \\
\hline Cx.sacchettee & 1 & 10 & 11 & 5,5 & & 1 & 1 & 0,5 & 15 & 2 & 17 & 8,5 & 29 & 4 & 33 & 16.5 & 1 & & 1 & 0,5 & 1 & & 1 & 0,5 \\
\hline Cx.spissipes & & & 0 & 0 & & & 0 & 0 & & & 0 & 0 & & & 0 & 0 & & & 0 & 0 & & & 0 & 0 \\
\hline Cx.(Mel.)grupo Atratus & & & 0 & 0 & & & 0 & 0 & & & 0 & 0 & & 1 & 1 & 0,5 & & & 0 & 0 & & & 0 & 0 \\
\hline Cx.(Mel.)grupo Pilosus & & & 0 & 0 & & & 0 & 0 & & & 0 & 0 & & & 0 & 0 & & & 0 & 0 & & & 0 & 0 \\
\hline CX.(Mel.)seçăo Melanoconion & & 1 & 1 & 0,5 & & & 0 & 0 & & & 0 & 0 & & & 0 & 0 & & & 0 & 0 & & & 0 & 0 \\
\hline Cx.(Mel.)sp danificado & & & 0 & 0 & & & 0 & 0 & & & 0 & 0 & & & 0 & 0 & & & 0 & 0 & & & 0 & 0 \\
\hline Cx.sp danificado & & & 0 & 0 & & & 0 & 0 & & & 0 & 0 & & & 0 & 0 & 1 & & 1 & 0,5 & & & 0 & 0 \\
\hline Limatus & & & 0 & 0 & & & 0 & 0 & & & 0 & 0 & & & 0 & 0 & & & 0 & 0 & & & 0 & 0 \\
\hline Mansonia & 1 & & 1 & 0,5 & & & 0 & 0 & & & 0 & 0 & & & 0 & 0 & & & 0 & 0 & & & 0 & 0 \\
\hline Phoniomyia & & 5 & 5 & 2,5 & & & 0 & 0 & 11 & 4 & 15 & 7,5 & 21 & 6 & 27 & 13,5 & 42 & 67 & 109 & 54,5 & 15 & 22 & 37 & 18,5 \\
\hline Psorophora & & & 0 & 0 & & & 0 & 0 & & & 0 & 0 & & & 0 & 0 & 1 & 3 & 4 & 2 & & & 0 & 0 \\
\hline Runchomyia & & 1 & 1 & 0,5 & & & 0 & 0 & & & 0 & 0 & 2 & 3 & 5 & 2,5 & & 1 & 1 & 0,5 & & 2 & 2 & 1 \\
\hline Sabethes & & & 0 & 0 & & & 0 & 0 & & & 0 & 0 & 1 & & 1 & 0,5 & & & 0 & 0 & & & 0 & 0 \\
\hline Uranotaenia & & & 0 & 0 & & & 0 & 0 & 1 & & 1 & 0,5 & 1 & & 1 & 0,5 & & & 0 & 0 & & & 0 & 0 \\
\hline Wyeomyia & & & 0 & 0 & & & 0 & 0 & & & 0 & 0 & & & 0 & 0 & 4 & & 4 & 2 & & & 0 & 0 \\
\hline
\end{tabular}


(cont) Tabela III: Culicideos capturados em dois pontos (P1 e P2; $T=$ total; $M=$ =média) em amadilha CDC+ $\mathrm{CO}_{2}$ a 12m do solo, das 17-20h.llha Comprida, 21/08/2001 a 17/09/2002.

\begin{tabular}{|c|c|c|c|c|c|c|c|c|c|c|c|c|c|c|c|c|c|c|c|c|}
\hline \multirow[b]{2}{*}{ ESPECCIE } & \multicolumn{4}{|c|}{$20 / 11 / 01$} & \multicolumn{4}{|c|}{$05 / 12 / 01$} & \multicolumn{4}{|c|}{$18 / 12 / 01$} & \multicolumn{4}{|c|}{$08 / 01 / 02$} & \multicolumn{4}{|c|}{$29 / 01 / 02$} \\
\hline & P1 & $\mathrm{P} 2$ & $T$ & M & $\mathrm{P} 1$ & $\mathrm{P} 2$ & $T$ & $M$ & $\mathrm{P}_{1}$ & P2 & $\mathrm{T}$ & $M$ & P1 & $\mathrm{P} 2$ & $\mathrm{~T}$ & $M$ & P1 & $\mathrm{P} 2$ & $T$ & $M$ \\
\hline \multicolumn{21}{|l|}{ Ad.squamipennis } \\
\hline An.bellator & 1 & 2 & 3 & 1,5 & 4 & 1 & 5 & 2,5 & 3 & 20 & 23 & 11,5 & 25 & 52 & 77 & 38,5 & 7 & 26 & 33 & 16,5 \\
\hline An.cruzii & 4 & 7 & 11 & 5,5 & 2 & 0 & 2 & 1 & 14 & 33 & 47 & 23,5 & 58 & 88 & 146 & 73 & 4 & 41 & 45 & 22,5 \\
\hline An.(Ker.)sp danificado & 1 & 0 & 1 & 0,5 & 0 & 0 & 0 & 0 & 0 & 2 & 2 & 1 & 3 & 2 & 5 & 2,5 & 0 & 1 & 1 & 0,5 \\
\hline An.mediopunctatus/costailforattinii & 1 & 1 & 2 & 1 & & & 0 & 0 & & & 0 & 0 & & 1 & 1 & 0,5 & 12 & 17 & 29 & 14,5 \\
\hline Ae.fulvus & & & 0 & 0 & & & 0 & 0 & & & 0 & 0 & & & 0 & 0 & & 1 & 1 & 0,5 \\
\hline Ae.hortator & & & 0 & 0 & & & 0 & 0 & & & 0 & 0 & & 3 & 3 & 1,5 & & 3 & 3 & 1,5 \\
\hline Ae.scapularis & 1 & 2 & 3 & 1.5 & & & 0 & 0 & 4 & & 4 & 2 & & 2 & 2 & 1 & 3 & 13 & 16 & 8 \\
\hline Ae.serratus & & & 0 & 0 & & & 0 & 0 & & & 0 & 0 & & & 0 & 0 & 2 & 2 & 4 & 2 \\
\hline Ae.serratus/nubilus & & 4 & 4 & 2 & & & 0 & 0 & 1 & & 1 & 0,5 & 11 & & 11 & 5,5 & 9 & 5 & 14 & 7 \\
\hline Ae.sp danificado & & & 0 & 0 & & & 0 & 0 & & & 0 & 0 & & & 0 & 0 & & & 0 & 0 \\
\hline Coquillettidia & 483 & 2034 & 2517 & 1258,5 & 235 & 100 & 335 & 167,5 & 223 & 152 & 375 & 187,5 & 109 & 82 & 191 & 95,5 & 98 & 116 & 214 & 107 \\
\hline Cx.nignipalpus & & & 0 & 0 & & & 0 & 0 & & & 0 & 0 & & & 0 & 0 & & & 0 & 0 \\
\hline \multicolumn{21}{|l|}{ Cx.(Cux.)grupo Coronator } \\
\hline \multicolumn{21}{|l|}{ Cx.Inadmirabilis } \\
\hline Cx.pedrol & & & 0 & 0 & & & 0 & 0 & & & 0 & 0 & & & 0 & 0 & & & 0 & 0 \\
\hline Cx.ntbeirensis & & & 0 & 0 & & & 0 & 0 & & & 0 & 0 & & & 0 & 0 & & & 0 & 0 \\
\hline Cx.sacchettae & & & 0 & 0 & & 6 & 6 & 3 & 3 & & 3 & 1,5 & 9 & 6 & 15 & 7,5 & 11 & 3 & 14 & 7 \\
\hline Cx.spissipes & & & 0 & 0 & & & 0 & 0 & & & 0 & 0 & & & 0 & 0 & & & 0 & 0 \\
\hline Cx.(Mel.)grupo Atratus & & & 0 & 0 & & & 0 & 0 & 1 & & 1 & 0,5 & & & 0 & 0 & 1 & & 1 & 0,5 \\
\hline Cx.(Mel.)grupo Pilosus & & & 0 & 0 & & & 0 & 0 & & & 0 & 0 & & & 0 & 0 & & & 0 & 0 \\
\hline CX.(Mel.)seçăo Melanoconion & & & 0 & 0 & & & 0 & 0 & & & 0 & 0 & & & 0 & 0 & & & 0 & 0 \\
\hline Cx.(Mel.)sp danificado & & & 0 & 0 & & & 0 & 0 & & & 0 & 0 & & & 0 & 0 & & & 0 & 0 \\
\hline Cx.sp danificado & & & 0 & 0 & & & 0 & 0 & & & 0 & 0 & & & 0 & 0 & & & 0 & 0 \\
\hline Limstus & & & 0 & 0 & & & 0 & 0 & & & 0 & 0 & & & 0 & 0 & & & 0 & 0 \\
\hline Mansonia & & & 0 & 0 & & & 0 & 0 & & & 0 & 0 & & & 0 & 0 & & & 0 & 0 \\
\hline Phoniomyia & 39 & 38 & 77 & 38,5 & 12 & 28 & 40 & 20 & 143 & 105 & 248 & 124 & & 11 & 11 & 5,5 & 248 & 327 & 575 & 287,5 \\
\hline Psorophora & & & 0 & 0 & & & 0 & 0 & & & 0 & 0 & & 1 & 1 & 0,5 & 51 & 40 & 91 & 45,5 \\
\hline Runchomyia & 8 & 2 & 10 & 5 & & 3 & 3 & 1,5 & 2 & 2 & 4 & 2 & & & 0 & 0 & & 1 & 1 & 0,5 \\
\hline Sabethes & & & 0 & 0 & & & 0 & 0 & & & 0 & 0 & & & 0 & 0 & 1 & & 1 & 0,5 \\
\hline Uranotaenia & & & 0 & 0 & & & 0 & 0 & & & 0 & 0 & & & 0 & 0 & & & 0 & 0 \\
\hline Wyeomyia & & & 0 & 0 & & & 0 & 0 & & & 0 & 0 & & & 0 & 0 & & & 0 & 0 \\
\hline
\end{tabular}


(cont.) Tabela III: Culicideos capturados em dois pontos (P1 e P2; T=total; $M=$ média) em armadilha $C D C+\mathrm{CO}_{2}$ a 12m do solo, das 17-20h.llha Comprida, 21/08/2001 a 17/09/2002.

\begin{tabular}{|c|c|c|c|c|c|c|c|c|c|c|c|c|c|c|c|c|c|c|c|c|}
\hline \multirow[b]{2}{*}{ ESPÉCIE } & \multicolumn{4}{|c|}{$05 / 02 / 02$} & \multicolumn{4}{|c|}{$19 / 02 / 02$} & \multicolumn{4}{|c|}{ 05/03/02 } & \multicolumn{4}{|c|}{ 19/03/02 } & \multicolumn{4}{|c|}{$02 / 04 / 02$} \\
\hline & $\mathrm{P} 1$ & $\mathrm{P} 2$ & $I$ & $M$ & $\mathrm{P1}$ & P2 & $\mathrm{T}$ & $M$ & P1 & $\mathrm{P} 2$ & $\mathrm{~T}$ & $M$ & P1 & $\mathrm{P} 2$ & $T$ & $M$ & P1 & $\mathrm{P} 2$ & $T$ & $M$ \\
\hline \multicolumn{21}{|l|}{ Ad.squamipennis } \\
\hline An.bellator & 11 & 7 & 18 & 9 & 7 & 40 & 47 & 23,5 & 10 & 86 & 96 & 48 & 4 & 24 & 28 & 14 & 3 & 8 & 11 & 5,5 \\
\hline An.cruzii & 18 & 4 & 22 & 11 & 40 & 82 & 122 & 61 & 41 & 176 & 217 & 108,5 & 47 & 72 & 119 & 59,5 & 49 & 46 & 95 & 47,5 \\
\hline An.(Ker.)sp danificado & 0 & 0 & 0 & 0 & 0 & 8 & 8 & 4 & 4 & 7 & 11 & 5,5 & 0 & 5 & 5 & 2,5 & 2 & 1 & 3 & 1,5 \\
\hline An.mediopunctatus/costailforattinil & 23 & 10 & 33 & 16,5 & 3 & 4 & 7 & 3,5 & 2 & 2 & 4 & 2 & 3 & 9 & 12 & 6 & 37 & 28 & 65 & 32,5 \\
\hline Ae.fulvus & 7 & 2 & 9 & 4,5 & 2 & & 2 & 1 & 2 & 1 & 3 & 1,5 & 2 & 1 & 3 & 1,5 & & 1 & 1 & 0,5 \\
\hline Ae.hortator & 2 & 1 & 3 & 1,5 & 1 & & 1 & 0,5 & & 1 & 1 & 0,5 & & 1 & 1 & 0.5 & & & 0 & 0 \\
\hline Ae.scapularis & & & 0 & 0 & 1 & 3 & 4 & 2 & 1 & 1 & 2 & 1 & 4 & & 4 & 2 & 1 & 2 & 3 & 1.5 \\
\hline Ae.serratus & & 3 & 3 & 1,5 & & 2 & 2 & 1 & 2 & & 2 & 1 & & & 0 & 0 & 4 & 1 & 5 & 2,5 \\
\hline Ae.serratus/nubilus & 2 & 2 & 4 & 2 & 1 & 5 & 6 & 3 & 13 & 5 & 18 & 9 & 8 & 3 & 11 & 5,5 & 4 & 3 & 7 & 3,5 \\
\hline Ae.sp danificado & & & 0 & 0 & & & 0 & 0 & & & 0 & 0 & & & 0 & 0 & & & 0 & 0 \\
\hline Coquillettidia & 139 & 49 & 188 & 94 & 646 & 2608 & 3254 & 1627 & 106 & 467 & 573 & 286.5 & 490 & 1196 & 1686 & 843 & 692 & 2315 & 3007 & 1503,5 \\
\hline Cx.nigripalpus & & & 0 & 0 & & & 0 & 0 & & 1 & 1 & 0,5 & & & 0 & 0 & & & 0 & 0 \\
\hline \multicolumn{21}{|l|}{ CX.(Cux.)grupo Coronator } \\
\hline \multicolumn{21}{|l|}{ Cx.inadmirabllis } \\
\hline Cx.pedrol & & & 0 & 0 & & & 0 & 0 & & 2 & 2 & 1 & & & 0 & 0 & & & 0 & 0 \\
\hline Cx.ribeirensis & & & 0 & 0 & & & 0 & 0 & & & 0 & 0 & & & 0 & 0 & & 3 & 3 & 1,5 \\
\hline Cx.sacchettae & 17 & 5 & 22 & 11 & 1 & 3 & 4 & 2 & 3 & 28 & 31 & 15,5 & & 12 & 12 & 6 & 13 & 1 & 14 & 7 \\
\hline Cx.spissipes & & & 0 & 0 & & & 0 & 0 & & & 0 & 0 & & & 0 & 0 & & & 0 & 0 \\
\hline Cx.(Mel.)grupo Atratus & 1 & & 1 & 0,5 & & & 0 & 0 & & & 0 & 0 & 1 & & 1 & 0,5 & 1 & & 1 & 0.5 \\
\hline Cx.(Mel.)grupo Pilosus & & & 0 & 0 & & & 0 & 0 & & & 0 & 0 & & & 0 & 0 & & & 0 & 0 \\
\hline CX.(Mel.)seçăo Melanoconion & & & 0 & 0 & & & 0 & 0 & & & 0 & 0 & & & 0 & 0 & & & 0 & 0 \\
\hline Cx.(Mel.)sp danificado & & & 0 & 0 & & & 0 & 0 & & & 0 & 0 & & & 0 & 0 & & & 0 & 0 \\
\hline Cx.sp danificado & & & 0 & 0 & & & 0 & 0 & & & 0 & 0 & & & 0 & 0 & & & 0 & 0 \\
\hline Limatus & & & 0 & 0 & & 1 & 1 & 0,5 & & & 0 & 0 & & & 0 & 0 & & & 0 & 0 \\
\hline Mansonia & & & 0 & 0 & & & 0 & 0 & & 1 & 1 & 0,5 & & 1 & 1 & 0,5 & & 1 & 1 & 0,5 \\
\hline Phoniomyia & 309 & 290 & 599 & 299,5 & 238 & 298 & 536 & 268 & 112 & 107 & 219 & 109,5 & 76 & 91 & 167 & 83,5 & 51 & 11 & 62 & 31 \\
\hline Psorophora & 27 & 1 & 28 & 14 & 3 & 1 & 4 & 2 & 1 & 1 & 2 & 1 & & 3 & 3 & 1,5 & 10 & 1 & 11 & 5,5 \\
\hline Runchomyia & 1 & 1 & 2 & 1 & 3 & 1 & 4 & 2 & 3 & 2 & 5 & 2,5 & & 2 & 2 & 1 & 3 & 1 & 4 & 2 \\
\hline Sabethes & 6 & & 6 & 3 & & 4 & 4 & 2 & 1 & & 1 & 0,5 & & 1 & 1 & 0,5 & & & 0 & 0 \\
\hline Uranotaenia & & & 0 & 0 & & & 0 & 0 & & & 0 & 0 & & & 0 & 0 & & & 0 & 0 \\
\hline Wyeomyia & & & 0 & 0 & & & 0 & 0 & & & 0 & 0 & & & 0 & 0 & & & 0 & 0 \\
\hline
\end{tabular}




\begin{tabular}{|c|c|c|c|c|c|c|c|c|c|c|c|c|c|c|c|c|c|c|c|c|c|c|c|c|}
\hline \multirow[b]{2}{*}{ ESPECIE } & \multicolumn{4}{|c|}{$16 / 04 / 02$} & \multicolumn{4}{|c|}{$01 / 05 / 02$} & \multicolumn{4}{|c|}{$14 / 05 / 02$} & \multicolumn{4}{|c|}{$28 / 05 / 02$} & \multicolumn{4}{|c|}{$11 / 06 / 02$} & \multicolumn{4}{|c|}{$25 / 06 / 02$} \\
\hline & $\mathrm{P} 1$ & P2 & $\mathrm{T}$ & $M$ & P1 & $\mathrm{P} 2$ & $\mathrm{~T}$ & $M$ & $\mathrm{P} 1$ & $\mathrm{P} 2$ & $T$ & $M$ & P1 & $\mathrm{P} 2$ & $T$ & $M$ & P1 & $\mathrm{P} 2$ & $\mathrm{~T}$ & $M$ & P1 & P2 & $T$ & $M$ \\
\hline Ad.squamipennis & & & & & & & & & 3 & 3 & 6 & 3 & & & & & & & & & & & & \\
\hline An.bellator & 10 & 36 & 46 & 23 & 17 & 42 & 59 & 29,5 & 36 & 47 & 83 & 41,5 & 1 & 4 & 5 & 2,5 & 2 & 5 & 7 & 3,5 & 5 & 7 & 12 & 6 \\
\hline An.cruzii & 119 & 66 & 185 & 92,5 & 948 & 1132 & 2080 & 1040 & 199 & 230 & 429 & 215 & 13 & 12 & 25 & 13 & 13 & 16 & 29 & 15 & 38 & 26 & 64 & 32 \\
\hline An.(Ker.)sp danificado & 1 & 1 & 2 & 1 & 37 & 14 & 51 & 25,5 & 3 & 6 & 9 & 4,5 & 0 & 0 & 0 & 0 & 0 & 0 & 0 & 0 & 0 & 0 & 0 & 0 \\
\hline An.mediopunctatus/costal/forattinii & 38 & 35 & 73 & 36,5 & 50 & 47 & 97 & 48,5 & 45 & 12 & 57 & 28,5 & 2 & & 2 & 1 & 28 & 10 & 38 & 19 & 8 & 1 & 9 & 4,5 \\
\hline Ae.fulvus & 15 & 27 & 42 & 21 & 59 & 10 & 69 & 34,5 & 16 & 38 & 54 & 27 & 5 & 15 & 20 & 10 & 8 & 19 & 27 & 14 & 3 & 3 & 6 & 3 \\
\hline Ae.hortator & & & 0 & 0 & 2 & 6 & 8 & 4 & 1 & 2 & 3 & 1.5 & & & 0 & 0 & & & 0 & 0 & & & 0 & 0 \\
\hline Ae.scapularis & 2 & 2 & 4 & 2 & 4 & 10 & 14 & 7 & 3 & 2 & 5 & 2,5 & & 1 & 1 & 0,5 & & 3 & 3 & 1.5 & & & 0 & 0 \\
\hline Ae.serratus & 4 & & 4 & 2 & & 1 & 1 & 0,5 & & & 0 & 0 & & & 0 & 0 & 1 & & 1 & 0,5 & & & 0 & 0 \\
\hline Ae.serratus/nubilus & 6 & 10 & 16 & 8 & 12 & 10 & 22 & 11 & 4 & 13 & 17 & 8.5 & 1 & 1 & 2 & 1 & 3 & 4 & 7 & 3,5 & 4 & 1 & 5 & 2,5 \\
\hline Ae.sp danificado & 1 & & 1 & 0,5 & & & 0 & 0 & & & 0 & 0 & & & 0 & 0 & & & 0 & 0 & & & 0 & 0 \\
\hline Coquillettidia & 54 & 173 & 227 & 113,5 & 142 & 362 & 504 & 252 & 417 & 169 & 586 & 293 & 7 & 12 & 19 & 9,5 & 12 & 18 & 30 & 15 & & 1 & 1 & 0,5 \\
\hline Cx.nigripalpus & & 2 & 2 & 1 & & 1 & 1 & 0,5 & & & 0 & 0 & & & 0 & 0 & & & 0 & 0 & & & 0 & 0 \\
\hline Cx.(Cux.)grupo Coronator & & & 0 & 0 & & 1 & 1 & 0,5 & & & 0 & 0 & & & 0 & 0 & & & 0 & 0 & & & 0 & 0 \\
\hline Cx.inadmirabilis & & & 0 & 0 & & 1 & 1 & 0,5 & & & 0 & 0 & & & 0 & 0 & & & 0 & 0 & & & 0 & 0 \\
\hline Cx.pedrol & 2 & & 2 & 1 & & & 0 & 0 & 1 & & 1 & 0,5 & & & 0 & 0 & & & 0 & 0 & & & 0 & 0 \\
\hline Cx.ribeirensis & & 1 & 1 & 0,5 & & 1 & 1 & 0,5 & 1 & & 1 & 0,5 & & & 0 & 0 & 1 & & 1 & 0,5 & & & 0 & 0 \\
\hline Cx.sacchettee & 22 & 23 & 45 & 22,5 & 51 & 47 & 98 & 49 & 30 & 13 & 43 & 21,5 & 5 & 7 & 12 & 6 & 37 & 22 & 59 & 30 & 97 & 119 & 216 & 108 \\
\hline Cx.spissipes & & & 0 & 0 & 1 & 1 & 2 & 1 & & & 0 & 0 & & & 0 & 0 & & & 0 & 0 & & & 0 & 0 \\
\hline Cx.(Mel.)grupo Atratus & 2 & & 2 & 1 & 2 & & 2 & 1 & 2 & & 2 & 1 & 2 & 1 & 3 & 1,5 & & & 0 & 0 & 1 & & 1 & 0,5 \\
\hline Cx.(Mel.)grupo Pilosus & & & 0 & 0 & & & 0 & 0 & & & 0 & 0 & & 1 & 1 & 0,5 & & & 0 & 0 & & & 0 & 0 \\
\hline Cx.(Mel.)seçăo Melanoconion & & 1 & 1 & 0,5 & 1 & 2 & 3 & 1,5 & & & 0 & 0 & & & 0 & 0 & & 1 & 1 & 0,5 & & & 0 & 0 \\
\hline Cx.(Mel.)sp danificado & 1 & & 1 & 0,5 & & & 0 & 0 & & & 0 & 0 & & & 0 & 0 & & & 0 & 0 & & & 0 & 0 \\
\hline Cx.sp danificado & & & 0 & 0 & 4 & & 4 & 2 & & & 0 & 0 & & & 0 & 0 & & & 0 & 0 & & & 0 & 0 \\
\hline Limatus & & 1 & 1 & 0.5 & & & 0 & 0 & & & 0 & 0 & & & 0 & 0 & & & 0 & 0 & & & 0 & 0 \\
\hline Mansonia & 2 & 1 & 3 & 1,5 & & & 0 & 0 & & & 0 & 0 & & 2 & 2 & 1 & 1 & & 1 & 0,5 & & & 0 & 0 \\
\hline Phoniomyia & 47 & 109 & 156 & 78 & 5 & 15 & 20 & 10 & 16 & 18 & 34 & 17 & 6 & 9 & 15 & 7,5 & 21 & 31 & 52 & 26 & 11 & 10 & 21 & 10,5 \\
\hline Psorophora & 50 & 175 & 225 & 112,5 & 22 & 10 & 32 & 16 & 2 & 1 & 3 & 1,5 & & & 0 & 0 & & & 0 & 0 & & & 0 & 0 \\
\hline Runchomyia & 4 & 9 & 13 & 6,5 & & & 0 & 0 & 3 & 1 & 4 & 2 & 5 & 1 & 6 & 3 & 2 & 2 & 4 & 2 & & 1 & 1 & 0,5 \\
\hline Sabethes & & & 0 & 0 & & & 0 & 0 & & & 0 & 0 & & & 0 & 0 & & & 0 & 0 & & & 0 & 0 \\
\hline Uranotaenia & 2 & & 2 & 1 & & & 0 & 0 & 4 & 1 & 5 & 2,5 & & & 0 & 0 & & & 0 & 0 & & & 0 & 0 \\
\hline Wyeomyia & & & 0 & 0 & & & 0 & 0 & & & 0 & 0 & & & 0 & 0 & & & 0 & 0 & & & 0 & 0 \\
\hline
\end{tabular}


(cont) Tabela III: Culicideos capturados em dois pontos (P1 e P2; T=total; $M=$ média) em armadilha CDC+CO a 12m do solo, das 17-20h.llha Comprida, 21/08/2001 a 17/09/2002

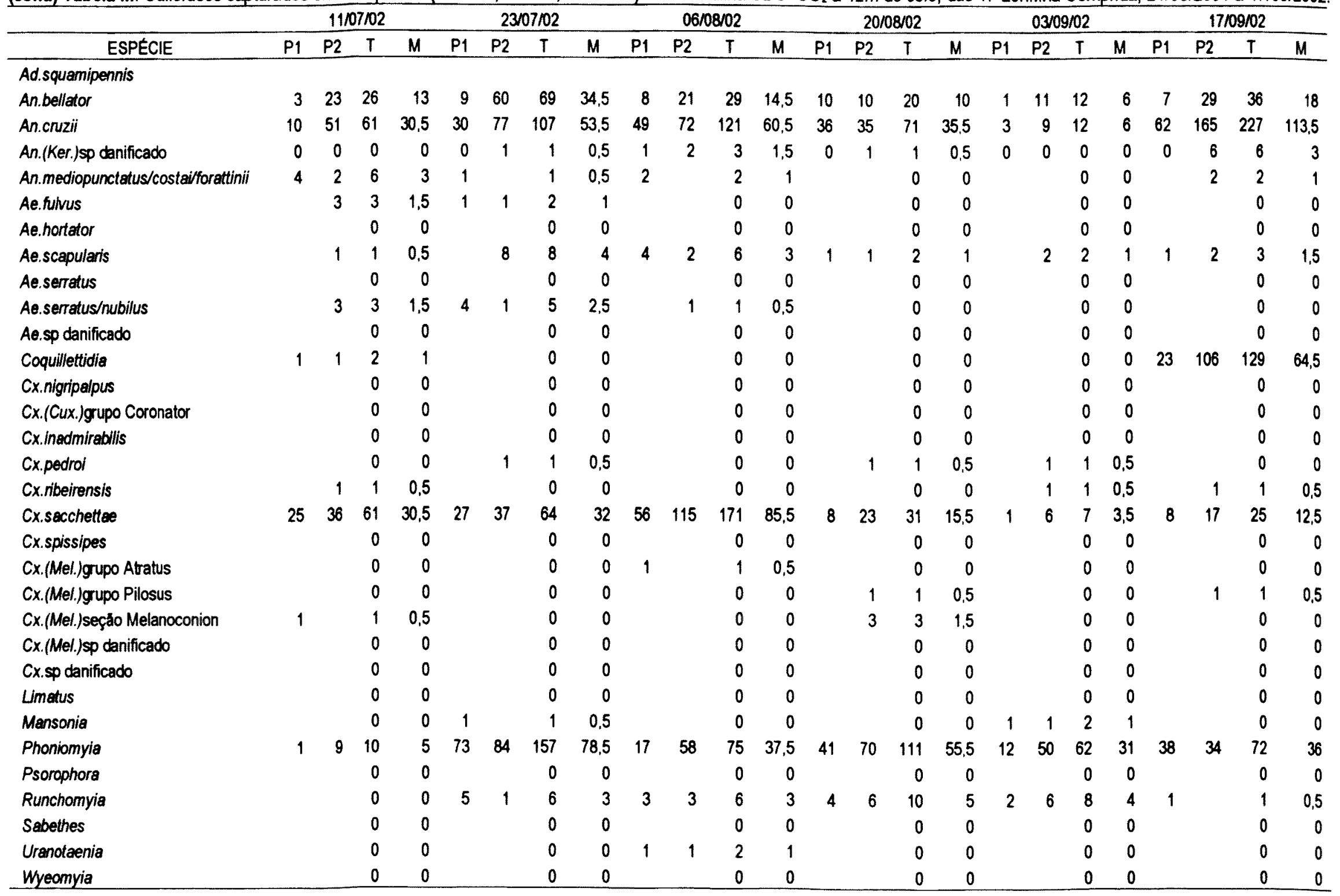


Tabela IV: Resultados da criação de larvas do subgènero Kerteszia coletadas em bromélias. Municipio de liha Comprida, 04/set/01 a 17/set/02

\begin{tabular}{|c|c|c|c|c|c|c|c|c|c|c|}
\hline \multirow{2}{*}{ Coleta } & \multirow{2}{*}{$\begin{array}{c}\text { Ponto } \\
\text { Altura (m) }\end{array}$} & \multirow{2}{*}{ larvas } & \multirow{2}{*}{ actultos } & \multicolumn{3}{|c|}{ An. cruzii } & \multicolumn{3}{|c|}{ An. bellator } & \multirow{2}{*}{ N.I. } \\
\hline & & & & 8 & 오 & total & $\delta$ & 오 & total & \\
\hline \multirow[t]{8}{*}{$4 /$ set/01 } & Solo-praia & 2 & 2 & 0 & 0 & 0 & 2 & 0 & 2 & 0 \\
\hline & Solo-mata & 79 & 71 & 33 & 37 & 70 & 0 & 0 & 0 & 1 \\
\hline & $1 \vdash 2$ & 1 & 1 & 0 & 0 & 0 & 1 & 0 & 1 & 0 \\
\hline & $2 \vdash 3$ & 16 & 16 & 6 & 6 & 12 & 1 & 3 & 4 & 0 \\
\hline & $3 \vdash 4$ & 21 & 21 & 4 & 4 & 8 & 7 & 6 & 13 & 0 \\
\hline & $4 \vdash 5$ & 48 & 47 & 1 & 1 & 2 & 24 & 21 & 45 & 0 \\
\hline & $8 \vdash 9$ & 20 & 18 & 0 & 1 & 1 & 7 & 10 & 17 & 0 \\
\hline & $10 \vdash-11$ & 4 & 3 & 0 & 0 & 0 & 2 & 1 & 3 & 0 \\
\hline \multirow[t]{7}{*}{$18 /$ set/01 } & Solo-praia & 4 & 3 & 0 & 0 & 0 & 1 & 2 & 3 & 0 \\
\hline & Solo-mata & 24 & 22 & 10 & 12 & 22 & 0 & 0 & 0 & 0 \\
\hline & $1 \vdash 2$ & 16 & 16 & 9 & 6 & 15 & 0 & 1 & 1 & 0 \\
\hline & $31-4$ & 1 & 1 & 1 & 0 & 1 & 0 & 0 & 0 & 0 \\
\hline & $4 \vdash 5$ & 8 & 5 & 0 & 0 & 0 & 4 & 1 & 5 & 0 \\
\hline & $7 \vdash 8$ & 2 & 2 & 0 & 2 & 2 & 0 & 0 & 0 & 0 \\
\hline & $9 \vdash 10$ & 5 & 5 & 1 & 2 & 3 & 1 & 1 & 2 & 0 \\
\hline \multirow[t]{6}{*}{ 09/outt01 } & Solo-mata & 18 & 16 & 6 & 8 & 14 & 0 & 2 & 2 & 0 \\
\hline & $2 \vdash 3$ & 4 & 2 & 2 & 0 & 2 & 0 & 0 & 0 & 0 \\
\hline & $3 \vdash 4$ & 3 & 3 & 0 & 0 & 0 & 3 & 0 & 3 & 0 \\
\hline & $4 \vdash 5$ & 41 & 28 & 3 & 0 & 3 & 17 & 8 & 25 & 0 \\
\hline & $8 \vdash 9$ & 14 & 12 & 2 & 0 & 2 & 3 & 7 & 10 & 0 \\
\hline & $10 \vdash-11$ & 18 & 16 & 0 & 0 & 0 & 9 & 7 & 16 & 0 \\
\hline \multirow[t]{5}{*}{ 23/out/01 } & Solo-mata & 9 & 9 & 2 & 4 & 6 & 1 & 2 & 3 & 0 \\
\hline & $1 \vdash 2$ & 20 & 16 & 6 & 7 & 13 & 2 & 1 & 3 & 0 \\
\hline & $6 \vdash 7$ & 2 & 1 & 1 & 0 & 1 & 0 & 0 & 0 & 0 \\
\hline & $8 \vdash 9$ & 13 & 13 & 1 & 1 & 2 & 4 & 7 & 11 & 0 \\
\hline & $10 \vdash 11$ & 1 & 0 & 0 & 0 & 0 & 0 & 0 & 0 & 0 \\
\hline \multirow[t]{3}{*}{ 06/nov/01 } & Solo-mata & 6 & 5 & 1 & 3 & 4 & 1 & 0 & 1 & 0 \\
\hline & $2 \vdash 3$ & 3 & 2 & 1 & 0 & 1 & 1 & 0 & 1 & 0 \\
\hline & $4 \vdash 5$ & 6 & 6 & 1 & 0 & 1 & 3 & 2 & 5 & 0 \\
\hline \multirow[t]{5}{*}{ 20/nov/01 } & Solo-mata & 17 & 16 & 5 & 6 & 11 & 4 & 1 & 5 & 0 \\
\hline & $2 \vdash 3$ & 1 & 1 & 0 & 0 & 0 & 1 & 0 & 1 & 0 \\
\hline & $6 \vdash 7$ & 1 & 1 & 0 & 0 & 0 & 0 & 1 & 1 & 0 \\
\hline & $8 \vdash 9$ & 1 & 1 & 0 & 0 & 0 & 1 & 0 & 1 & 0 \\
\hline & $10 \vdash-11$ & 6 & 5 & 0 & 0 & 0 & 2 & 3 & 5 & 0 \\
\hline \multirow[t]{6}{*}{ 05/dez/01 } & Solo-mata & 7 & 6 & 0 & 0 & 6 & 0 & 0 & 0 & 0 \\
\hline & $3 \vdash 4$ & 7 & 3 & 0 & 0 & 2 & 0 & 0 & 1 & 0 \\
\hline & $4 \vdash 5$ & 18 & 14 & 0 & 1 & 1 & 4 & 4 & 13 & 0 \\
\hline & $8 \vdash 9$ & 4 & 3 & 0 & 0 & 2 & 0 & 0 & 1 & 0 \\
\hline & $10 \vdash 11$ & 10 & 10 & 0 & 0 & 0 & 3 & 0 & 10 & 0 \\
\hline & $11 \vdash 12$ & 7 & 7 & 0 & 0 & 0 & 0 & 0 & 7 & 0 \\
\hline \multirow[t]{5}{*}{ 18/dez/01 } & Solo-mata & 3 & 3 & 0 & 2 & 3 & 0 & 0 & 0 & 0 \\
\hline & $1 \vdash 2$ & 2 & 2 & 0 & 0 & 0 & 0 & 1 & 2 & 0 \\
\hline & $8 \vdash 9$ & 4 & 3 & 0 & 0 & 0 & 0 & 1 & 3 & 0 \\
\hline & $9 \vdash 10$ & 2 & 2 & 0 & 0 & 0 & 0 & 0 & 2 & 0 \\
\hline & $10-11$ & 1 & 1 & 0 & 0 & 0 & 0 & 0 & 1 & 0 \\
\hline
\end{tabular}


(continuaçāo Tab.IV: Resultados da criaçäo de lanas do subgènero Kerteszia coletadas em bromélias. Municipio de llha Compridat_04/set/01 a 17/set/02.)

\begin{tabular}{|c|c|c|c|c|c|c|c|c|c|c|}
\hline \multirow{2}{*}{ Coleta } & \multirow{2}{*}{$\begin{array}{c}\text { Ponto } \\
\text { Atura (m) }\end{array}$} & \multirow{2}{*}{ larvas } & \multirow{2}{*}{ adultos } & \multicolumn{3}{|c|}{ An. cruzll } & \multicolumn{3}{|c|}{ An. bellator } & \multirow{2}{*}{ N.I. } \\
\hline & & & & $\delta^{7}$ & 오 & total & $\delta$ & 오 & total & \\
\hline \multirow[t]{7}{*}{$8 \mathrm{an} 102$} & Solo-meta & 4 & 1 & 0 & 0 & 0 & 0 & 0 & 0 & 1 \\
\hline & $2 \vdash-3$ & 1 & 0 & 0 & 0 & 0 & 0 & 0 & 0 & 0 \\
\hline & $3 \vdash-4$ & 8 & 8 & 3 & 1 & 4 & 2 & 2 & 4 & 0 \\
\hline & $4 \vdash 5$ & 7 & 5 & 0 & 0 & 0 & 3 & 2 & 5 & 0 \\
\hline & $8 \vdash 9$ & 6 & 5 & 0 & 0 & 0 & 3 & 2 & 5 & 0 \\
\hline & $9 \vdash 10$ & 1 & 0 & 0 & 0 & 0 & 0 & 0 & 0 & 0 \\
\hline & $10 \vdash 11$ & 15 & 11 & 1 & 0 & 1 & 4 & 6 & 10 & 0 \\
\hline \multirow[t]{6}{*}{ 29/janV2 } & Solo-mata & 3 & 3 & 1 & 1 & 2 & 0 & 1 & 1 & 0 \\
\hline & $1 \vdash 2$ & 12 & 11 & 2 & 2 & 4 & 2 & 4 & 6 & 1 \\
\hline & $7 \vdash 8$ & 3 & 2 & 0 & 0 & 0 & 1 & 1 & 2 & 0 \\
\hline & $8 \vdash 9$ & 8 & 7 & 0 & 0 & 0 & 4 & 3 & 7 & 0 \\
\hline & $9 \vdash 10$ & 4 & 4 & 0 & 0 & 0 & 0 & 4 & 4 & 0 \\
\hline & $10 \vdash 11$ & 1 & 1 & 0 & 0 & 0 & 1 & 0 & 1 & 0 \\
\hline \multirow[t]{8}{*}{$5 /$ fev/02 } & Solo-mata & 1 & 1 & 1 & 0 & 1 & 0 & 0 & 0 & 0 \\
\hline & $1 \vdash 2$ & 6 & 4 & 0 & 0 & 0 & 1 & 3 & 4 & 0 \\
\hline & $2 \vdash 3$ & 2 & 1 & 0 & 1 & 1 & 0 & 0 & 0 & 0 \\
\hline & $3 \vdash 4$ & 11 & 9 & 2 & 2 & 4 & 3 & 2 & 5 & 0 \\
\hline & $4 \vdash 5$ & 12 & 11 & 0 & 0 & 0 & 5 & 5 & 10 & 1 \\
\hline & $6 \vdash 7$ & 1 & 1 & 0 & 0 & 0 & 0 & 1 & 1 & 0 \\
\hline & $9 \vdash 10$ & 1 & 1 & 0 & 0 & 0 & 0 & 0 & 1 & 0 \\
\hline & $11 \mapsto 12$ & 2 & 2 & 0 & 0 & 0 & 1 & 1 & 2 & 0 \\
\hline \multirow[t]{6}{*}{ 19ffev/02 } & Solo-mata & 13 & 13 & 2 & 4 & 6 & 1 & 4 & 5 & 2 \\
\hline & $1 \vdash 2$ & 8 & 5 & 0 & 0 & 0 & 2 & 3 & 5 & 0 \\
\hline & $4 \vdash 5$ & 3 & 3 & 0 & 0 & 0 & 0 & 3 & 3 & 0 \\
\hline & $7 \vdash 8$ & 1 & 1 & 0 & 0 & 0 & 0 & 1 & 1 & 0 \\
\hline & $8 \vdash 9$ & 9 & 9 & 0 & 0 & 0 & 3 & 4 & 7 & 2 \\
\hline & $10 \vdash 11$ & 6 & 4 & 0 & 0 & 0 & 3 & 0 & 3 & 1 \\
\hline \multirow[t]{7}{*}{$5 /$ mar/02 } & Solo-mata & 2 & 2 & 0 & 2 & 2 & 0 & 0 & 0 & 0 \\
\hline & $1 \vdash 2$ & 1 & 0 & 0 & 0 & 0 & 0 & 0 & 0 & 0 \\
\hline & $3 \vdash 4$ & 13 & 9 & 1 & 2 & 3 & 3 & 2 & 5 & 1 \\
\hline & $4 \vdash 5$ & 4 & 3 & 0 & 1 & 1 & 1 & 1 & 2 & 0 \\
\hline & $8 \vdash 9$ & 13 & 13 & 0 & 0 & 0 & 3 & 7 & 10 & 3 \\
\hline & $10 \vdash 11$ & 3 & 1 & 0 & 0 & 0 & 1 & 0 & 1 & 0 \\
\hline & $11 \vdash 12$ & 4 & 4 & 0 & 0 & 0 & 1 & 3 & 4 & 0 \\
\hline \multirow[t]{6}{*}{$19 /$ mar/02 } & Solo-mata & 9 & 9 & 5 & 2 & 7 & 2 & 0 & 2 & 0 \\
\hline & $1 \vdash 2$ & 1 & 1 & 0 & 0 & 0 & 1 & 0 & 1 & 0 \\
\hline & $6 \vdash 7$ & 1 & 0 & 0 & 0 & 0 & 0 & 0 & 0 & 0 \\
\hline & $7 \vdash 8$ & 1 & 1 & 0 & 0 & 0 & 0 & 1 & 1 & 0 \\
\hline & $8 \vdash 9$ & 6 & 5 & 0 & 0 & 0 & 3 & 2 & 5 & 0 \\
\hline & $10 \vdash-11$ & 13 & 12 & 0 & 0 & 0 & 3 & 8 & 11 & 1 \\
\hline \multirow[t]{9}{*}{ 2/abro2 } & Solo-mata & 3 & 2 & 0 & 0 & 0 & 0 & 2 & 2 & 0 \\
\hline & $1 \vdash 2$ & 3 & 3 & 1 & 1 & 2 & 0 & 1 & 1 & 0 \\
\hline & $2 \vdash 3$ & 2 & 2 & 1 & 1 & 2 & 0 & 0 & 0 & 0 \\
\hline & $3 \vdash 4$ & 7 & 5 & 0 & 2 & 2 & 2 & 1 & 3 & 0 \\
\hline & $4 \vdash 5$ & 8 & 8 & 0 & 0 & 0 & 3 & 3 & 6 & 2 \\
\hline & $7 \vdash 8$ & 1 & 1 & 0 & 1 & 1 & 0 & 0 & 0 & 0 \\
\hline & $8 \vdash 9$ & 24 & 20 & 0 & 0 & 0 & 8 & 8 & 16 & 4 \\
\hline & $10 \vdash 11$ & 15 & 9 & 0 & 0 & 0 & 5 & 3 & 8 & 1 \\
\hline & $11 \vdash 12$ & 2 & 2 & 0 & 0 & 0 & 1 & 1 & 2 & 0 \\
\hline
\end{tabular}


(continuação Tab.IV: Resultados de criação de lanas do subgênero Kerteszia coletadas em bromélias. Municipio de llha Comprida/-04/set/01 a 17/set/22.)

\begin{tabular}{|c|c|c|c|c|c|c|c|c|c|c|}
\hline \multirow{2}{*}{ Coleta } & \multirow{2}{*}{$\begin{array}{c}\text { Ponto } \\
\text { Altura (m) }\end{array}$} & \multirow{2}{*}{ larvas } & \multirow{2}{*}{ actultos } & \multicolumn{3}{|c|}{ An. cruzii } & \multicolumn{3}{|c|}{ An. bellator } & \multirow{2}{*}{ N.I. } \\
\hline & & & & $\delta^{*}$ & 오 & total & $\hat{0}^{\pi}$ & 오 & total & \\
\hline \multirow[t]{8}{*}{ 16/abr/02 } & Solo-praia & 1 & 1 & 0 & 0 & 0 & 1 & 0 & 1 & 0 \\
\hline & Solo-mata & 2 & 0 & 0 & 0 & 0 & 0 & 0 & 0 & 0 \\
\hline & $1 \vdash 2$ & 8 & 8 & 1 & 1 & 2 & 3 & 3 & 6 & 0 \\
\hline & $2 \vdash 3$ & 1 & 1 & 0 & 0 & 0 & 1 & 0 & 1 & 0 \\
\hline & $4 \vdash 5$ & 2 & 2 & 0 & 0 & 0 & 2 & 0 & 2 & 0 \\
\hline & $7 \vdash 8$ & 5 & 4 & 0 & 0 & 0 & 3 & 1 & 4 & 0 \\
\hline & $8 \vdash 9$ & 15 & 13 & 0 & 0 & 0 & 5 & 8 & 13 & 0 \\
\hline & $10 \vdash-11$ & 6 & 5 & 0 & 0 & 0 & 1 & 4 & 5 & 0 \\
\hline \multirow[t]{10}{*}{$1 /$ maio/02 } & Solo-praia & 1 & 0 & 0 & 0 & 0 & 0 & 0 & 0 & 0 \\
\hline & Solo-mata & 21 & 19 & 8 & 8 & 16 & 2 & 1 & 3 & 0 \\
\hline & $1 \vdash 2$ & 2 & 2 & 0 & 1 & 1 & 1 & 0 & 1 & 0 \\
\hline & $2 \vdash 3$ & 5 & 5 & 1 & 2 & 3 & 1 & 1 & 2 & 0 \\
\hline & $31-4$ & 11 & 7 & 3 & 2 & 5 & 1 & 1 & 2 & 0 \\
\hline & $4 \vdash 5$ & 17 & 17 & 2 & 0 & 2 & 6 & 9 & 15 & 0 \\
\hline & $8 \vdash 9$ & 25 & 24 & 0 & 1 & 1 & 17 & 6 & 23 & 0 \\
\hline & $9 \vdash 10$ & 2 & 2 & 0 & 0 & 0 & 1 & 0 & 1 & 1 \\
\hline & $10 \vdash 11$ & 31 & 29 & 0 & 0 & 0 & 17 & 9 & 26 & 3 \\
\hline & $11 \vdash 12$ & 18 & 17 & 0 & 0 & 0 & 8 & 9 & 17 & 0 \\
\hline \multirow[t]{9}{*}{$14 /$ maio $/ 02$} & Solo-praia & 3 & 3 & 0 & 0 & 0 & 3 & 0 & 3 & 0 \\
\hline & Solomata & 18 & 17 & 4 & 5 & 9 & 5 & 3 & 8 & 0 \\
\hline & $1 \vdash 2$ & 14 & 13 & 2 & 4 & 6 & 3 & 4 & 7 & 0 \\
\hline & $4 \vdash 5$ & 4 & 4 & 0 & 0 & 0 & 3 & 1 & 4 & 0 \\
\hline & $5 \vdash 6$ & 1 & 1 & 0 & 0 & 0 & 0 & 1 & 1 & 0 \\
\hline & $6 \vdash 7$ & 3 & 2 & 0 & 0 & 0 & 1 & 1 & 2 & 0 \\
\hline & $7 \vdash 8$ & 12 & 12 & 0 & 1 & 1 & 10 & 0 & 10 & 1 \\
\hline & $8 \vdash 9$ & 16 & 16 & 0 & 0 & 0 & 6 & 9 & 15 & 1 \\
\hline & $10 \vdash 11$ & 5 & 5 & 0 & 0 & 0 & 3 & 2 & 5 & 0 \\
\hline \multirow[t]{7}{*}{$28 /$ maio $/ 02$} & Solo-mata & 35 & 32 & 16 & 16 & 32 & 0 & 0 & 0 & 0 \\
\hline & $1 \vdash 2$ & 9 & 9 & 3 & 6 & 9 & 0 & 0 & 0 & 0 \\
\hline & $2 \vdash 3$ & 4 & 4 & 1 & 2 & 3 & 1 & 0 & 1 & 0 \\
\hline & $3 \vdash 4$ & 5 & 5 & 3 & 2 & 5 & 0 & 0 & 0 & 0 \\
\hline & $4 \vdash 5$ & 3 & 3 & 1 & 1 & 2 & 1 & 0 & 1 & 0 \\
\hline & $8 \vdash 9$ & 17 & 16 & 1 & 1 & 2 & 11 & 3 & 14 & 0 \\
\hline & $10 \vdash 11$ & 26 & 18 & 0 & 0 & 0 & 10 & 8 & 18 & 0 \\
\hline \multirow[t]{6}{*}{ 11/jun/02 } & Solo-praia & 1 & 1 & 0 & 0 & 0 & 0 & 1 & 1 & 0 \\
\hline & Solo-mata & 46 & 30 & 9 & 9 & 18 & 6 & 6 & 12 & 0 \\
\hline & $1 \vdash 2$ & 40 & 25 & 7 & 16 & 23 & 1 & 0 & 1 & 1 \\
\hline & $5 \vdash-6$ & 2 & 2 & 0 & 1 & 1 & 1 & 0 & 1 & 0 \\
\hline & $8 \vdash 9$ & 8 & 8 & 0 & 0 & 0 & 3 & 4 & 7 & 1 \\
\hline & $10 \vdash-11$ & 8 & 8 & 0 & 0 & 0 & 5 & 3 & 8 & 0 \\
\hline \multirow[t]{9}{*}{ 25/jun/02 } & Solo-mata & 45 & 35 & 16 & 17 & 33 & 0 & 1 & 1 & 1 \\
\hline & $1 \vdash 2$ & 16 & 16 & 5 & 11 & 16 & 0 & 0 & 0 & 0 \\
\hline & $2 \vdash 3$ & 3 & 3 & 0 & 2 & 2 & 0 & 1 & 1 & 0 \\
\hline & $3 \vdash 4$ & 5 & 5 & 5 & 0 & 5 & 0 & 0 & 0 & 0 \\
\hline & $4 \vdash 5$ & 9 & 9 & 0 & 1 & 1 & 5 & 3 & 8 & 0 \\
\hline & $6 \vdash 7$ & 1 & 1 & 0 & 0 & 0 & 0 & 1 & 1 & 0 \\
\hline & $8 \vdash 9$ & 30 & 27 & 0 & 1 & 1 & 10 & 16 & 26 & 0 \\
\hline & $9 \vdash 10$ & 1 & 0 & 0 & 0 & 0 & 0 & 0 & 0 & 0 \\
\hline & $10 \vdash 11$ & 28 & 24 & 0 & 0 & 0 & 10 & 14 & 24 & 0 \\
\hline
\end{tabular}


(continuação Tab.IV: Resultados da criação de lavas do subgènero Kerteszia coletadas em bromélias. Municipio de liha Compridat-04/set/01 a 17/set/02.)

\begin{tabular}{|c|c|c|c|c|c|c|c|c|c|c|}
\hline \multirow{2}{*}{ Coleta } & \multirow{2}{*}{$\begin{array}{l}\text { Ponto } \\
\text { Altura (m) }\end{array}$} & \multirow{2}{*}{ lavas } & \multirow{2}{*}{ adultos } & \multicolumn{3}{|c|}{ An. cruzii } & \multicolumn{3}{|c|}{ An. bellator } & \multirow{2}{*}{ N.I. } \\
\hline & & & & 8 & 오 & total & 8 & 오 & total & \\
\hline \multirow{8}{*}{ 11/juv02 } & Solo-mata & 86 & 52 & 22 & 15 & 37 & 10 & 5 & 15 & 0 \\
\hline & $1 \vdash 2$ & 12 & 12 & 1 & 5 & 6 & 3 & 3 & 6 & 0 \\
\hline & $4 \vdash 5$ & 3 & 2 & 0 & 0 & 0 & 1 & 1 & 2 & 0 \\
\hline & $5 \vdash 6$ & 1 & 1 & 0 & 0 & 0 & 1 & 0 & 1 & 0 \\
\hline & $61-4$ & 1 & 1 & 0 & 1 & 1 & 0 & 0 & 0 & 0 \\
\hline & $7 \vdash 8$ & 4 & 4 & 0 & 0 & 0 & 0 & 4 & 4 & 0 \\
\hline & $8 \vdash 9$ & 8 & 7 & 0 & 0 & 0 & 3 & 4 & 7 & 0 \\
\hline & $10 \vdash 11$ & 19 & 14 & 0 & 0 & 0 & 7 & 7 & 14 & 0 \\
\hline \multirow[t]{8}{*}{$23 / \mathrm{Ju} / 02$} & Solo-praia & 1 & 1 & 0 & 0 & 0 & 1 & 0 & 1 & 0 \\
\hline & Solo-mata & 22 & 22 & 10 & 11 & 21 & 0 & 1 & 1 & 0 \\
\hline & $1 \vdash 2$ & 21 & 17 & 11 & 6 & 17 & 0 & 0 & 0 & 0 \\
\hline & $3 \vdash 4$ & 13 & 12 & 7 & 5 & 12 & 0 & 0 & 0 & 0 \\
\hline & $4 \vdash 5$ & 6 & 5 & 0 & 1 & 1 & 4 & 0 & 4 & 0 \\
\hline & $8 \vdash 9$ & 26 & 25 & 0 & 0 & 0 & 10 & 15 & 25 & 0 \\
\hline & $10 \vdash 11$ & 1 & 1 & 0 & 0 & 0 & 0 & 1 & 1 & 0 \\
\hline & $11 \mapsto^{12}$ & 1 & 1 & 0 & 0 & 0 & 0 & 1 & 1 & 0 \\
\hline \multirow[t]{9}{*}{ 6/ago/02 } & Solo-mata & 34 & 30 & 12 & 14 & 26 & 2 & 1 & 3 & 1 \\
\hline & $1 \vdash 2$ & 39 & 35 & 17 & 17 & 34 & 0 & 1 & 1 & 0 \\
\hline & $2 \vdash 3$ & 1 & 1 & 0 & 0 & 0 & 0 & 1 & 1 & 0 \\
\hline & $4 \vdash 5$ & 4 & 4 & 0 & 2 & 2 & 0 & 2 & 2 & 0 \\
\hline & $5 \vdash 6$ & 4 & 4 & 0 & 0 & 0 & 3 & 1 & 4 & 0 \\
\hline & $6 \vdash 7$ & 1 & 1 & 0 & 1 & 1 & 0 & 0 & 0 & 0 \\
\hline & $7 \vdash 8$ & 1 & 1 & 0 & 0 & 0 & 1 & 0 & 1 & 0 \\
\hline & $8 \vdash 9$ & 16 & 15 & 1 & 0 & 1 & 5 & 9 & 14 & 0 \\
\hline & $10 \vdash 11$ & 25 & 24 & 0 & 0 & 0 & 12 & 12 & 24 & 0 \\
\hline \multirow[t]{8}{*}{ 20/ago/02 } & Solo-praia & 2 & 2 & 0 & 0 & 0 & 1 & 1 & 2 & 0 \\
\hline & Solo-mata & 45 & 38 & 16 & 18 & 34 & 0 & 0 & 0 & 4 \\
\hline & $1 \vdash 2$ & 59 & 26 & 12 & 13 & 25 & 1 & 0 & 1 & 0 \\
\hline & $3 \vdash 4$ & 4 & 4 & 2 & 1 & 3 & 1 & 0 & 1 & 0 \\
\hline & $4 \vdash 5$ & 21 & 21 & 1 & 0 & 1 & 10 & 10 & 20 & 0 \\
\hline & $8 \vdash 9$ & 7 & 7 & 0 & 0 & 0 & 5 & 2 & 7 & 0 \\
\hline & $10 \vdash 11$ & 9 & 9 & 0 & 0 & 0 & 5 & 4 & 9 & 0 \\
\hline & $11 H^{12}$ & 6 & 6 & 0 & 0 & 0 & 3 & 3 & 6 & 0 \\
\hline \multirow[t]{7}{*}{ 3/set02 } & Solo-mata & 95 & 71 & 28 & 38 & 66 & 3 & 2 & 5 & 0 \\
\hline & $1 \vdash 2$ & 53 & 46 & 11 & 14 & 25 & 10 & 6 & 16 & 5 \\
\hline & $4 \vdash 5$ & 1 & 1 & 0 & 0 & 0 & 0 & 1 & 1 & 0 \\
\hline & $6 \vdash 7$ & 1 & 1 & 0 & 0 & 0 & 1 & 0 & 1 & 0 \\
\hline & $7 \vdash 8$ & 7 & 7 & 0 & 1 & 1 & 3 & 3 & 6 & 0 \\
\hline & $8 \vdash 9$ & 17 & 17 & 0 & 0 & 0 & 7 & 10 & 17 & 0 \\
\hline & $10 \vdash-11$ & 13 & 12 & 0 & 0 & 0 & 10 & 2 & 12 & 0 \\
\hline \multirow[t]{9}{*}{$17 /$ set/02 } & Solo-mata & 27 & 23 & 10 & 11 & 21 & 0 & 0 & 0 & 2 \\
\hline & $1 \vdash 2$ & 22 & 22 & 7 & 15 & 22 & 0 & 0 & 0 & 0 \\
\hline & $2 \vdash 3$ & 1 & 1 & 0 & 0 & 0 & 1 & 0 & 1 & 0 \\
\hline & $3 \vdash-4$ & 4 & 4 & 0 & 4 & 4 & 0 & 0 & 0 & 0 \\
\hline & $4 \vdash 5$ & 15 & 15 & 0 & 2 & 2 & 7 & 6 & 13 & 0 \\
\hline & $8 \vdash 9$ & 24 & 22 & 0 & 0 & 0 & 16 & 6 & 22 & 0 \\
\hline & $9 \vdash 10$ & 1 & 1 & 0 & 0 & 0 & 1 & 0 & 1 & 0 \\
\hline & $10 \vdash 11$ & 14 & 14 & 0 & 0 & 0 & 7 & 7 & 14 & 0 \\
\hline & $11 \vdash 12$ & 6 & 6 & 0 & 0 & 0 & 2 & 4 & 6 & 0 \\
\hline
\end{tabular}

